NASA/TM-2001-209619

USAAMCOM-TR-01-A-001
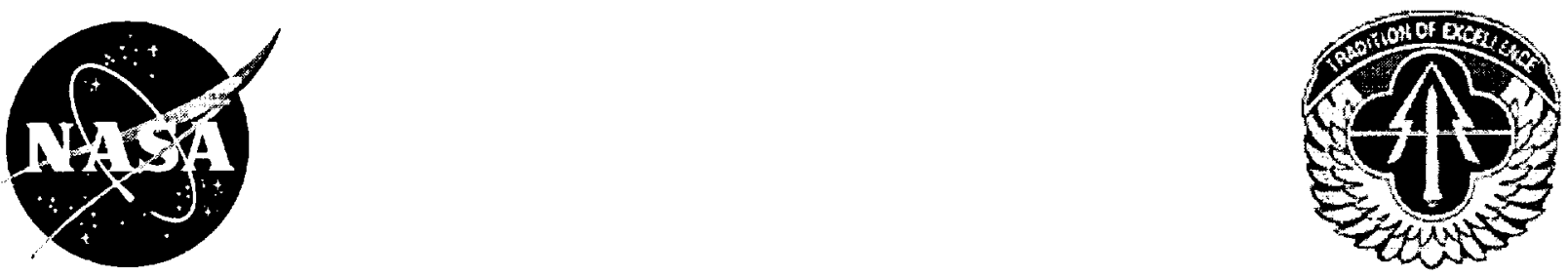

Flight Test Identification and Simulation of a UH-60A Helicopter and Slung Load

Luigi S. Cicolani, Ranjana Sahai, George E. Tucker, Allen H. McCoy, Peter H. Tyson, Mark B. Tischler, Aviv Rosen 
The NASA STI Program Office . . . in Profile

Since its founding, NASA has been dedicated to the advancement of aeronautics and space science. The NASA Scientific and Technical Information (STI) Program Office plays a key part in helping NASA maintain this important role.

The NASA STI Program Office is operated by Langley Research Center, the Lead Center for NASA's scientific and technical information. The NASA STI Program Office provides access to the NASA STI Database, the largest collection of aeronautical and space science STI in the world. The Program Office is also NASA's institutional mechanism for disseminating the results of its research and development activities. These results are published by NASA in the NASA STI Report Series, which includes the following report types:

- TECHNICAL PUBLICATION. Reports of completed research or a major significant phase of research that present the results of NASA programs and include extensive data or theoretical analysis. Includes compilations of significant scientific and technical data and information deemed to be of continuing reference value. NASA's counterpart of peer-reviewed formal professional papers but has less stringent limitations on manuscript length and extent of graphic presentations.

- TECHNICAL MEMORANDUM. Scientific and technical findings that are preliminary or of specialized interest, e.g., quick release reports, working papers, and bibliographies that contain minimal annotation. Does not contain extensive analysis.

- CONTRACTOR REPORT. Scientific and technical findings by NASA-sponsored contractors and grantees.
- CONFERENCE PUBLICATION. Collected papers from scientific and technical conferences, symposia, seminars, or other meetings sponsored or cosponsored by NASA.

- SPECIAL PUBLICATION. Scientific, technical, or historical information from NASA programs, projects, and missions, often concerned with subjects having substantial public interest.

- TECHNICAL TRANSLATION. Englishlanguage translations of foreign scientific and technical material pertinent to NASA's mission.

Specialized services that complement the STI Program Office's diverse offerings include creating custom thesauri, building customized databases, organizing and publishing research results ... even providing videos.

For more information about the NASA STI Program Office, see the following:

- Access the NASA STI Program Home Page at http://www.sti.nasa.gov

- E-mail your question via the Internet to help@sti.nasa.gov

- Fax your question to the NASA Access Help Desk at (301) 621-0134

- Telephone the NASA Access Help Desk at (301) 621-0390

- Write to:

NASA Access Help Desk

NASA Center for AeroSpace Information 7121 Standard Drive Hanover, MD 21076-1320 

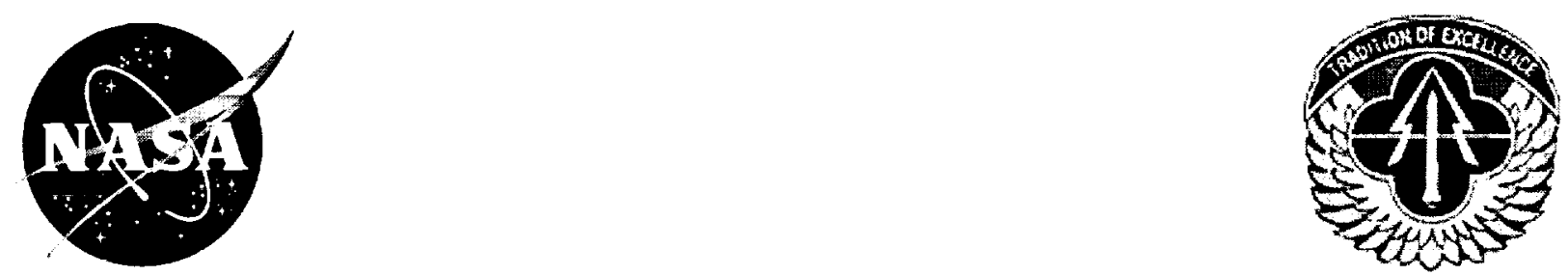

\section{Flight Test Identification and Simulation of a UH-60A Helicopter and Slung Load}

Luigi S. Cicolani, Ranjana Sahai, and George E. Tucker Army/NASA Rotorcraft Division, Aeroflightdynamics Directorate (AMRDEC), U.S. Army Aviation and Missile Command, Ames Research Center, Moffett Field, California 94035

Allen H. McCoy and Peter H. Tyson

U.S. Naval Postgraduate School, Monterey, California

Mark B. Tischler

Army/NASA Rotorcraft Division, Aeroflightdynamics Directorate (AMRDEC), U.S. Army Aviation and Missile Command, Ames Research Center, Moffett Field, California 94035

Aviv Rosen

Department of Aerospace Engineering, Technion Institute of Technology, Haifa, Israel

National Aeronautics and

Space Administration

Ames Research Center

Moffett Field, California 94035-1000 
Available from:

NASA Center for AeroSpace Information 7121 Standard Drive

Hanover, MD 21076-1320

(301) $621-0390$
National Technical Information Service 5285 Port Royal Road Springfield, VA 22161 (703) $487-4650$ 


\section{CONTENTS}

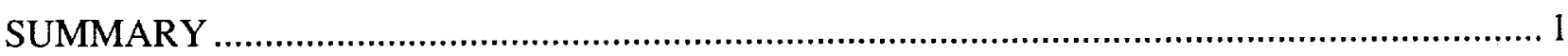

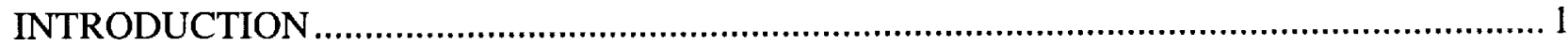

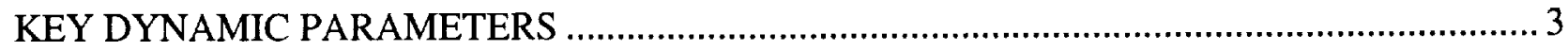

Dynamic System ................................................................................................... 3

Handling Qualities Parameters ...................................................................................... 3

Stability Margins.................................................................................................... 4

Load Pendulum Modes .................................................................................................. 4

FLIGHT TEST SETUP AND PRELIMINARY EVALUATIONS …….................................... 5

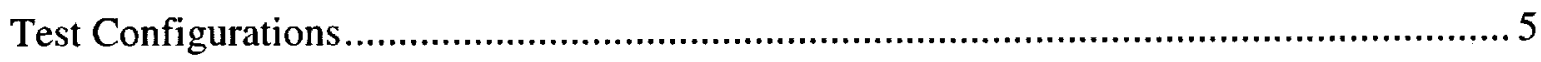

Instrumentation and Signals .................................................................................... 8

Flight Test Profile ..................................................................................................... 10

Data Acquisition and Flight-Time Identification ............................................................ 12

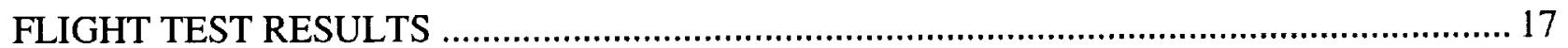

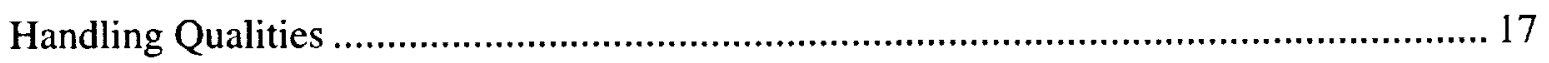

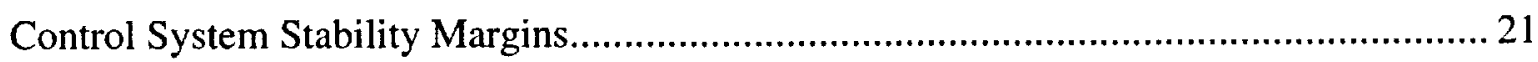

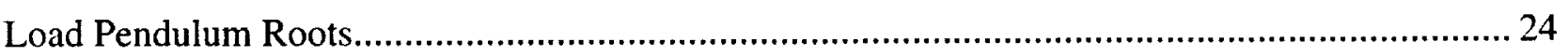

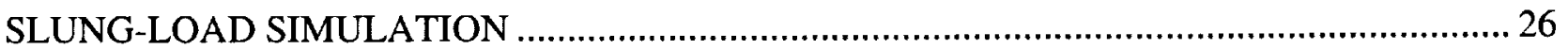

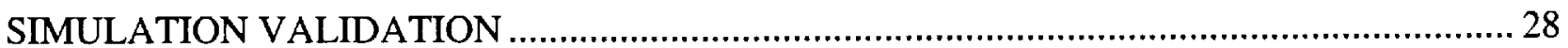

No-Load Simulation Fidelity ................................................................................... 28

Slung-Load Simulation Fidelity .................................................................................. 30

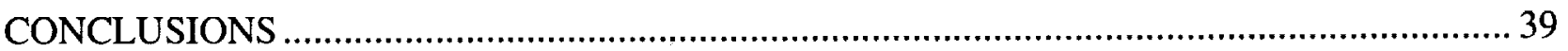

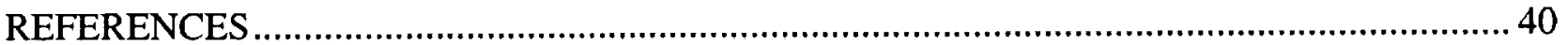

APPENDIX: COMPENDIUM OF UH-60A SLUNG LOAD TEST FLIGHTS ............................ 44

Summary of Flights by Load ......................................................................................... 44

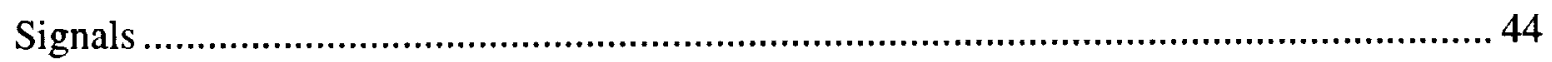

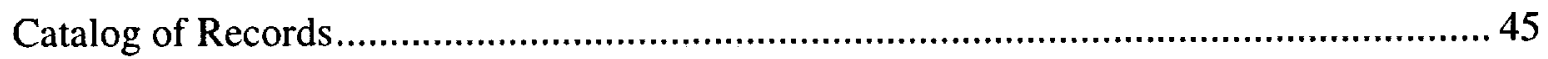

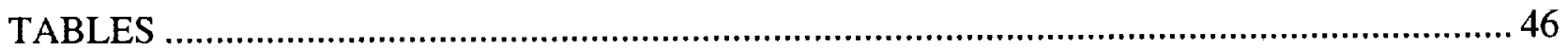




\section{SUMMARY}

Helicopter slung-load operations are common in both military and civil contexts. Helicopters and loads are often qualified for these operations by means of flight tests, which can be expensive and time consuming. There is significant potential to reduce such costs both through revisions in flighttest methods and by using validated simulation models. To these ends, flight tests were conducted at Moffett Field to demonstrate the identification of key dynamic parameters during flight tests (aircraft stability margins and handling-qualities parameters, and load pendulum stability), and to accumulate a data base for simulation development and validation. The test aircraft was a UH-60A Black Hawk, and the primary test load was an instrumented 8- by 6- by 6-ft cargo container. Tests were focused on the lateral and longitudinal axes, which are the axes most affected by the load pendulum modes in the frequency range of interest for handling qualities; tests were conducted at airspeeds from hover to 80 knots. Using telemetered data, the dynamic parameters were evaluated in near real time after each test airspeed and before clearing the aircraft to the next test point. These computations were completed in under $1 \mathrm{~min}$. A simulation model was implemented by integrating an advanced model of the UH-60A aerodynamics, dynamic equations for the two-body slung-load system, and load static aerodynamics obtained from wind-tunnel measurements. Comparisons with flight data for the helicopter alone and with a slung load showed good overall agreement for all parameters and test points; however, unmodeled secondary dynamic losses around $2 \mathrm{~Hz}$ were found in the helicopter model and they resulted in conservative stability margin estimates.

\section{INTRODUCTION}

Helicopter slung-load operations are common in both military and civil contexts. The slung load adds load rigid-body modes, sling stretching, and load aerodynamics to the system dynamics, which can degrade system stability and handling qualities and reduce the operating envelope of the combined system below that of the helicopter alone.

Military helicopters and loads are often qualified for external load operations by means of flight tests. This includes certification of loads for the multiservice Helicopter External Air Transport (HEAT) manuals (ref. 1), in which pilots evaluate specific load-helicopter combinations for flying qualities and airspeed limits without analytical support and without generating quantitative stability data. There can also be extended tests, including analyses, to certify a helicopter's load-carrying capacity (ref. 2). However, such tests are expensive and time consuming. Further, stability and envelope limits can vary significantly among the large range of loads and slings that a utility helicopter will encounter in its operating life so that flight tests cannot practically encompass the entire operating range of configurations. As a result, the history of slung-load operations records numerous incidents and accidents in which the dynamic limits of the system were unknowingly exceeded (refs. 3,4$)$. 
A 1994 industry paper advocated the accumulation of quantitative stability data from slung-load certification flight tests and pointed out the potentially significant reductions in cost and risk available from using a validated simulation to predict stability for a variety of sling-load combinations and to predict the critical cases for flight-test evaluation (ref. 2). Toward these objectives, an exploratory project was initiated at Ames in 1995 in which flight tests were conducted to identify aircraft stability and handling qualities and load-pendulum stability from telemetered data during the flight test. Stability evaluations were made after each test airspeed before going on to the next. Flight-time analysis has been used in several flight-test programs since the early 1980 s to identify structural damping or stability margins from telemetered data, allowing completion of envelope clearance tests in hours or in a single flight instead of days or on multiple flights (refs. 5-7). Such a capability would have the potential to significantly reduce slung-load qualification tests in comparison to point-by-point test and analysis. A data base was also accumulated for subsequent simulation development and validation efforts.

This report describes the flight-test methods and results, and the simulation model and validation results. The test aircraft was a UH-60A Black Hawk. Test loads included a 1,000-lb steel plate, two steel block loads of 4,000 and 6,000 lb, and an 8- by 6- by 6-ft CONEX (CONtainer Express) cargo container which was flown empty $(2,000 \mathrm{lb})$ and ballasted $(4,000 \mathrm{lb})$. The plate was suspended with a 23 -ft single cable and the remaining loads with a standard military 4-legged sling. The CONEX is a low-density load with significant aerodynamics and is limited to 60 knots in military operations owing to load stability limits (ref. 1). An instrumentation package was carried on the 4,000-lb block and the CONEX container which included accelerometers, angular rate sensors, and a fluxgate compass. The load instrumentation allowed computation of load-stability parameters during flight tests, and documented details of the load dynamics not previously available for simulation validation. Tests focused on the longitudinal and lateral axes in which the load-pendulum motions have their principal effects on aircraft control, and covered the frequency range of interest for handling qualities from 0.05 to $2 \mathrm{~Hz}$. Tests were conducted at airspeeds between hover and 80 knots. Flight-time identification was performed with the CIFER ${ }^{\circledR}$ integrated package for frequency domain analysis (refs. 8,9) operated through a special user interface designed for efficiency in the flight-test context.

The helicopter model used in the simulation was the Sikorsky GenHel blade-element model of the UH-60A (ref. 10) which was previously used and validated for handling qualities at Ames (refs. 11-13), as well as at Sikorsky (ref. 2). This helicopter model was integrated with the two-body dynamics of the helicopter-load-sling combination (ref. 14), a model of the rotor downwash field in the vicinity of the load, and a static aerodynamic model of the CONEX container obtained from wind-tunnel data (ref. 15). The validation was concerned mostly with lateral and longitudinal onaxis responses to control inputs over the frequency range of interest.

The work described here was conducted under the NASA Rotorcraft Program and as part of a U.S./Israel memorandum of agreement for cooperative research on rotorcraft aeromechanics and man-machine integration technology. Under this agreement the United States provided flight testing and data analysis and Israel provided the load instrumentation package and wind-tunnel testing of the CONEX container. 
The report begins with a discussion of the parameters to be identified and the required computations, followed by a description of the test setup, the flight-time identification system and its performance, the flight-test results for frequency responses and parameter values, and the simulation validation results. Additional documentation can be found in references 16 and 17 for the test equipment and early test results; in references 18 and 19 for the flight-time identification system; and in references 20 and 21 for the simulation and its validation.

Many individuals made significant contributions to the conduct of these flight tests including the Ames test pilots and crew chiefs, the aircraft support crew and load handlers, the telemetry ground station group, the engineering design and test services groups and wind-tunnel and instrumentation personnel. Special mention should be made of Dan Levine, Ronit Yaffe (Technion), S.Sgt. Dani Marmar (Israel Air Force), Bruce Gallmeyer, Y. S. Ng, Mei Wei, Mitch Aoyagi, Ricky Simmons, Munro Dearing (NASA), and Zoltan Szoboszlay, Lt.Col. Chris Sullivan, Chris Blanken (U.S. Army) for their extended efforts and critical contributions.

\section{KEY DYNAMIC PARAMETERS}

\section{Dynamic System}

The dynamic system (fig. 1) consists of the helicopter and load. A stability augmentation system (SAS) is closed around this, and the pilot closes another loop around that combination to regulate the system to a desired flight path and to carry out tasks associated with the helicopter's mission. The plant element is rich in dynamics, including the helicopter's rigid-body modes, rotor modes, engine and drive-train modes, and structural modes. The load adds its rigid body and elastic sling modes to this set.

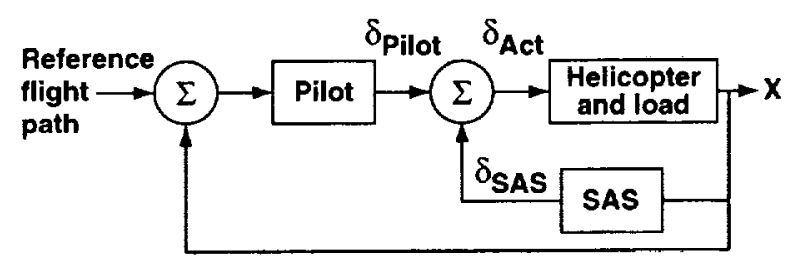

Figure 1. Dynamic system.

Over the years, the U.S. military has developed handling-qualities requirements that the closed-loop system must meet in order to provide satisfactory dynamics when the pilot exercises control to carry out the aircraft mission (ref. 22), and stability margins that the stability augmentation system must meet to avoid potentially destructive resonance with the plant dynamics (ref. 23). The clearance of loads is concerned with evaluating these handling qualities and stability margins for the combined system and the stability envelope of the load. Quantitative assessment of key stability and handlingqualities parameters for this study is based on frequency-domain analysis of the dynamic system. 


\section{Handling-Qualities Parameters}

The handling-qualities parameters of interest are properties of the on-axis closed-loop roll and

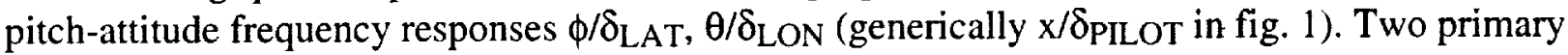
parameters are bandwidth and phase delay (ref. 22). Bandwidth is the largest input frequency for which there is at least $6 \mathrm{~dB}$ of gain margin and $45^{\circ}$ of phase margin; that is, it is the largest frequency the pilot can use and still maintain adequate margins from instability. Phase delay is a measure of the rate at which the phase changes at the frequency where the phase shift is $180^{\circ}$. Phase delay indicates how rapidly the pilot/vehicle closed-loop system is going unstable as the input frequency approaches the point of $180^{\circ}$ phase shift. Larger values result in pilot complaints about a lack of predictability and a tendency for uncommanded oscillations in attitude or flight path.

The U.S. Army's Aeronautical Design Standard, ADS-33D contains specifications for handling qualities, including boundaries for the combination of bandwidth and phase delay for Level 1 (satisfactory), Level 2 (adequate), and Level 3 (unsatisfactory) handling qualities based on pilot rating data (ref. 22). ADS-33D includes requirements for other dynamic parameters, as well as the on-axis response parameters computed in this study. Although those specifications were defined for the scout attack mission and did not consider slung loads, the ADS-33D Levels 1-3 were adopted as the reference specifications for the present study.

Another Army project at Ames undertaken to extend ADS-33D to utility helicopters and slung-load operations was recently completed (ref. 24). The results of that study and results from references 25 and 26 have been used to extend ADS-33D to cargo and utility helicopters (ref. 27). The results from reference 24 regarding slung-load configurations will be discussed in a later section.

\section{Stability Margins}

Stability margins define the stability robustness of the aircraft-SAS feedback loop to changes in gain (gain margin) and phase (phase margin). Typical requirements from MIL-F-9490D (ref. 23) for production aircraft are that the "broken loop" response of the SAS signal to the inputs to the primary actuators $\left(\delta_{\mathrm{SAS}} / \delta_{\mathrm{ACT}}\right.$ in fig. 1$)$ have $6 \mathrm{~dB}$ of gain margin (a factor of 2 ) and $45^{\circ}$ of phase margin. These requirements also ensure well damped responses to turbulence and pilot inputs. The UH-60A has roll, pitch, and yaw SAS channels, and stability margins can be computed for these channels. Phase margin is computed at the crossover frequency where gain crosses through $0 \mathrm{~dB}$, and is the margin from $-180^{\circ}$ of phase shift there. The gain margin is the value of gain where the phase angle goes through $-180^{\circ}$. There can be multiple crossings of $0 \mathrm{~dB}$ and $-180^{\circ}$, in which case the margins are taken as the smallest for the crossings in the frequency range of interest for handling-qualities analysis, $0.05-2.0 \mathrm{~Hz}$. The stiff airframe of the UH-60A precludes the potential for coupled structural/flight-control resonance at higher frequencies (above $2 \mathrm{~Hz}$ ), and the critical stability margins occur in the handling-qualities frequency range. Large flexible helicopters like the MH-53J can have such resonance, and frequency sweep data are generated with tailored automated inputs and structural monitoring. 


\section{Load Pendulum Modes}

Linear analysis indicates that the load adds a number of natural modes to those of the helicopter alone; these are two pendulum modes, two yaw roots (real or oscillatory, depending on load aerodynamics), and three oscillatory modes for sling vertical stretch and load pitch and roll attitude. Of these, only the pendulum modes interact with the helicopter in the frequency range of interest. Pendulum frequencies can be roughly estimated from a point-mass dumbbell approximation of the system as

$$
\omega_{p}=\sqrt{\frac{g}{\ell}\left(1+\frac{W 2}{W I}\right)}
$$

where $\ell, \mathrm{W} 1$, and $\mathrm{W} 2$ are the sling length and the load and helicopter weights, respectively. Pendulum frequencies between 1 and $2 \mathrm{rad} / \mathrm{sec}$ are estimated for the test configurations. (A more accurate approximation, which accounts for the effect of helicopter inertia, is given in ref. 20).

The pendulum modes at hover are decoupled lateral and longitudinal modes which are excited by lateral and longitudinal control inputs, respectively. Each mode can be identified by fitting a secondorder transfer function to the frequency response of the load angular rate in the region around the pendulum frequency.

\section{FLIGHT TEST SETUP AND PRELIMINARY EVALUATIONS}

\section{Test Configurations}

Slung-load configurations can be viewed as two rigid bodies connected by a sling, and defined by all the fixed parameters of the helicopter, load, and sling for which numerical values are required in the system's equations of motion. These parameters have a more or less important role which can be studied in simulations or with linear analysis. Out of the existing range of such configurations, the present tests are limited to a utility helicopter and a small sample of loads and slings rigged to a single-point suspension, but this suffices for the present objectives. Linear analysis for single and multi-cable slings indicates that the primary parameters affecting load motions are as follows. The load pendulum frequencies are set by sling length, load weight, and helicopter inertias, whereas helicopter c.g.-to-hook offset couples the load motions to the helicopter attitude dynamics which then are a source of pendulum damping in accordance with helicopter aerodynamics and inertias. Load aerodynamics increase with airspeed and have an increasing effect on load dynamics depending on the magnitude of the specific forces and moments produced.

Flight tests were performed with an instrumented UH-60A and with the test external loads and slings shown in figures 2 and 3 . These included a CONEX cargo container, a 4,000-lb steel block, a 6,000$\mathrm{lb}$ load made up of several steel blocks, and a 1,000-lb steel plate. The plate was suspended with a single cable and bridle, and the remaining loads with a standard military 4-legged sling. 


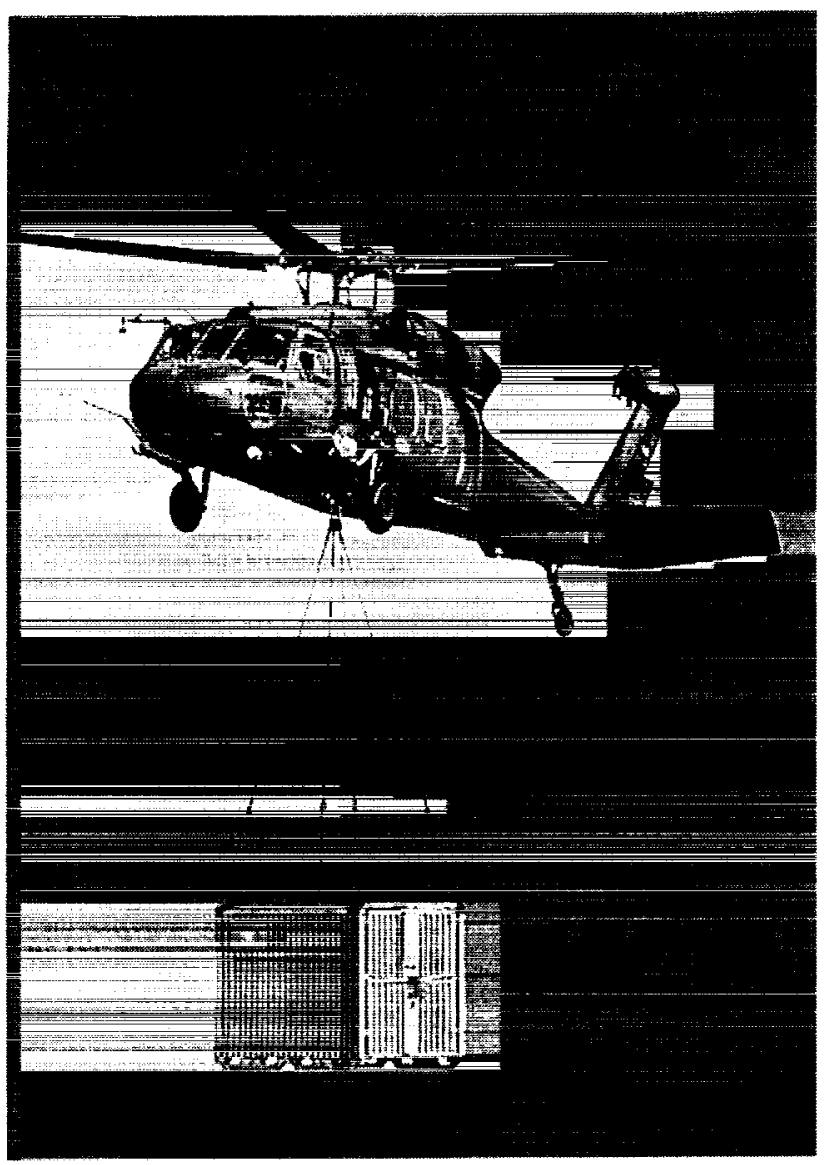

(a) Test configuration with CONEX.

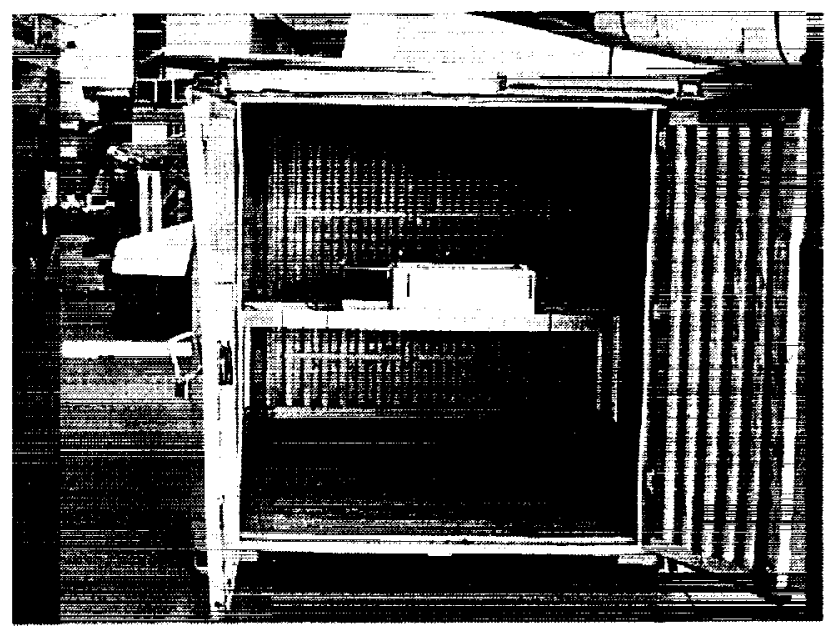

(b) CONEX, instrumentation package, compass boom.

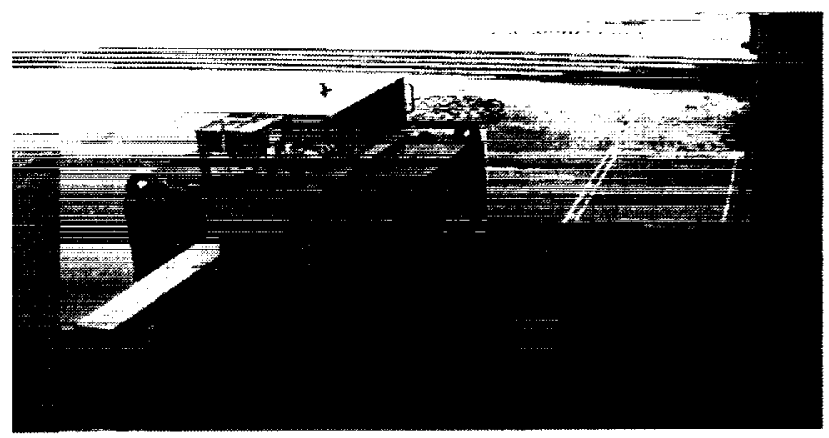

(c) 4,000-lb block, instrumentation package, compass boom.

Figure 2. Slung-load configuration and load instrumentation.

Helicopter-The normal aircraft takeoff gross weight for slung-load operations is 14,600 -lb, including two pilots, a crew chief, research instrumentation, and takeoff fuel. Approximately $1,800 \mathrm{lb}$ of fuel ( $2 \mathrm{hr}$ of flight) is available for use during a test, with corresponding changes in gross weight and with forward movement of the c.g. by 9 inches. Aerodynamic and other data for the UH$60 \mathrm{~A}$ can be found in references 10 and $28-30$.

The UH-60A hook is mounted in the floor of the helicopter and can be released manually at the hook or electronically from the right-seat stick. It is gimbaled only in roll so that the load-sling combination swings laterally about this axis, and longitudinally at the hook load beam about 8 inches lower. The hook is offset $4.3 \mathrm{ft}$ below the aircraft c.g. and up to $1 \mathrm{ft}$ forward of the c.g., depending on fuel weight, and is rated at $8,000-\mathrm{lb}$ carrying capacity. 

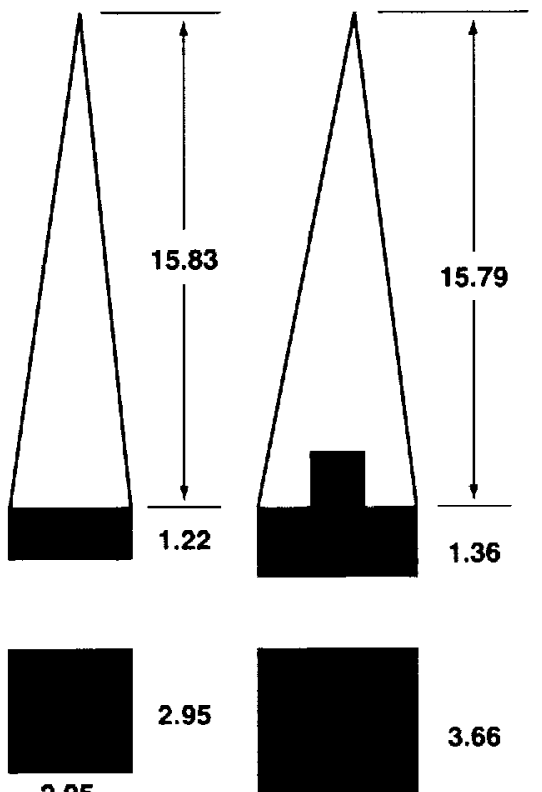

2.95

2.95

3.66

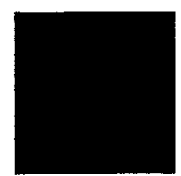

3.66
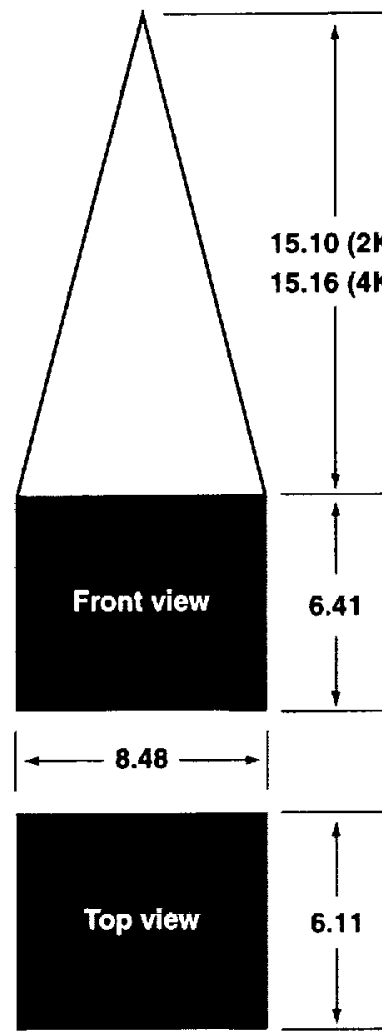

$15.10(2 K)$

$15.16(4 K)$

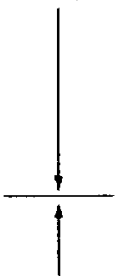

6.41
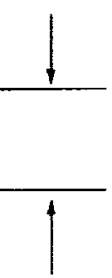

6.11

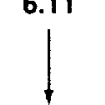

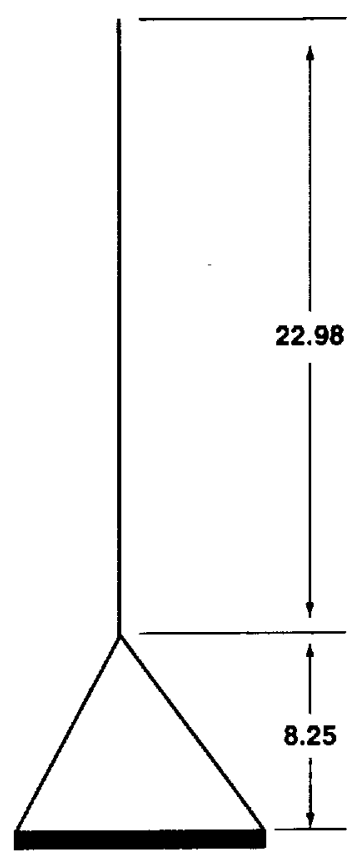

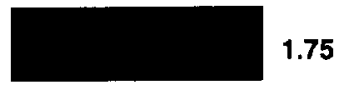

6.38

1K plate

$4 \mathrm{~K}$ block

6K block

CONEX

Units: ft, lbs, sec

\begin{tabular}{|l|l|l|l|l|l|}
\hline & $1 K$ plate & 4K block & 6K block & $\begin{array}{l}\text { Empty } \\
\text { CONEX }\end{array}$ & $\begin{array}{l}\text { Ballasted } \\
\text { CONEX }\end{array}$ \\
\hline Weight & 1130 & 3895 & 6384 & 1794 & 4105 \\
\hline Density & 456 & 391 & 315 & 5.4 & 12.5 \\
\hline Ixx & 108 & 104 & 308 & 785 & 1876 \\
\hline lyy & 212 & 104 & 296 & 569 & 1482 \\
\hline Izz & 121 & 174 & 471 & 766 & 1377 \\
\hline
\end{tabular}

Figure 3. Load-sling test configurations: units-ft, lb, sec.

Loads and slings-Flight-test data were obtained for the aircraft alone and with the load-sling combinations noted above. The dimensions and mass-inertia data for these loads are included in figure 3. Load weights ranged from 1,000 to $6,000 \mathrm{lb}$ (up to $41 \%$ of helicopter takeoff weight). The CONEX weight was varied by ballasting it with bags of loose material of density $43 \mathrm{lb} / \mathrm{ft}^{3}$. It was flown empty at about $2,000 \mathrm{lb}$ and ballasted at 4,000 lb.

The test loads other than the plate were suspended with a standard military four-legged sling set rated at 10,000 lb and weighing $52 \mathrm{lb}$. Each leg of this sling was $15.83 \mathrm{ft}$ long unloaded. Sling 
stretching was measured at $0.8 \mathrm{ft}$ for the heaviest test load, and stretching frequencies are well above the range of interest for handling qualities. The HEAT manual provides details of the sling hardware and construction, and specifies the method of rigging this sling to standard loads such as the CONEX (ref. 1). More generally, the military inventory includes single-cable slings from 3 to $140 \mathrm{ft}$, and multi-cable slings rated to $40,000 \mathrm{lb}$ which can be rigged with two to six legs, depending on the load (ref. 1). This sling was flown in the present tests with and without a swivel, which, for the CONEX, resulted in periodic or steady yaw rates depending on the presence of the swivel.

In preliminary flight evaluations the blocks were well-behaved out to the power-limited level flight speed of the aircraft (about 140 knots). These are very dense loads which generate little aerodynamic specific force over this speed range. The CONEX is a 6- by 6- by 8-ft steel container with corrugated sides and 6-inch skids along the long dimension. It is much less dense $\left(5-12 \mathrm{lb} / \mathrm{ft}^{3}\right.$ average density in the present tests) with substantial aerodynamics that limit its envelope to 60 knots in military operations (ref. 1). However, the critical speed varies with load weight, and the CONEX was flown out to 70 knots IAS when ballasted without encountering the onset of instability. The effects of its aerodynamics included a load trail angle in proportion to the drag specific force, and yaw rotations of the load. These rotations began in hover owing to the downwash rotational field, and increased beyond $100 \mathrm{deg} / \mathrm{sec}$ above 50 knots airspeed. More generally, load aerodynamics can couple the yaw degree of freedom with the load pendulum motions as instability is approached, but the high yaw rates of the CONEX appeared to prevent coupling of these degrees of freedom in the present tests.

\section{Instrumentation and Signals}

Sensors-The test aircraft was heavily instrumented for an earlier air-loads study at Ames, as described in reference 31 . The sensors recorded for the slung-load tests were those measuring the aircraft rigid-body states (accelerometers, rate and attitude gyros, air data, alpha-beta vanes, radar altimeter) and control deflections (stick positions, SAS outputs, mixer inputs, primary servo positions) with telemetry and recording rates of $209 \mathrm{~Hz}$. Further, the hook was instrumented with a strain gauge load weight cell, and a video camera mounted in the hook hole recorded load motions relative to the aircraft.

A portable load instrumentation package weighing about $100 \mathrm{lb}$ and costing approximately $\$ 40,000$ was assembled for these tests (ref. 32). It contained three-axis accelerometers and rate gyros along with a power supply, filters, a PCM encoder, and a telemetry transmitter with output rates of $260 \mathrm{~Hz}$. In addition, a gimbaled magnetic fluxgate compass was mounted on an aluminum boom extending $2.5 \mathrm{ft}$ from the load to minimize magnetic interference. The instrumentation package is shown in figure 2 mounted on a support rail at midheight in the CONEX and on the surface of the 4,000-lb block. The compass boom can be seen mounted on the sides of these loads.

This sensor set suffices for the identification of the dynamic parameters, which require only the helicopter and load angular rates and heading, and the control positions. Important limitations were the lack of sensors for load attitude and translational velocity, and the hook force, which could be used to extract load aerodynamics from the flight data and for more detailed simulation validation of the load dynamics. In addition, the load instrumentation did not cover the unanticipated large yaw 
rates of the CONEX load, which, at higher airspeeds, saturated the $120-\mathrm{deg} / \mathrm{sec}$ limit of the yaw rate gyro and induced large dynamic lags in the fluxgate compass signal. Nevertheless, the sensors provided good access to the load dynamics for the block loads at all test speeds, and for the CONEX up to 50 knots.

Signals-The helicopter sensors of principal interest are the angular rate and heading gyros. The rate signals typically contain a moderate amount of vibration at 2-3 deg/sec and at frequencies of 1-4 per rotor revolution, plus significant biases. Vibrations are well above and biases are well below the frequency range for the identification computations and have no effect on the frequency responses in this range. Initially the research directional gyro was not slaved and had a random startup bias and drift. This was replaced by a slaved gyro for the final set of tests.

The load signals from a lateral frequency sweep with the CONEX are shown in figure 4. The lateral pendulum is excited by inputs in the neighborhood of the pendulum frequency. The vertical accelerometer contains the centrifugal acceleration of the load pendulum swinging, which can be seen in figure 4 in the interval of $60-80 \mathrm{sec}$. The low-frequency variations in the $\mathrm{x}, \mathrm{y}$ accelerometers in this record (taken at $30 \mathrm{knots}$ ) are the signature of the steady load trail angle owing to load drag combined with load yaw motions which distribute the specific drag to the $\mathrm{x}$ and $\mathrm{y}$ accelerometers according to the yaw time-history. For a simple pendulum, the apparent gravity is aligned with the cable direction during pendulum swinging in the absence of load aerodynamic force. In this case, the $\mathrm{x}, \mathrm{y}$ accelerometer outputs are zero and the $\mathrm{z}$ accelerometer measures the hook force, assuming the $\mathrm{z}$ accelerometer is aligned with the cable direction. Aerodynamic force results in misalignment of the apparent gravity and the cable direction so that the $\mathrm{x}, \mathrm{y}$ accelerometers measure the $\mathrm{x}, \mathrm{y}$ aerodynamic force components, assuming again that the $\mathrm{z}$ accelerometer is aligned with the cable direction. For multi-cable slings, the line segment from hook to load c.g. is analogous to the cable direction of a simple pendulum and a similar argument can be traced concerning the accelerometer signals.

The yaw and yaw rate histories in this record indicate periodic yawing of the load during which the (unswiveled) sling wound up on itself and unwound. At airspeeds above 50 knots, the sling was seen in video recordings to wind up as many as 8-10 turns. The yaw motion is driven by the CONEX aerodynamics and, for the unswiveled attachment, this was countered by yaw resistance at the hook. The pitch and roll rate histories in figure 4 represent the angular velocity associated with load lateral pendulum motions which is distributed to the load pitch and roll rate sensors according to the load yaw history.

Signal Processing-Relatively little processing of the received signals was required for the identification computations. The helicopter stability margins and handling-qualities parameters were computed from the helicopter control and angular velocity signals with nothing more than scaling of the control signals. Computation of the load-pendulum roots required transformation of the load pitch and roll rate signals to axes aligned with the helicopter heading (p2', q2' in fig. 5) in order to obtain angular rates that measure swinging of the load c.g.. The transformed signals for the lateral sweep record in figure 4 are included in figure 5 , and show that the load angular rates for this sample resolve mainly into roll rotation about an axis aligned with helicopter heading. In the early flights 
with the CONEX, the first and last records of each flight were used to determine the bias of the unslaved helicopter heading gyro for these computations.
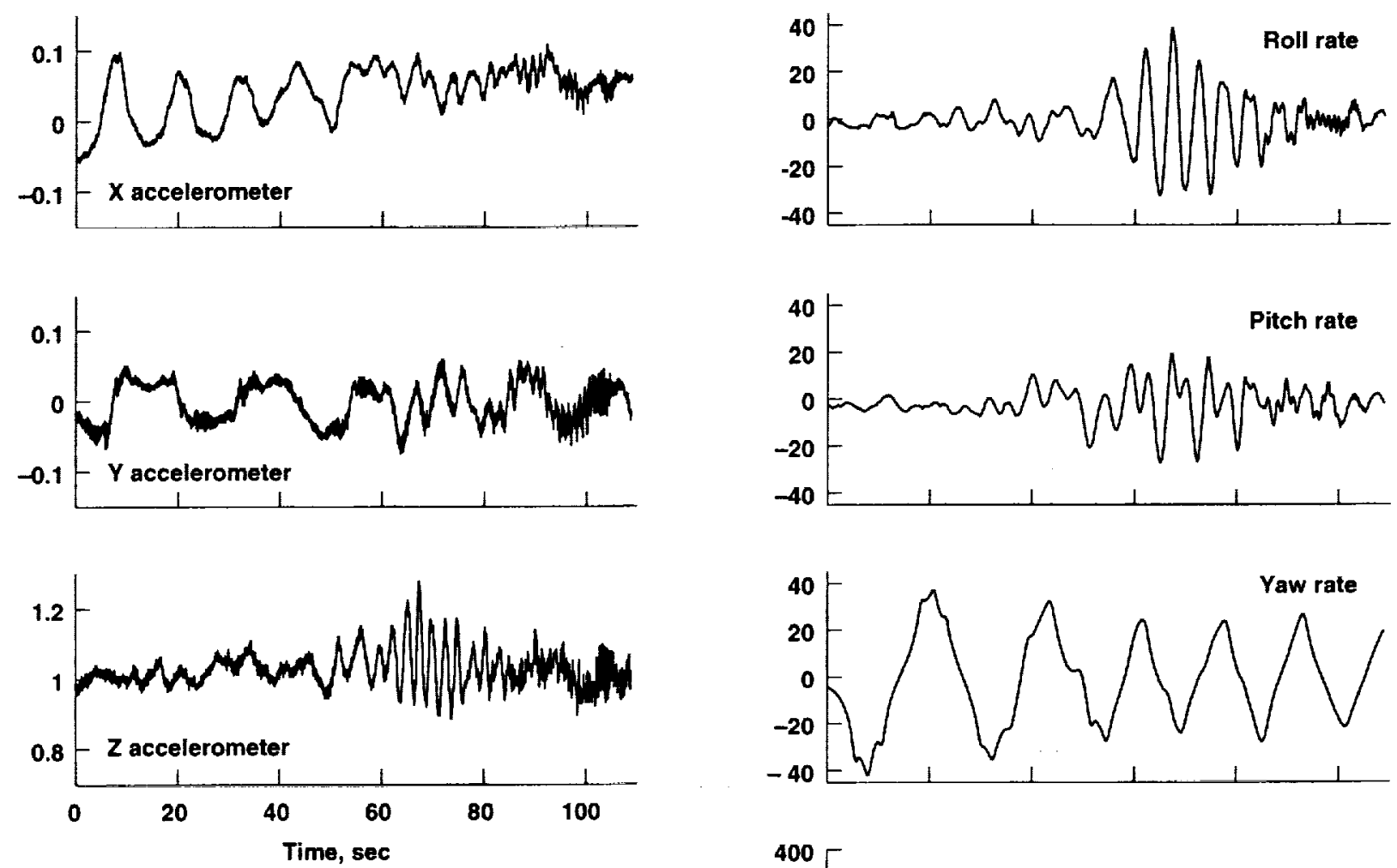

Units: g, deg, sec

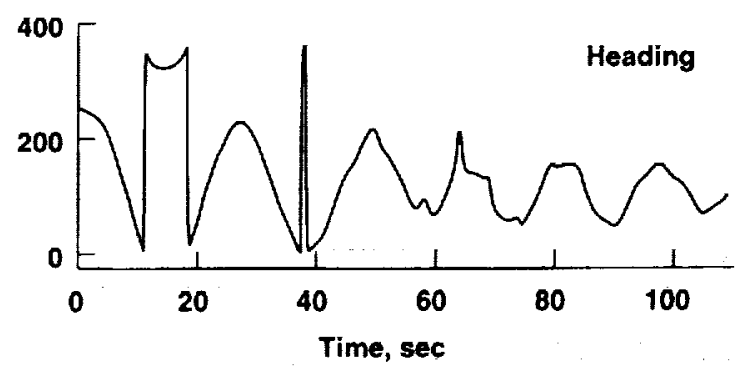

Figure 4. Load sensor signals: 30 knots, lateral sweep, 4,000-lb CONEX load.

\section{Flight Test Profile}

Two procedures were used to attach the external load to the helicopter. In the early flights, the CONEX hookup was carried out by two load handlers atop the load (ref. 17). The helicopter approached and stabilized overhead for the hookup, with guidance from the crew chief. The rotor wake carried a significant amount of debris which buffeted the handlers during the approach, but this lessened when the helicopter was directly overhead. In the later flights, load hookup was effected by the "self hook" procedure. The aircraft taxied up beside the load, which had been prepared on the 
ramp with the sling laid out lateral to the load, including an extension line if required. The crew chief then reached down through the hook hatch to pick up the hook or extension line and drew in the sling apex clevis and engaged it. The procedure was attended by a ground director and a safety monitor until the load was airborne. During the flight, the crew chief continually monitored the load for swinging in excess of a $30^{\circ}$ safety limit.

$$
\begin{gathered}
\Delta \psi \equiv \psi_{2}-\psi_{1} \\
\left(\begin{array}{l}
\mathrm{p} 2^{\prime} \\
\mathrm{q} 2^{\prime}
\end{array}\right)=\left[\begin{array}{ll}
\cos \Delta \psi & -\sin \Delta \psi \\
\sin \Delta \psi & \cos \Delta \psi
\end{array}\right]\left(\begin{array}{l}
\mathrm{p} 2 \\
\mathrm{q} 2
\end{array}\right)
\end{gathered}
$$

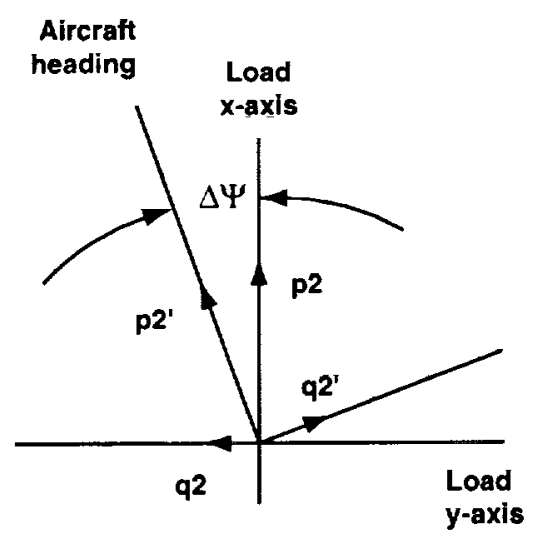

Transformed rates: 30 knots, lateral sweep, 4,000-lb CONEX
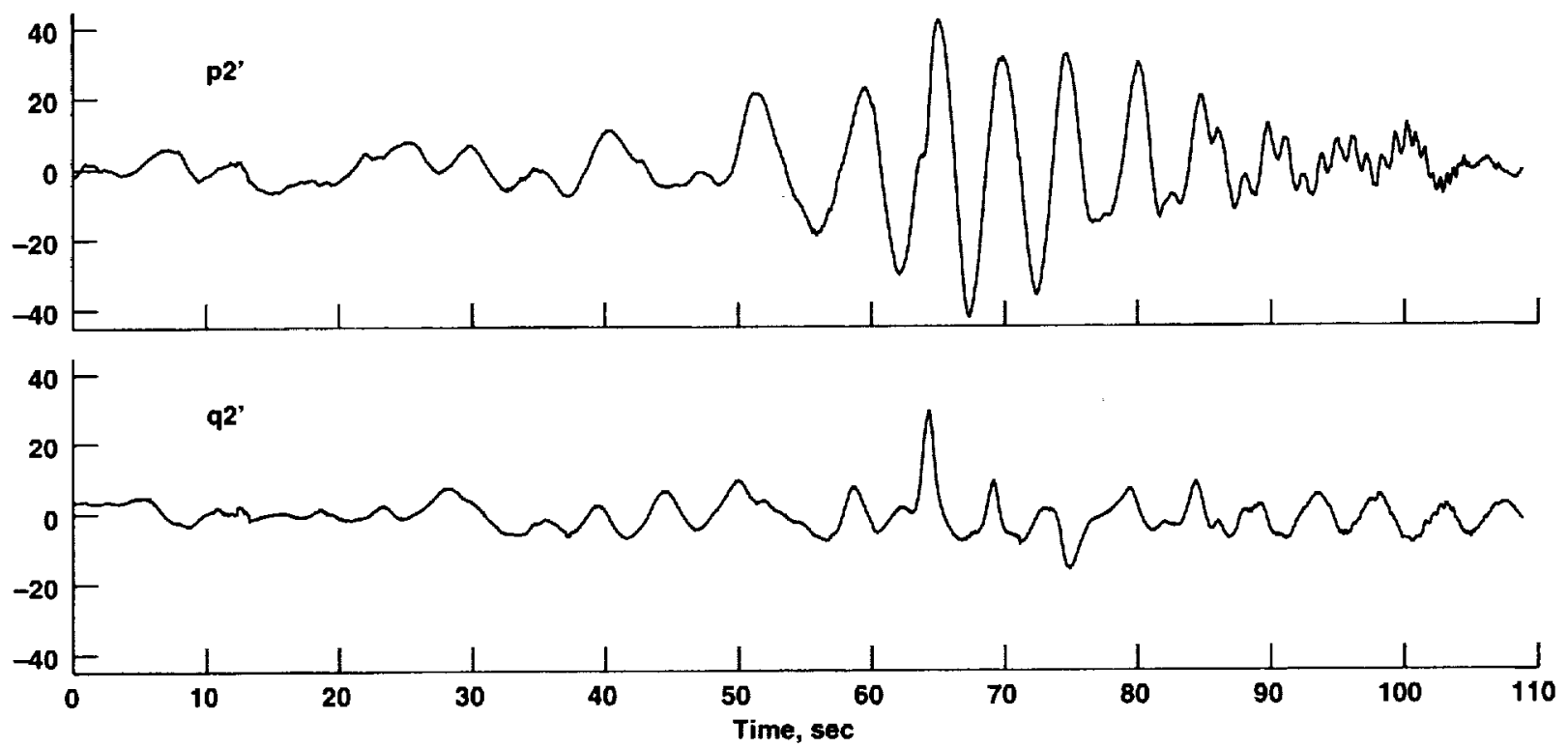

Figure 5. Transformed load angle rates (units: $\mathrm{deg} / \mathrm{sec}$ ).

Flight data were taken with the stability augmentation system (SAS) on and flight-path stabilization system (FPS) off. Otherwise the FPS would superpose control inputs on those of the pilot. 
Data records at each flight condition consisted of a trim record, followed by three repeated frequency-sweep records, and ended with a pair of doublets in opposite directions with sufficient record length to capture the lightly damped pendulum modes. The identification computations used only the frequency-sweep records, and the doublets were recorded for time-domain confirmations. This sequence was performed chiefly with the longitudinal and lateral controls and at hover and at speeds of 30, 50, and 80 knots. A total of 19 data flights (20 flight hours) were flown during 1995-97 and 1999 at Moffett Field in calm winds. The flight records are archived electronically at Ames and a compendium of these records is provided in the appendix.

Frequency sweeps-Identification based on frequency-sweep flight-test data has been developed over the past decade, and numerous examples have been reported in the literature. The design and execution of pilot-generated frequency-sweep inputs has been considered in detail in reference 33 and 34 . The main considerations in generating good data are to remain centered about the reference trim flight condition, and to avoid large correlated secondary control inputs, gust disturbances, control saturation, and excessive excitation of lightly damped modes in the frequency range of the test. Each aircraft and test-frequency range has its own unique considerations, but the UH-60A at forcing frequencies to $2 \mathrm{~Hz}$ presented no special problems.

A sample lateral axis control sweep is shown in figure 6. The pilot varied the forcing frequency smoothly over the range of interest for handling qualities, $0.05-2 \mathrm{~Hz}$, beginning and ending with a short period of trim. The pilot used reduced amplitude at low frequencies to avoid the large excursions in helicopter attitude associated with low-frequency inputs, held amplitude to 1-1.5 inches (10-15\% of control range) at mid-frequencies to avoid control saturation, and was careful to stop the sweep at $2 \mathrm{~Hz}$ to avoid resonance with the lowest frequency rotor and structural modes. The complete record was about $90 \mathrm{sec}$ long. Test engineers assisted with timing and frequency monitoring during the sweep. The pilot tried to maintain the reference conditions with occasional uncorrelated low-frequency off-axis inputs, and the off-axis controls and the pitch and yaw attitude departed very little from their trim values, as seen in figure 6. Generally, airspeed variations up to 10 knots around the reference speed can be tolerated without significant loss of linearity, and excursions of this size were common away from hover. Helicopter roll rate tracked the control history out to around $1 \mathrm{~Hz}$ (fig. 6), with amplitude up to $15 \mathrm{deg} / \mathrm{sec}$ around the mean; the

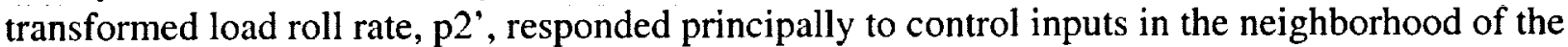
pendulum frequency (about $0.25 \mathrm{~Hz}$ ) with peak amplitude of $20 \mathrm{deg} / \mathrm{sec}$.

\section{Data Acquisition and Flight-Time Identification}

Data acquisition-The data acquisition system is shown in figure 7. All sensor signals were recorded on board the aircraft and telemetered simultaneously to the ground station, which was equipped for real-time strip-chart displays, data recording, and video monitoring of the aircraft when within camera range. The on-board load video was also recorded, but attempts to transmit it to a ground station monitor were only marginally successful. In addition, a server-client system provided data communications from the real-time telemetry receivers to a system of three workstations where the flight-time computations were performed. Data were input to the workstations using an on-off switch which allowed the test engineer to store and concatenate the three frequency-sweep records obtained at each test condition. These workstations were slow (36 MHz) compared to current 
workstations (200-500 MHz). The ground station and telemetry support was provided by Dryden's Western Aeronautical Test Range facility resident at Moffett Field. Details of the server-client system are reported in reference 18.
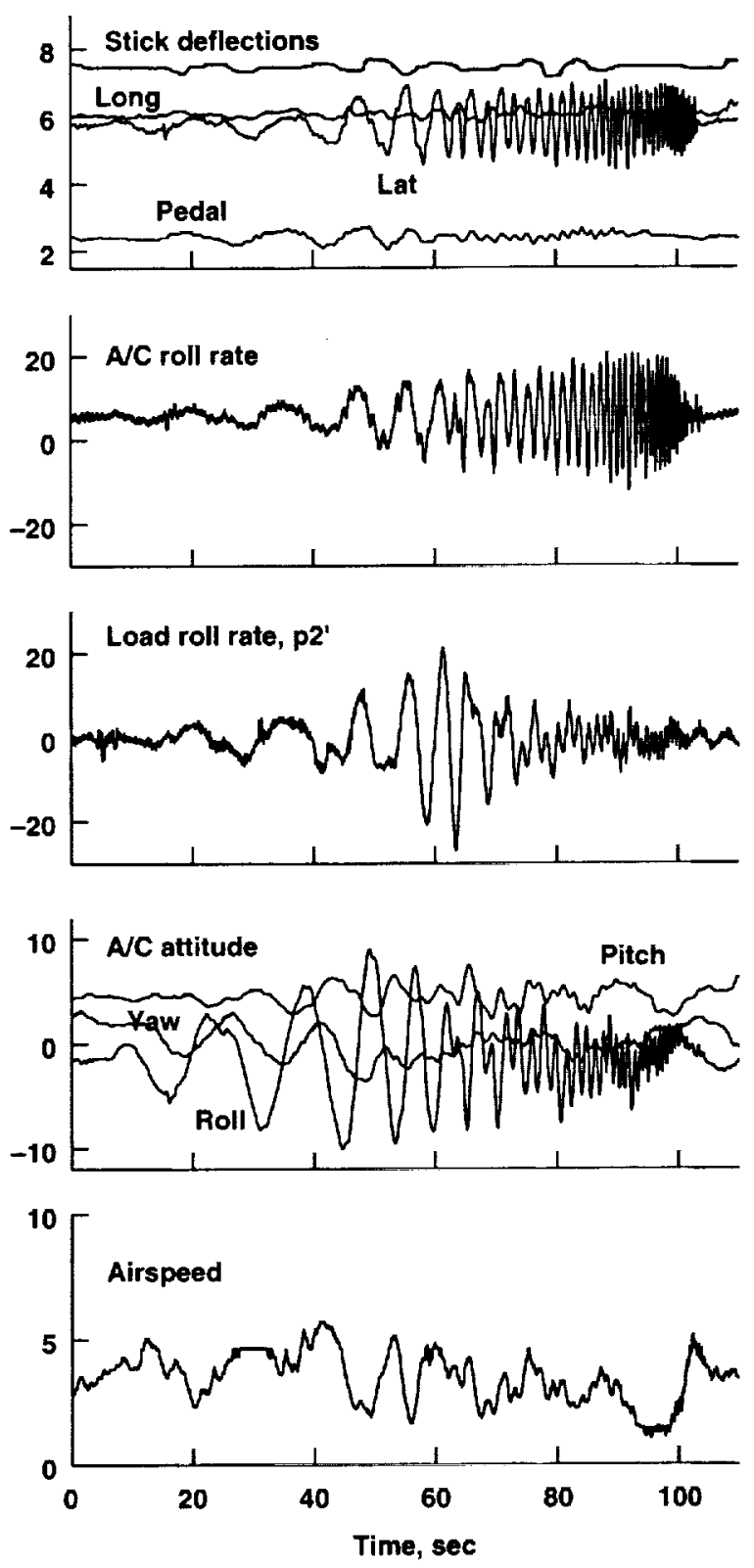

Units: in, deg, deg/sec, knots

Figure 6. Sample frequency sweep: hover, lateral sweep, 4,000-lb CONEX load. 


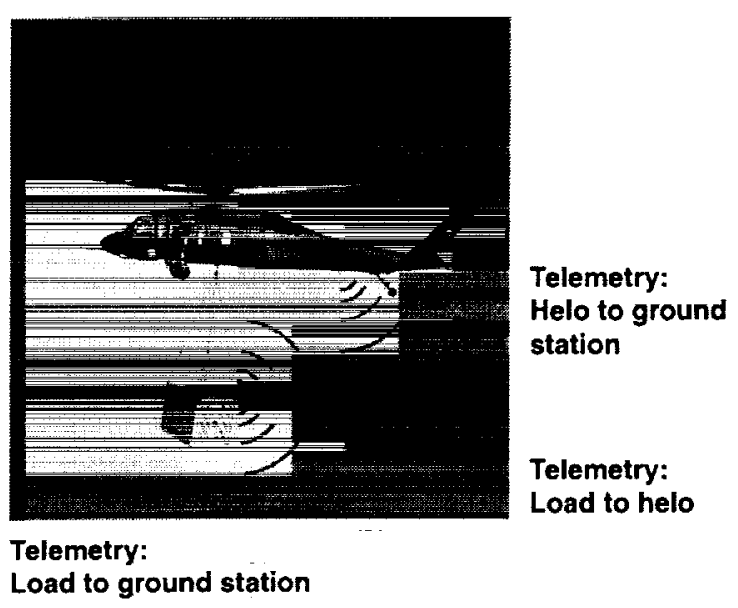

Ground Telemetry Station

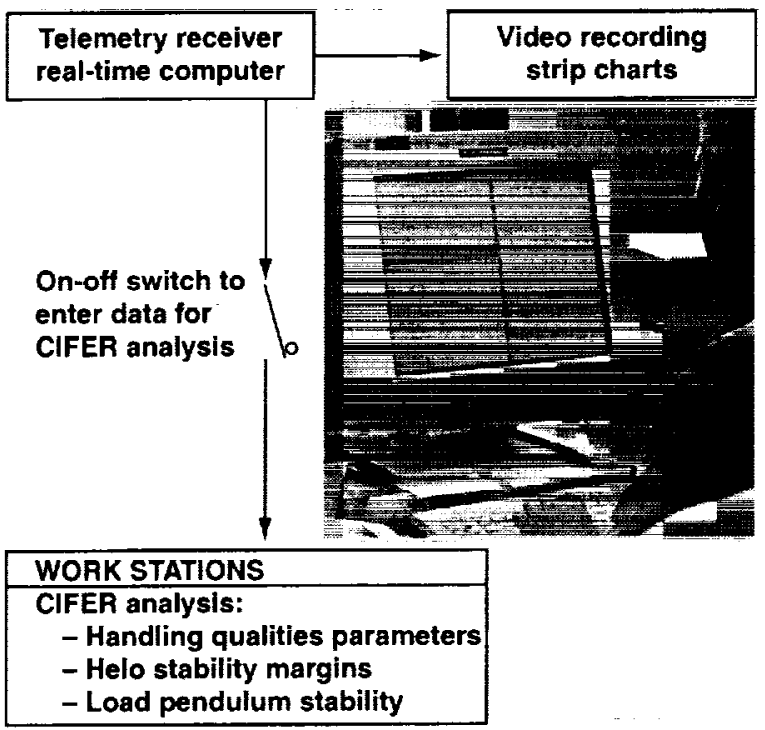

Figure 7. Data acquisition and flight-time analysis system.

Identification computations-The required computations were carried out using the CIFER ${ }^{\otimes}$ software for interactive frequency-domain analysis (refs. 8, 9). CIFER ${ }^{\circledast}$ provides a comprehensive set of utilities for aeronautical applications and has received wide application in the past decade to both helicopters and fixed-wing aircraft.

Frequency-response functions between input and output flight records are determined for the frequency-domain identification. These responses represent the first harmonic approximation of the nonlinear plant dynamics. The residual signal associated with the higher-order harmonics is seen as noise in this procedure. The quality of this approximation is measured by the coherence function, $\gamma^{2}$, which is the linear correlation between input and output as a function of frequency and has values in 
the interval $[0,1]$ (ref. 35). Turbulence, measurement errors, correlated off-axis inputs, and nonlinear dynamics reduce coherence. An objective of the computations is to maintain adequate coherence $\left(\gamma^{2}>0.6\right)$ at all frequencies in the frequency range of interest, and there are numerous devices aimed at doing this, both in generating the flight data and in the computational procedure (ref 9).

The CIFER ${ }^{\circledast}$ computational steps in the slung-load identification are outlined in figure 8 . First, the available frequency-sweep records are concatenated so as to maximize the information for the flight condition. Second, the single-input-single-output Bode plots are computed for one or more selected "window" sizes. The concatenated record is divided into overlapping time intervals, or windows, for these computations and the final frequency responses are obtained as averages of the results from these windows. Window size determines the lowest frequency for which the frequency response can be given and the frequency range in which coherence is optimized. Multiple window sizes can be used and combined to optimize the resulting coherence over the range of interest. Third, correlation of the responses with off-axis inputs is removed to yield conditional responses. Fourth, the multiwindow optimization is performed. Finally, the handling-qualities parameters and stability margins are computed using the CIFER ${ }^{\otimes}$ Bode plot analysis utility, and the load pendulum roots are determined by fitting a second-order pole to the load's frequency response in the neighborhood of the pendulum frequency using CIFER $^{\circledR}$ s fitting utility.

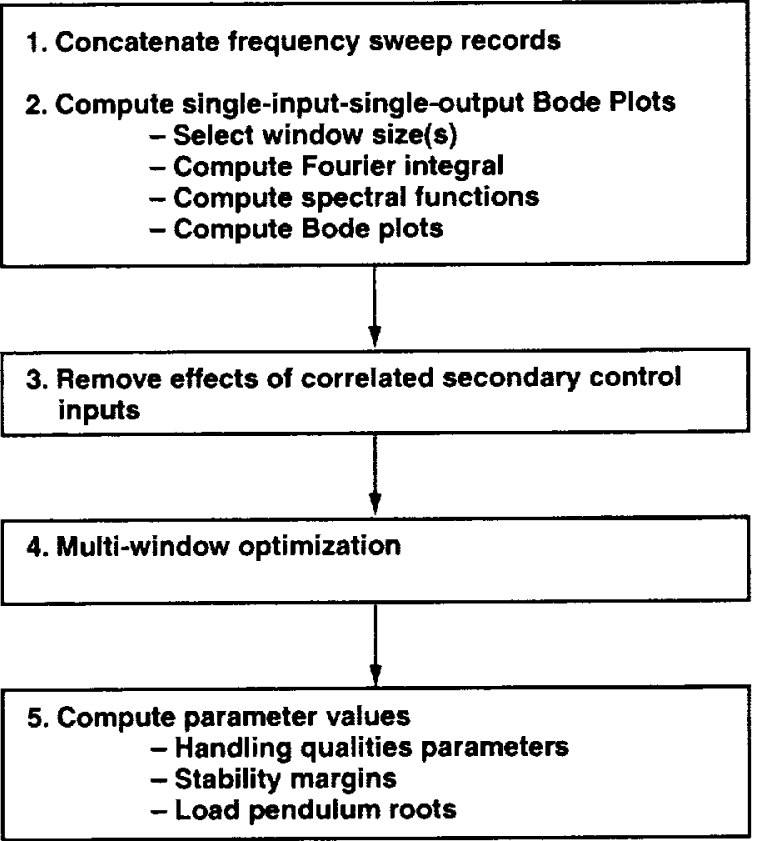

Figure 8. Identification procedure. 
Flight-time identification and user interface-Execution time is a factor of interest in the flight-test context. The computation time and accuracy of the procedure depend on several factors, including data rate, number of windows, conditional response computations, and data dropouts in the records. Postflight analysis used data at $100 \mathrm{~Hz}$, five windows $(10,20,25,30$, and $40 \mathrm{sec})$, and on-board data recordings which were normally free of data dropouts. In addition, execution time depends on user interface efficiency.

The flight-time procedure for the 1997 flights used the existing CIFER ${ }^{\circledast}$ user interface which required numerous screens and keyboard inputs to carry out the above procedure (ref. 16). Consequently, computation time reductions were important. The flight-time procedure used data decimated to $50 \mathrm{~Hz}$ and a single window $(20 \mathrm{sec})$. The $50-\mathrm{Hz}$ data rate satisfies the working rule of 16 times the highest frequency of interest. Computation time increases significantly with the number of windows, so a single 20 -sec window was used; it provided frequency responses down to $0.05 \mathrm{~Hz}$. The effects of correlation with off-axis inputs were found to be small in nearly all cases so the timeconsuming computations required for their removal were dropped from the flight-time procedure. The inevitable wild points and momentary dropouts in telemetered data were seen as high-frequency noise in the frequency-domain analysis and usually had no significant effect on data quality.

Extended dropouts owing to antenna shadowing occurred sometimes, depending on aircraft heading, but these were apparent on the strip charts, and the test record was repeated immediately. This system gave satisfactory accuracy in matching postflight results, and the entire identification procedure took an average of $4 \mathrm{~min}$ from the completion of the last frequency-sweep record to the appearance of frequency responses and parameter values on screen. This was a little longer than it took for the pilots to complete the doublets and to be ready for the next test point. The main problem was the excessive repetitive inputs of the user interface and its error-proneness in the flight-test context.

A graphical user interface was designed to address this problem and was demonstrated during the 1999 flights. The interface consists of a split screen (fig. 9) with keyboard and point/click inputs. The top left subscreen is used to enter the case (case name, control axis, record numbers to be processed, window sizes). The lower left subscreen changes with the computations to be performed (handling qualities, stability margins, or load modes) and provides for entry of basic parameters associated with each type of computation. The right screen provides for display and printout of numerical and graphical results. The time saved on input overhead was used in part to allow two windows in the computations. The resulting system required $3.5 \mathrm{~min}$ on the $36-\mathrm{MHz}$ workstations, and the results closely matched those of the postflight computations in all cases. The same procedure on a readily available $195-\mathrm{MHz}$ machine was found to require only $40 \mathrm{sec}$, which fits the flight-test pace very well. The flight-time identification system is discussed in greater detail in reference 19 , and the user interface is available for UNIX machines with the CIFER ${ }^{\$}$ liceñse. 


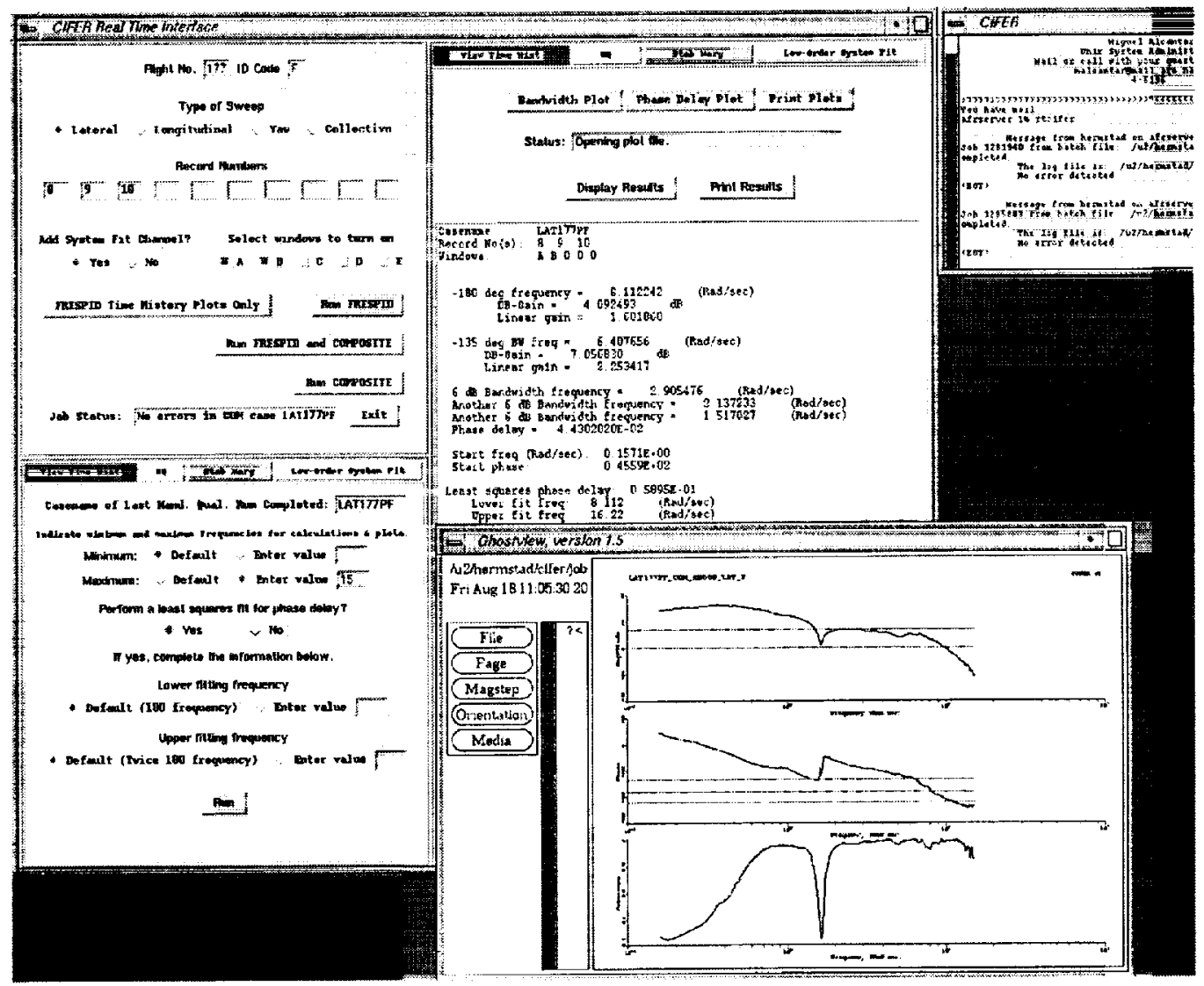

Figure 9. Graphical user interface for CIFER ${ }^{\circledR}$.

FLIGHT TEST RESULTS

\section{Handling Qualities}

The detailed effects of the load on the attitude responses $\phi / \delta_{\mathrm{LAT}}, \theta / \delta_{\mathrm{LON}}$ are seen in figure 10 , which compares hover responses for no load and for block loads. The no-load response is that of the rigid-body dynamics ( approximately

$$
\frac{\phi}{\delta_{L A T}}=\frac{L_{\delta L A T}}{s\left(s-L_{p}\right)}
$$

for the lateral axis) out to $1 \mathrm{~Hz}$. The load introduces a pole-zero combination at the pendulum frequency. For the lateral axis (fig. 10(a)) this reduces gain near the pendulum frequency (at about $1.5 \mathrm{rad} / \mathrm{sec}$ ), increases phase shift at frequencies below the pendulum frequency, decreases phase shift above the pendulum frequency, and reduces coherence at the pendulum frequency. These effects reflect excitation of the load pendulum modes by cyclic inputs in this frequency range (shown in a later figure) and a corresponding loss of helicopter response. These effects increase with load weight. The load effects on the gain curve can move the gain margin bandwidth below the pendulum frequency as in the figure, or result in multiple values below and above the pendulum 
frequency, thereby reducing the attitude bandwidth of the system significantly. The effects of the load on the Tongitudinal responses (fig. 10(b)) are much reduced compared to the Iateral axis. This is because of the much larger helicopter pitch inertia (by a factor of 7) which reduces coupling of the load longitudinal pendulum motions with the helicopter pitch-attitude dynamics. Physically, the specific moments of the load on the helicopter are proportional to the hook-to-c.g. offset and inversely proportional to inertia.

(a) Roll response: $\phi / \delta_{\mathrm{LAT}}$.
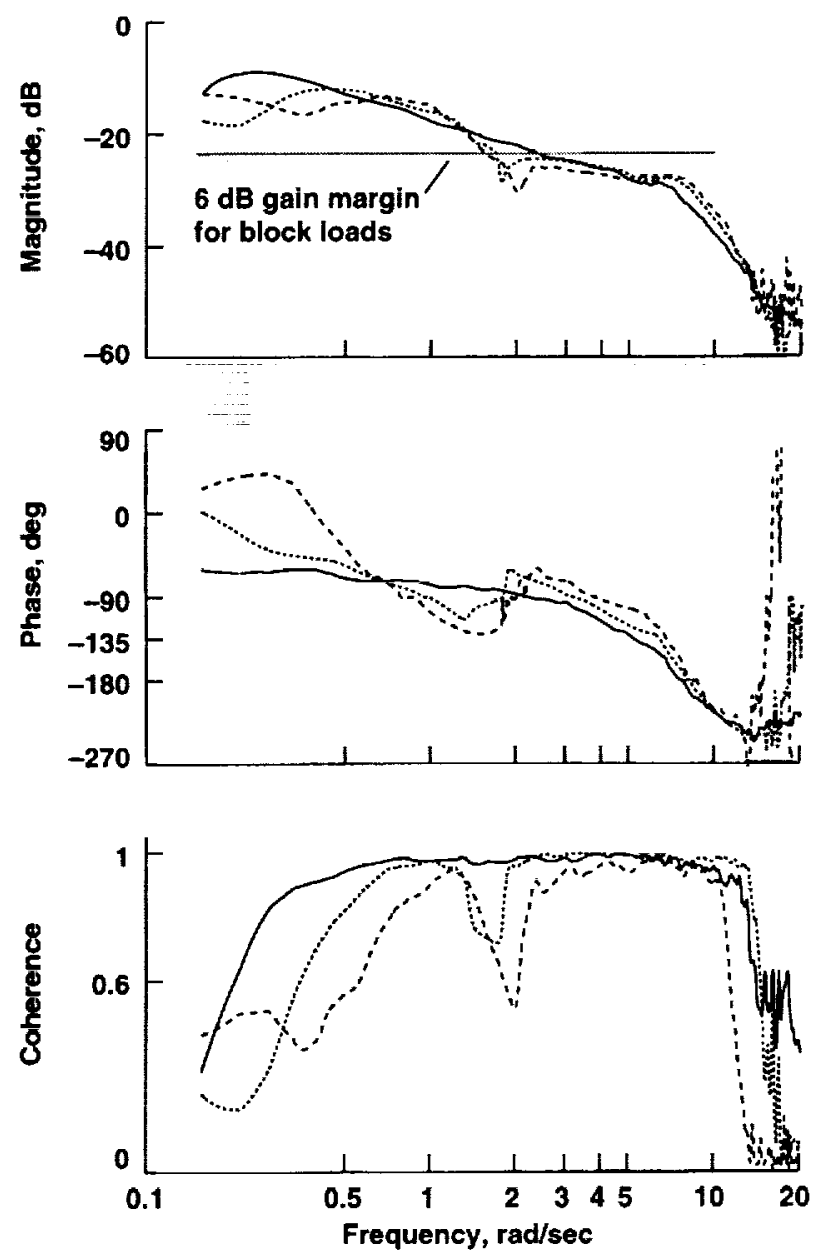

(b) Pitch response: $\phi / \delta_{\text {LON }}$.
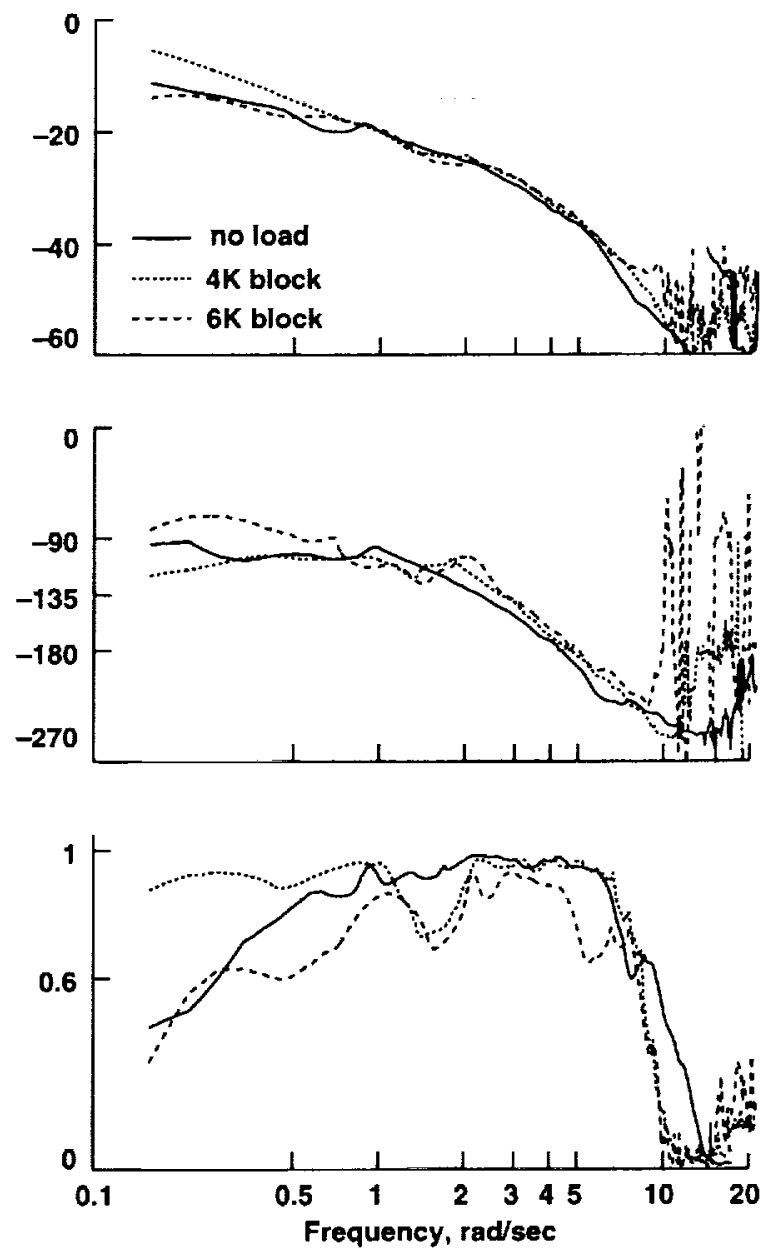

Figure 10. Effect of load on attitude frequency response - hover.

Results for the handling-qualities parameters are shown in figure 11 versus airspeed. In cases of multiple bandwidth values, the highest and lowest values are shown. For the lateral axis there is a significant loss of bandwidth because of the load at hover, and some differences among loads of the 
same weight. At forward speeds there are multiple values of bandwidth with the lower value below $2 \mathrm{rad} / \mathrm{sec}$. The longitudinal axis shows an increase in bandwidth owing to the load at all speeds.

(a) Lateral axis.
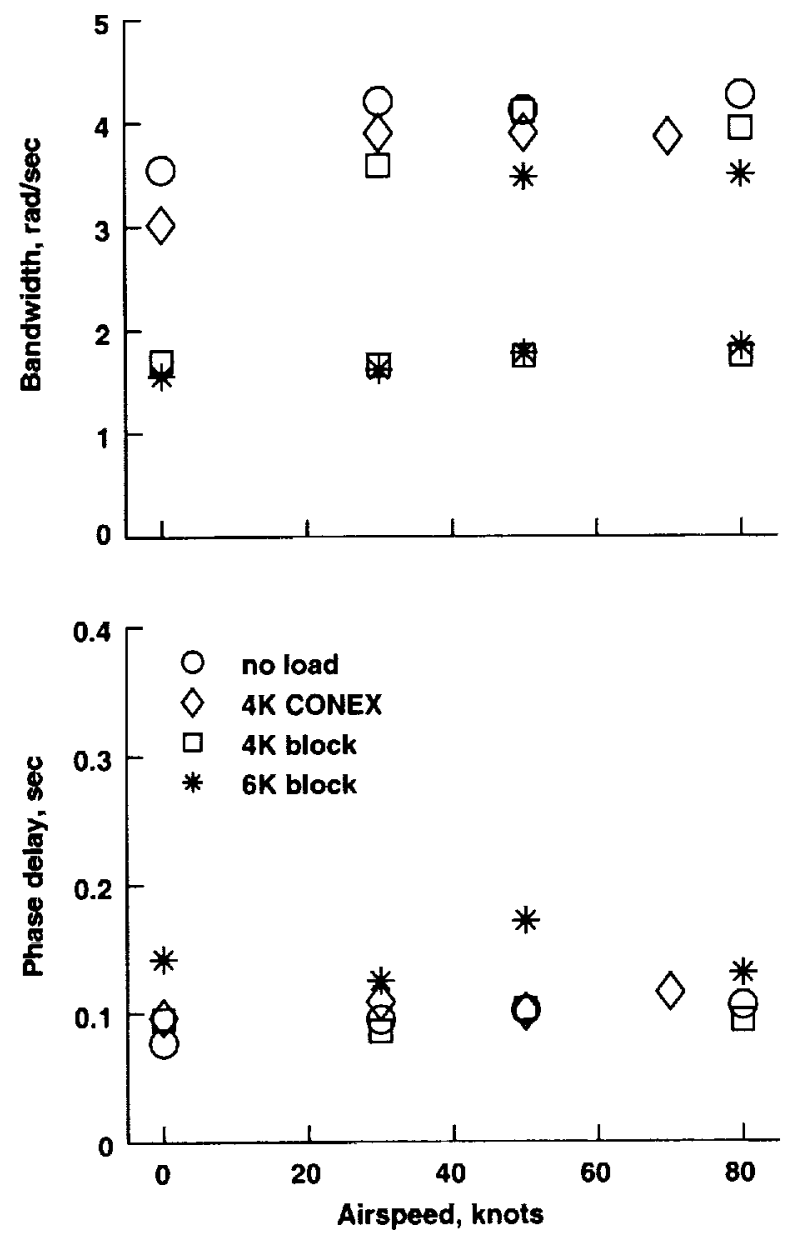

(b) Longitudinal axis.
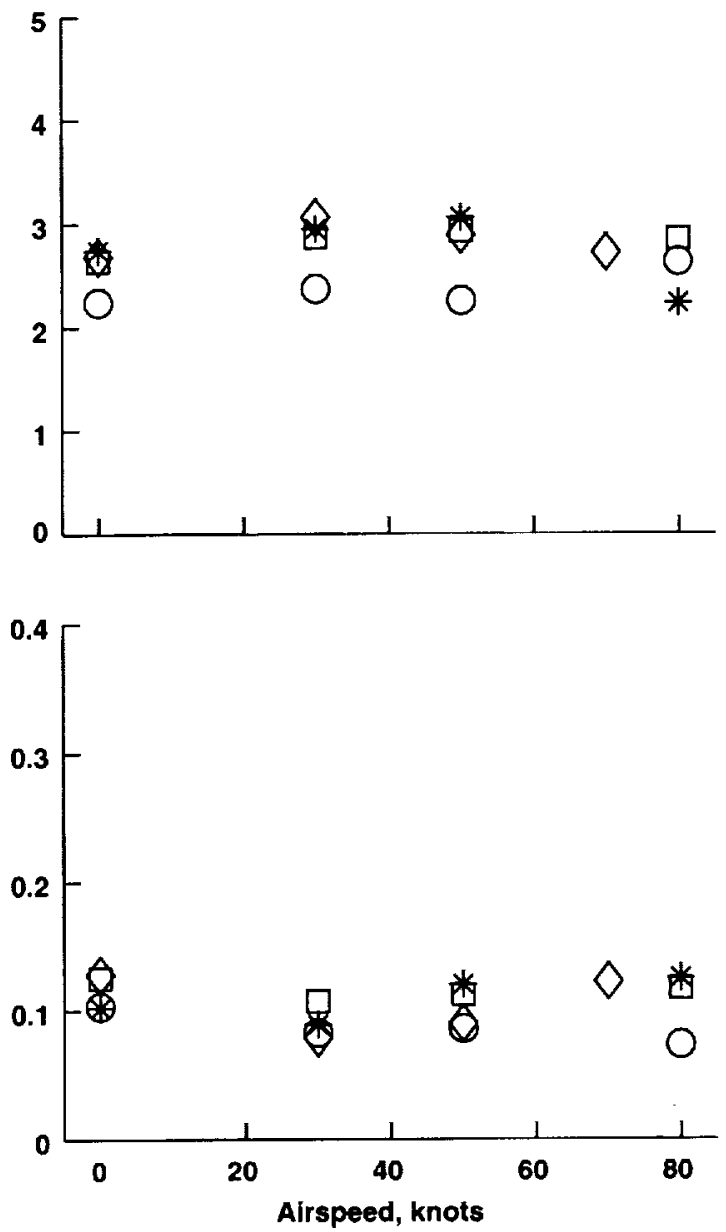

Figure 11. Handling-qualities parameters versus airspeed.

The lateral axis results are shown in figure 12 in a plot of phase delay versus bandwidth. The plot includes the ADS-33 Levels 1-3 boundaries for reference. Level 1 requires a bandwidth of $2 \mathrm{rad} / \mathrm{sec}$ or higher, depending on the phase delay. There is a general loss of attitude bandwidth for all loads, and an apparent loss of handling qualities to Level 2 for the block loads when measured against the no-load boundaries. However, the ADS-33 boundaries were established to predict handling-qualities ratings for scout-attack helicopters and may not predict handling-qualities ratings for slung-load configurations. It is beyond the present scope to establish new measures for quantitative evaluation of slung-load handling qualities, but a recent study of this issue at Ames on a moving-base simulation of the $\mathrm{CH}-47 \mathrm{D}$ should be noted. Several hover/low-speed tasks with potential excitation 
of load motions (precision hover, lateral reposition, normal depart/abort) were evaluated. No correlation of pilot ratings with attitude-control bandwidth for the helicopter-load combination was found. The main issue was whether the pilot could supply sufficient gain for precise aircraft and load control without driving either the aircraft or load dynamics unstable, which is related to translational control. Results showed a linear loss of handling-qualities ratings with increasing load weight, and a degradation to Level 2 handling qualities for weight ratios, $\mathrm{W}_{\mathrm{LOAD}} / \mathrm{W}_{\mathrm{TOTAL}}$, at and above $33 \%$. Further, the study found correlation of pilot ratings with bandwidth and helicopter-load coupling parameters computed from the closed-loop translational velocity response, and criteria for these parameters were proposed in reference 36 .

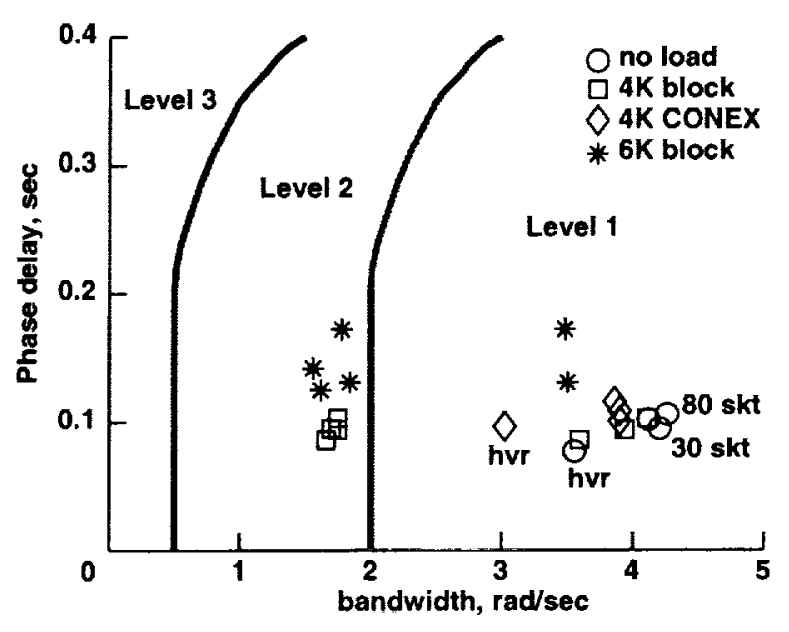

Figure 12. Lateral axis handling-qualities parameters.

Flight tests were conducted at Ames during 1999 to extend ADS-33D to utility helicopters and slung loads. A variety of tasks were defined and tailored to the utility helicopter mission, and pilot opinion ratings were obtained and reported in reference 24 . Results from that study for maneuvers with potential to excite the pendulum modes (hover acquisition, pirouette, lateral reposition, normal depart and abort, and slalom) are shown in figure 13 for the 6,000-lb block load (weight ratio at and above $30 \%$ ) and for no slung load (with internal ballast to approximately match total weight). These results show little evidence of degraded pilot ratings owing to the load for the near-hover tasks despite the loss of attitude-control bandwidth computed above. The results of the slalom task show a loss of ratings owing to difficulty in anticipating load-swinging motion to control the aircraft flight path around the course pylons. The new standard, ADS-33E, evaluates slung-load handling qualities based solely on qualitative pilot ratings and does not establish any quantitative specifications (ref. 27). 


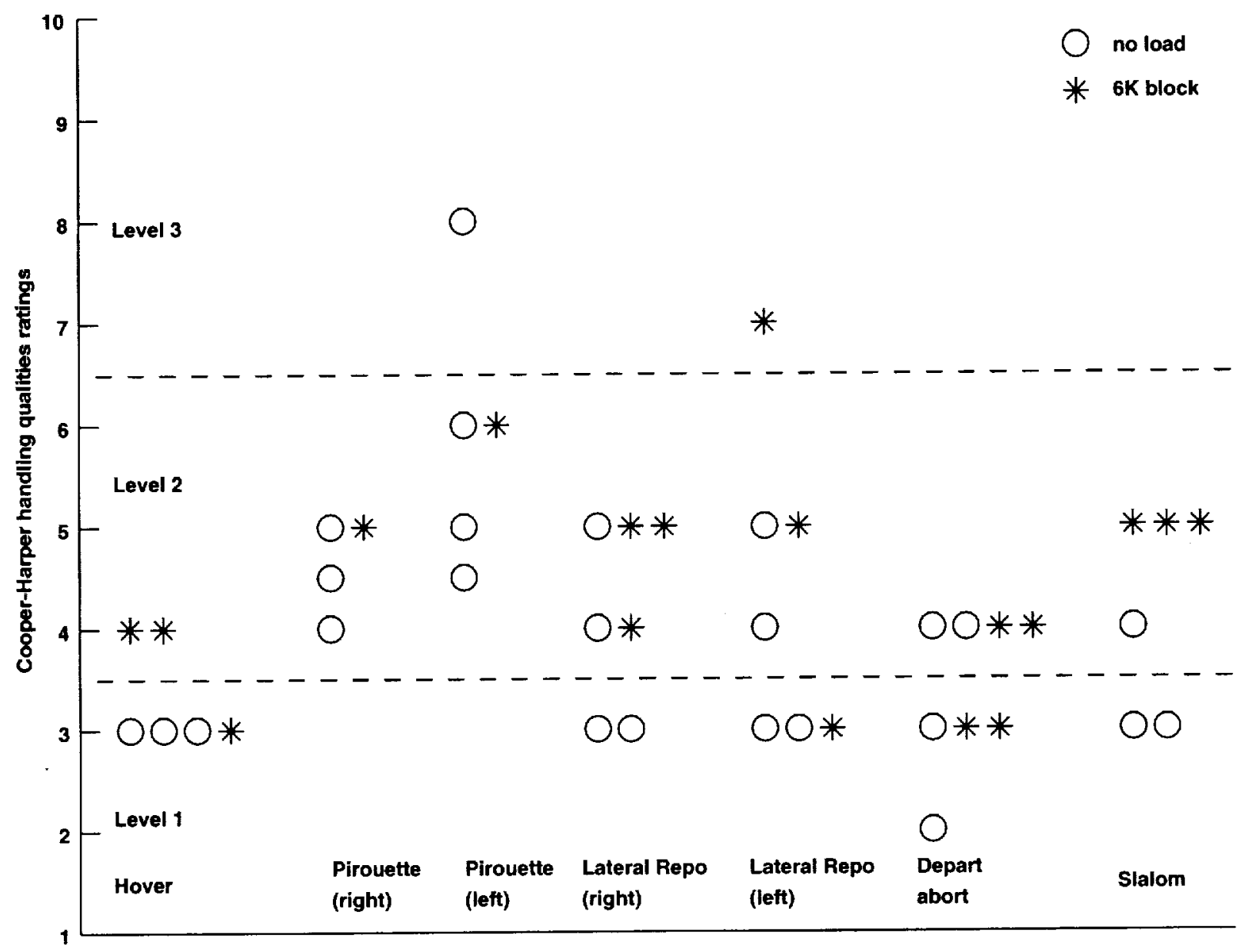

Figure 13. Pilot ratings.

\section{Control System Stability Margins}

The detailed effects of load weight on the stability loop response $\left(\delta_{\mathrm{SAS}} / \delta_{\mathrm{ACT}}\right.$ in figure 1$)$ are shown in figure 14. The effect of the load on the lateral axis gain and phase curves is similar to that previously seen for the closed-loop roll response; that is, a gain dip occurs around the pendulum frequency, and phase shift is increased at frequencies below the pendulum frequency and decreased at frequencies above the pendulum frequency. These effects are seen to increase with load weight. Both gain and phase margins are reduced by the load. The loss in phase margin is associated with the increased phase shift at frequencies below the pendulum frequency, and the loss of gain margin is associated with gain increases in the region of the $180^{\circ}$ phase shift (near $10 \mathrm{rad} / \mathrm{sec}$ ). The longitudinal axis responses exhibit reduced load effects compared to the lateral axis. Helicopter stability and control derivatives change with the increased thrust required by the load, and these changes are thought to produce the gain increases which result in loss of gain margin with load. 
(a) Lateral axis: $\left(\delta_{\text {SAS }} / \delta_{\text {ACT }}\right)$ LAT.
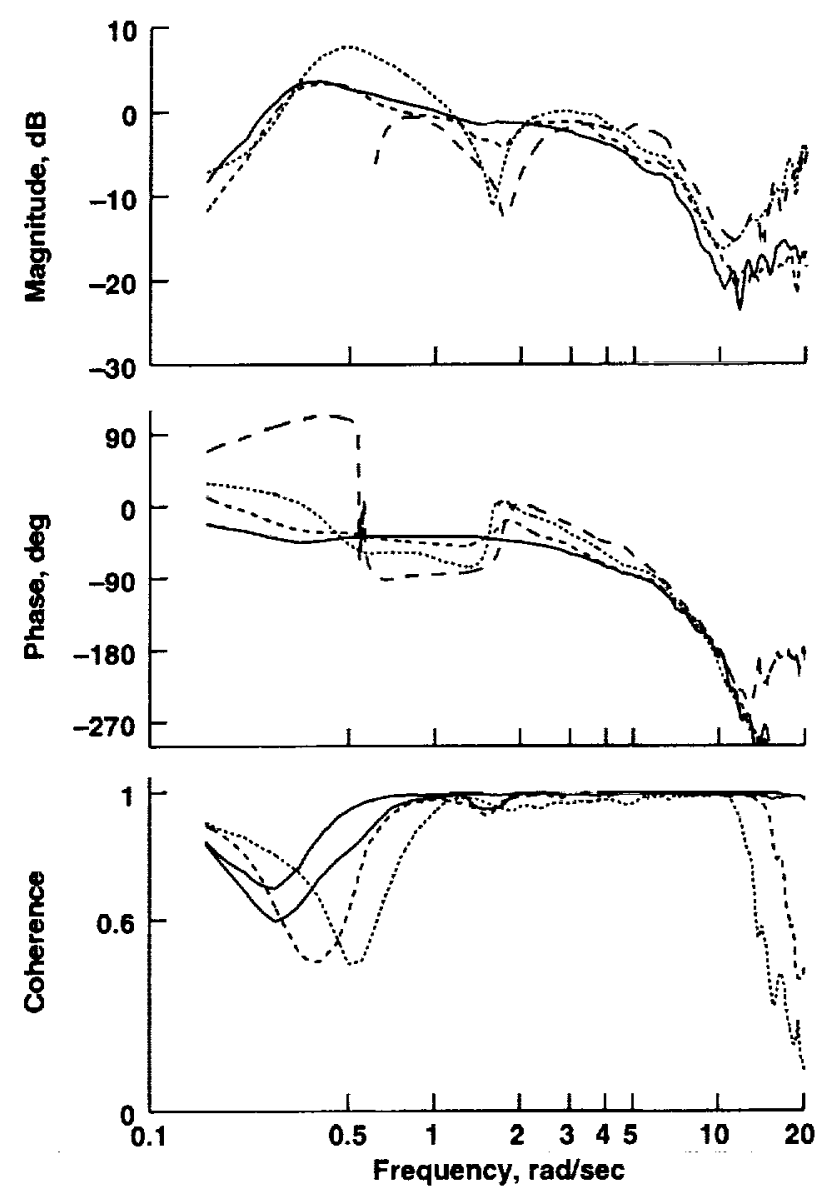

(b) Longitudinal axis: $\left(\delta_{\text {SAS }} / \delta_{\text {ACT }}\right)$ LON.
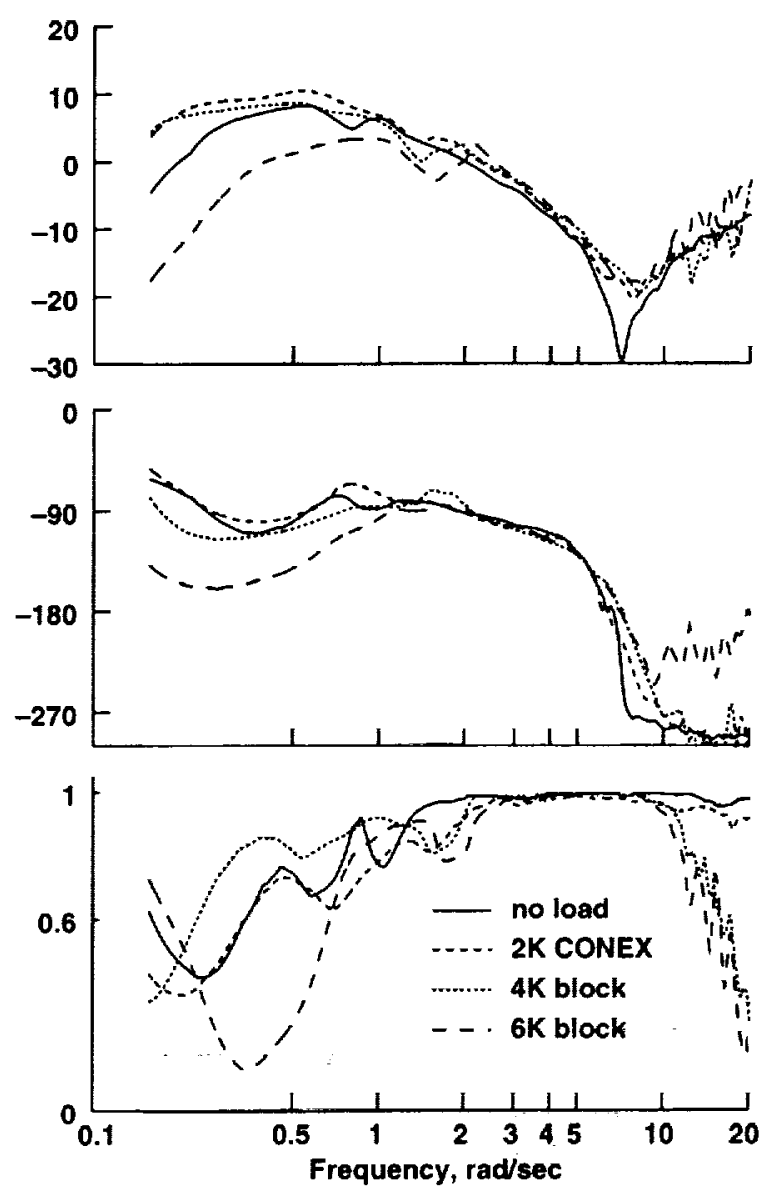

Figure 14. Effect of load on hover broken loop response.

Collected stability margin results are plotted versus airspeed in figure 15 . The lateral axis margins show a consistent loss of phase margin because of the load and a loss of gain margin, mainly at hover. This is consistent with industry experience that the lateral axis is the one for which stability is normally degraded by the load (ref. 2), particularly at hover. The longitudinal axis margins show little variation of phase margin whereas gain margins degrade for the block loads, with large losses at the higher speeds.

Lateral axis stability margin results are shown in figure 16 in a plot of gain margin versus phase margin. Margin losses at hover are about $4 \mathrm{~dB}$ and $30^{\circ}$ for the 4,000-lb block load. A flight-test data point for a 9,000-lb test load (ref. 2) is included to indicate the increased loss of margins with increasing load weight. The UH-60A is seen to have large margins from the specification minimums $\left(45^{\circ}, 6 \mathrm{~dB}\right)$ so that moderate losses in margin owing to the load do not threaten its stability. However, other aircraft exist with base margins close to the minimums and such losses would be more critical for them. 
(a) Lateral axis.
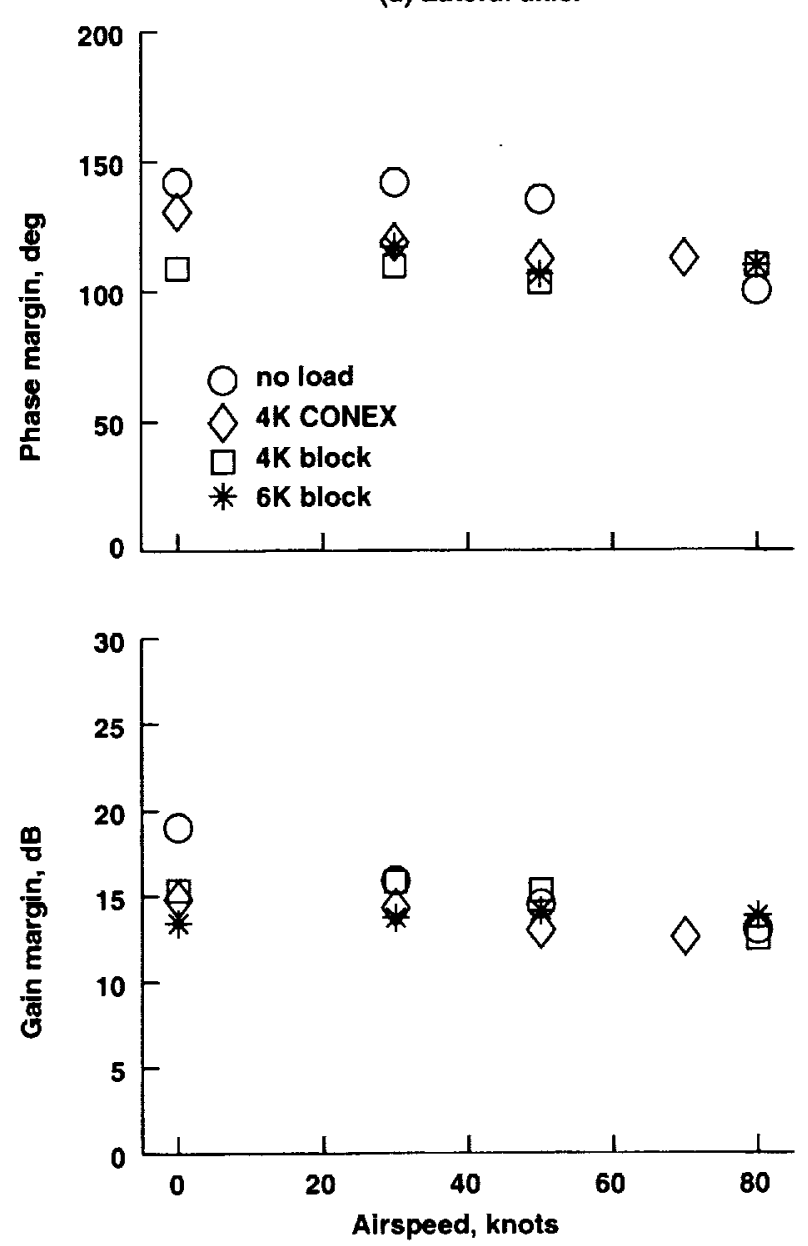

(b) Longitudinal axis.
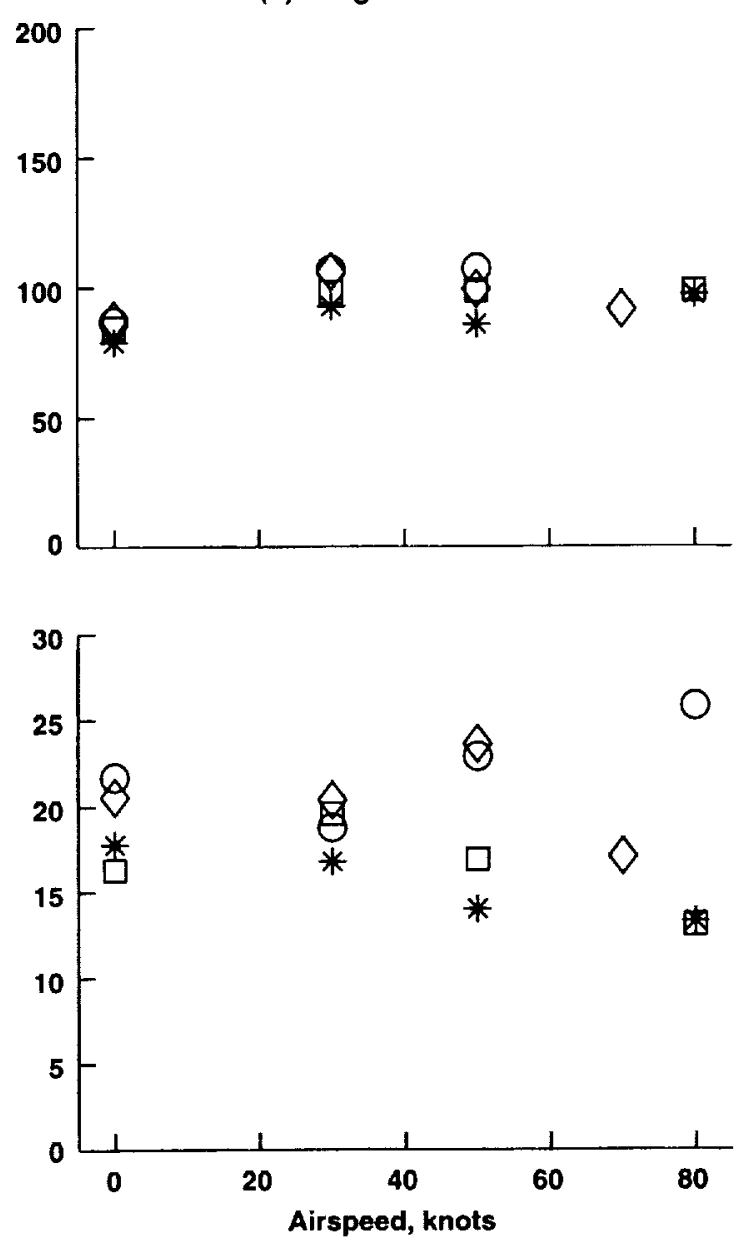

Figure 15 . Stability margins versus airspeed.

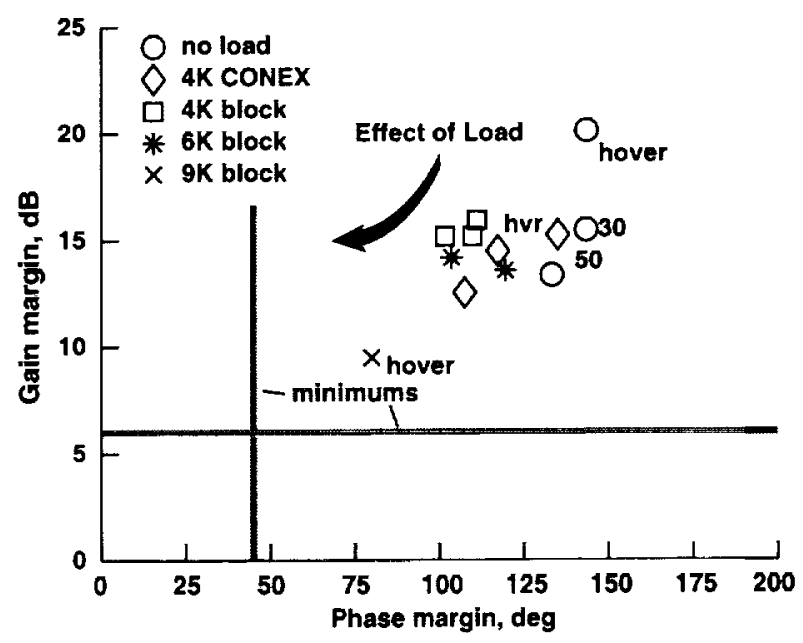

Figure 16. Lateral axis stability margins. 


\section{Load Pendulum Roots}

The load roots were identified by fitting the transformed load angular rate responses, $\mathrm{p}^{\prime} / \delta_{\mathrm{LAT}}$, $\mathrm{q} 2^{\prime} / \delta_{\mathrm{LON}}$, with a second-order pole. A sample fit is shown in figure 17 . The load responds chiefly around the pendulum frequency; gain rises to a maximum there and phase shifts through $180^{\circ}$ across this frequency. The coherence drop seen near the pendulum frequency in figure 17 was present in all load response results. The precise cause of this coherence loss at a response peak has not yet been identified.
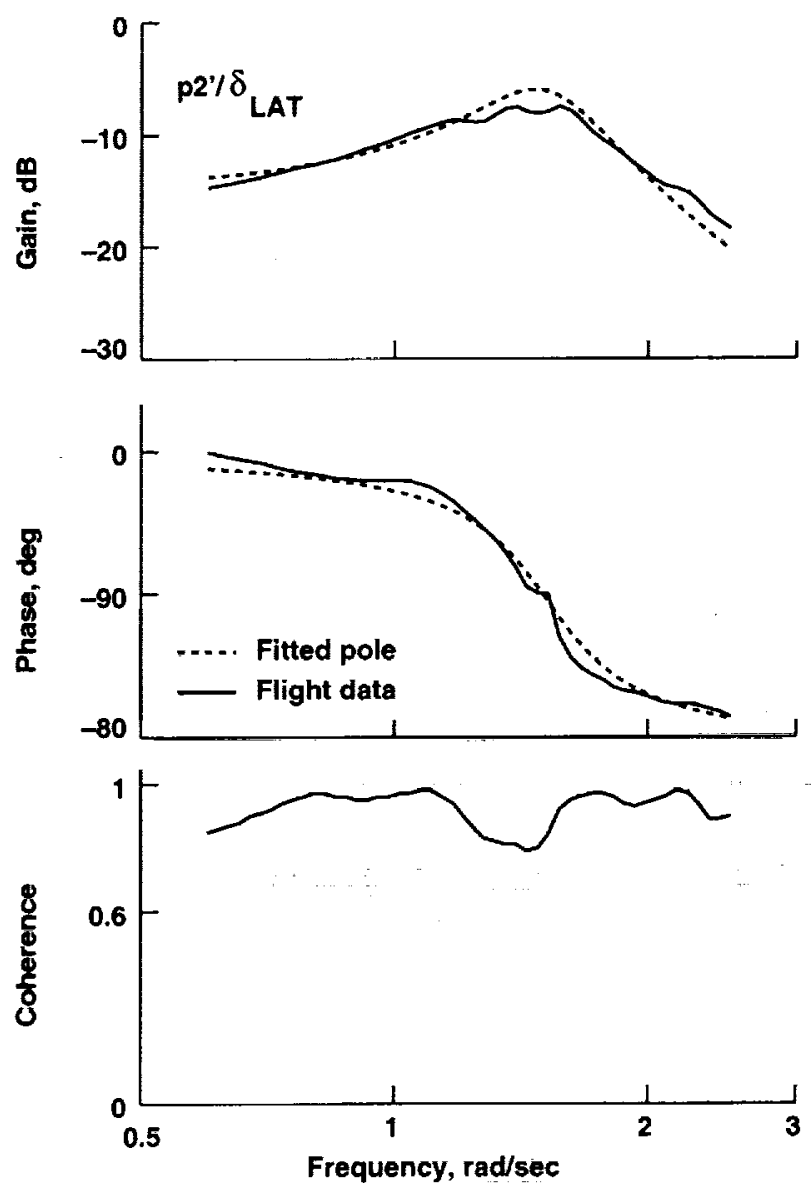

Figure 17. Identification of pendulum roots from load angular rate response: hover, lateral axis, $4,000-\mathrm{lb} \operatorname{CONEX}(\zeta=0.158, \omega=1.5 \mathrm{rad} / \mathrm{sec})$.

Results for damping and natural frequency are plotted versus airspeed in figure 18 for the ballasted CONEX and 4,000-lb block loads. Natural frequency is about the same for both axes and loads (1.5 $\mathrm{rad} / \mathrm{sec})$, and is independent of airspeed. Longitudinal axis damping is consistently lighter ( 0.1 or less in most cases) than lateral axis damping (above 0.15). Linear analysis indicates that the helicopter $\mathrm{Lp}, \mathrm{Mq}$ are the primary sources of damping for the pendulum modes, and that the reduced 
longitudinal axis damping is a result of the differences in inertia and the related coupling of attitude dynamics with load pendulum motions. This difference in damping was also clearly visible in the doublet response time-histories. Damping varies only a little with airspeed in these results. Considerable load yaw motion developed with airspeed for the ballasted CONEX but without coupling to the pendulum modes; that is, the load aerodynamics mostly drove the yaw degree of freedom without modifying the pendulum motions.

(a) Lateral axis.
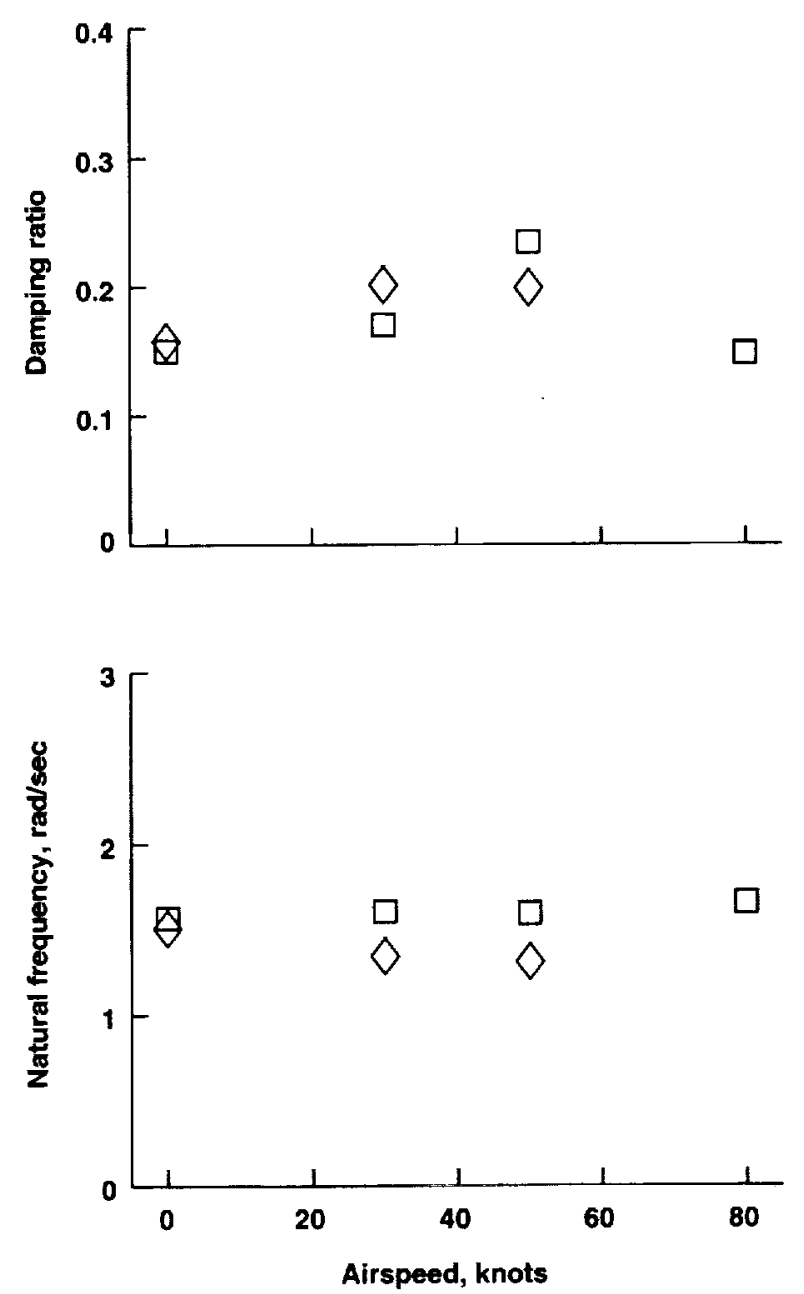

(b) Longitudinal axis.
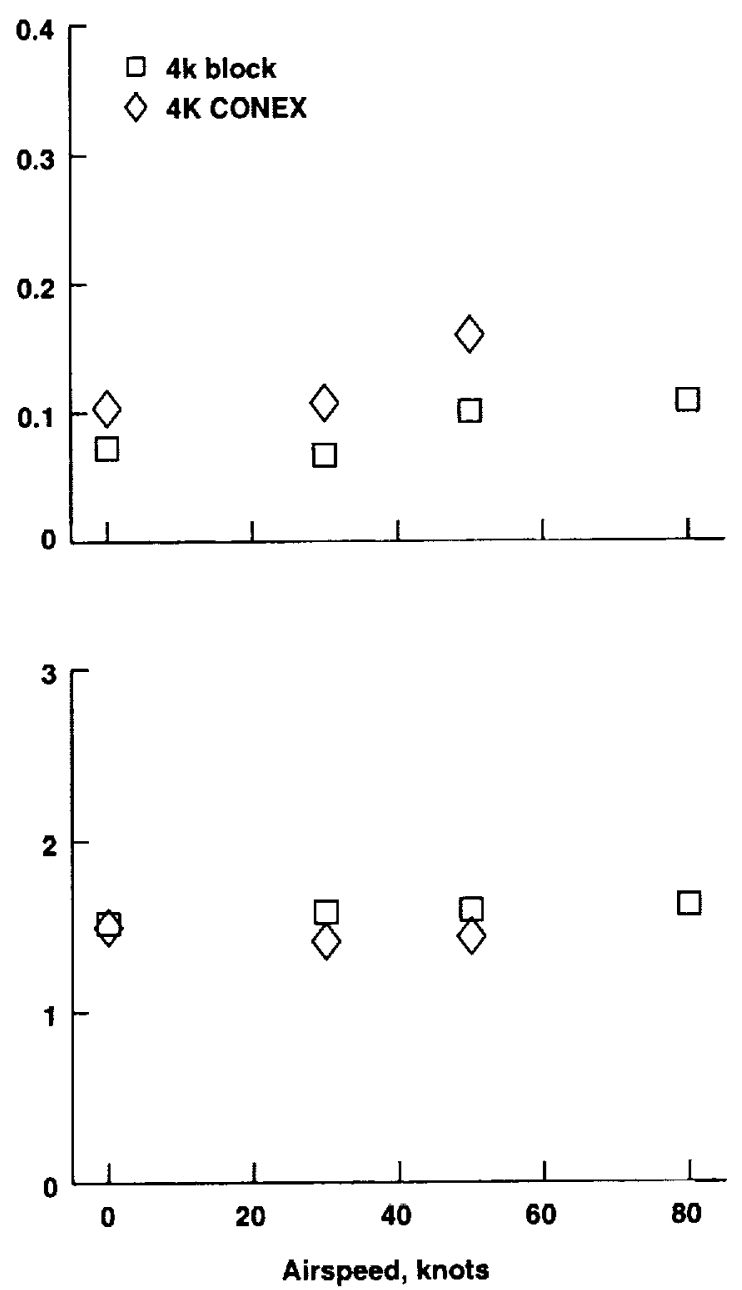

Figure 18. Load pendulum roots versus airspeed.

The load pendulum roots were also estimated by fitting the load angular rate time-history response to doublet inputs. Good agreement with the frequency-domain results was obtained. In the absence of load instrumentation, the pendulum roots can be estimated by fitting the helicopter broken loop response with a pole-zero combination in the region of the pendulum frequency. Results from this indirect computation agreed moderately well with results from the load signals. 


\section{SLUNG-LOAD SIMULATION}

The general objective is to implement and validate a simulation capable of accurately predicting the key dynamic parameters of slung-load configurations discussed in the foregoing text.

At Ames, aircraft simulations are normally available with a standardized implementation of the Newton-Euler rigid-body equations of motion. Such simulations can be extended to slung-load configurations by appending the slung-load model using the logical flow shown in figure 19 . The load aerodynamics and two-body equations of motion are appended as shown and used to compute the hook forces and c.g. moments applied to the helicopter, which are then added to the aircraft force and moment sums to drive its single rigid-body dynamics. The two-body dynamics module necessarily carries a duplicate copy of the aircraft Newton-Euler equations. The two sets of aircraft states are coordinated by resetting the helicopter position and velocity states in the two-body equations to those in the aircraft equations at the start of each integration step.

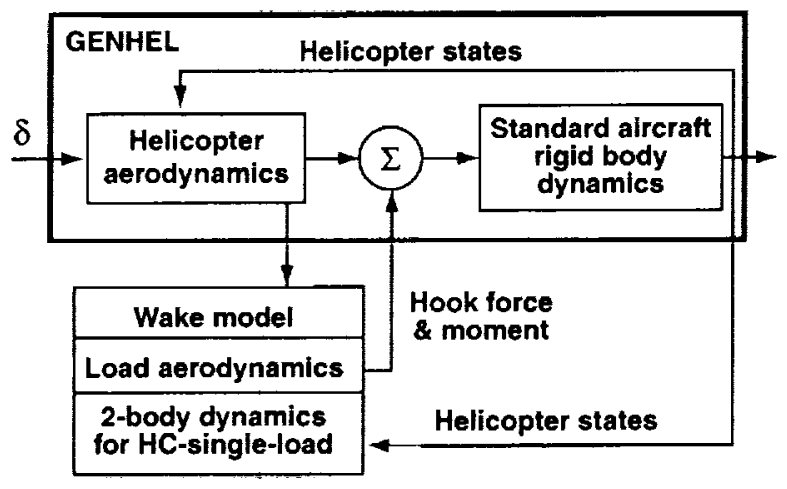

Figure 19. Integration of load model into standard helicopter simulation.

This arrangement was used in the present study, beginning with an existing UH-60A simulation based on Sikorsky's GenHel model. That model (ref. 10) has been independently extended and validated at Ames for handling-qualities studies (refs. 11, 12), and at Sikorsky (ref. 2). It contains a blade-element rotor model (five elements for each rigid blade, dynamic inflow), a rigid-body fuselage with aerodynamics based on wind-tunnel data, and component models of the engine, drive train, and control system. All the control system variables measured on the aircraft also occur in the simulation. The two-body slung-load equations of motion for general multi-cable slings and loads were implemented as given in reference 14. The sling legs can be elastic (12 rigid-body degrees of freedom (DOFs)) or inelastic (9 DOFs). The hook-sling attachment is modeled as one that can transmit forces but not moments. This is a standard attachment model consistent with a swiveled sling, but does not capture the sling windup of the unswiveled CONEX which affects the load yaw dynamics.

Load static aerodynamics and rotor downwash effects are included. Wind-tunnel data for the CONEX static aerodynamics were provided by the Technion Institute (ref. 15). The final set of 
tunnel data (fig. 20) was taken with model supports designed to minimize measurement errors. Measurement errors were revealed by studies of a cube model which has extensive known aerodynamic symmetry properties (ref. 15). The data cover angles of attack from $-90^{\circ}$ to $90^{\circ}$ and sideslip angles from $0^{\circ}$ to $90^{\circ}$ in $5^{\circ}$ intervals and comprise a uniquely comprehensive and accurate set of load wind-tunnel data. These are extended in the simulation to the complete range of load attitudes $(\alpha \in[-180,180]$ and $\beta \in[-90,90])$ using symmetry rules about zero sideslip angle, and about $\alpha=90^{\circ}$ and $-90^{\circ}$. The CONEX skids were included in the wind-tunnel model and these remove the symmetry of a strictly rectangular box about $\alpha=0$ (e.g., lift and pitching moment are nonzero at $\alpha=0)$, and symmetry about $\beta=90^{\circ}$ is modified to radial symmetry about the point $(\alpha, \beta)$ $=(0,90)$. These symmetries were confirmed by data taken well outside the region mapped in figure 20. The principal components are the drag, which determines the load trail angle and which varies moderately with orientation, and the yaw moment, which drives the CONEX to large yaw rates as airspeed increases and which is statically stable in yaw in limited ranges near $0^{\circ}$ and $90^{\circ}$ sideslip.
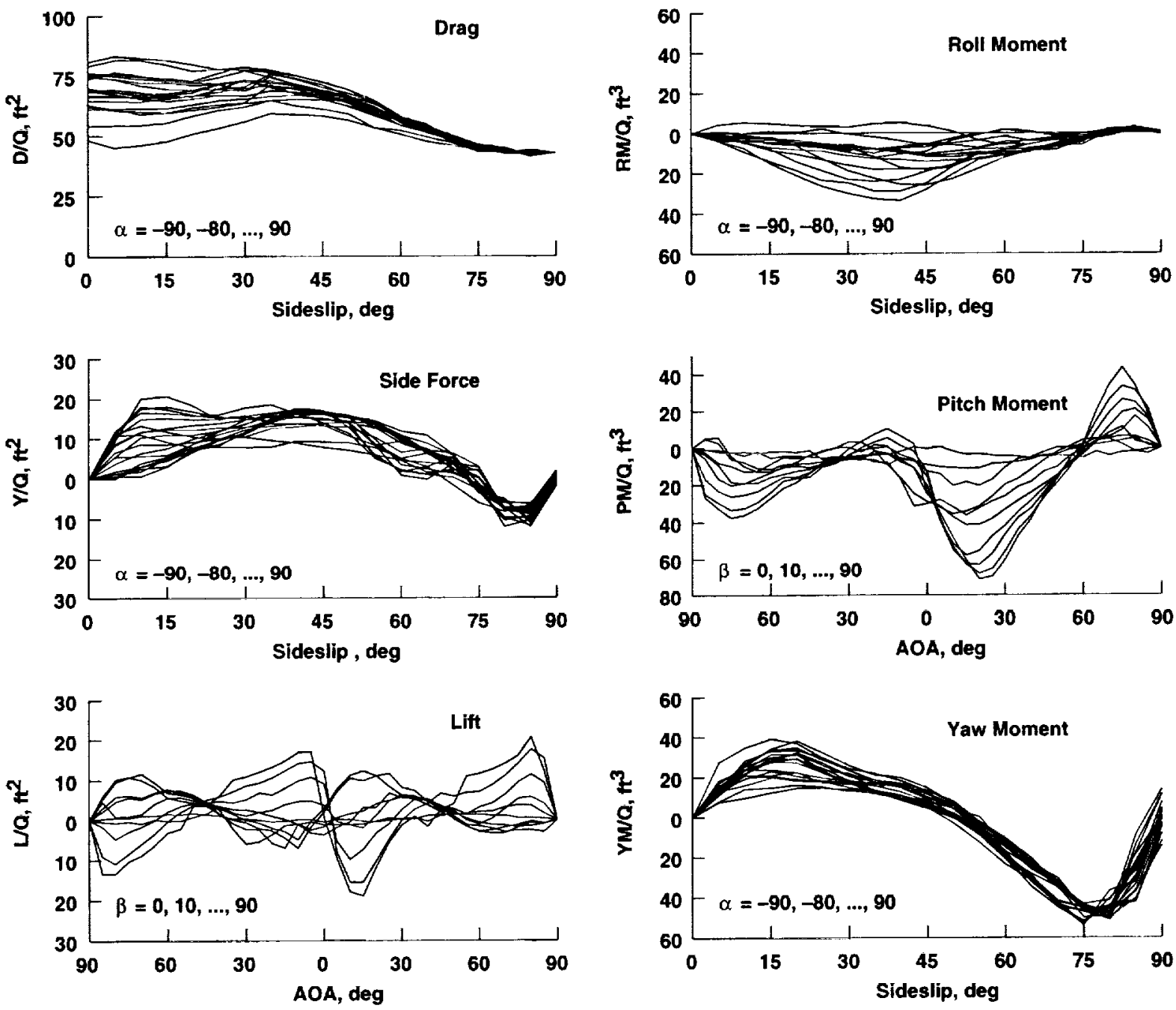

Figure 20. CONEX static aerodynamics wind-tunnel data (wind axes components divided by dynamic pressure). 
Main rotor downwash can result in significant airflow over the load in hover, of the order 50 knots. The rotor wake narrows to half the rotor diameter in the far wake (starting at about 1.5 rotor radii) and the axial wake velocity correspondingly increases to twice the inflow. Air velocity at the load was computed as a function of load c.g. location in the wake, using measured data from references 37 and 38. In addition, the (swiveled) CONEX was observed to spin at 30-40 deg/sec in hover because of the rotational component of the downwash. This simulation is described in greater detail in references 20 and 21.

\section{SIMULATION VALIDATION}

Validation is based on a comparison of the simulation and flight data frequency responses required to compute the key dynamic parameters of interest, and on a comparison of the parameter values obtained. The present work considers the lateral and longitudinal on-axis responses over the frequency range of interest in handling-qualities work, that is, 0.05 to $2 \mathrm{~Hz}$. The simulation aircraft was maintained centered about the reference flight condition by adding a three-channel low gain rate and attitude feedback loop, following reference 39 . The effects of correlated off-axis inputs from the stabilizing control were removed in the CIFER ${ }^{\otimes}$ analysis. In the following discussion, the fidelity of the GenHel helicopter model is reviewed before determining the fidelity of the GenHel-slung load model.

\section{No-Load Simulation Fidelity}

Handling qualities-The closed-loop attitude responses at hover are compared with flight results in figure 21 . An error function is formed by dividing the simulation response by the flight response. Identical responses would produce unity $\left(0 \mathrm{~dB}\right.$ gain and $0^{\circ}$ phase). The error functions are shown in the figure along with a frequency-dependent error boundary representing the threshhold at which a pilot can detect differences between simulation and aircraft dynamics (refs. 40, 41). Transfer functions for the upper and lower gain and phase fidelity boundaries are given in reference 40 as:

$$
\begin{gathered}
G_{U}(s)=\frac{3.16 s^{2}+31.61 s+22.79}{s^{2}+27.14 s+1.84} \\
G_{L}(s)=\frac{.0955 s^{2}+9.92 s+2.15}{s^{2}+11.6 s+4.96} \\
\Phi_{U}(s)=\frac{68.89 s^{2}+1100.12 s-275.22}{s^{2}+39.94 s+9.99} e^{.0059 s} \\
\Phi_{L}(s)=\frac{475.32 s^{2}+184100 s+29456.1}{s^{2}+11.66 s+.0389} e^{-.0072 s}
\end{gathered}
$$


(a) Roll response: $\phi / \delta_{\text {LAT }}$.
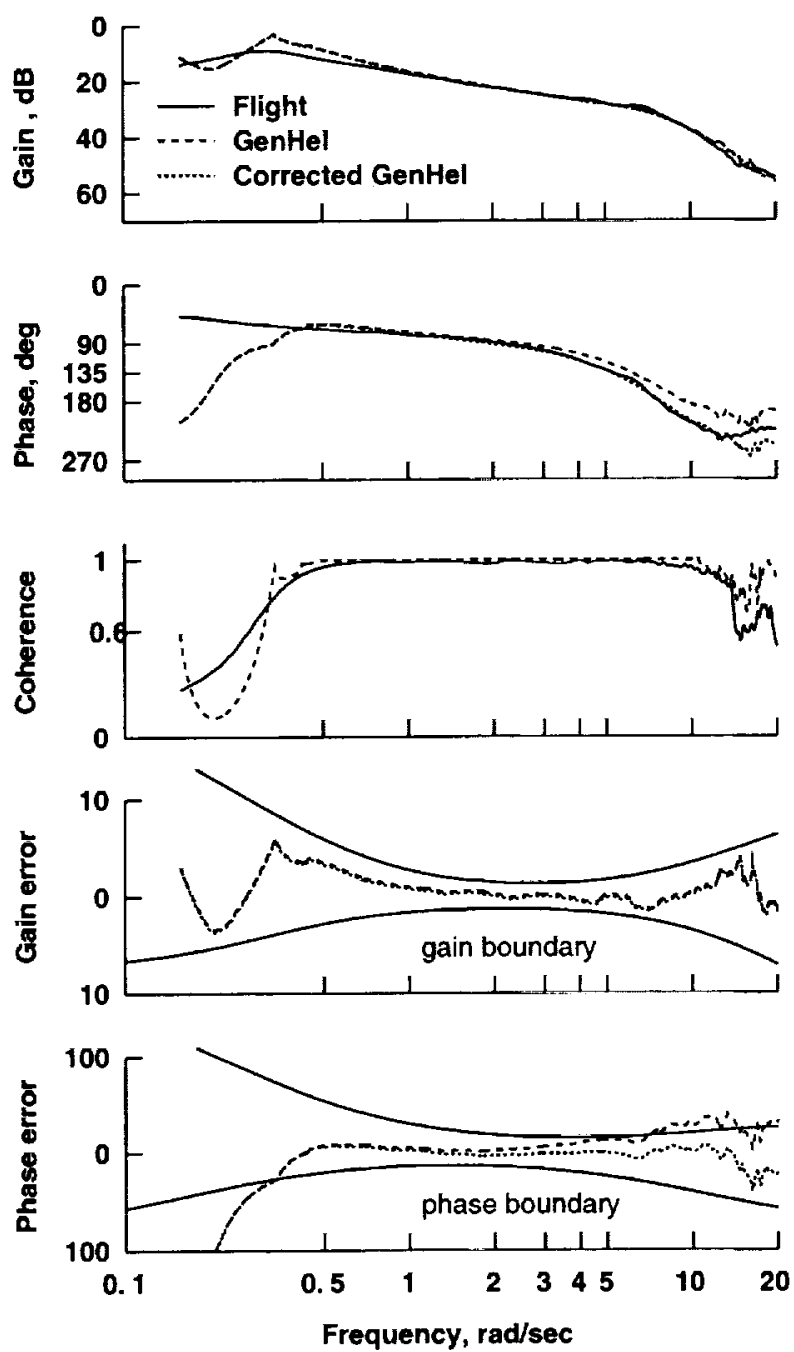

(b) Pitch response: $\phi / \delta_{\text {LON }}$
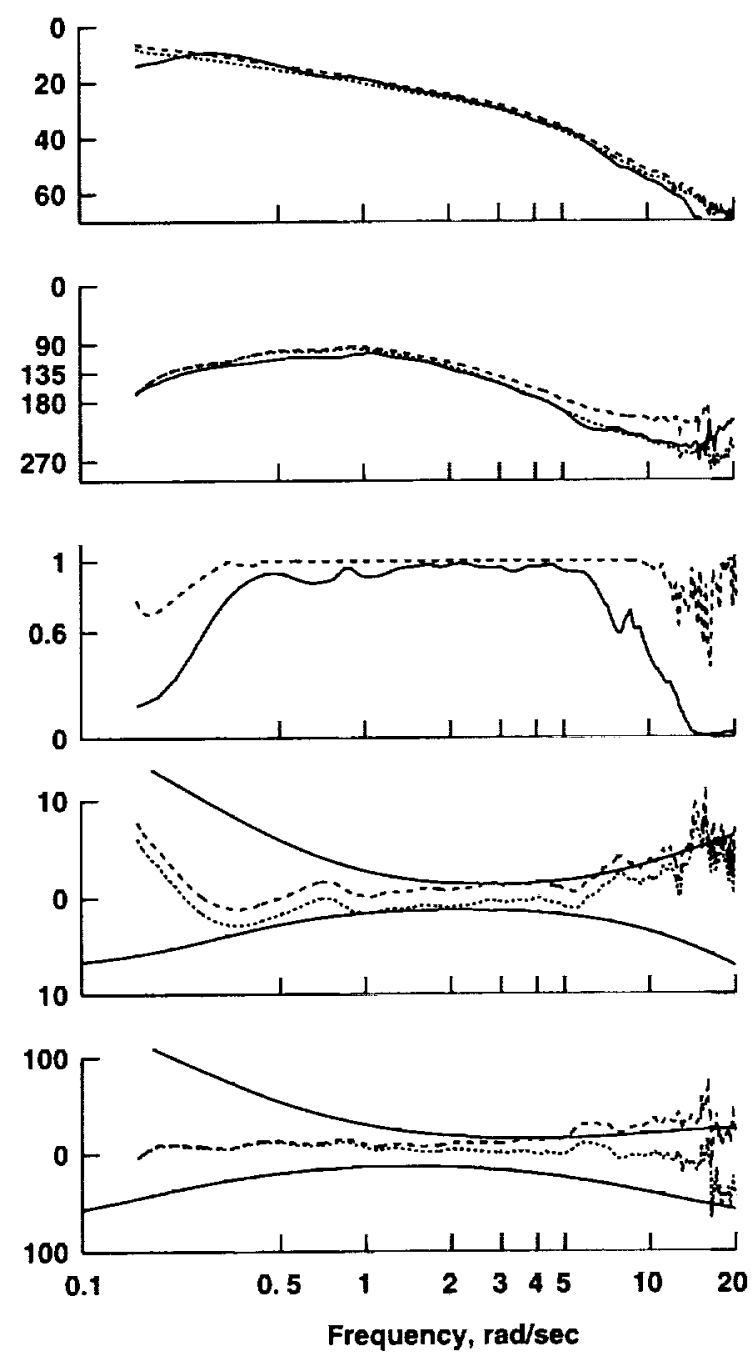

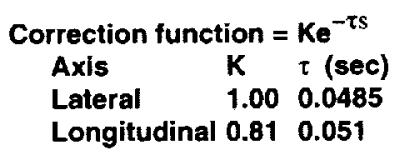

Figure 21. Helicopter attitude-response validation: no load, hover.

These boundaries were established in reference 41 for the longitudinal axis and can reasonably be applied to the lateral axis as well for the present discussion. Other proposed frequency-domain mismatch criteria for high-fidelity simulators are discussed in references 42 and 43 . The results in figure 21 show that the lateral axis error function magnitude is within the boundaries, but phase is outside the boundary above $8 \mathrm{rad} / \mathrm{sec}$, and the longitudinal axis error gain and phase are both outside the boundary at higher frequencies. Thus, the present GenHel simulation is inaccurate in the region where phase shift reaches $180^{\circ}$ and on which gain bandwidth and phase delay depend. 
The error function can be fitted with a low-order transfer function to obtain an empirical correction to the simulation frequency responses. In this case, a simple gain and time delay sufficed, and parameter values, given in figure 21 , were found to be insensitive to airspeed. The corrected responses in figure 21 show good agreement with flight data and residual errors are well within the fidelity boundaries. A comparison of the handling-qualities parameter values from the corrected simulation responses and flight data (not shown) showed good agreement at all airspeeds. The correction function will be applied to all closed-loop simulation responses in the remainder of this report.

The error function results are consistent with a previous validation exercise in which an end-to-end 50-msec delay in the flight data relative to the simulation was found (ref. 11). Further comparisons with flight measurements at several points in the control system were made, and they indicated that about half the unmodeled delay is in the rotor model and half in the control system. The servo dynamic models have been verified, so that the control portion of the delay is likely a result of unmodeled linkage and mixer dynamics. It was initially thought that the rotor portion of the delay was caused by the lack of in-plane (lead-lag) blade bending based on a CH-53 study in reference 44 . However, analysis has shown that this is not the case for the UH-60 and has pointed to the rotor integration scheme as a source of lead in the simulation model.

Stability margins-The SAS servo output sums with the pilot input as modeled in figure 22 to generate the mixer input. Flight data are available from sensors measuring the pilot stick deflection,

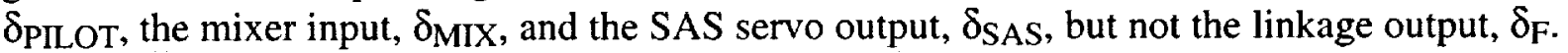

Stability margins are defined from the "broken loop" control response, $\delta_{\mathrm{F}}(\mathrm{s}) / \delta_{\mathrm{MIX}}(\mathrm{s})$, but are often evaluated from the SAS servo and mixer sensor signals (FR $F_{1}$ in fig. 22). However, $\delta_{F}$ can be constructed indirectly as the difference between the mixer input and pilot signals and the stability margins can be computed from the indirect response ( $F R_{2}$ in fig. 22). The simulation represents the summing linkage as a simple gain determined from low frequency data, and the simulation gives identical responses by either method. The flight data do not show identical responses, as seen in figure 23; this reveals the presence of linkage dynamics. Differences are large at higher frequencies, which implies a significant difference in gain margins, depending on the signals used for their computation. The indirect computation, $\mathrm{FR}_{2}$, has been used for all flight results herein since it measures the actual feedback to the rotor. The direct computation, $\mathrm{FR}_{1}$, would yield conservative (reduced) gain margin results owing to the higher gain in the region of $180^{\circ}$ phase shift. Similarly, simulation results for gain margin will usually be conservative owing to the unmodeled linkage dynamics. However, phase margin prediction is unaffected since it depends on response behavior at lower frequencies. A comparison of simulation and flight data results in reference 20 shows excellent phase margin agreement and conservative simulation gain margin results at all airspeeds.

\section{Slung-Load Simulation Fidelity}

Handling qualities-Closed-loop attitude responses for the 4,000-lb block at hover are compared in figure 24. Lateral axis gain and phase differences at higher frequencies $(6-11 \mathrm{rad} / \mathrm{sec})$ suggest some excitation of the rotor dynamics not captured by the simulation. A similar difference occurs at all airspeeds. The corresponding error function (not shown) is close to the limit of the accuracy boundary in this range. Differences near the pendulum frequency are more noticeable, but occur where scatter owing to reduced coherence can occur. Despite these frequency response differences, 
parameter values for the 4,000-lb block in figure 25 exhibit good agreement between flight and simulation at all flight conditions. The different number of lateral axis bandwidth values for the two cases at hover and at 80 knots is a result of small unimportant differences in their frequency responses.

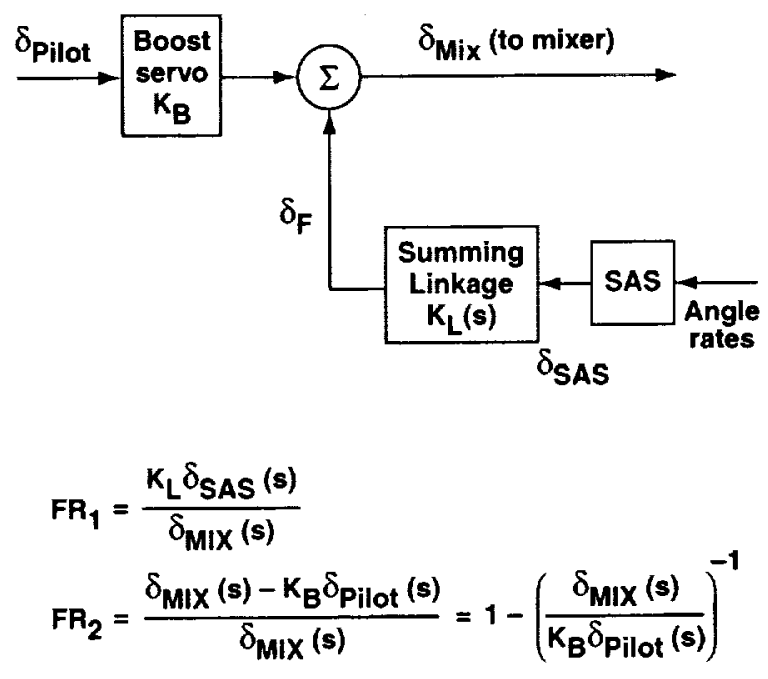

Figure 22. Computation of stability margins.

Stability margins-Parameter values for the 4,000-lb block (fig. 26) show good agreement with flight results at all flight-test conditions. Simulation gain margins are consistently below the flight values, a result of unmodeled control linkage losses as previously noted.

Pendulum modes-The on-axis load angular rate frequency responses at hover are compared in figure 27 for the 4,000-lb block load. The simulation is seen to reproduce the flight response closely. A dip in coherence occurs in the region of the pendulum frequency where the response gain reaches its peak, especially in the longitudinal axis response. The coherence dip is captured by the simulation but its physical cause has not been established.

A comparison of time-history doublet responses in figure 28 shows good agreement in apparent frequency and damping of the pendulum mode excited by the input. The simulation does not reproduce the small amplitude mode at about $4 \mathrm{~Hz}$ seen in the flight data. A detailed examination of time-history data shows that the smaller off-axis signals agree in magnitude and frequency content out to $2 \mathrm{~Hz}$, although flight-simulation differences can be as large as the signals.

Results for the CONEX pendulum roots are collected in figure 29. The simulation results are given with and without load static aerodynamics. Pendulum frequencies from flight and simulation data agree closely at all airspeeds and on both axes. The simulation predicts that frequency is nearly fixed with airspeed and that it is unaffected by load aerodynamics; these trends are matched by the flight data. Hover damping is well matched by both simulation cases and is therefore unaffected by the 
rotor downwash. The simulation predicts that damping is nearly fixed with airspeed in the absence of load aerodynamics, and rises with airspeed when load aerodynamics are included, particularly the lateral axis damping. The flight data show a tendency toward increased damping with airspeed.

(a) Lateral: $\left(\delta_{\mathrm{SAS}} / \delta_{\mathrm{ACT}}\right)_{\text {LAT }}$.
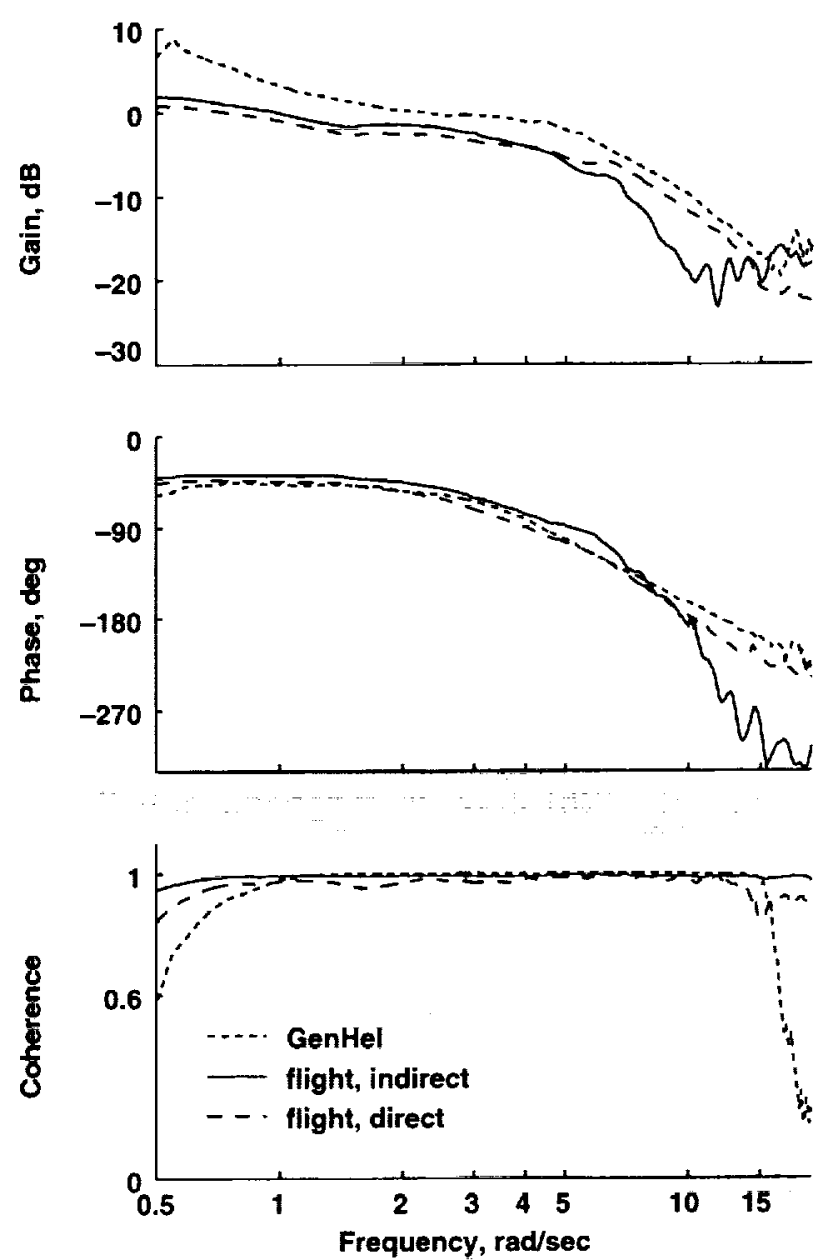

(b) Longitudinal: $\left(\delta_{\mathrm{SAS}} \delta_{\mathrm{ACT}}\right)$ LON
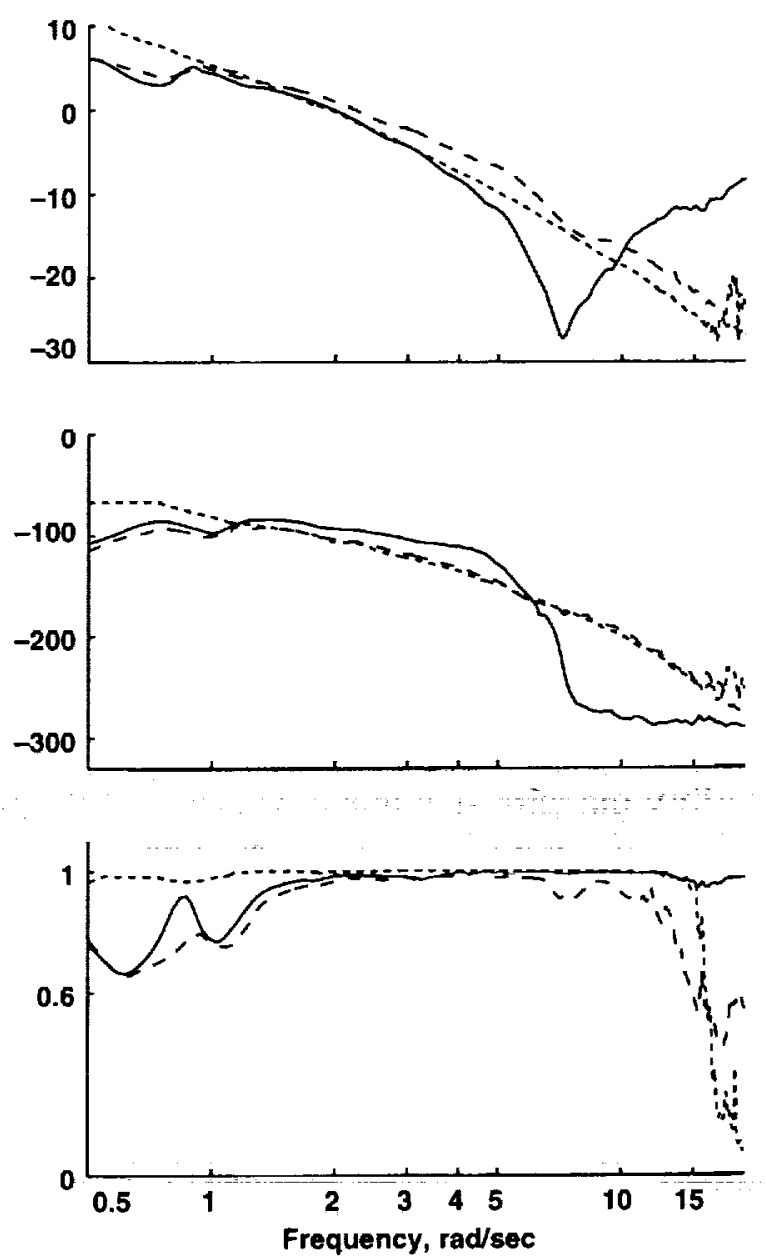

Figure 23. Broken loop response validation: no load, hover. 
(a) Roll response: $\phi / \delta_{\text {LAT }}$.
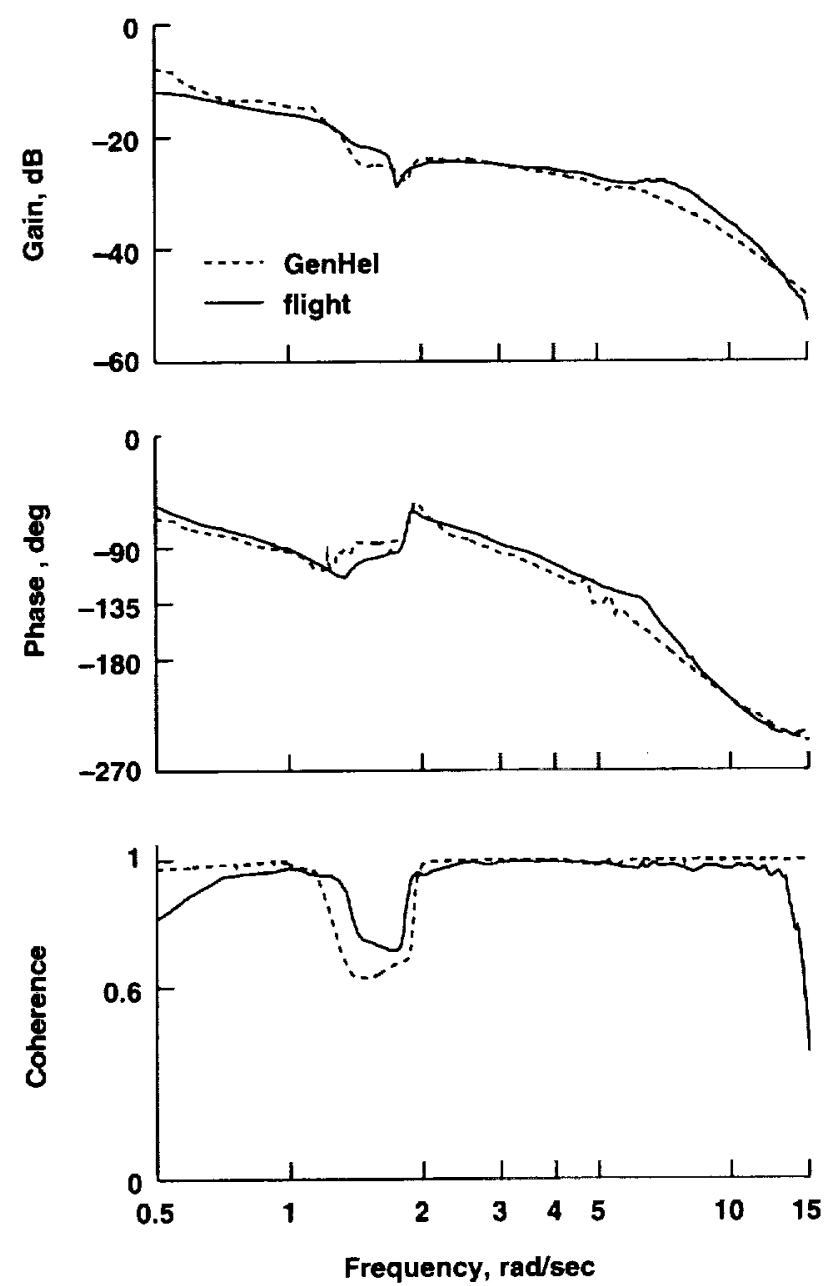

(b) Pitch response: $\phi / \delta_{\text {LAT }}$.
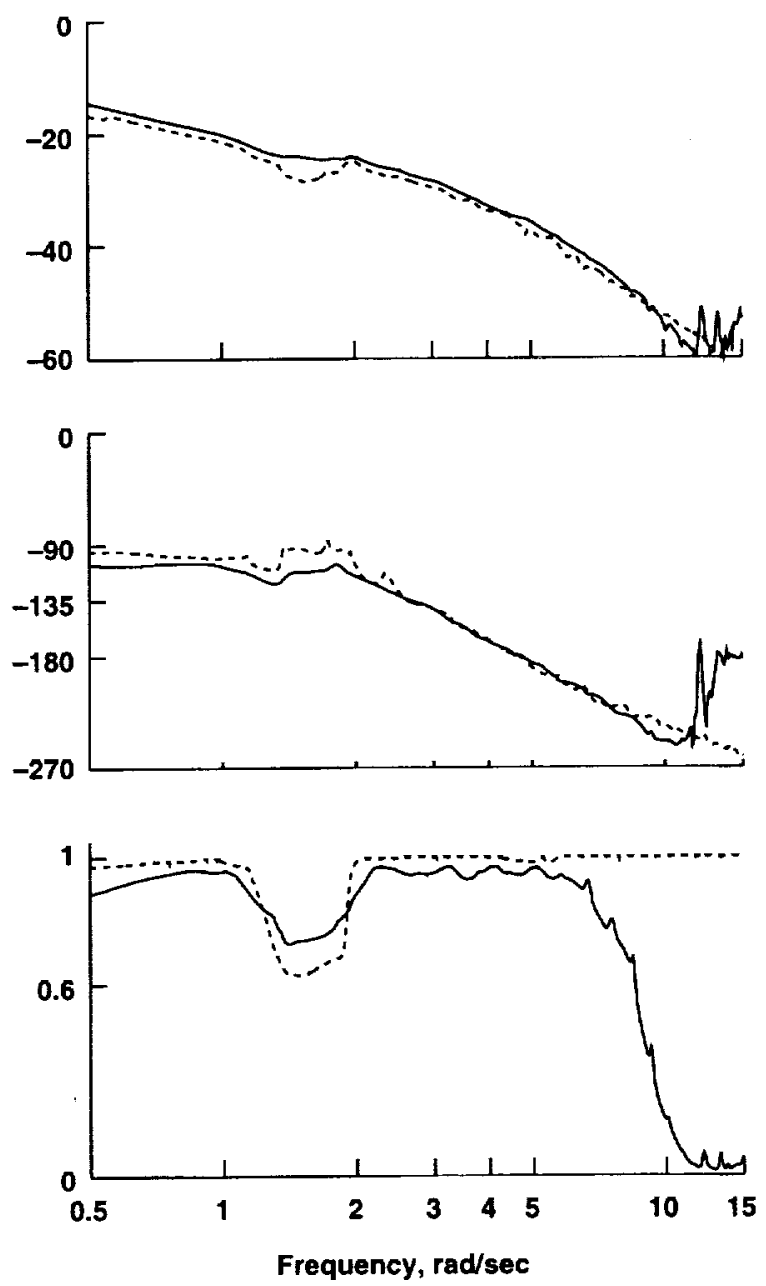

Figure 24. Helicopter attitude-response validation: 4,000-lb block load, hover. 
(a) Lateral axis.
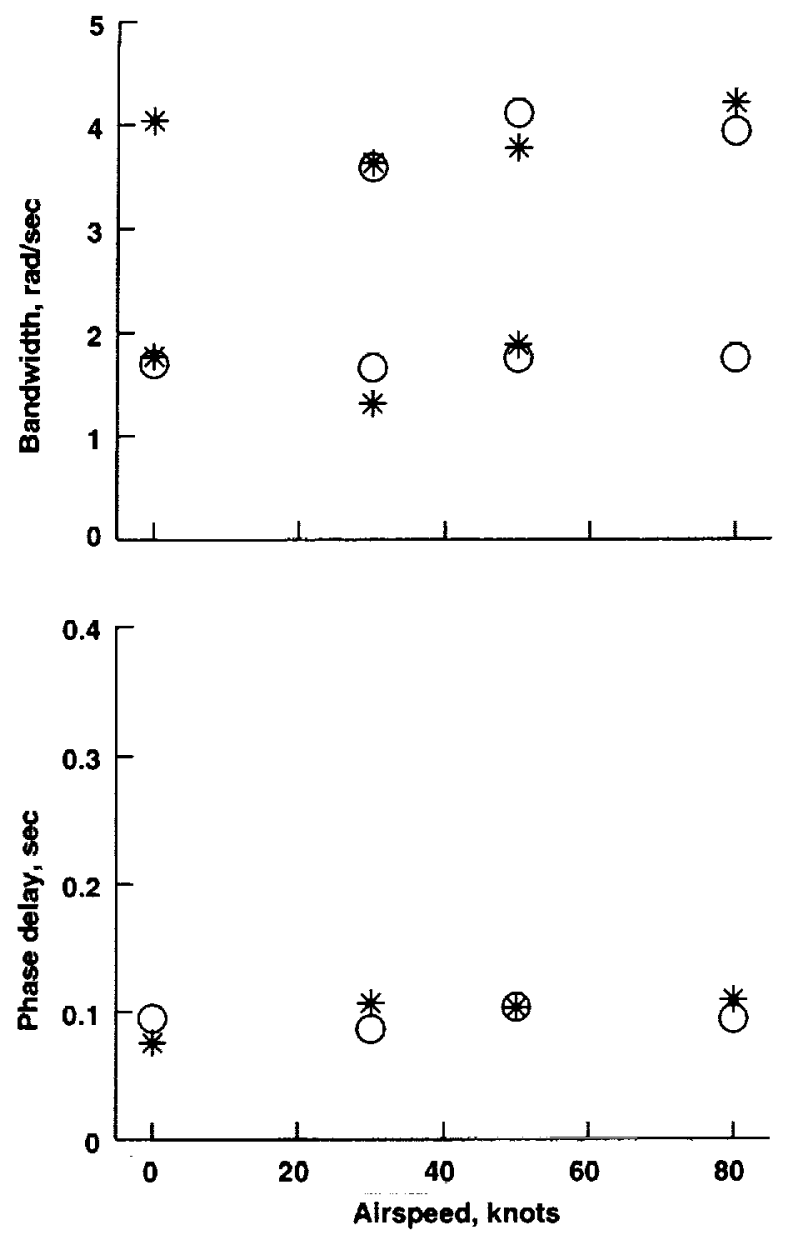

(b) Longitudinal axis.
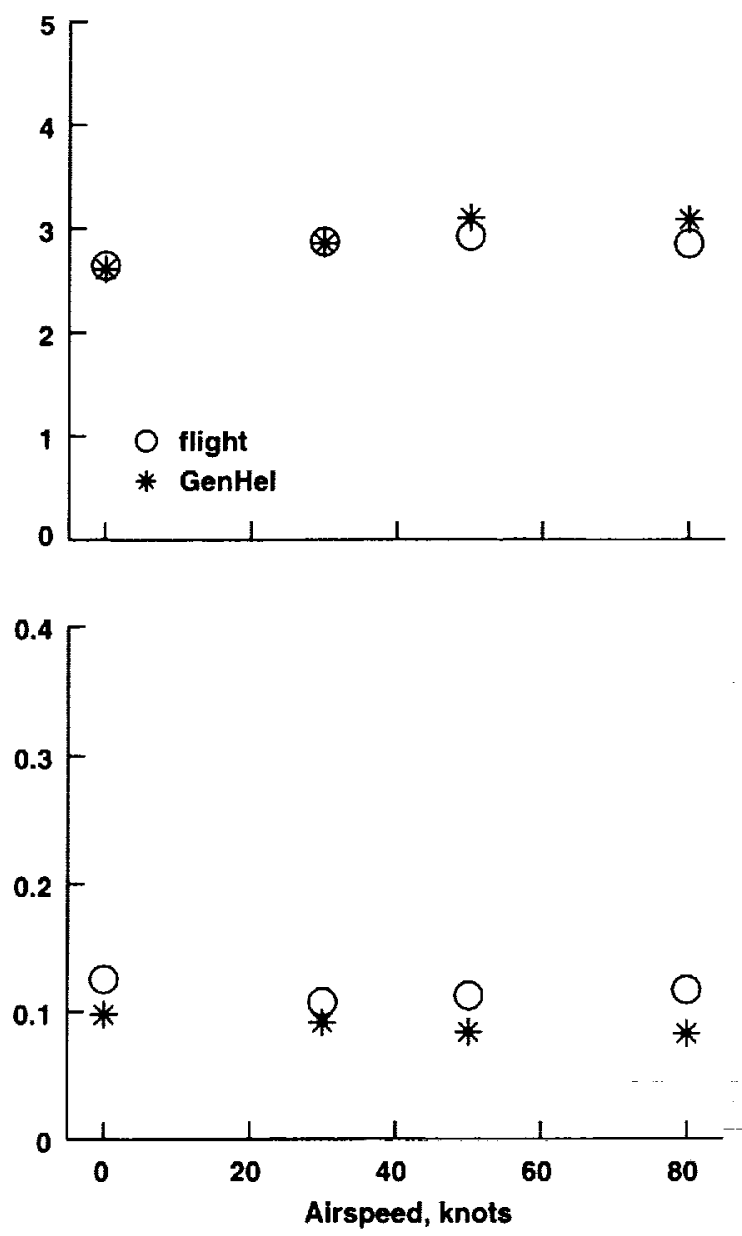

Figure 25. Handling-qualities parameters: 4,000-lb block load. 
(a) Lateral axis.
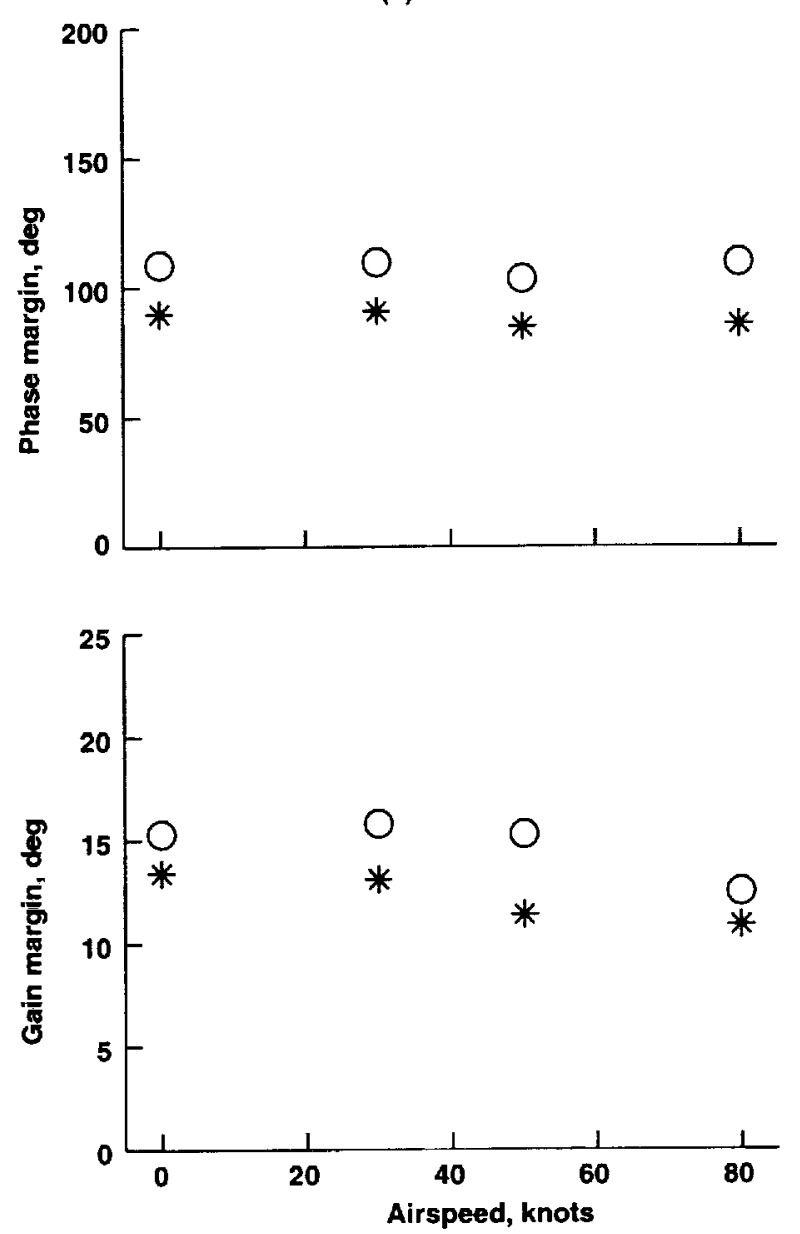

(b) Longltudinal axis.
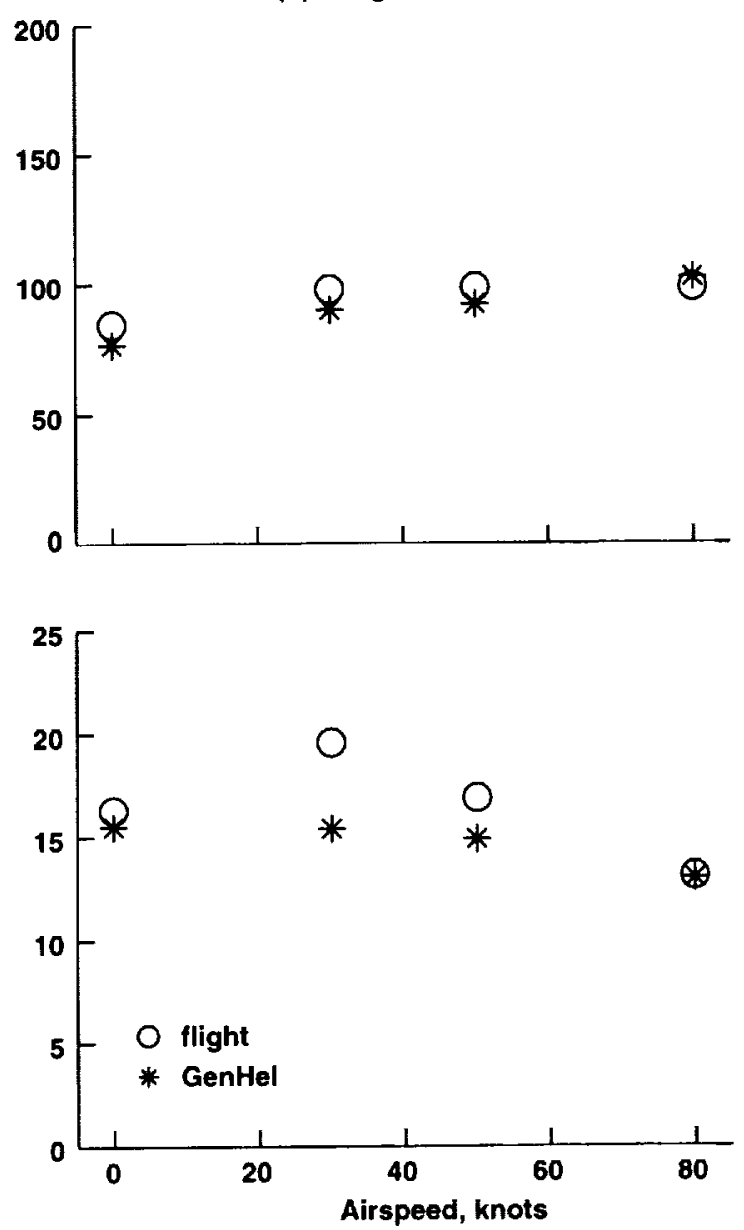

Figure 26 . Stability margins: 4,000-lb block load. 
(a) Lateral: p2' $/ \delta_{\mathrm{LAT}}$.
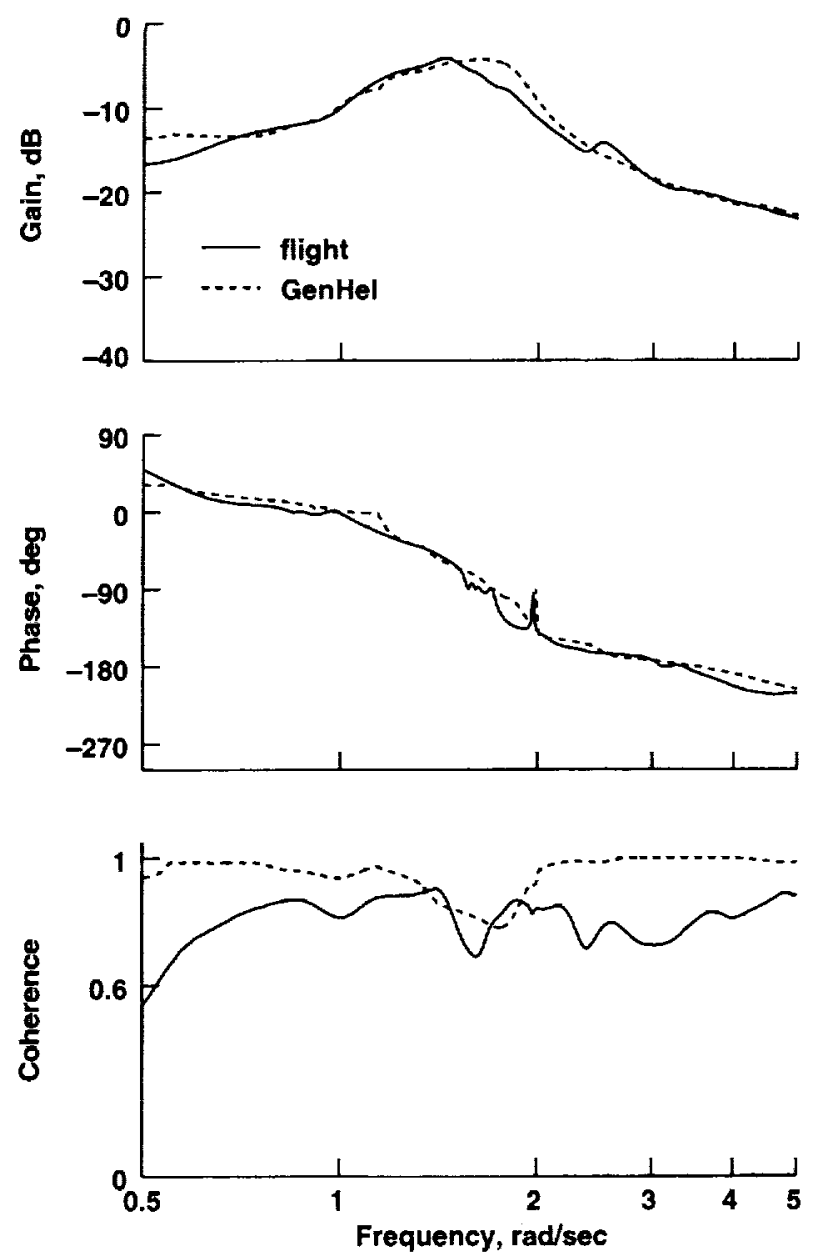

(b) Longitudinal: q2' $/ \delta_{\text {LON- }}$
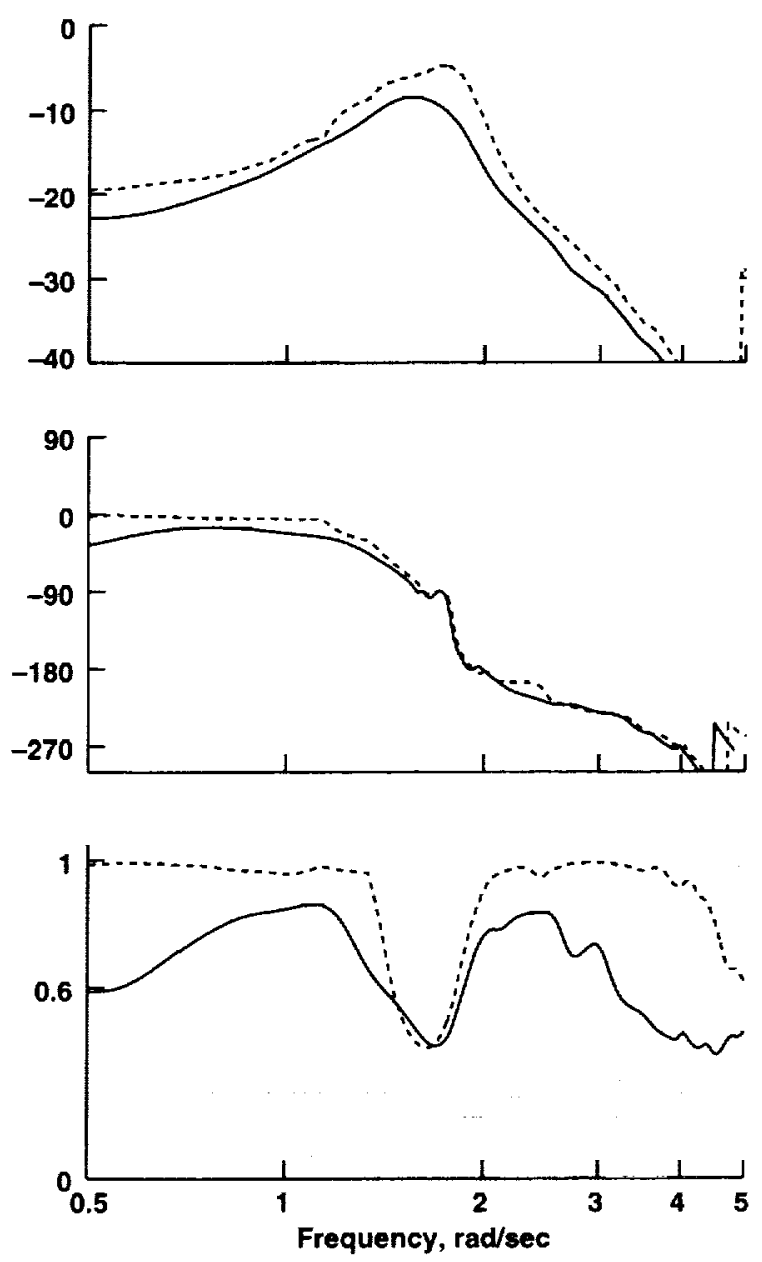

Figure 27. Load angular rate response validation: 4,000-lb block load, hover. 
(a) Lateral axis.
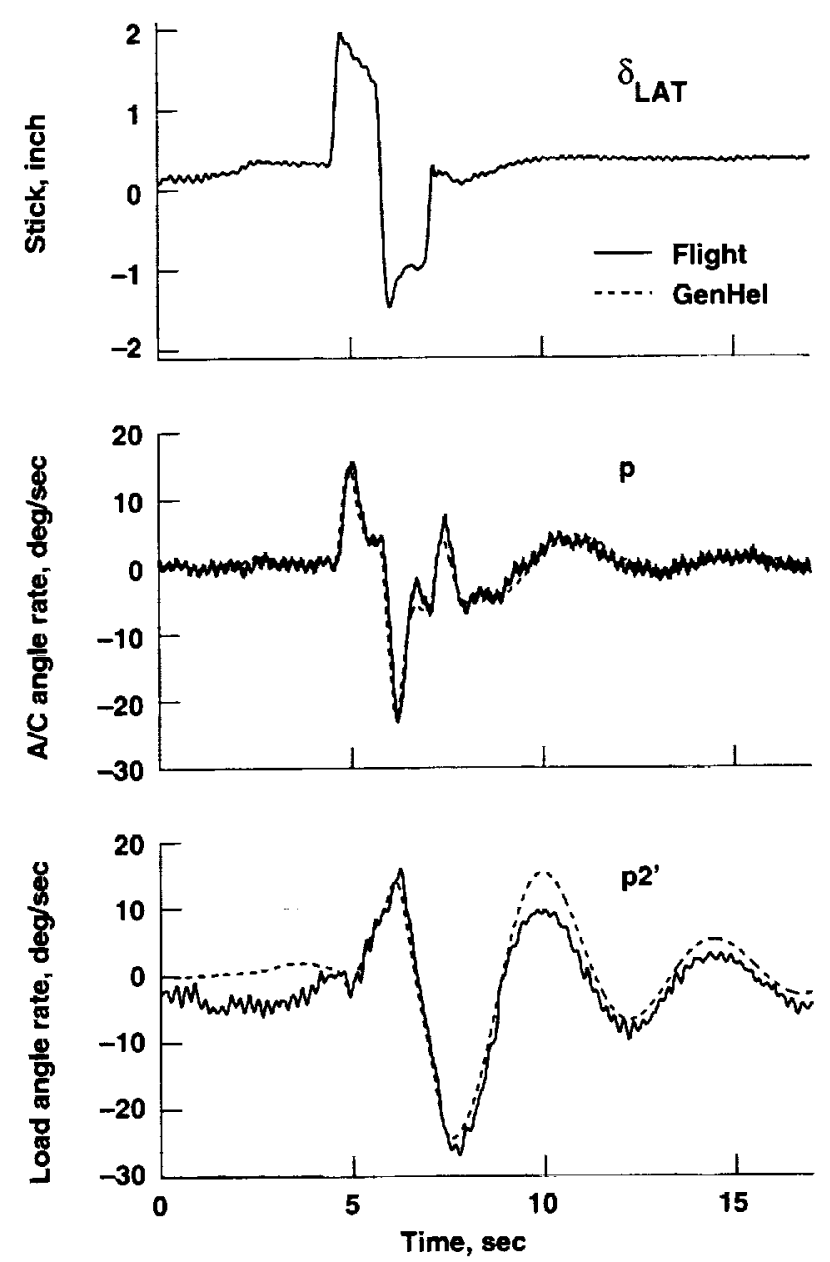

(b) Longitudinal axis.
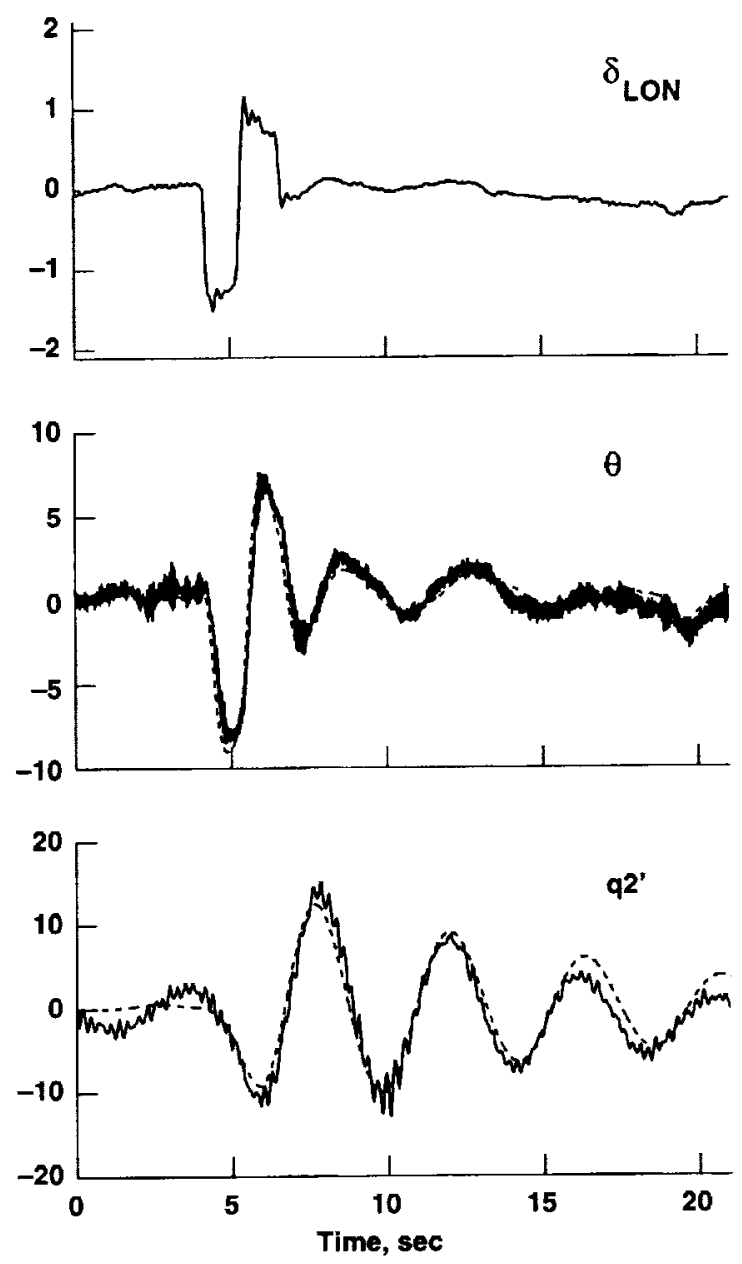

Figure 28. Doublet response comparison: 4,000-lb CONEX, hover. 
(a) Lateral axis.
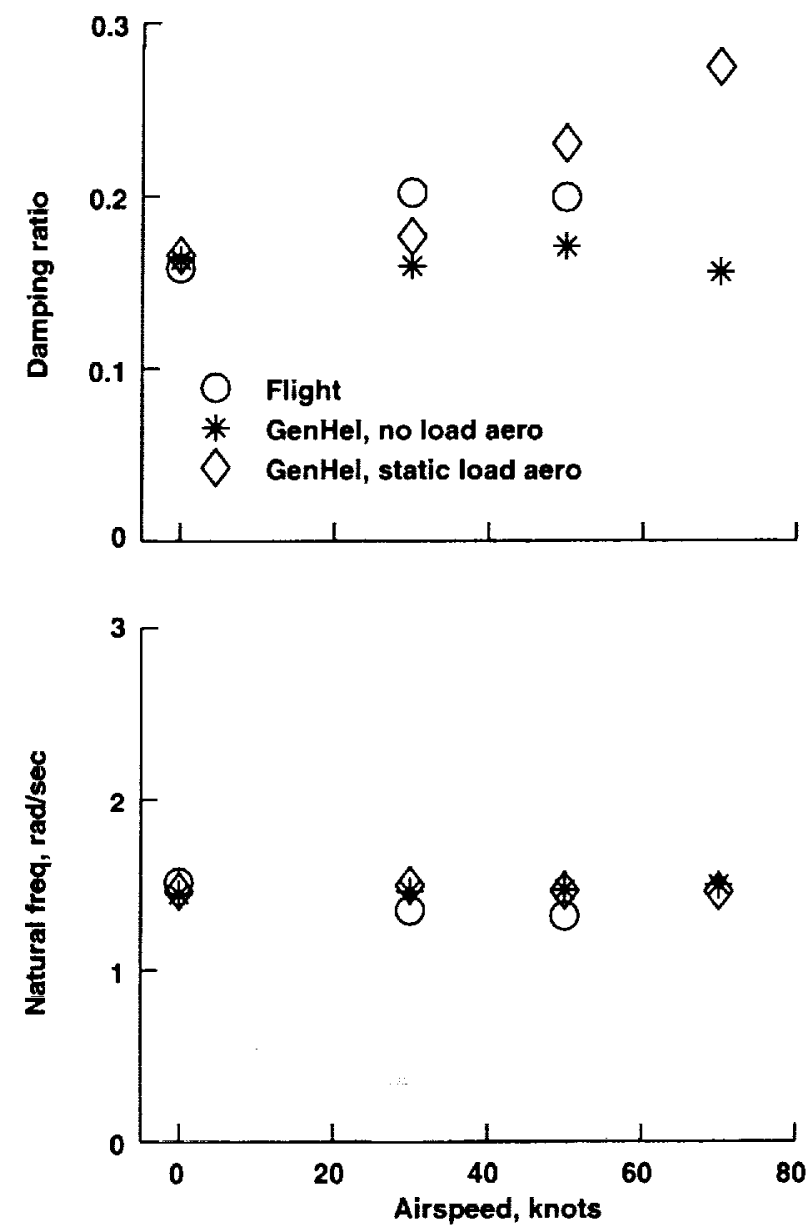

(b) Longitudinal axis.
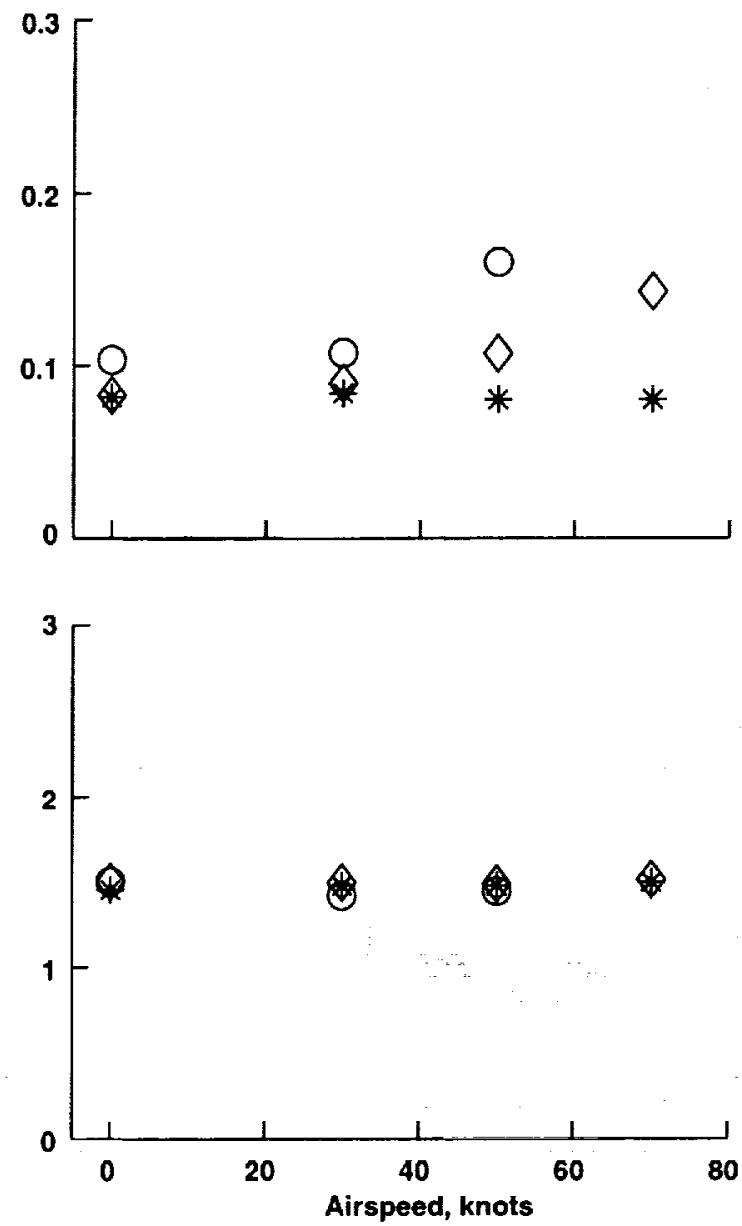

Figure 29. Pendulum roots: 4,000-lb CONEX load. 


\section{CONCLUSIONS}

The main objectives of the study were to (1) demonstrate an efficient method for flight-test evaluation of slung-load configurations and (2) develop a validated simulation capable of realistic prediction of the key dynamic characteristics of slung-load systems. The test configurations were a UH-60A Black Hawk helicopter and various loads, including an instrumented CONEX cargo container. These objectives were achieved. Some detailed results follow.

1. A system for computing aircraft stability and handling qualities, and load-stability parameters during flight testing using telemetered frequency-sweep data has been demonstrated. The required computations with $\mathrm{CIFER}^{\circledR}$ required $40 \mathrm{sec}$ on a $200-\mathrm{MHz}$ workstation. Accuracy as good as postflight analysis was obtained, limited only by the quality of the telemetered data.

2. A portable load instrumentation package was designed and used on two of the test loads. This instrumentation, composed of ordinary aircraft accelerometers, rate gyros, and a digital compass, sufficed for the identification objectives of the study. Improved sensors would be required to encompass the full dynamic range of aerodynamically active loads in forward flight, and additional sensors would be required to measure load aerodynamics from the flight data.

3. Numerical results for the test UH-60A aircraft sling-load configurations indicated strong load effects on the aircraft lateral and longitudinal axes frequency responses in the region of the load pendulum frequency and moderate effects at higher frequencies from 1 to $2 \mathrm{~Hz}$ owing to loadvehicle dynamic interactions and to the increased thrust levels required by the load. These effects increased with load weight. Stability margins and lateral axis bandwidth were reduced for most test conditions. The load pendulum modes were lightly damped with greater damping and greater coupling with aircraft attitude on the lateral axis than on the longitudinal axis. Similar results are expected to occur for single-point suspension configurations generally.

4. A slung-load simulation was implemented, validated, and shown to match flight-test frequency responses and key dynamic parameters in the evaluation of slung-load handling qualities, stability margins, and load pendulum stability. The validation focused on the longitudinal and lateral axes responses out to $2 \mathrm{~Hz}$, and revealed residual unmodeled dynamic effects in the helicopter model in the range of 1-2 Hz. Empirical response corrections were determined and excellent agreement with the flight results was obtained for handling qualities parameters, and phase margin; gain margin results were conservative. Close agreement with flight results for the load responses and pendulum roots was obtained, including the effect of the load static aerodynamics. 


\section{REFERENCES}

1. Multiservice Helicopter External Air Transport. Vols. I, II, and III, U. S. Army FM-55-450-3, -4, and -5 , Feb. 1991.

2. Lawrence, T.; Gerdes, W.; and Yakzan, S.: Use of Simulation for Qualification of Helicopter External Loads. Proceedings of the 50th Annual Forum of the American Helicopter Society, May 1994.

3. Negrette, A.: Slingloads and Arrows. Rotor and Wing, Feb. 1999, p. 99.

4. Conway, G. A.: Epidemiology and Prevention of Helicopter Logging Injuries. Logging Safety, M. L. Klatt, ed., National Institute for Occupational Safety and Health, July 1998.

5. Kehoe, W. M.: AFTI/F-16 Aeroservoelastic and Flutter Flight Test Program: Phase 1. NASA TM-80627, $19 \overline{85}$ (restricted distribution).

6. Bosworth, J.: Flight-Determined Longitudinal Stability Characteristics of the X-29 Aircraft Using Frequency Response Techniques. NASA TM-4122, 1989.

7. Balough, D.: Determination of X-36 Stability Margins Using Real-Time Frequency Response Techniques. Proceedings of AIAA Atmospheric Flight Mechanics Conference, Aug. 1998.

8. Tischler, M.; and Cauffman, M.: Frequency-Response Method for Rotorcraft Identification: Flight Applications to BO-105 Coupled Rotor/Fuselage Dynamics. J. Am. Helicopter Soc., vol. 37, no. 3, July 1992.

9. Tishler, M.; and Cauffman, M.: Comprehensive Identification from Frequency Responses (CIFER): An Interactive Facility for System Identification and Verification. Vols. 1 and 2, NASA CP-10149, USAATCOM TR-94-A-017, Sept. 1994.

10. Howlett, J.: UH-60A Black Hawk Engineering Simulation Program. NASA CR-166309, 1981.

11. Ballin, M. G.; and Dalang-Secratan, M.: Validation of the Dynamic Response of a BladeElement UH-60A Simulation Model in Hovering Flight. Proceedings of the 46th Annual National Forum of the American Helicopter Society, 1990.

12. Ballin, M. G.: Validation of a Real-Time Engineering Simulation of the UH-60A Helicopter. NASA TM-88360, 1987.

13. Rosen, A.; Yaffe, R.; Mansur, M. H.; and Tischler, M. B.: Methods for Improving the Modeling of Rotor Aerodynamics for Flight Mechanics Purposes. Proceedings of the 54th Annual National Forum of the American Helicopter Society, 1998. 
14. Cicolani, L. S.; and Kanning, G.: Equations of Motion of Slung-Load Systems, Including Multilift Systems. NASA TP-3280, 1992.

15. Rosen, A.; Cecutta, S.; and Yaffe, R.: Wind Tunnel Tests of Cube and CONEX Models. Technion Institute of Technology, Dept. of Aerospace Engineering, TAE 844, Nov. 1999.

16. McCoy, A.: Flight Testing and Real-Time System Identification Analysis of a UH-60A Black Hawk Helicopter with an Instrumented External Sling Load. NASA CR-196710, 1998. Also M. S. Thesis, U. S. Naval Postgraduate School, Monterey, Calif., Dec. 1997.

17. Cicolani, L. S.; McCoy, A. H.; Tischler, M. B.; Tucker, G. E.; Gatenio, P.; and Marmar, D.: Identification of a UH-60A Helicopter and Slung Load. RTO Meeting Proceedings 11, Symposium on System Identification for Integrated Aircraft Development and Flight Testing, Madrid Spain, May 1998. Also, NASA TM-112231, 1998.

18. Ng, Y. S.; Wei, M. Y.; Somes, A.; Aoyagi, M.; and Leung, J.: Real-Time Server-Client System for the Near Real-Time Research Analysis of Ensemble Data. Proceedings of the International Telemetry Conference, San Diego, Calif., Oct. 1998.

19. Sahai, R.; Cicolani, L.; Tischler, M.; Blanken, C.; Sullivan, C.; Wei, M.; Ng, Y. S.; and Pierce, L.: Flight-Time Identification of Helicopter Slung-Load Frequency Response Characteristics Using CIFER. Proceedings of the AIAA Atmospheric Flight Mechanics Conference, Portland, Oreg., Aug. 1999.

20. Tyson, P. H.: Simulation Validation and Flight Prediction of UH-60A Black Hawk Helicopter/Slung Load Characteristics. M. S. Thesis, U. S. Naval Postgraduate School, Monterey, Calif., Mar. 1999.

21. Tyson, P. H.; Cicolani, L. S.; Tischler, M. B.; Rosen, A.; Levine, D.; and Dearing, M.: Simulation Prediction and Flight Validation of UH-60A Black Hawk Slung Load Characteristics. Proceedings of the 55th Annual National Forum of the American Helicopter Society, May 1999.

22. Handling Qualities Requirements for Military Rotorcraft. U. S. Army Aeronautical Design Standard ADS-33D-PRF, USAATC/AVRDEC, U. S. Army Aviation and Troop Command, St. Louis, Mo., May 1999.

23. General Specification for Flight Control Systems: General Specification for Design, Installation, and Test of Piloted Aircraft. MIL-F-9490D (USAF), June 1975.

24. Blanken, C.; Cicolani, L.; Sullivan, C.; and Arterburn, D.: Evaluation of Aeronauatical Design Standard 33 Using a UH-60A Black Hawk. Proceedings of the 56th Annual National Forum of the American Helicopter Society, 2000. 
25. Strachan, A.; Shubert, M. W.; and Wilson, A. W.: Development and Evaluation of ADS-33C Handling Qualities Flight Test Maneuvers for Cargo Helicopters. Proceedings of the 50th Annual National Forum of the American Helicopter Society 1994.

26. Keller, J. F.; Hart, D. C.; Shubert, M. W.; and Feingold, A.: Handling Qualities Specification Development for Cargo Helicopters. 51st Annual National Forum of the American Helicopter Society, 1995.

27. Handling Qualities Requirements for Military Rotorcraft. Aeronautical Design Standard ADS33E-PRF, U. S. Army Aviation and Missile Command, Aviation Engineering Directorate, Redstone Arsenal, Alabama, Mar. 2000.

28. Hilbert, K.: Math Model of the Uh-60A Helicopter. NASA TM-85890, 1984.

29. Fletcher, J.: A Model Structure for Identification of Linear Models of the UH-60A Helicopter in Hover and Forward Flight. NASA TM-1 10362, 1995.

30. Operator's Manual for Army Models UH-60A, UH-60L, EH-60A Helicopters. Army TM-11520-237-10, 31 Aug. 1994.

31. Kufeld, R.; Balough, D.; Cross, J.; Studebaker, K.; Jennison, C.; and Bousman, W.: Flight Testing the UH-60A Airloads Aircraft. 50th Annual National Forum of the American Helicopter Society, 1994.

32. Black Hawk Slung Load Instrumentation Package: Development Report and User Manual. IAF Flight Test Center, Instrumentation Department Report for the MOA, Oct. 1996.

33. Tischler, M. B.; Fletcher, J. W.; Diekman, V. L.; Williams, R. A.; and Cason, R. W.: Demonstration of Frequency Sweep Test Techniques Using a Bell-214-T Helicopter. NASA TM-89422, $19 \overline{87}$.

34. Williams, J. N.; Ham, J. A.; and Tischler, M. B.: Flight Test Manual: Rotorcraft Frequency Domain Flight Testing. AQTD Project 93-14, U. S. Army Aviation Technical Test Center, Sept. 1995.

35. Tischler, M. B.: Frequency-Response Identification of XV-15 Tilt Rotor Aircraft Dynamics. NASA TM-89428, 1987.

36. Hoh, R. H.; and Hefley, R. K.: Development of ADS-33E Criteria for External Load Based on VMS Piloted Simulations. Working Paper 1075-1, Hoh Aereonautics, Inc., Feb. 2000.

37. McKee, J. W.; and Naeseth, R. L.: Experimental Investigation of the Drag of Flat Plates and Cylinders in the Slipstream of a Hovering Rotor. NACA TN-4939, 1958.

38. Boatwright, D. W.: Measurements of Velocity Components in the Wake of a Full-Scale Helicopter Rotor in Hover. USAAMRDL TR-72-33, Ft. Eustis, Va., Aug. 1972. 
39. Mansur, M. H.; and Tischler, M. B.: An Empirical Correction for Improving Off-Axes Response in Flight Mechanics Helicopter Models. J. Am. Helicopter Soc., April 1998.

40. Hodgkinson, J.; and Mitchell, D.: Flight Control Systems. Ch. 4, AIAA Progress in Astronautics and Aeronautics, vol. 184, R. W. Pratt ed., 2000.

41. Hoh, R. H.; Mitchell, D. G.; Askenas, I. L.; Klein, R. H.; Hefley, R. K.; and Hodgkinson, J.: Proposed MIL Standard and Handbook Flying Qualities of Air Vehicles. AFWAL-TR-823081, vol. 2, 1982.

42. Hamel, P. G.; and Jategaonkar, R. V.: Evolution of Flight Vehicle System Identification. J. Aircraft, Jan. 1996

43. Buchholz, J. J.; Baushat, J. M.; and Pausder, H. J.: ATTAS and ATHeS In-Flight Simulators-Recent Application Experiences and Future Programs. AGARD Flight Vehicle Integration Panel Symposium: Simulation-Where Are the Challenges, Braunschweig, Germany, 1995.

44. Curtiss, H. C.: On the Calculation of the Response of Helicopters to Control Inputs. Proceedings of the 18th European Rotorcraft Forum, Avignon, France, Sept. 1992.

45. Bondi, M. J.; and Bjorkman, W. S.: TRENDS Flight Test Relational Database: User's Guide and Reference Manual. NASA TM-108806, 1994

46. Bach, R. E.: State Estimation Applications in Aircraft Flight Data Analysis: A User's Manual for SMACK. NASA RP-1252, 1991. 


\section{APPENDIX}

\section{COMPENDIUM OF UH-60A SLUNG-LOAD TEST FLIGHTS}

This appendix provides a compendium of slung-load flight test data archived at Ames Research Center in the TRENDS data base utility (ref. 45) under tail number BSL. This includes base-line flights with no load and with the various load-sling configurations shown in figure 3 of the text. This appendix contains a summary of flights by load (table 1), a master list of available signals (table 2), and a catalog of records for each flight (table 3 ). All records have been stored at $100-\mathrm{Hz}$ data rate. The flight records consist principally of lateral and longitudinal control frequency sweeps, steps, and doublets. A limited amount of data is included for directional and collective control inputs. The BSL data base contains additional flight records for the test UH-60A aircraft beyond those listed in this compendium, including the flight data of the handling qualities study of reference 24 .

\section{Summary of Flights by Load}

Flights are summarized by load in table 1. The table indicates the airspeeds, control axes, control inputs, and signal groups available for each flight, as well as the record numbers archived in TRENDS. Load sensor signals are available for nearly all flights with the CONEX and for flights with the 4,000-lb block starting with flight 177 .

\section{Signals}

A master list of signals is given in table 2. These are divided into three groups. Group TC ("test conditions") contains helicopter sensor signals plus some scaled control system signals. This group subdivides broadly into control system sensors, aircraft rigid-body state sensors, and air data sensors. Group LD contains the load instrumentation package signals, which are rigid-body state sensors. Group DP ("derived parameters") contains derived parameters which subdivide into (1) control system signals scaled to inches, (2) smoothed or derived variables for the helicopter rigid body states, (3) derived signals from the air data sensors, and (4) smoothed and derived signals from the load instrumentation.

A diagram of the helicopter control system and the control sensor locations is given in figure 30 along with the gains and scale factors used to scale the sensor outputs to inches. A backward/forward smoothing filter from reference 46 was used to remove vibration frequencies from the accelerometer, rate gyro, and some air data signals, and to obtain altitude rates and derivatives of the angular rate signals. The filter cutoff frequency for the filtered signals was $0.25 \mathrm{~Hz}$ for the altitude rate computations and $2.5 \mathrm{~Hz}$ for all other smoothed signals. Smoothed signals and derivatives were similarly generated for the load accelerometer and rate gyro outputs. The helicopter angular accelerometer signals are dominated by vibration and generally saturated. However, derivatives of the angular rate signals are provided in the derived parameters. The low airspeed sensor (LASSIE) y, $\mathrm{z}$ signal calibrations are doubtful. The load inclinometer signals are 
proportional to the load accelerometer signals and measure angles relative to the apparent gravity rather than true gravity. The nonstandard sign convention for the load pitch rate gyro signal should be noted.

For some early flights data storage is incomplete; derived parameters were not generated for some flights or for records other than sweeps in some flights, and the basic signal group TC was incompletely archived in some cases. Signals in TRENDS can be addressed using the designations given in either the "item code" or "alias" columns of table 2.

\section{Catalog of Records}

Table 3 contains a detailed catalog of the records available in TRENDS for each flight.

The helicopter heading signal, item code DA02, was obtained from an unslaved directional gyro for flights prior to flight 177 and contained a random startup bias and drift. This bias was required to compute the CONEX load pendulum roots. Calibration records were taken, and the resulting starting bias and average drift rate are noted in the records catalog for flights 167 to 173. Heading is corrected by subtracting the bias value from DA02.

The record catalog notes the aircraft reference gross weight and c.g. station corresponding to aircraft, crew, and full fuel tanks $(2,446 \mathrm{lb})$. The weight and c.g. station for any record can be adjusted for fuel use after noting that the fuel tank c.g. station is at 420.8 inches. This correction was included in the derived parameter computations.

\section{TABLE 1. TRENDS DATA BASE: SUMMARY OF FLIGHTS BY LOAD}

\begin{tabular}{|c|c|c|c|c|c|c|c|}
\hline Load & Flight & $\begin{array}{l}\text { Record } \\
\text { numbers }\end{array}$ & $\begin{array}{l}\text { IAS } \\
\text { kts }\end{array}$ & \begin{tabular}{|l|}
$\begin{array}{l}\text { Control } \\
\text { axes }\end{array}$ \\
\end{tabular} & \begin{tabular}{|l|} 
Control \\
inputs
\end{tabular} & $\begin{array}{l}\text { Signal } \\
\text { groups }\end{array}$ & Notes \\
\hline \multirow[t]{4}{*}{ none } & 153 & $1-18$ & 80 & all axes & sweeps, dblts & TC, DP & \\
\hline & 154 & $1-14$ & 80 & lat, lon & sweeps, dblts & TC & \\
\hline & 157 & $1-49$ & $0-130$ & $\mathrm{NA}$ & trims only & $\mathrm{TC}$ & air data cals \\
\hline & 170 & $1-71$ & $\begin{array}{l}0 \\
0 \\
30 \\
50 \\
50 \\
\end{array}$ & $\begin{array}{l}\text { lat, lon } \\
\text { coll } \\
\text { lat, lon } \\
\text { lat, lon } \\
\text { coll } \\
\end{array}$ & $\begin{array}{l}\text { sweeps,dblts } \\
\text { doublets } \\
\text { sweeps, dblts } \\
\text { sweeps,dblts } \\
\text { dblts } \\
\end{array}$ & TC, DP & \\
\hline \multirow[t]{2}{*}{$1 \mathrm{~K}$ plate } & 151 & 2.17 & 0 & all axes & sweeps, dblts & $\mathrm{TC}$ & \\
\hline & 160 & $1-42$ & 80 & lat, lon & sweeps, dblts & TC & reduced signals \\
\hline
\end{tabular}




\section{TABLE 1. TRENDS DATA BASE: SUMMARY OF FLIGHTS BY LOAD (CONTINUED)}

\begin{tabular}{|c|c|c|c|c|c|c|c|}
\hline Load & Flight & \begin{tabular}{|l|} 
Record \\
numbers
\end{tabular} & \begin{tabular}{|l|} 
IAS \\
kts
\end{tabular} & \begin{tabular}{|l|}
$\begin{array}{l}\text { Control } \\
\text { axes }\end{array}$ \\
\end{tabular} & \begin{tabular}{|l|}
$\begin{array}{l}\text { Control } \\
\text { inputs }\end{array}$ \\
\end{tabular} & $\begin{array}{l}\text { Signal } \\
\text { groups }\end{array}$ & Notes \\
\hline \multirow[t]{8}{*}{$4 \mathrm{~K}$ block } & 156 & $15-59$ & $20-120$ & lat, lon, pedal & steps, dblts & $\mathrm{TC}$ & \\
\hline & 158 & $1-93$ & $0,60,80,100$ & all axes & steps, dblts & $\mathrm{TC}$ & \\
\hline & 159 & $1-57$ & 0 & all axes & sweeps, dblts & TC, DP & \\
\hline & 161 & $1-55$ & 80 & all axes & sweeps, dblts & TC & reduced signals \\
\hline & 177 & $2-17$ & $\begin{array}{l}0 \\
0 \\
30 \\
\end{array}$ & \begin{tabular}{|l|} 
lat, lon \\
coll \\
lon \\
\end{tabular} & $\begin{array}{l}\text { sweeps, dblts } \\
1 \mathrm{dblt} \\
\text { sweeps }\end{array}$ & TC, LD, DP & $\begin{array}{l}\text { uncalibrated } \\
\text { SAS signals }\end{array}$ \\
\hline & 178 & $1-31$ & $\begin{array}{l}0 \\
30 \\
30 \\
50 \\
\end{array}$ & \begin{tabular}{|l|} 
lon \\
lat, lon \\
coll \\
lat, lon \\
\end{tabular} & $\begin{array}{l}\text { sweeps } \\
\text { sweeps, dblts } \\
\text { dblts } \\
\text { sweeps, dblts } \\
\end{array}$ & TC, LD, DP & $\begin{array}{l}\text { no mixers, } \\
\text { SAS, boom, } \\
\text { radalt signals }\end{array}$ \\
\hline & 180 & $4-20$ & $\begin{array}{l}0 \\
50 \\
\end{array}$ & $\begin{array}{l}\text { lon } \\
\text { lat, lon }\end{array}$ & $\begin{array}{l}\text { sweeps, dblts } \\
\text { sweeps, dblts }\end{array}$ & TC, LD, DP & $\begin{array}{l}\text { uncalibrated } \\
\text { SAS signals }\end{array}$ \\
\hline & 182 & $1-31$ & \begin{tabular}{|l|}
0 \\
30 \\
80 \\
\end{tabular} & \begin{tabular}{|l|} 
lat \\
lat, Ion \\
lat, lon \\
\end{tabular} & $\begin{array}{l}\text { sweeps, dblts } \\
\text { sweeps, dblts } \\
\text { sweeps, dblts } \\
\end{array}$ & $\mathrm{TC}, \mathrm{LD}, \mathrm{DP}$ & \\
\hline \multirow[t]{3}{*}{$2 \mathrm{KCONEX}$} & 162 & $12-21$ & 0 to 60 & NA & Trims, turns & $\mathrm{TC}$ & $\begin{array}{l}\text { envelope } \\
\text { clearance }\end{array}$ \\
\hline & 164 & $1-4$ & 40 & lat & 1 sweep & TC, LD, DP & \\
\hline & 167 & $1-32$ & $\begin{array}{l}0 \\
0\end{array}$ & $\begin{array}{l}\text { lat, lon } \\
\text { coll }\end{array}$ & $\begin{array}{l}\text { sweeps, dblts } \\
\text { dblts }\end{array}$ & TC, LD, DP & \\
\hline \multirow[t]{2}{*}{$\begin{array}{l}\text { 4KCONEX } \\
\text { w swivel }\end{array}$} & 169 & $1-18$ & $\begin{array}{l}0 \\
30 \\
\end{array}$ & \begin{tabular}{|l|} 
lat \\
lon
\end{tabular} & \begin{tabular}{|l|} 
sweeps \\
sweeps
\end{tabular} & TC, LD, DP & \\
\hline & 179 & $4-22$ & $\begin{array}{l}0 \\
0 \\
30 \\
30 \\
\end{array}$ & $\begin{array}{l}\text { lat,lon } \\
\text { coll } \\
\text { lat, lon } \\
\text { coll } \\
\end{array}$ & $\begin{array}{l}\text { sweeps, dblts } \\
\text { dblts } \\
\text { sweeps, dblts } \\
\text { dblts } \\
\end{array}$ & TC, LD, DP & \\
\hline \multirow[t]{3}{*}{ 4KCONEX } & 168 & $1-35$ & $\begin{array}{l}0 \\
0 \\
\end{array}$ & \begin{tabular}{|l|}
$\begin{array}{l}\text { lat, Ion } \\
\text { coll }\end{array}$ \\
\end{tabular} & \begin{tabular}{|l|}
$\begin{array}{l}\text { sweeps, dblts } \\
\text { dblts }\end{array}$ \\
\end{tabular} & TC, LD, DP & \\
\hline & 172 & $1-52$ & $\begin{array}{l}0 \\
30 \\
50 \\
\end{array}$ & \begin{tabular}{|l|} 
lat \\
lat, lon \\
lat, lon \\
\end{tabular} & \begin{tabular}{|l|} 
sweeps \\
sweeps, dblts \\
sweeps, dblts \\
\end{tabular} & TC, LD, DP & \\
\hline & $\overline{173}$ & $1-50$ & $\begin{array}{l}0 \\
60 \\
70 \\
\end{array}$ & $\begin{array}{l}\text { lon } \\
\text { lat, lon } \\
\text { lat, lon }\end{array}$ & $\begin{array}{l}\text { sweeps } \\
\text { sweeps, dblts } \\
\text { sweeps, dblts }\end{array}$ & TC, LD, DP & \\
\hline \multirow[t]{2}{*}{$6 \mathrm{~K}$ Block } & 181 & $1-30$ & $\begin{array}{l}0 \\
30 \\
50\end{array}$ & $\begin{array}{l}\text { lat,lon } \\
\text { lat,lon } \\
\text { lat, lon }\end{array}$ & $\begin{array}{l}\text { sweeps, dblts } \\
\text { sweeps, dblts } \\
\text { sweeps, dblts } \\
\end{array}$ & TC, LD, DP & \\
\hline & 183 & $1-25$ & $\begin{array}{l}50 \\
80 \\
\end{array}$ & $\begin{array}{l}\text { lat, lon } \\
\text { lat,lon }\end{array}$ & $\begin{array}{l}\text { sweeps, dblts } \\
\text { sweeps, dblts }\end{array}$ & TC, LD, DP & \\
\hline
\end{tabular}


TABLE 2. TRENDS SIGNALS AND VARIABLES

(a) Group TC: Helicopter Sensors

\begin{tabular}{|c|c|c|c|c|c|c|}
\hline \multirow{2}{*}{$\begin{array}{l}\text { Item } \\
\text { code }\end{array}$} & \multirow[t]{2}{*}{ Alias } & \multirow{2}{*}{ Description } & \multirow{2}{*}{$\begin{array}{l}\text { Positive } \\
\text { direction }\end{array}$} & \multirow[t]{2}{*}{ Units } & \multicolumn{2}{|c|}{ Range } \\
\hline & & & & & Min & Max \\
\hline D 100 & LONSTK & longitudinal cylic stick position & aft & $\%$ & 0 & 100 \\
\hline Di0I & LATSTK & lateral cyclic stick position & right & $\%$ & 0 & 100 \\
\hline D 102 & PEDAL & directional control position & right pedal & $\%$ & 0 & 100 \\
\hline D 103 & COLLSTK & collective stick position & up & $\%$ & 0 & 100 \\
\hline $\mathrm{D} 003$ & STBLR & stabilator angle & TE down & deg & -10 & 40 \\
\hline DM00 & DMO0 & longitudinal mixer input & aft & $\%$ & 0 & 100 \\
\hline DM01 & DM01 & lateral mixer input & right & $\%$ & 0 & 100 \\
\hline DM02 & DM02 & directional mixer input & right pedal & $\%$ & 0 & 100 \\
\hline MIXA & DMIXA & lateral mixer input & right & in & 0 & 2.1 \\
\hline MIXE & DMIXE & longitudinal mixer input & aft & in & 0 & 2.1 \\
\hline MIXR & DMIXR & directional mixer input & right pedal & in & 0 & 1.9 \\
\hline DPO0 & DPO0 & forward primary servo input & & $\%$ & 0 & 100 \\
\hline DP01 & DP01 & lateral primary servo input & & $\%$ & 0 & 100 \\
\hline DP03 & DP02 & aft primary servo input & & $\%$ & 0 & 100 \\
\hline PAFT & PSAFT & aft primary servo input & & in & 0 & 4.1 \\
\hline PFWD & PSFWD & forward primary servo input & & in & 0 & 3.3 \\
\hline PLAT & PSLAT & lateral primary servo & & in & 0 & 4.3 \\
\hline DSO0 & SASE & longitudinal SAS output & nose up & $\%$ & 0 & 100 \\
\hline DSO1 & SASA & lateral SAS output & turn right & $\%$ & 0 & 100 \\
\hline DSO2 & SASR & directional SAS output & nose right & $\%$ & 0 & 100 \\
\hline R021 & TRIP & tail rotor imprest pitch & left pedal & $\%$ & 0 & 100 \\
\hline DAO0 & PITCHATT & pitch attitude & nose up & $\operatorname{deg}$ & -50 & 50 \\
\hline DA01 & ROLLATT & roll attitude & turn right & deg & -100 & 100 \\
\hline $\mathrm{DA} 02$ & HEADING & magnetic heading & nose rightnose & deg & 0 & 360 \\
\hline DR00 & PITCHR8 & pitch rate gyro & & $\mathrm{deg} / \mathrm{sec}$ & -50 & 50 \\
\hline DRO1 & ROLLR8 & roll rate gyro & turn right & $\mathrm{deg} / \mathrm{sec}$ & -50 & 50 \\
\hline $\mathrm{DRO} 2$ & YAWR8 & yaw rate gyro & nose right & $\mathrm{deg} / \mathrm{sec}$ & -50 & 50 \\
\hline DACO & PITCHACC & pitch angular accelerometer & nose up & $\mathrm{deg} / \mathrm{sec} 2$ & -600 & 600 \\
\hline DACl & ROLLACC & roll angular accelerometer & turn right & $\mathrm{deg} / \mathrm{sec} 2$ & -200 & 200 \\
\hline DAC2 & YAWACC & yaw angular accelerometer & nose right & $\mathrm{deg} / \mathrm{sec} 2$ & -100 & 100 \\
\hline DLOO & AMGX & $\mathrm{x}$ accelerometer & forward & $\mathrm{g}$ & -2 & 2 \\
\hline DLO1 & AMGY & y accelerometer & right & $\mathrm{g}$ & -2 & 2 \\
\hline DL02 & AMGZ & $z$ accelerometer & up & $\mathrm{g}$ & -2 & 4 \\
\hline DAA0 & ALPHA & boom alpha vane & nose up & deg & -100 & 100 \\
\hline DSSO & BETA & boom sideslip vane & nose left & deg & -100 & 100 \\
\hline V001 & V001 & boom dynamic pressure & & in $\mathrm{Hg}$ & 0 & 2 \\
\hline H001 & H001 & boom static pressure & & in $\mathrm{Hg}$ & 20 & 32 \\
\hline H003 & RALT & radar altimeter & & $\mathrm{ft}$ & 0 & 1500 \\
\hline $\mathrm{T} 100$ & $\mathrm{~T} 100$ & stagnation temperature & & $\operatorname{deg} C$ & -20 & 50 \\
\hline VX03 & LSSX & LASSIE forward airspeed & forward & kts & -35 & 165 \\
\hline VY03 & LSSY & LASSIE lateral airspeed & right & kts & -50 & 50 \\
\hline VZ03 & LSSZ & LASSIE vertical airspeed & up & $\mathrm{ft} / \mathrm{min}$ & -300 & 2000 \\
\hline HKLD & HKLD & hook load & & lbs & 0 & 10000 \\
\hline
\end{tabular}




\section{TABLE 2. TRENDS SIGNALS AND VARIABLES (CONTINUED)}

(b) Group LD: Load Sensors

\begin{tabular}{|l|l|l|l|l|l|l|}
\hline $\begin{array}{l}\text { Item } \\
\text { code }\end{array}$ & Alias & Description & $\begin{array}{l}\text { Positive } \\
\text { direction }\end{array}$ & & Units & Range \\
\cline { 5 - 7 } & & & Min & Max \\
\hline AL01 & AMGXL & load $x$ accelerometer & forward & $\mathrm{g}$ & -2.5 & 2.5 \\
AL02 & AMGYL & load y accelerometer & right & $\mathrm{g}$ & -2.5 & 2.5 \\
AL03 & AMGZL & load z accelerometer & up & $\mathrm{g}$ & -12.5 & 12.5 \\
DAL1 & PANGL & load pitch inclinometer & nose up & counts $*$ & 0 & 4096 \\
DAL2 & RANGL & load roll inclinometer & roll right & counts * & 0 & 4096 \\
DAL3 & YAWANG & load magnetic heading & nose right & deg & 0 & 360 \\
DRL1 & PITCHR8L & load pitch rate gyro & nose DOWN & deg/sec & -60 & 60 \\
DRL2 & ROLLR8L & load roll rate gyro & roll right & deg/sec & -90 & 90 \\
DRL3 & YAWR8L & load yaw rate gyro & nose right & deg/sec & -120 & 120 \\
\hline
\end{tabular}

* conversion of inclinometers to deg $=\sin -1(\operatorname{count} / 2048-1)$ 
TABLE 2. TRENDS SIGNALS AND VARIABLES (CONTINUED)

(c) Group DP: Derived Parameters

\begin{tabular}{|c|c|c|c|c|c|c|}
\hline \multirow[t]{2}{*}{ Alias } & \multirow{2}{*}{$\begin{array}{l}\text { Item } \\
\text { code }\end{array}$} & \multirow[t]{2}{*}{ Description *,+ } & \multirow{2}{*}{\begin{tabular}{|l|} 
Positive \\
direction
\end{tabular}} & \multirow[t]{2}{*}{ Units } & \multicolumn{2}{|l|}{ Range } \\
\hline & & & & & Min & Max \\
\hline XAIN & XAIN & lateral stick position & turn right & in & & \\
\hline XBIN & XBIN & longitudinal stick position & forward & in & & \\
\hline XPIN & XPIN & pedal position & nose right & in & & \\
\hline XCIN & XCIN & collective position & up & in & & \\
\hline XABST & ABST & lateral boost servo output & turn right & in & & \\
\hline XEBST & EBST & longitudinal boost servo output & forward & in & & \\
\hline XPBST & PBST & pedal boost servo output & turn right & in & & \\
\hline XCBST & CBST & collective boost servo output & up & in & & \\
\hline DMIXC & MIXC & collective mixer input & & in & & \\
\hline PSTRIN & PSTR & tail rotor servo output & left pedal & in & & \\
\hline & DROS & smoothed pitch rate $*$ & nose up & $\mathrm{deg} / \mathrm{sec}$ & & \\
\hline $\begin{array}{l}\text { DRUOS } \\
\text { DRO1S }\end{array}$ & DR1S & smoothed roll rate $*$ & right tum & $\mathrm{deg} / \mathrm{sec}$ & & \\
\hline DR02S & DR2S & smoothed yaw rate $*$ & nose right & $\mathrm{deg} / \mathrm{sec}$ & & \\
\hline DROOD & DROD & derivative of DRO0S & nose up & $\mathrm{deg} / \mathrm{sec} 2$ & & \\
\hline DR01D & DRID & derivative of DR01S & right tum & $\mathrm{deg} / \mathrm{sec} 2$ & & \\
\hline DR02D & DR2D & derivative of DR02S & nose right & $\mathrm{deg} / \mathrm{sec} 2$ & & \\
\hline DLOOS & DLOS & smoothed $\mathrm{x}$ accelerometer & forward & & & \\
\hline DL01S & DL1S & smoothed y accelerometer & right & $\mathrm{g}$ & & \\
\hline DL02S & DL2S & smoothed $\mathrm{z}$ accelerometer & up & $\mathrm{g}$ & & \\
\hline DVISNX & XIDD & $\mathrm{x}$ inertial cg acceleration & forward & $\mathrm{ft} / \mathrm{sec} 2$ & & \\
\hline DVISNY & YIDD & $\mathrm{y}$ inertial cg acceleration & right & $\mathrm{ft} / \mathrm{sec} 2$ & & \\
\hline DVISNZ & Z1DD & $\mathrm{z}$ inertial $\mathrm{cg}$ acceleration & down & $\mathrm{ft} / \mathrm{sec} 2$ & & \\
\hline & & & & & & \\
\hline VICB & IASX & boom indicated airspeed & & kts & & \\
\hline VCALB & CASX & boom calibrated airspeed & & kts & & \\
\hline VEB & EASX & boom equivalent airspeed & & kts & & \\
\hline VTB & VTBX & boom true airspeed & & kts & & \\
\hline U1 & $\mathrm{U} 1 \mathrm{XX}$ & $\operatorname{cg~x}$ body velocity, boom data & forward & $\mathrm{f} t / \mathrm{sec}$ & & \\
\hline V1 & V1XX & cg y body velocity, boom data & right & $\mathrm{f} / \mathrm{sec}$ & & \\
\hline WI & WIXX & $\operatorname{cg~z}$ body velocity, boom data & down & $\mathrm{ft} / \mathrm{sec}$ & & \\
\hline VT & VTXX & TAS from boom and/or LASSIE & & $\mathrm{ft} / \mathrm{sec}$ & & \\
\hline LSSXC & LSSU & calibrated LASSIE $x$ velocity & forward & kts & & \\
\hline LSSYC & LSSV & calibrated LASSIE y velocity & right & kts & & \\
\hline VTBS & VTBS & TAS from smoothed boom data* & & kts & & \\
\hline VICBS & IASS & IAS from smoothed boom data* & & kts & & \\
\hline HDB & HDBX & density altitude from boom data & & $\mathrm{ft}$ & & \\
\hline HDBS & HDBS & density alt frm smoothed data * & & $\mathrm{ft}$ & & \\
\hline HMHRWS & HPXX & pressure alt frm smoothed data* & & $\mathrm{ft}$ & & \\
\hline HMHRWD & HPDX & pressure altitude rate + & up & $\mathrm{ft} / \mathrm{sec}$ & & \\
\hline H003D & HRDX & radar altimeter rate + & up & $\mathrm{ft} / \mathrm{sec}$ & & \\
\hline $\mathrm{TA}$ & TAXX & ambient temperature & & $\operatorname{deg} C$ & & \\
\hline TASMTH & AATS & TA from smoothed boom data * & & $\operatorname{deg} C$ & & \\
\hline
\end{tabular}




\section{TABLE 2. TRENDS SIGNALS AND VARIABLES (CONTINUED)}

(c) Group DP, cont.

\begin{tabular}{|c|c|c|c|c|c|c|}
\hline \multirow[t]{2}{*}{ Alias } & \multirow{2}{*}{$\begin{array}{l}\text { Item } \\
\text { code }\end{array}$} & \multirow[t]{2}{*}{ Description } & \multirow{2}{*}{$\begin{array}{l}\text { Positive } \\
\text { direction }\end{array}$} & \multirow[t]{2}{*}{ Units } & \multicolumn{2}{|c|}{ Range } \\
\hline & & & & & Min & $\operatorname{Max}$ \\
\hline ALO1S & AL1S & Smoothed Load $x$ Accelerometer * & Forward & $\mathrm{g}$ & & \\
\hline AL02S & AL2S & Smoothed Load y Accelerometer * & Right & $\mathrm{g}$ & & \\
\hline AL03S & AL3S & Smoothed Load z Accelerometer * & Up & & & \\
\hline DV2S2X & $\mathrm{X} 2 \mathrm{DD}$ & Load cg Body x Acceleration & Forward & $\mathrm{ft} / \mathrm{sec} 2$ & & \\
\hline DV2S2Y & Y2DD & Load cg Body y Acceleration & Right & $\mathrm{ft} / \mathrm{sec} 2$ & & \\
\hline DV2S2Z & Z2DD & Load cg Body z Acceleration & Down & $\mathrm{ft} / \sec 2$ & & \\
\hline DAL3C & PS2C & Load Heading, Transient Removed & Nose Right & $\operatorname{deg}$ & & \\
\hline DAL3CC & PS2C & Continuous Load Heading & Nose Right & $\operatorname{deg}$ & & \\
\hline PS2P & PS2P & Load Heading - HC Heading & & $\operatorname{deg}$ & & \\
\hline DRLIS & $\mathrm{P} 2 \mathrm{SX}$ & Smoothed Load Pitch Rate * & Nose DOWN & $\mathrm{deg} / \mathrm{sec}$ & & \\
\hline DRL2S & MQ2S & Smoothed Load Roll Rate * & Roll Right & $\mathrm{deg} / \mathrm{sec}$ & & \\
\hline DRL3S & $\mathrm{R} 2 \mathrm{SX}$ & Smoothed Load Yaw Rate * & Nose Right & $\mathrm{deg} / \mathrm{sec}$ & & \\
\hline DRLID & $\mathrm{P} 2 \mathrm{DX}$ & Derivative of DRLIS & Nose DOWN & $\mathrm{deg} / \mathrm{sec} 2$ & & \\
\hline DRL2D & MQ2D & Derivative of DRL2S & Roll Right & $\mathrm{deg} / \mathrm{sec} 2$ & & \\
\hline DRL3D & R2DX & Derivative of DRL2S & Nose Right & $\mathrm{deg} / \mathrm{sec} 2$ & & \\
\hline $\mathbf{P} 2$ & $\mathrm{P} 2 \mathrm{XX}$ & De-Biased Load Roll Rate & Roll Right & $\mathrm{deg} / \mathrm{sec}$ & & \\
\hline Q2 & Q2XX & De-Biased Load Pitch Rate & Nose UP & $\mathrm{deg} / \mathrm{sec}$ & & \\
\hline R2 & R2XX & De-Biased Load Yaw Rate & Nose Right & $\mathrm{deg} / \mathrm{sec}$ & & \\
\hline P2P & P2PX & Load Roll Rate in HC Heading Axes & Roll Right & $\mathrm{deg} / \mathrm{sec}$ & & \\
\hline Q2P & Q2PX & Load Pitchr8 in HC Heading Axes & Nose UP & $\mathrm{deg} / \mathrm{sec}$ & & \\
\hline
\end{tabular}

Notes:

* cutoff frequency for smoothing filter $=2.5 \mathrm{~Hz}$

+ cutoff frequency for smoothing filter $=.25 \mathrm{~Hz}$ 


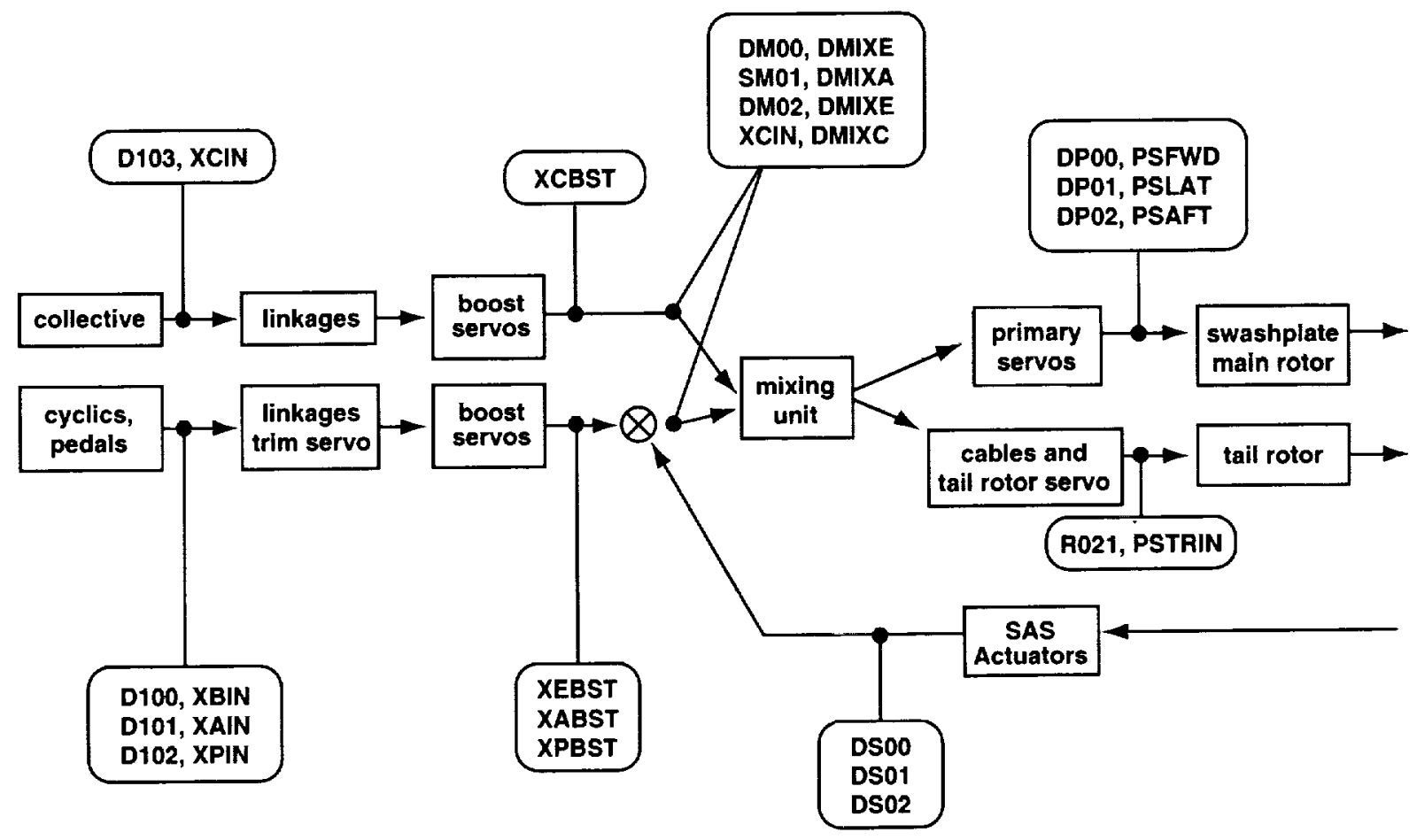

\begin{tabular}{|c|c|c|c|c|c|}
\hline SIGNAL & ITEM CODE & UNITS & MULTIPLY BY & CONVERT TO & NEW SIGNAL \\
\hline $\begin{array}{l}\text { Cockpit sticks } \\
\text { Longitudinal } \\
\text { Lateral } \\
\text { Pedal } \\
\text { Collective }\end{array}$ & $\begin{array}{l}\text { D100 } \\
\text { D101 } \\
\text { D102 } \\
\text { D103 }\end{array}$ & $\begin{array}{l}\text { percent } \\
\text { percent } \\
\text { percent } \\
\text { percent }\end{array}$ & $\begin{array}{l}.1125 \\
.095625 \\
.056875 \\
.10625\end{array}$ & $\begin{array}{l}\text { inches } \\
\text { inches } \\
\text { inches } \\
\text { inches }\end{array}$ & $\begin{array}{l}\text { XBIN } \\
\text { XAIN } \\
\text { XPIN } \\
\text { XCIN }\end{array}$ \\
\hline $\begin{array}{l}\text { Boost servo outputs } \\
\text { Longitudinal } \\
\text { Lateral } \\
\text { Pedal } \\
\text { Collective }\end{array}$ & $\begin{array}{l}\text { XBIN } \\
\text { XCIN } \\
\text { XPIN } \\
\text { XCIN }\end{array}$ & $\begin{array}{l}\text { inches } \\
\text { inches } \\
\text { inches } \\
\text { inches }\end{array}$ & $\begin{array}{l}.21 \\
.24 \\
.36 \\
.20\end{array}$ & $\begin{array}{l}\text { inches } \\
\text { inches } \\
\text { inches } \\
\text { inches }\end{array}$ & $\begin{array}{l}\text { XEBST } \\
\text { XABST } \\
\text { XPBST } \\
\text { XCBST }\end{array}$ \\
\hline $\begin{array}{l}\text { Mixer Inputs } \\
\text { Longitudinal } \\
\text { Lateral } \\
\text { Directional } \\
\text { Collective }\end{array}$ & $\begin{array}{l}\text { DM00 } \\
\text { DM01 } \\
\text { DM02 } \\
\text { XCIN }\end{array}$ & $\begin{array}{l}\text { percent } \\
\text { percent } \\
\text { percent } \\
\text { percent }\end{array}$ & $\begin{array}{l}.02108 \\
.02065 \\
.0189 \\
.2025\end{array}$ & $\begin{array}{l}\text { inches } \\
\text { inches } \\
\text { inches } \\
\text { inches }\end{array}$ & $\begin{array}{l}\text { DMIXE } \\
\text { DMIXA } \\
\text { DMIXR } \\
\text { DMIXC }\end{array}$ \\
\hline $\begin{array}{l}\text { Primary servo outputs } \\
\text { Forward } \\
\text { Lateral } \\
\text { Aft } \\
\text { Tail rotor }\end{array}$ & $\begin{array}{l}\text { DP00 } \\
\text { DP01 } \\
\text { DP03 } \\
\text { R021 }\end{array}$ & $\begin{array}{l}\text { percent } \\
\text { percent } \\
\text { percent } \\
\text { percent }\end{array}$ & $\begin{array}{l}.0406 \\
.0327 \\
.0429 \\
.0308\end{array}$ & $\begin{array}{l}\text { inches } \\
\text { inches } \\
\text { inches } \\
\text { inches }\end{array}$ & $\begin{array}{l}\text { PSFWD } \\
\text { PSLAT } \\
\text { PSAFT } \\
\text { PSTRIN }\end{array}$ \\
\hline
\end{tabular}

Figure 30. Control system sensor locations and and signal scalings. 


\section{TABLE 3. CATALOG OF DATA RECORDS BY FLIGHT}

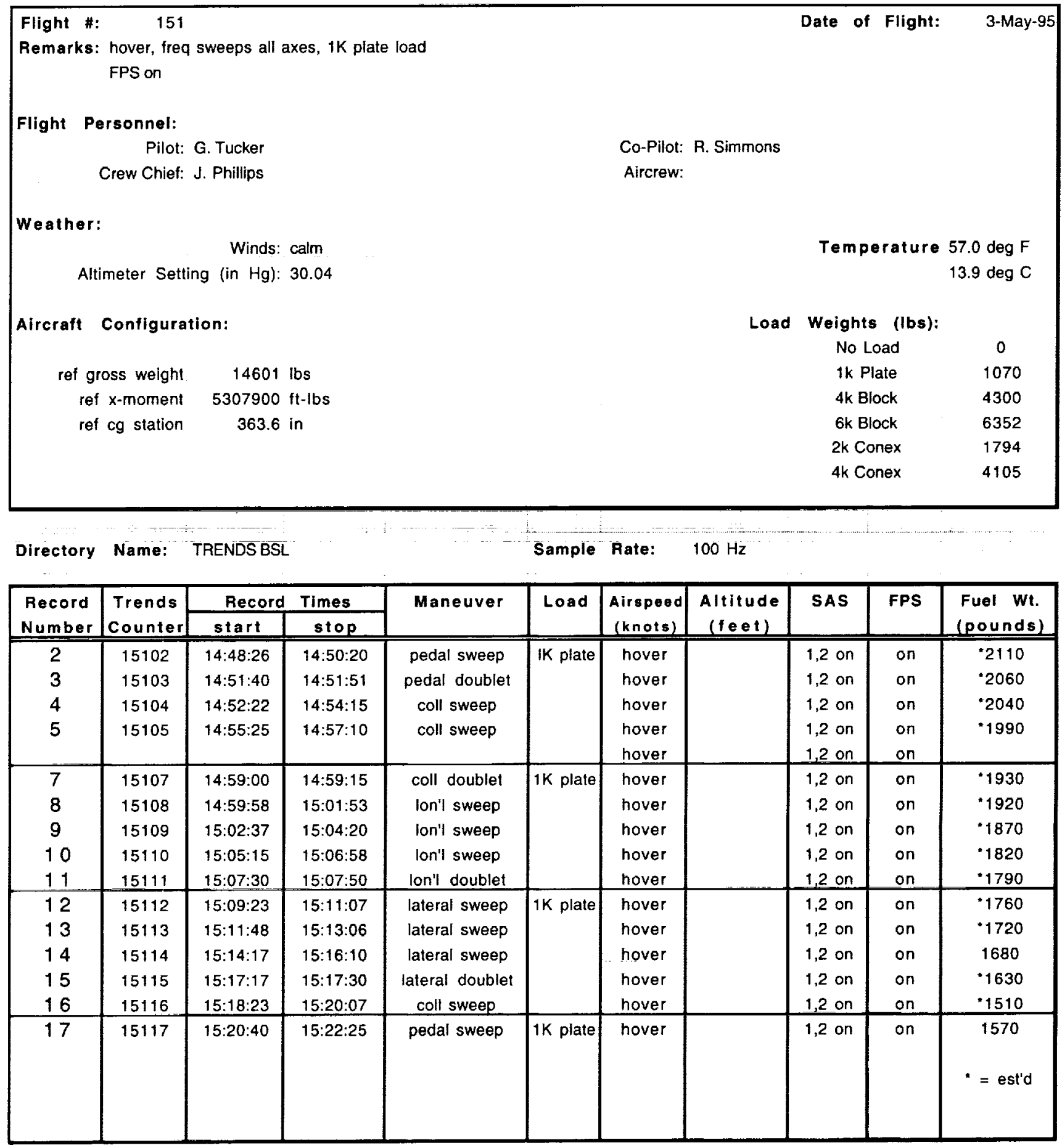




\section{TABLE 3. CATALOG OF DATA RECORDS BY FLIGHT (CONTINUED)}

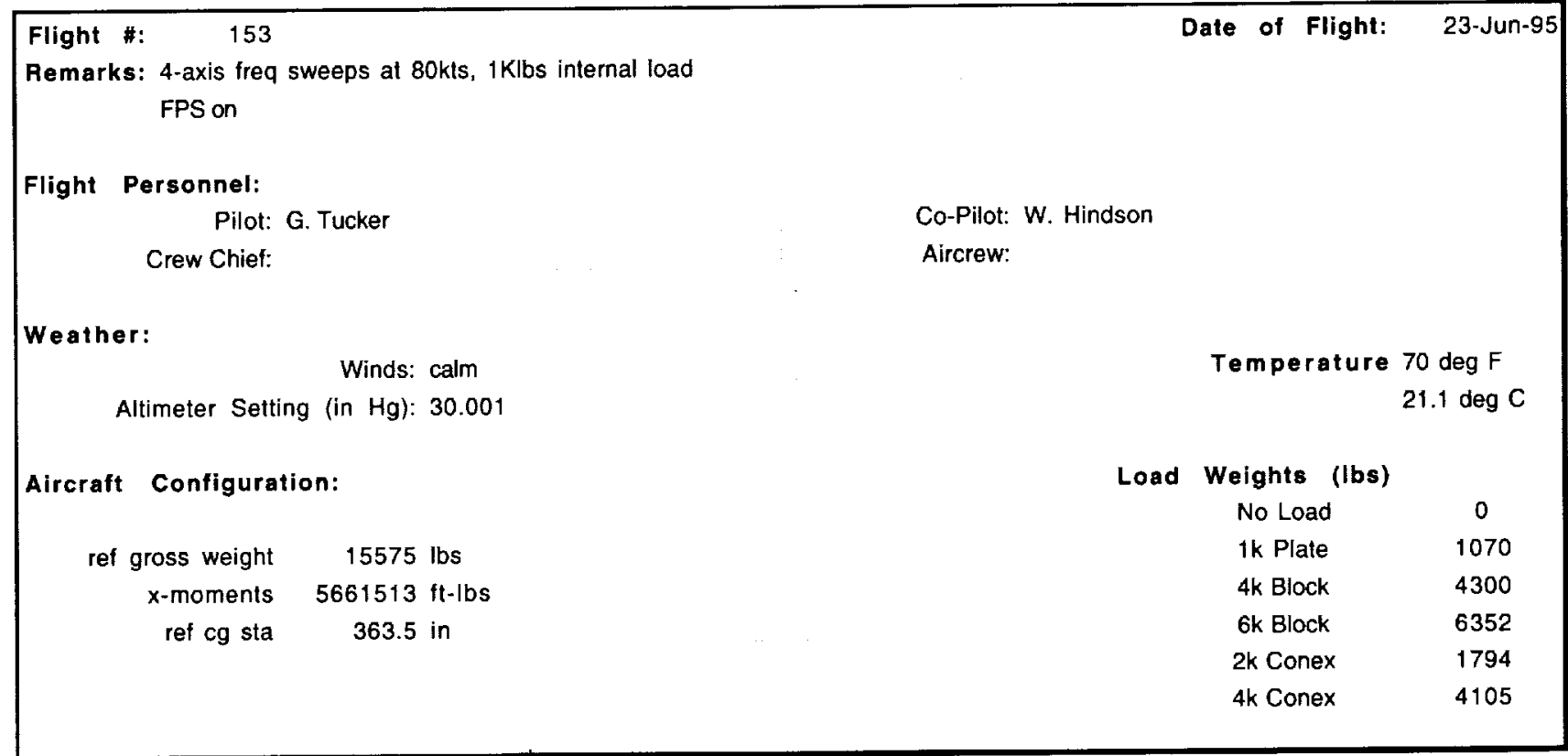

\section{Directory Name: TRENDSBSL Sample Rate: $100 \mathrm{~Hz}$}

\begin{tabular}{|c|c|c|c|c|c|c|c|c|c|c|}
\hline \multirow{2}{*}{$\begin{array}{l}\text { Record } \\
\text { Number }\end{array}$} & \multirow{2}{*}{$\begin{array}{c}\text { Trends } \\
\text { Counter }\end{array}$} & \multicolumn{2}{|c|}{ Record Tlmes } & \multirow[t]{2}{*}{ Maneuver } & \multirow[t]{2}{*}{ Load } & \multirow{2}{*}{$\begin{array}{l}\text { Airspeed } \\
\text { (knols) } \\
\end{array}$} & \multirow{2}{*}{$\begin{array}{c}\text { Altitude } \\
\text { (feet) }\end{array}$} & \multirow[t]{2}{*}{ SAS } & \multirow[t]{2}{*}{ FPS } & \multirow{2}{*}{$\begin{array}{l}\text { Fuel Wt. } \\
\text { (pounds) }\end{array}$} \\
\hline & & start & slop & & & & & & & \\
\hline 1 & 15301 & 15:09:11 & $15: 09: 54$ & control throws & & & on ground & & & \\
\hline 2 & 15302 & $15: 24: 25$ & $15: 26: 14$ & Ion'l sweep & none & 80 & 1000 & 1,2 on & on & 2250 \\
\hline 3 & 15303 & $15: 27: 29$ & $15: 29: 26$ & coll sweep & & 80 & 1000 & 1,2 on & on & 2210 \\
\hline 4 & 15304 & $15: 30: 49$ & $15: 32: 36$ & coll sweep & & 80 & 1000 & 1,2 on & on & 2180 \\
\hline 5 & 15305 & $15: 34: 58$ & $15: 36: 43$ & Ion'l sweep & & 80 & 1000 & 1,2 on & on & 2130 \\
\hline 6 & 15306 & $15: 37: 54$ & $15: 39: 31$ & Ion'l sweep & none & 80 & 1000 & 1,2 on & on & 2090 \\
\hline 7 & 15307 & $15: 39: 59$ & $15: 40: 05$ & Ion'l doublet & & 80 & 1000 & 1,2 on & on & 2080 \\
\hline 8 & 15308 & $15: 41: 32$ & $15: 43: 17$ & lateral sweep & & 80 & 1000 & 1,2 on & on & 2050 \\
\hline 9 & 15309 & $15: 44: 47$ & $15: 46: 29$ & lateral sweep & & 80 & 1000 & 1,2 on & on & 2010 \\
\hline 10 & 15310 & $15: 48: 07$ & $15: 49: 47$ & lateral sweep & & 80 & 1000 & 1,2 on & on & 1980 \\
\hline 11 & 15311 & $15: 50: 07$ & $15: 50: 23$ & lateral doublet & none & 80 & 1000 & 1,2 on & on & 1950 \\
\hline 12 & 15312 & $15: 51: 57$ & $15: 52: 09$ & lateral doublet & & 80 & 1000 & 1,2 on & on & 1940 \\
\hline 13 & 15313 & $15: 54: 08$ & $15: 55: 52$ & coll sweep & & 80 & 1000 & 1,2 on & on & 1900 \\
\hline 14 & 15314 & $15: 56: 53$ & $15: 57: 06$ & coll doublet & & 80 & 1000 & 1,2 on & on & 1890 \\
\hline 15 & 15315 & 15:58:04 & $15: 59: 48$ & pedal sweep & & 80 & 1000 & 1,2 on & on & 1840 \\
\hline 16 & 15316 & $16: 02: 00$ & $16: 03: 38$ & pedal sweep & none & 80 & 1000 & 1,2 on & on & 1810 \\
\hline 18 & 15318 & $16: 06: 31$ & $16: 08: 24$ & pedal sweep & & 80 & 1000 & 1,2 on & 0 & 1760 \\
\hline
\end{tabular}




\section{TABLE 3. CATALOG OF DATA RECORDS BY FLIGHT (CONTINUED)}

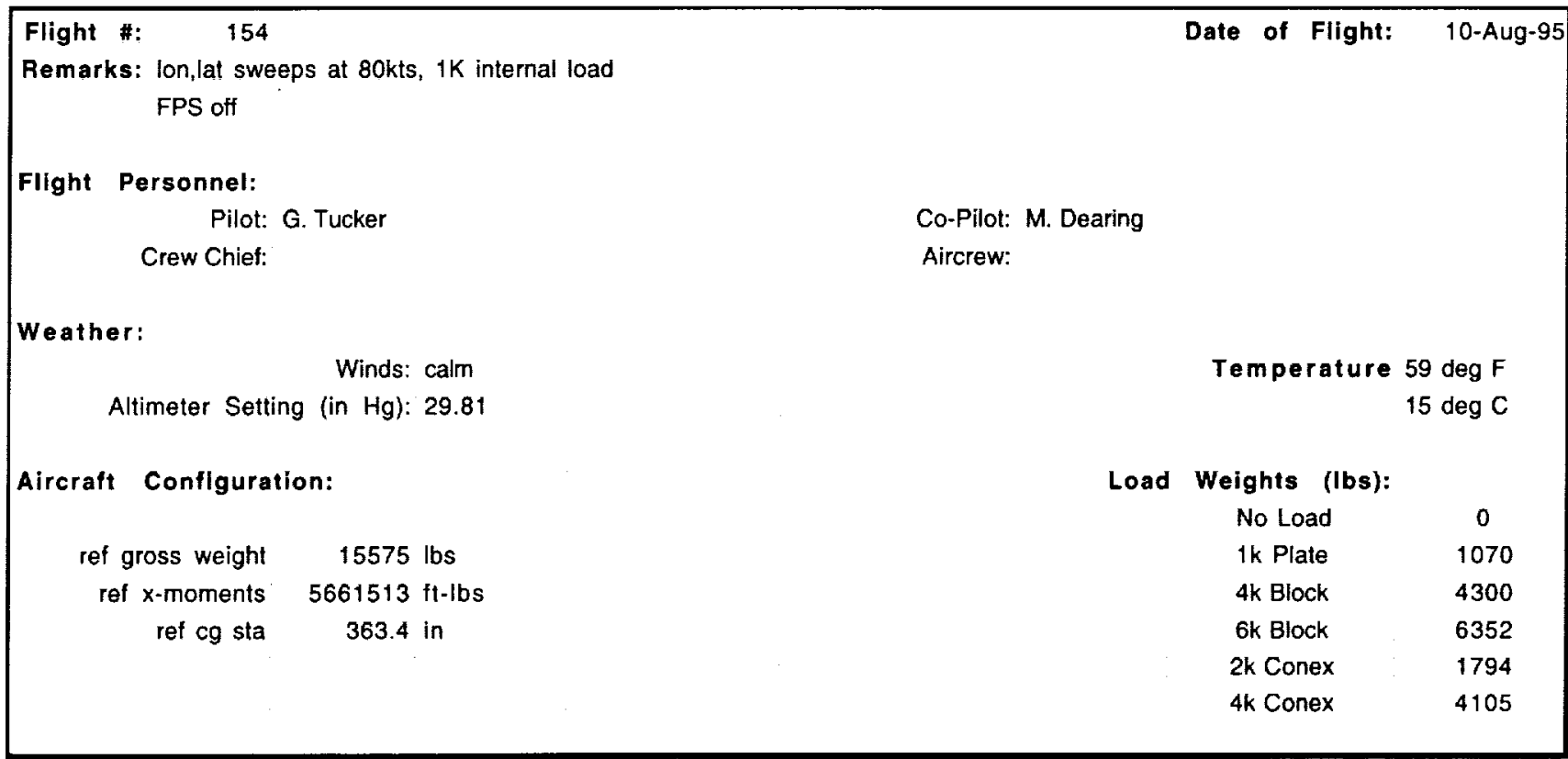

\footnotetext{
Directory Name: TRENDSBSL Sample Rate: $100 \mathrm{~Hz}$
}

\begin{tabular}{|c|c|c|c|c|c|c|c|c|c|c|}
\hline \multirow{2}{*}{$\begin{array}{l}\text { Record } \\
\text { Number }\end{array}$} & \multirow{2}{*}{$\begin{array}{l}\text { Trends } \\
\text { Counter }\end{array}$} & \multicolumn{2}{|c|}{ Record Times } & \multirow[t]{2}{*}{ Maneuver } & \multirow[t]{2}{*}{ Load } & \multirow{2}{*}{$\begin{array}{c}\text { Airspeed } \\
\text { (knots) }\end{array}$} & \multirow{2}{*}{$\begin{array}{c}\text { Altitude } \\
\text { (feet) }\end{array}$} & \multirow[t]{2}{*}{ SAS } & \multirow[t]{2}{*}{ FPS } & \multirow{2}{*}{$\begin{array}{l}\text { Fuel Wt. } \\
\text { (pounds) }\end{array}$} \\
\hline & & start & stop & & & & & & & \\
\hline 1 & 15401 & $0: 00: 30$ & $0: 01: 10$ & control throws & & & on ground & & & \\
\hline 2 & 15402 & $0: 52: 09$ & $0: 54: 03$ & Ion'l sweep & none & 80 & 1000 & 1,2 on & off & 1960 \\
\hline 3 & 15403 & $0: 56: 40$ & $0: 58: 32$ & lon'l sweep & none & 80 & 1000 & 1,2 on & off & 1900 \\
\hline 4 & 15404 & $1: 00: 50$ & $1: 02: 41$ & Ion'l sweep & none & 80 & 1000 & 1,2 on & off & 1840 \\
\hline 5 & 15405 & 1:05:24 & $1: 07: 21$ & Ion'l sweep & none & 80 & 1000 & 1,2 on & off & 1770 \\
\hline 6 & 15406 & $1: 09: 25$ & $1: 09: 49$ & Ion'l doublet & none & 80 & 1000 & 1,2 on & off & 1720 \\
\hline 7 & 15407 & $1: 10: 38$ & $1: 10: 56$ & Ion'l doublet & none & 80 & 1000 & 1,2 on & off & 1710 \\
\hline 8 & 15408 & $1: 12: 49$ & $1: 14: 25$ & lon'l sweep & none & 80 & 1000 & 1,2 on & off & 1680 \\
\hline 9 & 15409 & $1: 17: 11$ & 1:19:22 & Ion'l sweep & none & 80 & 1000 & 1,2 on & off & 1610 \\
\hline 10 & 15410 & $1: 21: 00$ & 1:21:22 & Ion'l doublet & none & 80 & 1000 & 1,2 on & off & 1580 \\
\hline 11 & 15411 & $1: 24: 32$ & $1: 26: 22$ & Iateral sweep & none & 80 & 1000 & 1,2 on & off & 1530 \\
\hline 12 & 15412 & $1: 28: 42$ & $1: 30: 21$ & lateral sweep & none & 80 & 1000 & 1,2 on & off & 1480 \\
\hline 13 & 15413 & $1: 32: 04$ & $1: 34: 02$ & lateral sweep & none & 80 & 1000 & 1,2 on & off & 1430 \\
\hline 14 & 15414 & $1: 35: 33$ & $1: 37: 18$ & lateral sweep & none & 80 & 1000 & 1,2 on & off & 1390 \\
\hline & & & & & & & & & & \\
\hline & & & & & & & & & & \\
\hline & & & & & & & & & & \\
\hline
\end{tabular}




\section{TABLE 3. CATALOG OF DATA RECORDS BY FLIGHT (CONTINUED)}

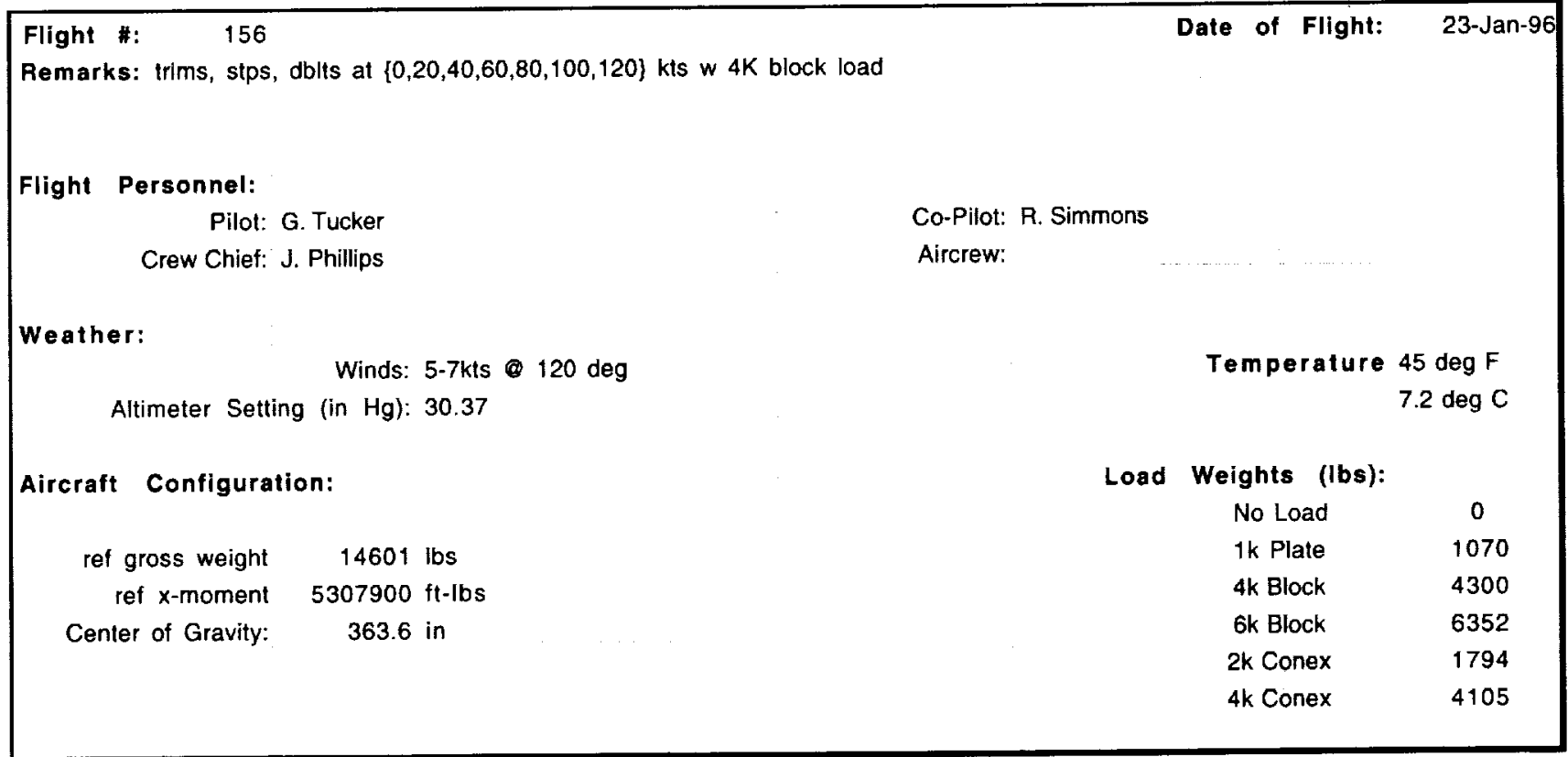

\section{Directory Name: TRENDSBSL Sample Rate: $100 \mathrm{~Hz}$}

\begin{tabular}{|c|c|c|c|c|c|c|c|c|c|c|}
\hline \multirow{2}{*}{$\begin{array}{l}\text { Record } \\
\text { Number }\end{array}$} & \multirow{2}{*}{$\begin{array}{c}\text { Trends } \\
\text { Counter }\end{array}$} & \multicolumn{2}{|c|}{ Record Length } & \multirow[t]{2}{*}{ Maneuver } & \multirow[t]{2}{*}{ Load } & \multirow{2}{*}{$\begin{array}{l}\text { Airspeed } \\
\text { (knots) }\end{array}$} & \multirow{2}{*}{$\begin{array}{c}\text { Altitude } \\
\text { (feet) }\end{array}$} & \multirow[t]{2}{*}{ SAS } & \multirow[t]{2}{*}{ FPS } & \multirow{2}{*}{$\begin{array}{l}\text { Fuel Wt. } \\
\text { (pounds) }\end{array}$} \\
\hline & & secs & & & & & & & & \\
\hline 15 & 15615 & $17: 01: 40$ & $17: 01: 50$ & & $4 \mathrm{~K}$ block & hover & & 1,2 on & off & 2040 \\
\hline 16 & 15616 & $17: 04: 57$ & $17: 05: 30$ & trim & & 20 & & 1,2 on & off & *1990 \\
\hline 17 & 15617 & $17: 06: 10$ & $17: 06: 18$ & long'l step & & 20 & & 1,2 on & off & 1980 \\
\hline 18 & 15618 & $17: 06: 55$ & $17: 07: 05$ & lateral sweep & & 20 & & 1,2 on & off & 1970 \\
\hline 19 & 15619 & $17: 07: 35$ & 17:07:49 & pedal step & & 20 & & 1,2 on & off & 1960 \\
\hline 20 & 15620 & $17: 10: 40$ & $17: 10: 50$ & Ion'I doublet & $4 \mathrm{~K}$ block & 20 & & 1,2 on & off & 1950 \\
\hline 21 & 15621 & $17: 11: 23$ & $17: 11: 33$ & lateral doublet & & 20 & & 1,2 on & off & 1940 \\
\hline 22 & 15622 & $17: 12: 00$ & $17: 12: 15$ & pedal doublet & & 20 & & 1,2 on & off & 1930 \\
\hline 23 & 15623 & $17: 12: 30$ & $17: 12: 41$ & pedal doublet & & 20 & & 1,2 on & off & .1925 \\
\hline 24 & 15624 & $17: 16: 40$ & 17:16:50 & trim & & 40 & & 1,2 on & off & $* 1870$ \\
\hline 25 & 15625 & $17: 20: 18$ & $17: 20: 31$ & long'l step & $4 \mathrm{~K}$ block & 40 & & 1,2 on & off & 1810 \\
\hline 26 & 15626 & $17: 21: 00$ & $17: 21: 10$ & lateral step & & 40 & & 1,2 on & off & 1800 \\
\hline 27 & 15627 & $17: 21: 25$ & $17: 21: 36$ & pedal step & & 40 & & 1,2 on & off & 1790 \\
\hline 28 & 15628 & $17: 24: 49$ & $17: 24: 59$ & long'l doublet & & 40 & & 1,2 on & off & 1740 \\
\hline 29 & 15629 & $17: 27: 41$ & 17:27:51 & pedal doublet & & 40 & & 1,2 on & off & 1700 \\
\hline 30 & 15630 & $17: 31: 20$ & $17: 31: 32$ & lateral doublet & $4 \mathrm{~K}$ block & 40 & & 1,2 on & off & 1650 \\
\hline 31 & 15631 & $17: 35: 11$ & $17: 35: 21$ & trim & & 60 & & 1,2 on & off & $* 1585$ \\
\hline 32 & 15632 & $17: 36: 24$ & 17L36:34 & long'l slep & & 60 & & 1,2 on & off & 1570 \\
\hline 33 & 15633 & $17: 38: 07$ & $17: 38: 17$ & lateral slep & & 60 & & 1,2 on & off & 1550 \\
\hline 34 & 15634 & 17:39:31 & $17: 39: 41$ & pedal step & & 60 & & 1,2 on & off & 1530 \\
\hline
\end{tabular}


TABLE 3. CATALOG OF DATA RECORDS BY FLIGHT (CONTINUED)

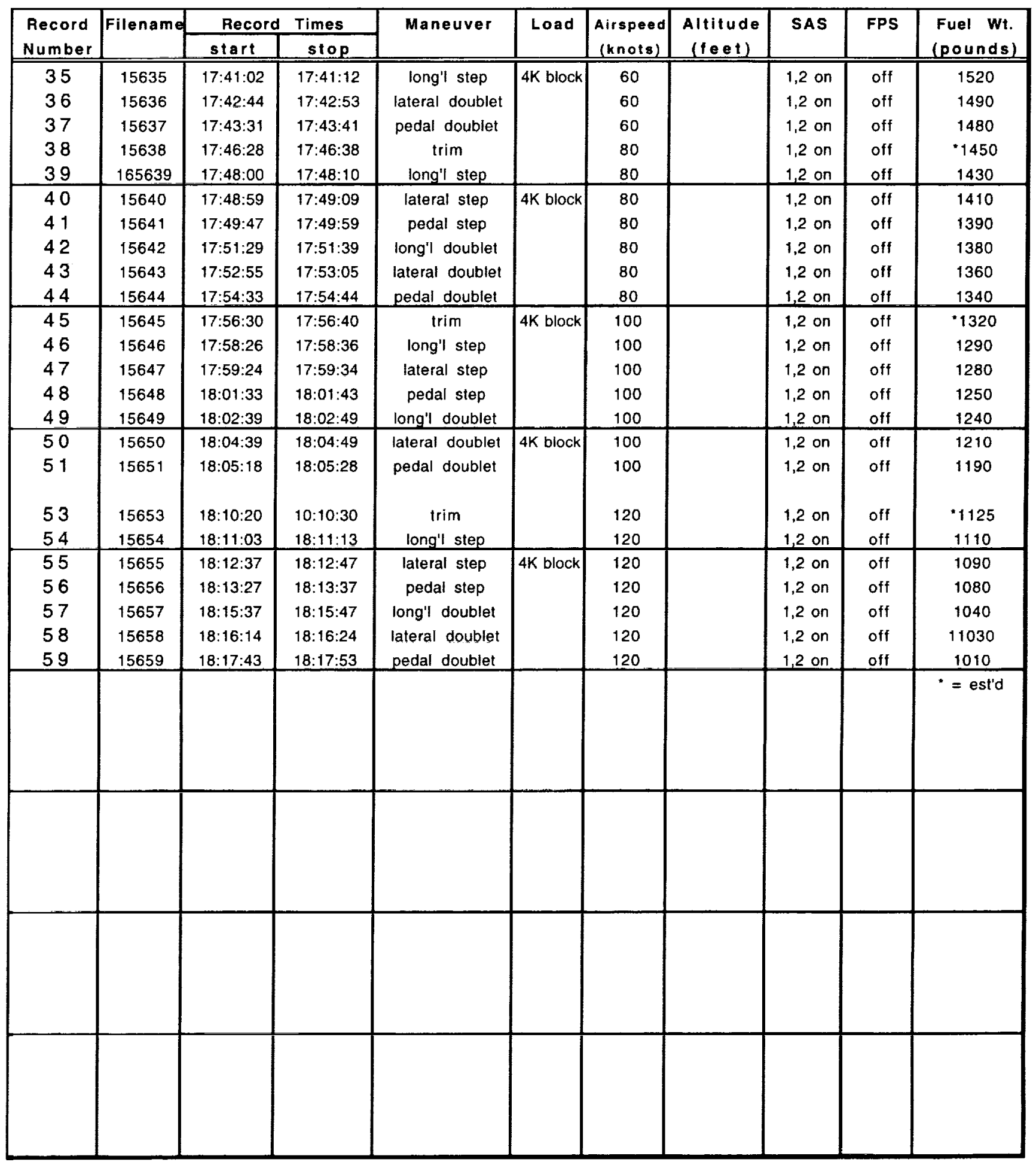




\section{TABLE 3. CATALOG OF DATA RECORDS BY FLIGHT (CONTINUED)}

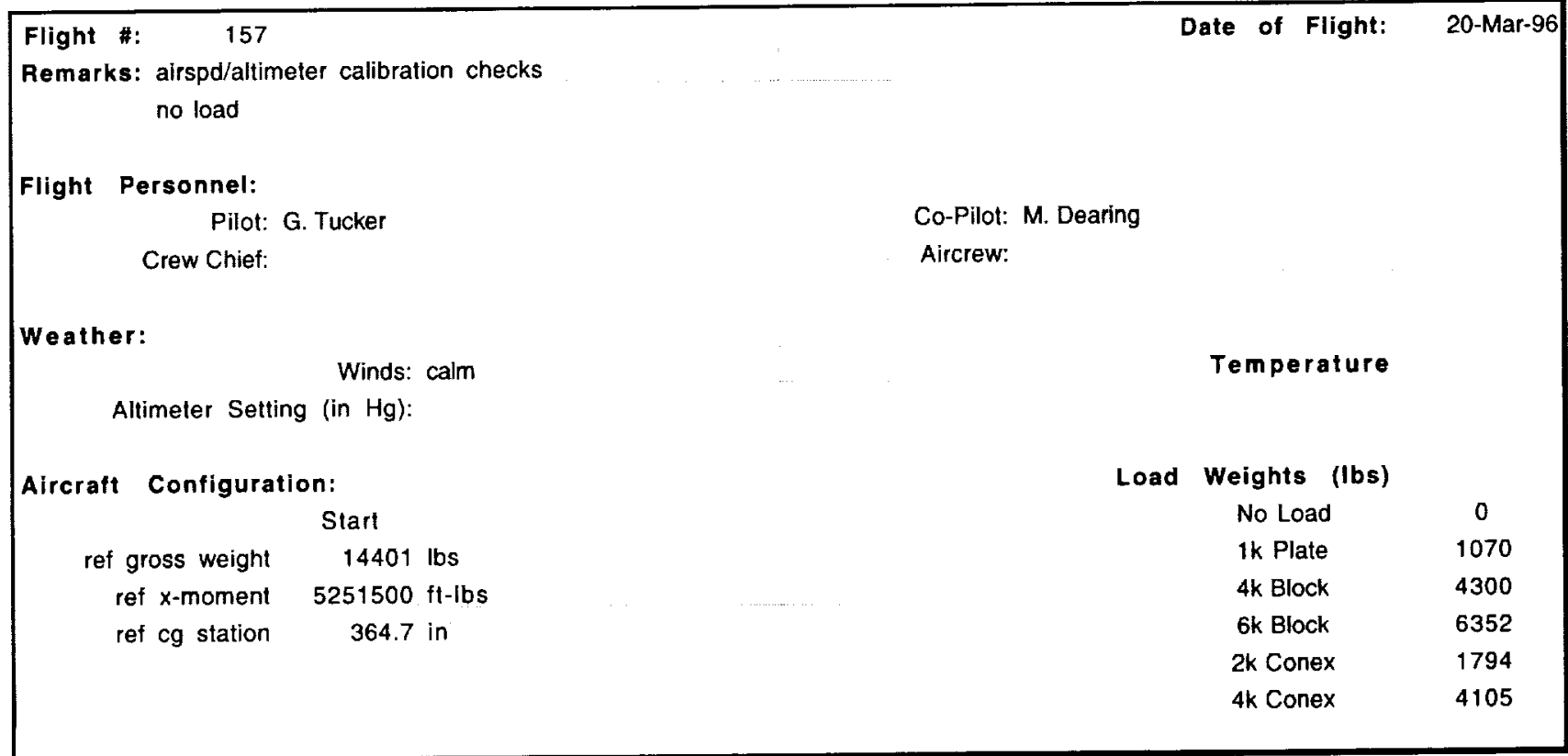

Directory Name: TRENDSBSL Sample Rate: $100 \mathrm{~Hz}$

\begin{tabular}{|c|c|c|c|c|c|c|c|c|c|c|}
\hline \multirow{2}{*}{$\begin{array}{l}\text { Record } \\
\text { Number }\end{array}$} & \multirow{2}{*}{$\begin{array}{l}\text { Trends } \\
\text { Counter }\end{array}$} & \multicolumn{2}{|c|}{ Record Time } & \multirow[t]{2}{*}{ Maneuver } & \multirow[t]{2}{*}{ Load } & \multirow{2}{*}{$\begin{array}{c}\text { Airspeed } \\
\text { (knots) } \\
\end{array}$} & \multirow{2}{*}{$\begin{array}{c}\text { Altitude } \\
\text { (teet) }\end{array}$} & \multirow[t]{2}{*}{ SAS } & \multirow[t]{2}{*}{ FPS } & \multirow{2}{*}{$\begin{array}{l}\text { Fuel Wt. } \\
\text { (pounds) }\end{array}$} \\
\hline & & Start & Stop & & & & & & & \\
\hline 1 & 15701 & $15: 10: 21$ & $15: 10: 42$ & trim & none & 80 & & & & 1820 \\
\hline 2 & 15702 & $15: 12: 33$ & $15: 12: 54$ & trim & & 80 & & & & 1780 \\
\hline 3 & 15703 & $15: 14: 23$ & $15: 14: 48$ & trim & & 60 & & & & 1760 \\
\hline 4 & 15704 & $15: 17: 54$ & $15: 18: 16$ & trim & & 60 & & & & 1730 \\
\hline 5 & 15705 & $15: 19: 44$ & 15:20:11 & trim & & 40 & & & & 1710 \\
\hline 6 & 15706 & $15: 21: 42$ & 15:22:05 & trim & none & 40 & & & & 1680 \\
\hline 7 & 15707 & $15: 24: 33$ & $15: 25: 00$ & trim & & 20 & & & & 1650 \\
\hline 8 & 15708 & $15: 27: 12$ & $15: 27: 35$ & trim & & 20 & & & & 1610 \\
\hline 9 & 15709 & $15: 30: 23$ & $15: 30: 59$ & trim & & 10 & & & & 1580 \\
\hline 10 & 15710 & $15: 33: 42$ & $15: 34: 16$ & trim & & 10 & & & & 1540 \\
\hline 11 & 15711 & $15: 36: 31$ & $15: 36: 56$ & trim & none & 30 & & & & 1500 \\
\hline 12 & 15712 & $15: 38: 59$ & $15: 39: 27$ & Irim & & 30 & & & & 1470 \\
\hline 13 & 15713 & $15: 41: 14$ & $15: 41: 40$ & Irim & & 50 & & & & 1450 \\
\hline 14 & 15714 & $15: 43: 19$ & $15: 43: 44$ & trim & & 50 & & & & 1430 \\
\hline 15 & 15715 & $15: 45: 19$ & $15: 45: 39$ & Irim & & 70 & & & & 1400 \\
\hline 16 & 15716 & $15: 47: 02$ & $15: 47: 19$ & trim & none & 70 & & & & 1380 \\
\hline 17 & 15717 & $15: 48: 40$ & $15: 49: 00$ & trim & & 90 & & & & 1360 \\
\hline 18 & 15718 & $15: 50: 43$ & $15: 51: 00$ & trim & & 90 & & & & 1330 \\
\hline 19 & 15719 & $15: 52: 16$ & $15: 52: 39$ & trim & & 110 & & & & 1330 \\
\hline 20 & 15720 & $15: 53: 57$ & $15: 54: 24$ & trim & & 110 & & & & 1300 \\
\hline
\end{tabular}


TABLE 3. CATALOG OF DATA RECORDS BY FLIGHT (CONTINUED)

\begin{tabular}{|c|c|c|c|c|c|c|c|c|c|c|}
\hline \multirow{2}{*}{$\begin{array}{l}\text { Record } \\
\text { Number }\end{array}$} & \multirow{2}{*}{\begin{tabular}{|l|} 
Trends \\
Counter
\end{tabular}} & \multicolumn{2}{|c|}{ Record Time } & \multirow[t]{2}{*}{ Maneuver } & \multirow[t]{2}{*}{ Load } & \multirow{2}{*}{$\mid \begin{array}{c}\text { Airspeed } \\
\text { (knots) }\end{array}$} & \multirow{2}{*}{$\begin{array}{c}\text { Altitude } \\
(f e \in t)\end{array}$} & \multirow[t]{2}{*}{ SAS } & \multirow[t]{2}{*}{ FPS } & \multirow{2}{*}{$\begin{array}{l}\text { Fuel Wt. } \\
\text { (pounds) }\end{array}$} \\
\hline & & Start & Stop & & & & & & & \\
\hline 21 & 15721 & $15: 55: 59$ & $15: 55: 44$ & trim & none & 130 & & & & 1270 \\
\hline 22 & 15722 & $15: 57: 25$ & $15: 57: 39$ & trim & & 130 & & & & 1250 \\
\hline 23 & 15723 & $15: 59: 02$ & $15: 59: 17$ & trim & & 120 & & & & 1230 \\
\hline 24 & 15724 & $16: 00: 37$ & $16: 00: 51$ & trim & & 120 & & & & 1210 \\
\hline 25 & 15725 & 16:02:14 & 16:02:30 & trim & & 100 & & & & 1190 \\
\hline 26 & 15726 & $16: 03: 54$ & $16: 04: 10$ & trim & none & 100 & & & & 1170 \\
\hline 27 & 15727 & $16: 08: 13$ & $16: 08: 24$ & trim & & hover & 20 & & & \\
\hline 28 & 15728 & $16: 09: 33$ & $16: 09: 45$ & trim & & hover & 10 & & & \\
\hline 29 & 15729 & 16:10:55 & 16:11:07 & trim & & hover & 5 & & & \\
\hline 30 & 15730 & $16: 12: 00$ & $16: 12: 12$ & trim & & hover & 30 & & & \\
\hline 31 & 15731 & $16: 13: 08$ & $16: 13: 20$ & trim & none & hover & 40 & & & \\
\hline 32 & 15732 & $16: 14: 37$ & $16: 14: 46$ & trim & & hover & 50 & & & \\
\hline 33 & 15733 & $16: 15: 36$ & $16: 15: 50$ & trim & & hover & 60 & & & \\
\hline 34 & 15734 & $16: 17: 12$ & $16: 17: 26$ & trim & & hover & 80 & & & \\
\hline 35 & 15735 & 16:18:36 & 16:20:22 & trim & & hover & 100 & & & \\
\hline 36 & 15736 & $16: 20: 25$ & 16:20:38 & trim & none & hover & 120 & & & \\
\hline 37 & 15737 & 16:22:01 & $16: 22: 17$ & 10deg pitch up & & hover & & & & \\
\hline 38 & 15738 & $16: 23: 01$ & $16: 23: 23$ & 10deg pitch dwn & & hover & & & & \\
\hline 39 & 15739 & $16: 24: 08$ & $16: 24: 24$ & 10 deg roll Ift & & hover & & & & \\
\hline 40 & 15740 & $16: 24: 26$ & $16: 25: 11$ & 10 deg roll $\mathrm{rt}$ & & hover & & & & \\
\hline $41-9$ & $15741-9$ & 16:33:10 & $16: 42: 12$ & control throws & none & & on ground & 1 on & off & \\
\hline & & & & & & & & & & \\
\hline & & & & & & & & & & \\
\hline & & & & & & & & & & \\
\hline & & & & & & & & & & \\
\hline & & & & & & & & & & \\
\hline & & & & & & & & & & \\
\hline & & & & & & & & & & \\
\hline & & & & & & & & & & \\
\hline & & & & & & & & & & \\
\hline & & & & & & & & & & \\
\hline
\end{tabular}




\section{TABLE 3. CATALOG OF DATA RECORDS BY FLIGHT (CONTINUED)}

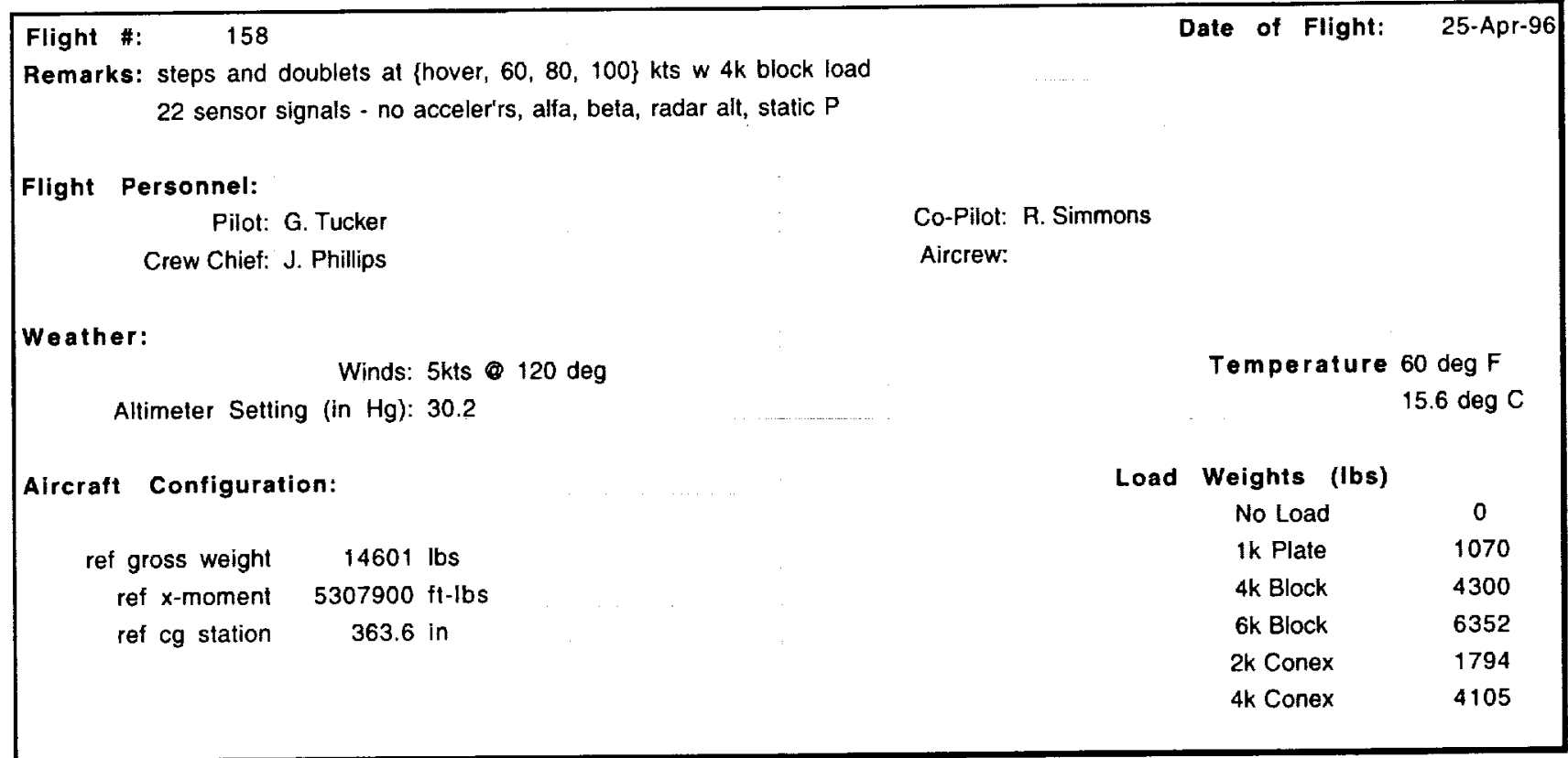

Directory Name: TRENDSBSL Sample Rate: $100 \mathrm{~Hz}$

\begin{tabular}{|c|c|c|c|c|c|c|c|c|c|c|}
\hline \multirow{2}{*}{$\begin{array}{l}\text { Record } \\
\text { Number }\end{array}$} & \multirow{2}{*}{$\begin{array}{c}\text { Trends } \\
\text { Counter }\end{array}$} & \multicolumn{2}{|c|}{ Record Times } & \multirow[t]{2}{*}{ Maneuver } & \multirow[t]{2}{*}{ Load } & \multirow{2}{*}{$\begin{array}{c}\text { Airspeed } \\
\text { (knots) }\end{array}$} & \multirow{2}{*}{$\begin{array}{c}\text { Altitude } \\
\text { (feet) } \\
\end{array}$} & \multirow[t]{2}{*}{ SAS } & \multirow[t]{2}{*}{ FPS } & \multirow{2}{*}{$\begin{array}{l}\text { Fuel Wt. } \\
\text { (pounds) }\end{array}$} \\
\hline & & Start & Stop & & & & & & & \\
\hline $\begin{array}{c}\text { thru } \\
12 \\
12 \\
13 \\
14 \\
15 \\
\end{array}$ & \begin{tabular}{|c|}
$15801-11$ \\
15812 \\
15813 \\
15814 \\
15815 \\
\end{tabular} & $\begin{array}{l}14: 47: 39 \\
15: 18: 14 \\
15: 19: 33 \\
15: 20: 23 \\
15: 21: 02 \\
\end{array}$ & $\begin{array}{l}14: 55: 54 \\
15: 18: 24 \\
15: 19: 46 \\
15: 20: 36 \\
15: 21: 14 \\
\end{array}$ & $\begin{array}{l}\text { control throws } \\
\text { trim } \\
\text { long'l step } \\
\text { long'l doubler } \\
\text { long'l step }\end{array}$ & $4 \mathrm{k}$ block & $\begin{array}{l}\text { hover } \\
\text { hover } \\
\text { hover } \\
\text { hover }\end{array}$ & $\begin{array}{c}\text { on ground } \\
\text { OGE } \\
\text { OGE } \\
\text { OGE } \\
\text { OGE } \\
\end{array}$ & $\begin{array}{l}1,2 \text { on } \\
1,2 \text { on } \\
1,2 \text { on } \\
1,2 \text { on }\end{array}$ & $\begin{array}{l}\text { on } \\
\text { on } \\
\text { on } \\
\text { on }\end{array}$ & $\begin{array}{l}2230 \\
2210 \\
2200 \\
2190 \\
\end{array}$ \\
\hline $\begin{array}{l}16 \\
17 \\
18 \\
19 \\
20 \\
\end{array}$ & $\begin{array}{l}15816 \\
15817 \\
15818 \\
15819 \\
15820 \\
\end{array}$ & $\begin{array}{l}15: 21: 53 \\
15: 22: 39 \\
15: 23: 27 \\
15: 24: 10 \\
15: 25: 03 \\
\end{array}$ & $\begin{array}{l}15: 22: 05 \\
15: 22: 51 \\
15: 23: 40 \\
15: 24: 22 \\
15: 25: 15 \\
\end{array}$ & $\begin{array}{l}\text { long'l doubler } \\
\text { lateral step } \\
\text { lateral doublet } \\
\text { lateral step } \\
\text { lateral doublet }\end{array}$ & $4 \mathrm{k}$ block & $\begin{array}{l}\text { hover } \\
\text { hover } \\
\text { hover } \\
\text { hover } \\
\text { hover }\end{array}$ & $\begin{array}{l}\text { OEE } \\
\text { OEE } \\
\text { OEE } \\
\alpha E E \\
\alpha E \\
\end{array}$ & $\begin{array}{l}1,2 \text { on } \\
1,2 \text { on } \\
1,2 \text { on } \\
1,2 \text { on } \\
1,2 \text { on }\end{array}$ & $\begin{array}{l}\text { on } \\
\text { on } \\
\text { on } \\
\text { on } \\
\text { on }\end{array}$ & $\begin{array}{l}2180 \\
2170 \\
2160 \\
2150 \\
2140 \\
\end{array}$ \\
\hline $\begin{array}{l}21 \\
22 \\
23 \\
24 \\
25\end{array}$ & $\begin{array}{l}15821 \\
15822 \\
15823 \\
15824 \\
15825 \\
\end{array}$ & $\begin{array}{l}15: 25: 47 \\
15: 26: 33 \\
15: 27: 11 \\
15: 27: 57 \\
15: 28: 52 \\
\end{array}$ & $\begin{array}{l}15: 25: 59 \\
15: 26: 46 \\
15: 27: 25 \\
15: 28: 10 \\
15: 29: 04 \\
\end{array}$ & $\begin{array}{c}\text { yaw step } \\
\text { yaw doublet } \\
\text { yaw step } \\
\text { yaw doublet } \\
\text { coll step }\end{array}$ & $4 \mathrm{k}$ block & $\begin{array}{l}\text { hover } \\
\text { hover } \\
\text { hover } \\
\text { hover } \\
\text { hover }\end{array}$ & $\begin{array}{l}\infty E E \\
\alpha E E \\
\alpha E E \\
\infty E E \\
\infty E E\end{array}$ & $\begin{array}{l}1,2 \text { on } \\
1,2 \text { on } \\
1,2 \text { on } \\
1,2 \text { on } \\
1,2 \text { on }\end{array}$ & $\begin{array}{l}\text { on } \\
\text { on } \\
\text { on } \\
\text { on } \\
\text { on }\end{array}$ & $\begin{array}{l}2130 \\
2120 \\
2110 \\
2100 \\
2080 \\
\end{array}$ \\
\hline $\begin{array}{l}26 \\
27 \\
28 \\
29 \\
30\end{array}$ & $\begin{array}{l}15826 \\
15827 \\
15828 \\
15829 \\
15830 \\
\end{array}$ & $\begin{array}{l}15: 29: 56 \\
15: 30: 47 \\
15: 31: 41 \\
15: 38: 20 \\
15: 39: 44\end{array}$ & $\begin{array}{l}15: 30: 08 \\
15: 31: 01 \\
15: 31: 54 \\
15: 38: 33 \\
15: 39: 56 \\
\end{array}$ & $\begin{array}{l}\text { coll doublet } \\
\text { coll step } \\
\text { coll doublet } \\
\text { trim } \\
\text { long'l step }\end{array}$ & $4 \mathrm{~K}$ block & $\begin{array}{c}\text { hover } \\
\text { hover } \\
\text { hover } \\
80 \\
80\end{array}$ & $\begin{array}{c}\text { OEE } \\
\text { OCE } \\
\text { OGE } \\
1000 \\
1000\end{array}$ & $\begin{array}{l}1,2 \text { on } \\
1,2 \text { on } \\
1,2 \text { on } \\
1,2 \text { on } \\
1,2 \text { on }\end{array}$ & $\begin{array}{l}\text { on } \\
\text { on } \\
\text { on } \\
\text { on } \\
\text { on } \\
\end{array}$ & $\begin{array}{l}2070 \\
2060 \\
2040 \\
1950 \\
1930 \\
\end{array}$ \\
\hline
\end{tabular}


TABLE 3. CATALOG OF DATA RECORDS BY FLIGHT (CONTINUED)

\begin{tabular}{|c|c|c|c|c|c|c|c|c|c|c|}
\hline \multirow{2}{*}{$\begin{array}{l}\text { Record } \\
\text { Number }\end{array}$} & \multirow[t]{2}{*}{ Filename } & \multicolumn{2}{|c|}{ Record Time } & \multirow[t]{2}{*}{ Maneuver } & \multirow[t]{2}{*}{ Load } & \multirow{2}{*}{$\begin{array}{c}\text { Airspeed } \\
\text { (knots) }\end{array}$} & \multirow{2}{*}{$\begin{array}{c}\text { Altitude } \\
(\text { feet) }\end{array}$} & \multirow[t]{2}{*}{ SAS } & \multirow[t]{2}{*}{ FPS } & \multirow{2}{*}{$\begin{array}{l}\text { Fuel Wt. } \\
\text { (pounds) }\end{array}$} \\
\hline & & Start & Stop & & & & & & & \\
\hline 31 & 15831 & $15: 41: 18$ & $15: 41: 31$ & long'l doublet & $4 \mathrm{k}$ block & 80 & 1000 & 1,2 on & on & 1920 \\
\hline 32 & 15832 & $15: 42: 10$ & $15: 42: 23$ & long'l doublet & & 80 & 1000 & 1,2 on & on & 1910 \\
\hline 33 & 15833 & $15: 43: 11$ & $15: 43: 25$ & long'l doublet & & 80 & 1000 & 1,2 on & on & 1900 \\
\hline 34 & 15834 & $15: 44: 43$ & $15: 44: 55$ & lateral slep & & 80 & 1000 & 1,2 on & on & 1870 \\
\hline 35 & 15835 & $15: 46: 00$ & $15: 46: 13$ & Jateral doublet & & 80 & 1000 & 1,2 on & on & 1860 \\
\hline 36 & 15836 & $15: 47: 08$ & $15: 47: 21$ & lateral doublet & $4 \mathrm{k}$ block & 80 & 1000 & 1,2 on & on & 1850 \\
\hline 37 & 15837 & $15: 48: 22$ & $15: 48: 35$ & lateral doublet & & 80 & 1000 & 1,2 on & on & 1840 \\
\hline 38 & 15838 & $15: 49: 46$ & $15: 49: 59$ & pedal step & & 80 & 1000 & 1,2 on & on & 1820 \\
\hline 39 & 15839 & $15: 50: 50$ & $15: 51: 03$ & pedal doublet & & 80 & 1000 & 1,2 on & on & 1810 \\
\hline 40 & 15840 & $15: 52: 18$ & 15:52:30 & pedal step & & 80 & 1000 & 1,2 on & on & 1790 \\
\hline 41 & 15841 & $15: 53: 51$ & $15: 54: 04$ & pedal doublet & $4 \mathrm{k}$ block & 80 & 1000 & 1,2 on & on & 1770 \\
\hline 42 & 15842 & $15: 55: 48$ & $15: 56: 01$ & coll step & & 80 & 1000 & 1,2 on & on & 1760 \\
\hline 43 & 15843 & $15: 57: 24$ & $15: 57: 37$ & coll doublet & & 80 & 1000 & 1,2 on & on & 1740 \\
\hline 44 & 15844 & $15: 58: 52$ & $15: 59: 08$ & coll step & & 80 & 1000 & 1,2 on & on & 1730 \\
\hline 45 & 15845 & 16:00:00 & $16: 00: 13$ & coll doublet & & 80 & 1000 & 1,2 on & on & 1710 \\
\hline 46 & 15846 & $16: 02: 55$ & $16: 03: 08$ & trim & $4 \mathrm{k}$ block & 60 & 1000 & 1,2 on & on & 1670 \\
\hline 47 & 15847 & $16: 04: 03$ & $16: 04: 13$ & long'l step & & 60 & 1000 & 1,2 on & on & 1660 \\
\hline 48 & 15848 & 16:05:11 & $16: 05: 24$ & long'l doublet & & 60 & 1000 & 1,2 on & on & 1650 \\
\hline 49 & 15849 & $16: 06: 51$ & $16: 07: 14$ & long'l step & & 60 & 1000 & 1,2 on & on & 1640 \\
\hline 50 & 15850 & 16:08:13 & 16:08:26 & long'l doublet & & 60 & 1000 & 1,2 on & on & 1620 \\
\hline 51 & 15851 & $16: 10: 51$ & $16: 11: 03$ & lateral step & $4 \mathrm{k}$ block & 60 & 1000 & 1,2 on & on & 1590 \\
\hline 52 & 15852 & $16: 11: 37$ & $16: 11: 49$ & laleral doublet & & 60 & 1000 & 1,2 on & on & 1580 \\
\hline 53 & 15853 & $16: 12: 59$ & $16: 13: 12$ & lateral slep & & 60 & 1000 & 1,2 on & on & 1570 \\
\hline 54 & 15854 & $16: 14: 39$ & $16: 14: 53$ & lateral doublet & & 60 & 1000 & 1,2 on & on & 1550 \\
\hline 55 & 15855 & $16: 15: 54$ & $16: 16: 06$ & pedal step & & 60 & 1000 & 1,2 on & on & 1540 \\
\hline 56 & 15856 & $16: 17: 15$ & $16: 17: 28$ & pedal doublet & $4 \mathrm{k}$ block & 60 & 1000 & 1,2 on & on & 1520 \\
\hline 57 & 15857 & $16: 18: 29$ & $16: 18: 39$ & pedal step & & 60 & 1000 & 1,2 on & on & 1510 \\
\hline 58 & 15858 & $16: 20: 06$ & $16: 20: 18$ & pedal doublet & & 60 & 1000 & 1,2 on & on & 1490 \\
\hline 59 & 15859 & $16: 21: 40$ & $16: 21: 51$ & coll step & & 60 & 1000 & 1,2 on & on & 1470 \\
\hline 60 & 15860 & $16: 22: 50$ & $16: 23: 03$ & coll doublet & & 60 & 1000 & 1,2 on & on & 1460 \\
\hline 61 & 15861 & $16: 24: 03$ & $16: 24: 16$ & coll step & $4 \mathrm{k}$ block & 60 & 1000 & 1,2 on & on & 1440 \\
\hline 62 & 15862 & $16: 25: 07$ & $16: 25: 20$ & coll doublet & & 60 & 1000 & 1,2 on & on & 1430 \\
\hline 63 & 15863 & $16: 28: 23$ & $16: 28: 36$ & trim & & 60 & 1000 & 1,2 on & on & 1390 \\
\hline 64 & 15864 & $16: 29: 14$ & $16: 29: 26$ & long'| step & & 100 & 1000 & 1,2 on & on & 1380 \\
\hline 65 & 15865 & $16: 30: 35$ & $16: 30: 48$ & long'l doublet & & 100 & 1000 & 1,2 on & on & 1360 \\
\hline 66 & 15866 & $16: 31: 40$ & $16: 31: 52$ & long'l step & $4 \mathrm{k}$ biock & 100 & 1000 & 1,2 on & on & 1350 \\
\hline 67 & 15867 & $16: 32: 35$ & $16: 32: 48$ & long'l doublet & & 100 & 1000 & 1,2 on & on & 1340 \\
\hline 68 & 15868 & $16: 33: 47$ & $16: 34: 00$ & lateral step & & 100 & 1000 & 1,2 on & on & 1330 \\
\hline 69 & 15869 & $16: 34: 50$ & $16: 35: 02$ & lateral doublet & & 100 & 1000 & 1,2 on & on & 1320 \\
\hline 70 & 15870 & $16: 35: 47$ & $16: 36: 00$ & lateral step & & 100 & 1000 & 1,2 on & on & 1300 \\
\hline 72 & 15872 & 16:38:07 & $16: 38: 20$ & lateral doublet & 4k block & 100 & 1000 & 1,2 on & on & 1270 \\
\hline 73 & 15873 & $16: 39: 25$ & $16: 39: 40$ & pedal step & & 100 & 1000 & 1,2 on & on & 1260 \\
\hline 74 & 15874 & $16: 40: 19$ & $16: 40: 33$ & pedal doublet & & 100 & 1000 & 1,2 on & on & 1240 \\
\hline 75 & 15875 & $16: 41: 43$ & $16: 41: 55$ & pedal step & & 100 & 1000 & 1,2 on & on & 1230 \\
\hline
\end{tabular}


TABLE 3. CATALOG OF DATA RECORDS BY FLIGHT (CONTINUED)

\begin{tabular}{|c|c|c|c|c|c|c|c|c|c|c|}
\hline \multirow{2}{*}{$\begin{array}{l}\text { Record } \\
\text { Number }\end{array}$} & \multirow[t]{2}{*}{ Counter } & \multicolumn{2}{|c|}{ Record Times } & \multirow[t]{2}{*}{ Maneuver } & \multirow[t]{2}{*}{ Load } & \multirow{2}{*}{\begin{tabular}{|l|}
$\begin{array}{c}\text { Airspeed } \\
\text { (knots) }\end{array}$ \\
\end{tabular}} & \multirow{2}{*}{$\begin{array}{c}\text { Altitude } \\
\text { (feet) }\end{array}$} & \multirow[t]{2}{*}{ SAS } & \multirow[t]{2}{*}{ FPS } & \multirow{2}{*}{$\begin{array}{c}\text { Fuel Weigh } \\
\text { (Ibs) }\end{array}$} \\
\hline & & Sdtart & Stop & & & & & & & \\
\hline 76 & 15876 & $16: 42: 48$ & 16:43:00 & pedal doublet & $4 \mathrm{~K}$ block & 100 & 1000 & 1,2 on & on & 1230 \\
\hline 77 & 15877 & $16: 44: 07$ & 16:44:20 & coll step & & 100 & 1000 & 1,2 on & on & 1220 \\
\hline 78 & 15878 & $16: 44: 51$ & $16: 45: 04$ & coll doublet & & 100 & 1000 & 1,2 on & on & 1200 \\
\hline 79 & 15879 & $16: 45: 49$ & $16: 46: 03$ & coll step & & 100 & 1000 & 1,2 on & on & 1190 \\
\hline 80 & 15880 & $16: 47: 19$ & $16: 47: 32$ & coll doublet & & 100 & 1000 & 1,2 on & on & 1170 \\
\hline 81 & 15881 & 16:48:39 & $16: 48: 52$ & trim & $4 \mathrm{~K}$ block & 100 & 1000 & 1,2 on & on & 1150 \\
\hline 82 & 15882 & $16: 51: 54$ & 16:52:06 & & & 40 & 1000 & 1,2 on & on & 1110 \\
\hline $83-93$ & 15883-93 & & 17:14:51 & control throws & none & & on ground & & & \\
\hline & & & & & & & & & & \\
\hline & & & & & & & & & & \\
\hline & & & & & & & & & & \\
\hline & & & & & & & & & & \\
\hline & & & & & & & & & & \\
\hline & & & & & & & & & & \\
\hline & & & & & & & & & & \\
\hline & & & & & & & & & & \\
\hline & & & & & & & & & & \\
\hline & & & & & & & & & & \\
\hline & & & & & & & & & & \\
\hline & & & & & & & & & & \\
\hline & & & & & & & & & & \\
\hline & & & & & & & & & & \\
\hline & & & & & & & & & & \\
\hline & & & & & & & & & & \\
\hline & & & & & & & & & & \\
\hline & & & & & & & & & & \\
\hline
\end{tabular}




\section{TABLE 3. CATALOG OF DATA RECORDS BY FLIGHT (CONTINUED)}

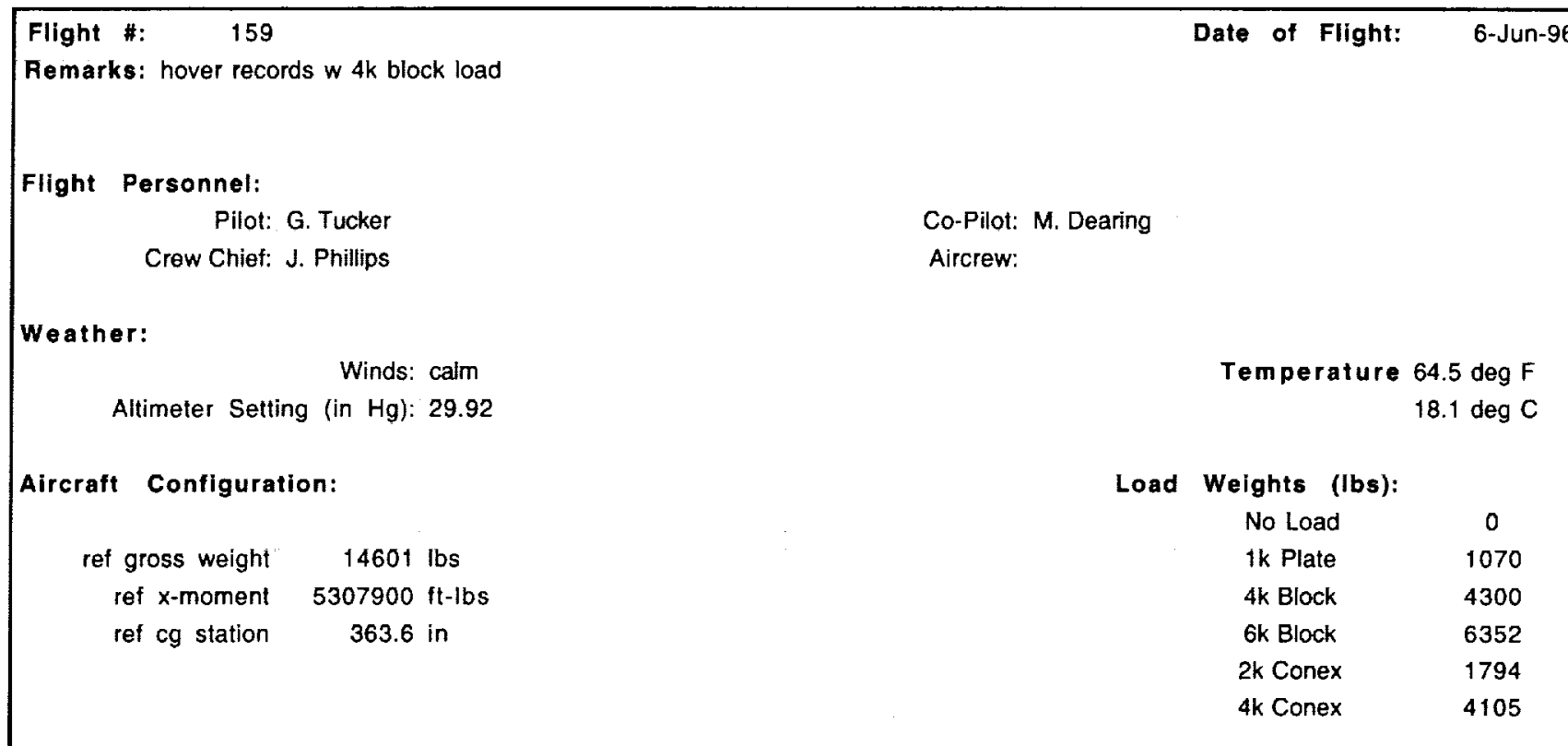

\section{Directory Name: TRENDSBSL Sample Rate: $\quad 100 \mathrm{~Hz}$}

\begin{tabular}{|c|c|c|c|c|c|c|c|c|c|c|}
\hline $\begin{array}{l}\text { Record } \\
\text { Number }\end{array}$ & $\begin{array}{l}\text { Trends } \\
\text { Counter }\end{array}$ & \multicolumn{2}{|c|}{\begin{tabular}{c|c}
\multicolumn{2}{c}{ Record Times } \\
Start & Stop
\end{tabular}} & Maneuver & Load & $\begin{array}{l}\text { Airspeed } \\
\text { (knots) }\end{array}$ & $\begin{array}{c}\text { Altitude } \\
\text { (feet) }\end{array}$ & SAS & FPS & $\begin{array}{l}\text { Fuel Wt. } \\
\text { (pounds) }\end{array}$ \\
\hline $\begin{array}{c}1 \text { thru } 11 \\
12 \\
13 \\
14 \\
15 \\
16\end{array}$ & $\begin{array}{c}15901-11 \\
15912 \\
15913 \\
15914 \\
15915 \\
15916\end{array}$ & $\begin{array}{l}0: 41: 46 \\
0: 42: 55 \\
0: 44: 41 \\
0: 47: 46 \\
0: 49: 54 \\
0: 52: 11\end{array}$ & $\begin{array}{l}0: 08: 59 \\
0: 43: 06 \\
0: 46: 58 \\
0: 49: 29 \\
0: 51: 53 \\
0: 52: 22\end{array}$ & $\begin{array}{c}\text { control throws } \\
\text { trim } \\
\text { pedal sweep } \\
\text { pedal sweep } \\
\text { pedal sweep } \\
\text { pedal step }\end{array}$ & $4 \mathrm{k}$ block & $\begin{array}{l}\text { hover } \\
\text { hover } \\
\text { hover } \\
\text { hover } \\
\text { hover }\end{array}$ & $\begin{array}{l}\text { on ground } \\
\text { OCE } \\
\text { OEE } \\
\text { OEE } \\
\text { OEE } \\
\text { OGE }\end{array}$ & $\begin{array}{l}1 \text { on } \\
1,2 \text { on } \\
1,2 \text { on } \\
1,2 \text { on } \\
1,2 \text { on } \\
1,2 \text { on }\end{array}$ & $\begin{array}{l}\text { off } \\
\text { off } \\
\text { off } \\
\text { off } \\
\text { off } \\
\text { off }\end{array}$ & $\begin{array}{l}2030 \\
1990 \\
1940 \\
1880 \\
1860\end{array}$ \\
\hline $\begin{array}{l}17 \\
18 \\
19 \\
20 \\
21\end{array}$ & $\begin{array}{l}15917 \\
15918 \\
15919 \\
15920 \\
15921 \\
\end{array}$ & $\begin{array}{l}0: 52: 46 \\
0: 53: 25 \\
0: 53: 58 \\
0: 56: 17 \\
0: 57: 15\end{array}$ & $\begin{array}{l}0: 52: 59 \\
0: 53: 34 \\
0: 54: 09 \\
0: 56: 49 \\
0: 57: 35\end{array}$ & $\begin{array}{l}\text { pedal doublet } \\
\text { pedal step } \\
\text { pedal doublet } \\
\text { coll step } \\
\text { coll doublet }\end{array}$ & $4 \mathrm{k}$ block & $\begin{array}{l}\text { hover } \\
\text { hover } \\
\text { hover } \\
\text { hover } \\
\text { hover }\end{array}$ & $\begin{array}{l}\text { OEE } \\
\text { OGE } \\
\text { OGE } \\
\text { OGE } \\
\text { OEE }\end{array}$ & $\begin{array}{l}1,2 \text { on } \\
1,2 \text { on } \\
1,2 \text { on } \\
1,2 \text { on } \\
1,2 \text { on }\end{array}$ & $\begin{array}{l}\text { off } \\
\text { off } \\
\text { off } \\
\text { off } \\
\text { off }\end{array}$ & $\begin{array}{l}1860 \\
1830 \\
1820 \\
1790 \\
1760 \\
\end{array}$ \\
\hline $\begin{array}{l}22 \\
23 \\
24 \\
25 \\
26\end{array}$ & $\begin{array}{l}15922 \\
15923 \\
15924 \\
15925 \\
15926 \\
\end{array}$ & $\begin{array}{l}0: 58: 06 \\
0: 58: 44 \\
0: 59: 43 \\
1: 00: 45 \\
1: 03: 07\end{array}$ & $\begin{array}{l}0: 58: 18 \\
0: 59: 00 \\
1: 00: 00 \\
1: 02: 30 \\
1: 04: 52\end{array}$ & $\begin{array}{l}\text { coll step } \\
\text { coll doublet } \\
\text { coll doublet } \\
\text { coll sweep } \\
\text { coll sweep }\end{array}$ & $4 \mathrm{k}$ block & $\begin{array}{l}\text { hover } \\
\text { hover } \\
\text { hover } \\
\text { hover } \\
\text { hover }\end{array}$ & $\begin{array}{l}\text { OEE } \\
\text { OGE } \\
O G E \\
O G E \\
O G E\end{array}$ & $\begin{array}{l}1,2 \text { on } \\
1,2 \text { on } \\
1,2 \text { on } \\
1,2 \text { on } \\
1,2 \text { on }\end{array}$ & $\begin{array}{l}\text { off } \\
\text { off } \\
\text { off } \\
\text { off } \\
\text { off }\end{array}$ & $\begin{array}{l}1750 \\
1740 \\
1710 \\
1690 \\
1650\end{array}$ \\
\hline $\begin{array}{l}27 \\
28 \\
29 \\
30\end{array}$ & $\begin{array}{l}15927 \\
15928 \\
15929 \\
15930\end{array}$ & $\begin{array}{l}1: 05: 34 \\
1: 08: 10 \\
1: 10: 41 \\
1: 12: 05\end{array}$ & $\begin{array}{l}1: 07: 06 \\
1: 09: 53 \\
1: 11: 19 \\
1: 12: 22\end{array}$ & $\begin{array}{l}\text { coll sweep } \\
\text { long'l sweep } \\
\text { long'l sweep } \\
\text { bad record }\end{array}$ & $4 \mathrm{k}$ block & $\begin{array}{l}\text { hover } \\
\text { hover } \\
\text { hover } \\
\text { hover }\end{array}$ & $\begin{array}{l}\text { OEE } \\
\text { OGE } \\
\text { OCE } \\
\text { OGE }\end{array}$ & $\begin{array}{l}1,2 \text { on } \\
1,2 \text { on } \\
1,2 \text { on } \\
1,2 \text { on }\end{array}$ & $\begin{array}{l}\text { off } \\
\text { off } \\
\text { off } \\
\text { off }\end{array}$ & $\begin{array}{l}1600 \\
1550 \\
1510 \\
1480\end{array}$ \\
\hline
\end{tabular}




\section{TABLE 3. CATALOG OF DATA RECORDS BY FLIGHT (CONTINUED)}

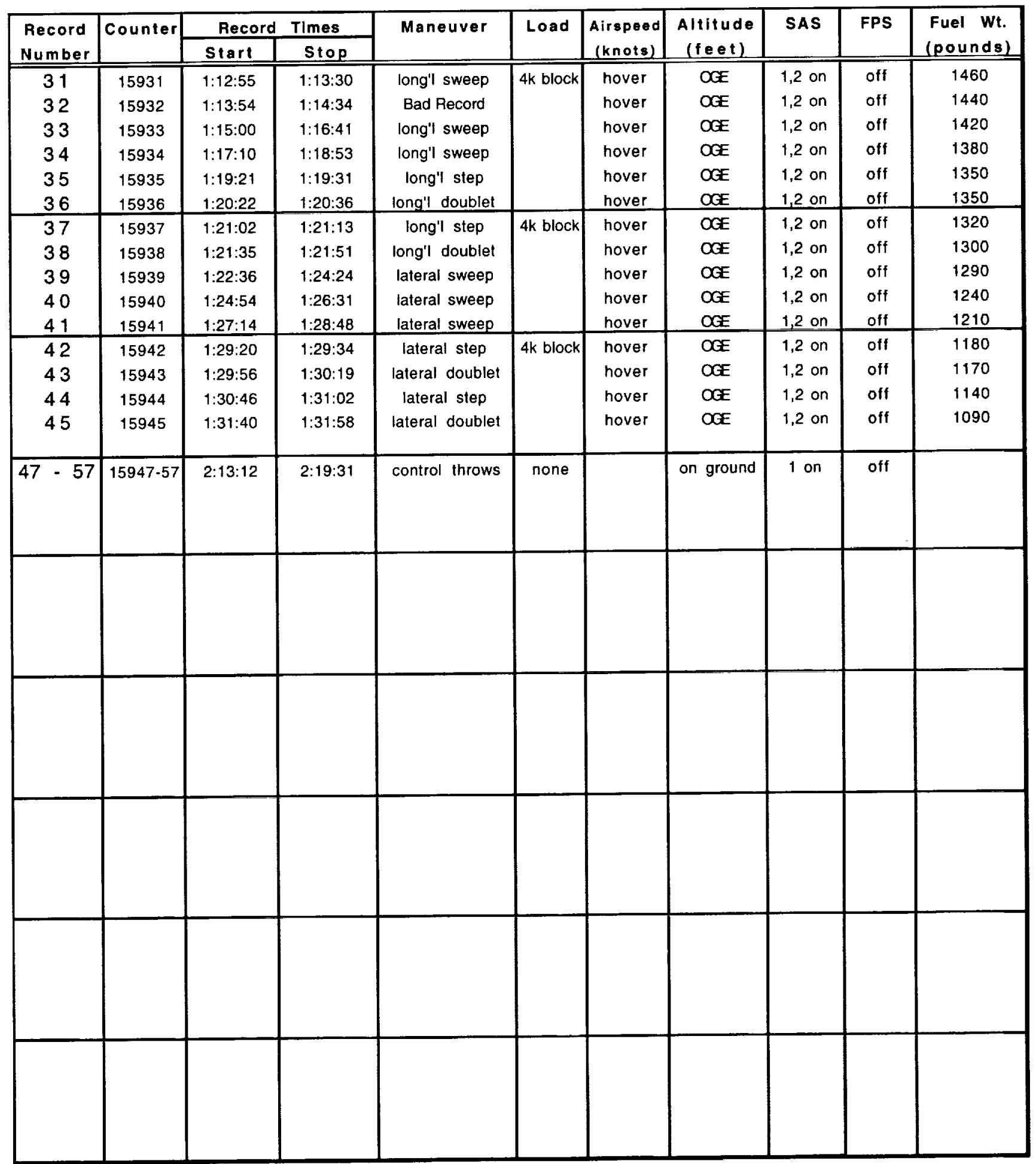




\section{TABLE 3. CATALOG OF DATA RECORDS BY FLIGHT (CONTINUED)}

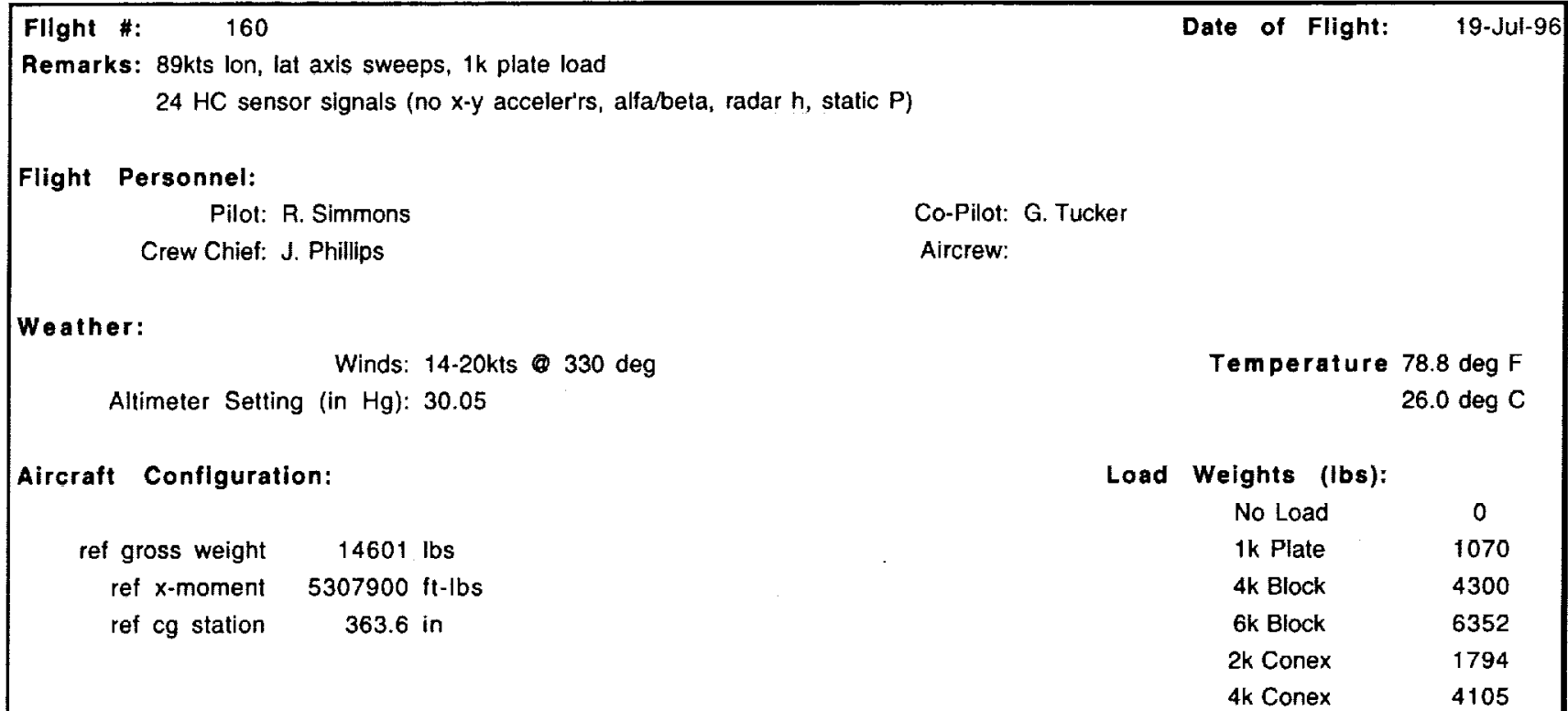

Weather:

Winds: $14-20 \mathrm{kts} 330 \mathrm{deg}$ Altimeter Setting (in $\mathrm{Hg}$ ): 30.05

Aircraft Conflguration:

ref gross weight ref $\mathrm{x}$-moment ref $\mathrm{cg}$ station

$14601 \mathrm{lbs}$ $5307900 \mathrm{ft}-\mathrm{lbs}$

363.6 in

Temperature $78.8 \mathrm{deg} F$ $26.0 \mathrm{deg} C$

Load Weights (lbs):

No Load

1k Plate

4k Block

6k Block

2k Conex

4k Conex

0
1070
4300
6352
1794
4105

Directory Name: TRENDSBSL

Sample Rate: $100 \mathrm{~Hz}$

\begin{tabular}{|c|c|c|c|c|c|c|c|c|c|c|}
\hline \multirow{2}{*}{$\begin{array}{l}\text { Record } \\
\text { Number }\end{array}$} & \multirow{2}{*}{$\begin{array}{l}\text { Trends } \\
\text { Counter }\end{array}$} & \multicolumn{2}{|c|}{ Record Times } & \multirow[t]{2}{*}{ Maneuver } & \multirow[t]{2}{*}{ Load } & \multirow{2}{*}{$\begin{array}{l}\text { Airspeed } \\
(k n o t s)\end{array}$} & \multirow{2}{*}{$\begin{array}{c}\text { Altitude } \\
\text { (feet) }\end{array}$} & \multirow[t]{2}{*}{ SAS } & \multirow[t]{2}{*}{ FPS } & \multirow{2}{*}{$\begin{array}{l}\text { Fuel Wt. } \\
\text { (pounds) }\end{array}$} \\
\hline & & Start & Stop & & & & & & & \\
\hline $\begin{array}{r}1 \text { thru } 11 \\
12 \\
13 \\
14 \\
15 \\
\end{array}$ & \begin{tabular}{|c|}
$16001-11$ \\
16012 \\
16013 \\
16014 \\
16015 \\
\end{tabular} & $\begin{array}{l}18: 02: 59 \\
19: 03: 50 \\
19: 12: 06 \\
19: 14: 06 \\
19: 17: 02\end{array}$ & $\begin{array}{l}18: 09: 41 \\
19: 04: 07 \\
19: 12: 22 \\
19: 15: 51 \\
19: 18: 46 \\
\end{array}$ & $\begin{array}{c}\text { control throws } \\
\text { trim } \\
\text { trim } \\
\text { long'l sweep } \\
\text { long'l sweep }\end{array}$ & $1 \mathrm{k}$ plate & $\begin{array}{c}0 \\
80 \\
80 \\
80 \\
\end{array}$ & $\begin{array}{l}\text { on ground } \\
\text { OGE } \\
1500 \\
1500 \\
1500\end{array}$ & $\begin{array}{l}1 \text { on } \\
1,2 \text { on } \\
1,2 \text { on } \\
1,2 \text { on } \\
1,2 \text { on }\end{array}$ & $\begin{array}{l}\text { off } \\
\text { off } \\
\text { off } \\
\text { off } \\
\text { off }\end{array}$ & $\begin{array}{r}1790 \\
1690 \\
1650 \\
1610 \\
\end{array}$ \\
\hline $\begin{array}{l}16 \\
17 \\
18 \\
19 \\
20\end{array}$ & $\begin{array}{l}16016 \\
16017 \\
16018 \\
16019 \\
16020 \\
\end{array}$ & $\begin{array}{c}19: 20: 28 \\
19: 23: 45 \\
19: 24: 57 \\
19: 26: 00 \\
19: 26: 44\end{array}$ & $\begin{array}{l}19: 22: 11 \\
19: 24: 12 \\
19: 25: 14 \\
19: 26: 17 \\
19: 26: 59\end{array}$ & $\begin{array}{c}\text { long'l sweep } \\
\text { long'l step } \\
\text { long'l step } \\
\text { long'l doublet } \\
\text { long'l step }\end{array}$ & ik plate & $\begin{array}{l}80 \\
80 \\
80 \\
80 \\
80 \\
\end{array}$ & $\begin{array}{l}1500 \\
1500 \\
1500 \\
1500 \\
1500 \\
\end{array}$ & $\begin{array}{l}1,2 \text { on } \\
1,2 \text { on } \\
1,2 \text { on } \\
1,2 \text { on } \\
1,2 \text { on }\end{array}$ & $\begin{array}{l}\text { off } \\
\text { off } \\
\text { off } \\
\text { off } \\
\text { off } \\
\end{array}$ & $\begin{array}{l}1580 \\
1560 \\
1530 \\
1530 \\
1520 \\
\end{array}$ \\
\hline $\begin{array}{l}21 \\
22 \\
23 \\
24 \\
25\end{array}$ & $\begin{array}{l}16021 \\
16022 \\
16023 \\
16024 \\
16025 \\
\end{array}$ & $\begin{array}{l}19: 27: 43 \\
19: 29: 11 \\
19: 32: 20 \\
19: 34: 43 \\
19: 38: 20 \\
\end{array}$ & $\begin{array}{l}19: 27: 59 \\
19: 30: 09 \\
19: 34: 03 \\
19: 36: 06 \\
19: 38: 35 \\
\end{array}$ & $\begin{array}{l}\text { long'l doublet } \\
\text { lateral sweep } \\
\text { lateral sweep } \\
\text { lateral sweep } \\
\text { lateral step }\end{array}$ & 1k plate & $\begin{array}{l}80 \\
80 \\
80 \\
80 \\
80 \\
\end{array}$ & $\begin{array}{l}1500 \\
1500 \\
1500 \\
1500 \\
1500 \\
\end{array}$ & $\begin{array}{l}1,2 \text { on } \\
1,2 \text { on } \\
1,2 \text { on } \\
1,2 \text { on } \\
1,2 \text { on }\end{array}$ & $\begin{array}{l}\text { off } \\
\text { off } \\
\text { off } \\
\text { off } \\
\text { off }\end{array}$ & $\begin{array}{l}1500 \\
1460 \\
1440 \\
1410 \\
1380 \\
\end{array}$ \\
\hline $\begin{array}{l}26 \\
27 \\
28 \\
29 \\
30\end{array}$ & $\begin{array}{l}16026 \\
16027 \\
16028 \\
16029 \\
16030 \\
\end{array}$ & $\begin{array}{l}19: 39: 00 \\
19: 40: 21 \\
19: 41: 09 \\
19: 42: 42 \\
19: 45: 35\end{array}$ & $\begin{array}{l}19: 39: 15 \\
19: 40: 34 \\
19: 41: 25 \\
19: 44: 24 \\
19: 47: 21\end{array}$ & $\begin{array}{l}\text { lateral doublet } \\
\text { lateral step } \\
\text { lateral doublet } \\
\text { long'l sweep } \\
\text { long'l sweep }\end{array}$ & 1k plate & $\begin{array}{l}80 \\
80 \\
80 \\
80 \\
80\end{array}$ & $\begin{array}{l}1500 \\
1500 \\
1500 \\
1500 \\
1500\end{array}$ & $\begin{array}{l}1,2 \text { on } \\
1,2 \text { on } \\
1,2 \text { on } \\
\text { off } \\
\text { off }\end{array}$ & $\begin{array}{l}\text { off } \\
\text { off } \\
\text { off } \\
\text { off } \\
\text { off }\end{array}$ & $\begin{array}{l}1370 \\
1350 \\
1340 \\
1320 \\
1280\end{array}$ \\
\hline
\end{tabular}


TABLE 3. CATALOG OF DATA RECORDS BY FLIGHT (CONTINUED)

\begin{tabular}{|c|c|c|c|c|c|c|c|c|c|c|}
\hline \multirow{2}{*}{$\begin{array}{l}\text { Record } \\
\text { Number }\end{array}$} & \multirow{2}{*}{$\begin{array}{l}\text { Trends } \\
\text { Counter }\end{array}$} & \multicolumn{2}{|c|}{ Record Times } & \multirow[t]{2}{*}{ Maneuver } & \multirow[t]{2}{*}{ Load } & \multirow{2}{*}{\begin{tabular}{|c|} 
Airspeed \\
kts
\end{tabular}} & \multirow{2}{*}{$\begin{array}{c}\begin{array}{c}\text { Altitude } \\
\mathrm{ft}\end{array} \\
\end{array}$} & \multirow[t]{2}{*}{ SAS } & \multirow[t]{2}{*}{ FPS } & \multirow{2}{*}{$\begin{array}{l}\text { Fuel Wt. } \\
\text { (pounds) }\end{array}$} \\
\hline & & Start & Stop & & & & & & & \\
\hline 31 & 16031 & 19:48:54 & $19: 50: 40$ & long'l sweep & $1 \mathrm{k}$ plate & 80 & 1500 & off & off & 1250 \\
\hline 32 & 16032 & 19:51:12 & 19:51:28 & long'l step & & 80 & 1500 & off & off & 1230 \\
\hline 33 & 16033 & 19:53:04 & $19: 53: 23$ & long'l doublet & & 80 & 1500 & off & off & 1210 \\
\hline 34 & 16034 & 19:53:55 & 19:54:07 & long'l step & & 80 & 1500 & off & off & 1200 \\
\hline 35 & 16035 & $19: 54: 48$ & 19:55:08 & long'l doublet & & 80 & 1500 & off & off & 1180 \\
\hline 36 & 16036 & 19:56:39 & 19:58:29 & lateral sweep & 1k plate & 80 & 1500 & off & off & 1150 \\
\hline 37 & 16037 & 19:59:07 & $20: 00: 46$ & lateral sweep & & 80 & 1500 & off & off & 1130 \\
\hline 38 & 16038 & 20:02:49 & 20:04:38 & lateral sweep & & 80 & 1500 & off & off & 1070 \\
\hline 39 & 16039 & 20:06:07 & $20: 06: 22$ & lateral step & & 80 & 1500 & off & off & 1060 \\
\hline 40 & 16040 & 20:06:56 & 20:07:13 & lateral doublet & & 80 & 1500 & off & off & 1040 \\
\hline 41 & 16041 & $20: 07: 57$ & $20: 08: 10$ & lateral step & 1k plate & 80 & 1500 & off & off & 1020 \\
\hline 42 & 16042 & 20:08:36 & 20:08:54 & lateral doublet & & 80 & 1500 & off & off & 1010 \\
\hline & & & & & & & & & & \\
\hline & & & & & & & & & & \\
\hline & & & & & & & & & & \\
\hline & & & & & & & & & & \\
\hline & & & & & & & & & & \\
\hline & & & & & & & & & & \\
\hline & & & & & & & & & & \\
\hline & & & & & & & & & & \\
\hline & & & & & & & & & & \\
\hline & & & & & & & & & & \\
\hline & & & & & & & & & & \\
\hline & & & & & & & & & & \\
\hline & & & & & & & & & & \\
\hline & & & & & & & & & & \\
\hline & & & & & & & & & & \\
\hline & & & & & & & & & & \\
\hline
\end{tabular}


TABLE 3. CATALOG OF DATA RECORDS BY FLIGHT (CONTINUED)

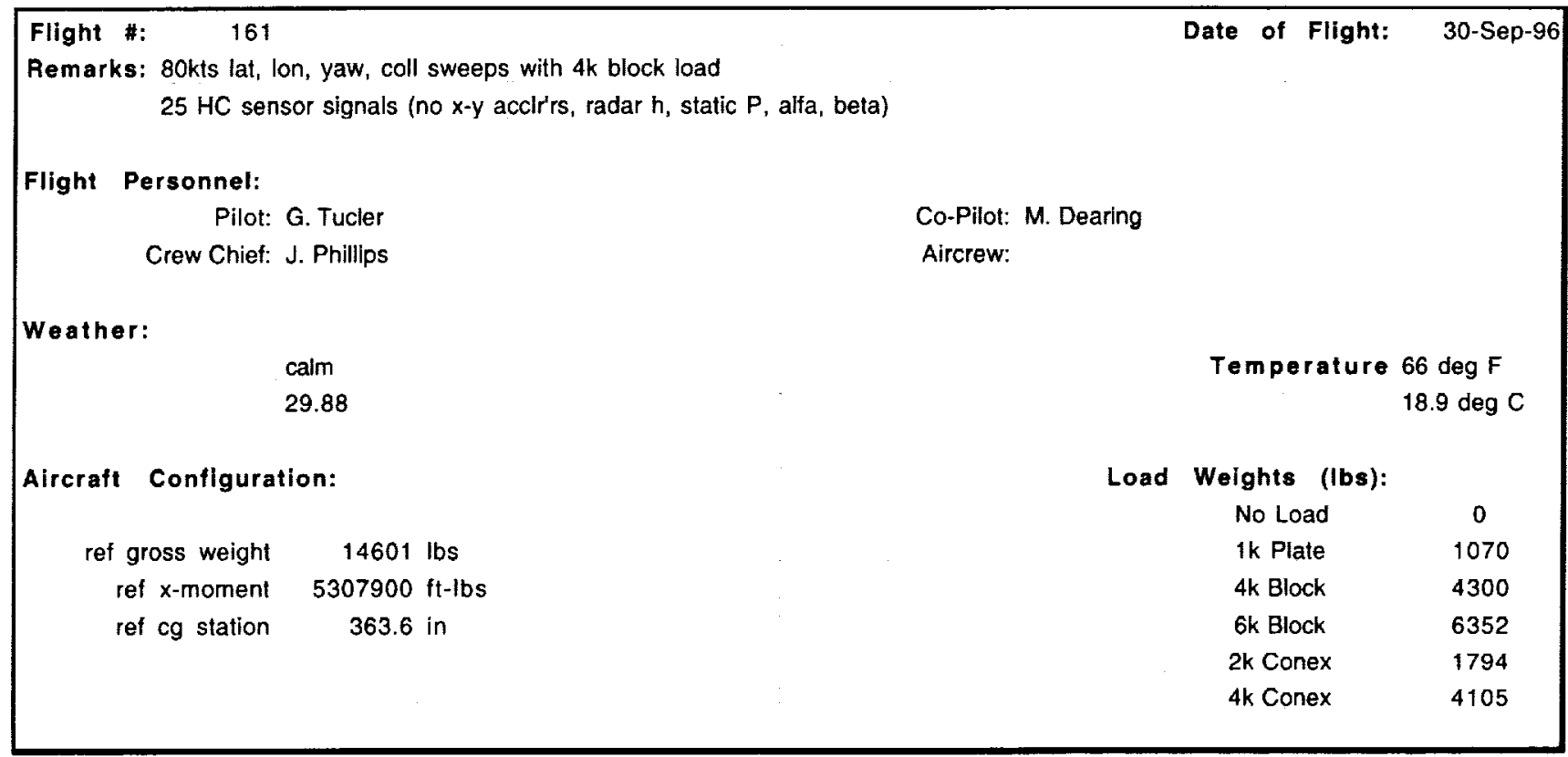

Directory Name: TRENDS BSL Sample Rate: $100 \mathrm{HZ}$

\begin{tabular}{|c|c|c|c|c|c|c|c|c|c|c|}
\hline \multirow{2}{*}{$\begin{array}{l}\text { Record } \\
\text { Number }\end{array}$} & \multirow{2}{*}{$\begin{array}{l}\text { Trends } \\
\text { Counter }\end{array}$} & \multicolumn{2}{|c|}{ Record Times } & \multirow[t]{2}{*}{ Maneuver } & \multirow[t]{2}{*}{ Load } & \multirow{2}{*}{$\begin{array}{c}\text { Airspeed } \\
\text { (knots) }\end{array}$} & \multirow{2}{*}{$\begin{array}{c}\text { Altitude } \\
(\text { feet) }\end{array}$} & \multirow[t]{2}{*}{ SAS } & \multirow[t]{2}{*}{ FPS } & \multirow{2}{*}{$\begin{array}{l}\text { Fuel Wt. } \\
\text { (pounds) }\end{array}$} \\
\hline & & Start & Stop & & & & & & & \\
\hline $\begin{array}{c}\text { thru } \\
12 \\
13 \\
14 \\
15 \\
\end{array}$ & \begin{tabular}{|c|}
$16101-11$ \\
16112 \\
16113 \\
16114 \\
16115 \\
\end{tabular} & $\begin{array}{l}20: 21: 20 \\
21: 06: 49 \\
21: 10: 15 \\
21: 12: 42 \\
21: 15: 42\end{array}$ & $\begin{array}{l}20: 28: 45 \\
21: 07: 20 \\
21: 10: 53 \\
21: 14: 30 \\
21: 17: 25 \\
\end{array}$ & $\begin{array}{c}\text { control throws } \\
\text { trim } \\
\text { trim } \\
\text { lateral sweep } \\
\text { lateral sweep }\end{array}$ & $4 \mathrm{k}$ block & $\begin{array}{c}0 \\
80 \\
80 \\
80 \\
\end{array}$ & $\begin{array}{l}\text { on ground } \\
\text { OCE } \\
1000 \\
1000 \\
1000 \\
\end{array}$ & $\begin{array}{l}1 \text { on } \\
1,2 \text { on } \\
1,2 \text { on } \\
1,2 \text { on } \\
1,2 \text { on }\end{array}$ & $\begin{array}{l}\text { off } \\
\text { off } \\
\text { off } \\
\text { off } \\
\text { off } \\
\end{array}$ & $\begin{array}{l}1980 \\
1920 \\
1890 \\
1850 \\
\end{array}$ \\
\hline $\begin{array}{l}16 \\
17 \\
18 \\
19 \\
20\end{array}$ & $\begin{array}{l}16116 \\
16117 \\
16118 \\
16119 \\
16120 \\
\end{array}$ & $\begin{array}{l}21: 19: 24 \\
21: 22: 09 \\
21: 25: 40 \\
21: 26: 41 \\
21: 27: 37\end{array}$ & $\begin{array}{l}21: 20: 58 \\
21: 25: 54 \\
21: 25: 54 \\
21: 26: 56 \\
21: 27: 48 \\
\end{array}$ & $\begin{array}{c}\text { lateral sweep } \\
\text { lateral sweep } \\
\text { lateral step } \\
\text { lateral doublet } \\
\text { lateral step }\end{array}$ & $4 \mathrm{k}$ block & $\begin{array}{l}80 \\
80 \\
80 \\
80 \\
80 \\
\end{array}$ & $\begin{array}{l}1000 \\
1000 \\
1000 \\
1000 \\
1000 \\
\end{array}$ & $\begin{array}{l}1,2 \text { on } \\
1,2 \text { on } \\
1,2 \text { on } \\
1,2 \text { on } \\
1,2 \text { on }\end{array}$ & $\begin{array}{l}\text { off } \\
\text { off } \\
\text { off } \\
\text { off } \\
\text { off }\end{array}$ & $\begin{array}{l}1810 \\
1760 \\
1740 \\
1710 \\
1700 \\
\end{array}$ \\
\hline 21 & $\begin{array}{l}16121 \\
1612 ?\end{array}$ & $21: 28: 41$ & $21: 28: 54$ & lateral doublet & $4 k$ block & 80 & $\begin{array}{l}1000 \\
1000\end{array}$ & 1,2 on & off & $\begin{array}{l}1680 \\
1660\end{array}$ \\
\hline $\begin{array}{l}24 \\
25\end{array}$ & $\begin{array}{l}16124 \\
16125\end{array}$ & $\begin{array}{l}21: 34: 08 \\
21: 37: 14\end{array}$ & $\begin{array}{l}21: 35: 57 \\
21: 38: 50\end{array}$ & $\begin{array}{l}\text { pedal sweep } \\
\text { pedal sweep }\end{array}$ & & $\begin{array}{l}80 \\
80\end{array}$ & $\begin{array}{l}1000 \\
1000\end{array}$ & $\begin{array}{l}1,2 \text { on } \\
1,2 \text { on }\end{array}$ & $\begin{array}{l}\text { off } \\
\text { off }\end{array}$ & $\begin{array}{l}1620 \\
1580\end{array}$ \\
\hline $\begin{array}{l}26 \\
27 \\
28 \\
29 \\
30\end{array}$ & $\begin{array}{l}16126 \\
16127 \\
16128 \\
16129 \\
16130 \\
\end{array}$ & $\begin{array}{l}21: 38: 48 \\
21: 41: 21 \\
21: 42: 38 \\
21: 43: 32 \\
21: 45: 42\end{array}$ & $\begin{array}{l}21: 40: 04 \\
21: 41: 34 \\
21: 42: 50 \\
21: 43: 44 \\
21: 45: 51\end{array}$ & $\begin{array}{c}\text { pedal step } \\
\text { pedal step } \\
\text { pedal doublet } \\
\text { pedal doublet } \\
\text { coll step }\end{array}$ & $4 \mathrm{k}$ block & $\begin{array}{l}80 \\
80 \\
80 \\
80 \\
80\end{array}$ & $\begin{array}{l}1000 \\
1000 \\
1000 \\
1000 \\
1000 \\
\end{array}$ & $\begin{array}{l}1,2 \text { on } \\
1,2 \text { on } \\
1,2 \text { on } \\
1,2 \text { on } \\
1,2 \text { on }\end{array}$ & $\begin{array}{l}\text { off } \\
\text { off } \\
\text { off } \\
\text { off } \\
\text { off } \\
\end{array}$ & $\begin{array}{l}1550 \\
1530 \\
1520 \\
1500 \\
1460\end{array}$ \\
\hline
\end{tabular}




\section{TABLE 3. CATALOG OF DATA RECORDS BY FLIGHT (CONTINUED)}

\begin{tabular}{|c|c|c|c|c|c|c|c|c|c|c|}
\hline \multirow{2}{*}{$\begin{array}{l}\text { Record } \\
\text { Number }\end{array}$} & \multirow{2}{*}{$\begin{array}{l}\text { Trends } \\
\text { Counter }\end{array}$} & \multicolumn{2}{|c|}{ Record Times } & \multirow[t]{2}{*}{ Maneuver } & \multirow[t]{2}{*}{ Load } & \multirow{2}{*}{$\begin{array}{c}\text { Airspeed } \\
\text { (knots) }\end{array}$} & \multirow{2}{*}{$\begin{array}{c}\text { Altitude } \\
\text { (feet) }\end{array}$} & \multirow[t]{2}{*}{ SAS } & \multirow[t]{2}{*}{ FPS } & \multirow{2}{*}{$\begin{array}{l}\text { Fuel Wt. } \\
\text { (pounds) }\end{array}$} \\
\hline & & Start & Stop & & & & & & & \\
\hline 31 & 16131 & $21: 46: 47$ & $21: 46: 59$ & coll doublet & $4 \mathrm{k}$ block & 80 & 1000 & 1,2 on & off & 1450 \\
\hline 32 & 16132 & $21: 47: 16$ & 21:47:28 & coll step & & 80 & 1000 & 1,2 on & off & 1450 \\
\hline 33 & 16133 & $21: 48: 16$ & $21: 48: 29$ & coll doublet & & 80 & 1000 & 1,2 on & off & 1440 \\
\hline 34 & 16134 & $21: 50: 15$ & $21: 51: 52$ & coll sweep & & 80 & 1000 & 1,2 on & off & 1400 \\
\hline 35 & 16135 & $21: 53: 39$ & 21:55:08 & coll sweep & & 80 & 1000 & 1,2 on & off & 1360 \\
\hline 36 & 16136 & $21: 56: 59$ & $21: 58: 48$ & coll sweep & $4 \mathrm{k}$ block & 80 & 1000 & 1,2 on & off & 1330 \\
\hline 37 & 16137 & $22: 00: 11$ & 22:02:03 & long'l sweep & & 80 & 1000 & 1,2 on & off & 1280 \\
\hline 38 & 16138 & $22: 04: 19$ & 22:06:01 & long'l sweep & & 80 & 1000 & 1,2 on & off & 1230 \\
\hline 39 & 16139 & $22: 07: 31$ & 22:09:18 & long'l sweep & & 80 & 1000 & 1,2 on & off & 1200 \\
\hline 40 & 16140 & $22: 10: 10$ & $22: 10: 15$ & long'l step & & 80 & 1000 & 1,2 on & off & 1160 \\
\hline 41 & 16141 & $22: 11: 00$ & $22: 11: 18$ & long'l doublet & 4k block & 80 & 1000 & 1,2 on & off & 1140 \\
\hline 42 & 16142 & $22: 12: 33$ & $22: 12: 46$ & long'l slep & & 80 & 1000 & 1,2 on & off & 1120 \\
\hline 43 & 16143 & $22: 13: 30$ & 12:13:50 & long'l doublet & & 80 & 1000 & 1,2 on & off & 1110 \\
\hline $44-55$ & $16144-55$ & $22: 28: 33$ & 22:35:43 & control throws & & & on ground & & off & \\
\hline & & & & & & & & & & \\
\hline & & & & & & & & & & \\
\hline & & & & & & & & & & \\
\hline & & & & & & & & & & \\
\hline & & & & & & & & & & \\
\hline & & & & & & & & & & \\
\hline & & & & & & & & & & \\
\hline & & & & & & & & & & \\
\hline & & & & & & & & & & \\
\hline & & & & & & & & & & \\
\hline & & & & & & & & & & \\
\hline & & & & & & & & & & \\
\hline & & & & & & & & & & \\
\hline & & & & & & & & & & \\
\hline & & & & & & & & & & \\
\hline & & & & & & & & & & \\
\hline
\end{tabular}




\section{TABLE 3. CATALOG OF DATA RECORDS BY FLIGHT (CONTINUED)}

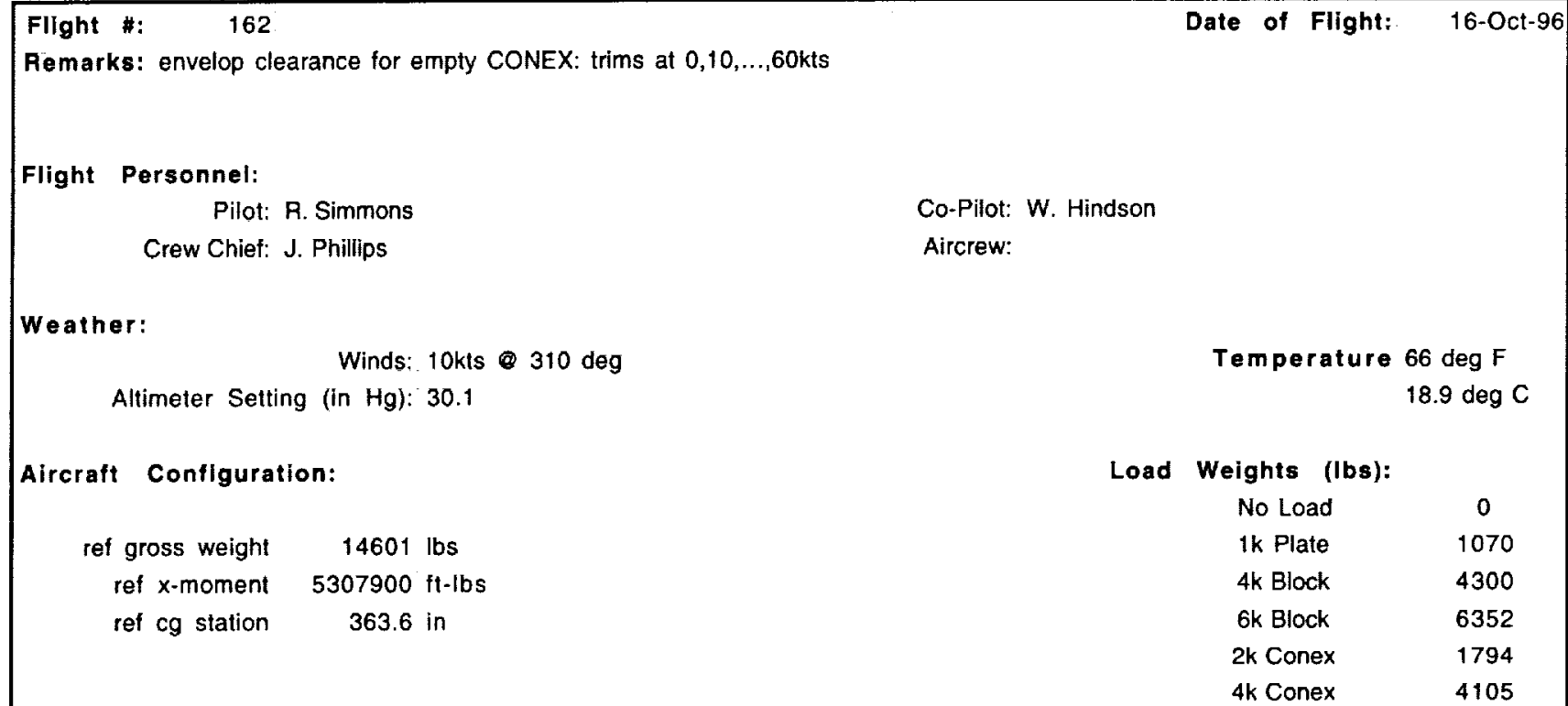

Remarks: envelop clearance for empty CONEX: trims at $0,10, \ldots, 60 \mathrm{kts}$

Flight Personnel:

Pilot: R. Simmons

Crew Chief: J. Phillips

Weather:

Winds: $10 \mathrm{kts} 310 \mathrm{deg}$

Altimeter Setting (in $\mathrm{Hg}$ ): 30.1

\section{Aircraft Configuration:}

ref gross weight 14601 lbs ref $\mathrm{x}$-moment $5307900 \mathrm{ft}$-lbs

ref $\mathrm{cg}$ station $\quad 363.6 \mathrm{in}$

Date of Flight: $16-$ Oct-96

Co-Pilot: W. Hindson

Aircrew:

Temperature 66 deg $F$ $18.9 \operatorname{deg} C$

Load Weights (Ibs):

No Load 0

1k Plate $\quad 1070$

4k Block $\quad 4300$

6k Block 6352

2k Conex 1794

4k Conex 4105

Directory Name: TRENDSBSL Sample Rate: $100 \mathrm{~Hz}$

\begin{tabular}{|c|c|c|c|c|c|c|c|c|c|c|}
\hline \multirow{2}{*}{$\begin{array}{l}\text { Record } \\
\text { Number }\end{array}$} & \multirow{2}{*}{$\begin{array}{l}\text { Trends } \\
\text { Counter }\end{array}$} & \multicolumn{2}{|c|}{ Record Time } & \multirow[t]{2}{*}{ Maneuver } & \multirow[t]{2}{*}{ Load } & \multirow{2}{*}{$\begin{array}{c}\text { Airspeed } \\
\text { (knots) }\end{array}$} & \multirow{2}{*}{$\begin{array}{c}\text { Altitude } \\
\text { (feet) }\end{array}$} & \multirow[t]{2}{*}{ SAS } & \multirow[t]{2}{*}{ FPS } & \multirow{2}{*}{$\begin{array}{l}\text { Fuel Wt. } \\
\text { (pounds) }\end{array}$} \\
\hline & & Start & Stop & & & & & & & \\
\hline 12 & 16212 & $20: 28: 51$ & $20: 29: 00$ & control throw & & & on ground & 1 on & off & \\
\hline 14 & 16214 & $20: 43: 32$ & $20: 43: 56$ & trim & $2 \mathrm{KCNX}$ & hover & OGE & 1,2 on & on & 2180 \\
\hline 15 & 16215 & $20: 48: 45$ & $20: 49: 07$ & trim & $2 K C N X$ & 30 & 1000 & 1,2 on & on & 2100 \\
\hline 16 & 16216 & $20: 50: 02$ & $20: 50: 35$ & trim & $2 k C N X$ & 40 & 1000 & 1,2 on & on & 2090 \\
\hline 17 & 16217 & $20: 51: 10$ & $20: 51: 34$ & trim & $2 k$ CNX & 50 & 1000 & 1,2 on & on & 2080 \\
\hline 18 & 16218 & $20: 52: 08$ & $20: 52: 31$ & right turn & $2 k C N X$ & 40 & 1000 & 1,2 on & on & 2060 \\
\hline 19 & 16219 & $20: 53: 36$ & $20: 54: 18$ & trim & $2 k C N X$ & 60 & 1000 & 1,2 on & on & 2050 \\
\hline 20 & 16220 & $21: 01: 54$ & $21: 02: 28$ & left turn & $2 \mathrm{k} C N X$ & 40 & 1000 & 1,2 on & on & 1940 \\
\hline 21 & 16221 & $21: 08: 14$ & $21: 08: 31$ & trim & $2 k C N X$ & hover & COE & 1,2 on & on & 1860 \\
\hline & & & & & & & & & & \\
\hline & & & & & & & & & & \\
\hline & & & & & & & & & & \\
\hline & & & & & & & & & & \\
\hline & & & & & & & & & & \\
\hline
\end{tabular}




\section{TABLE 3. CATALOG OF DATA RECORDS BY FLIGHT (CONTINUED)}

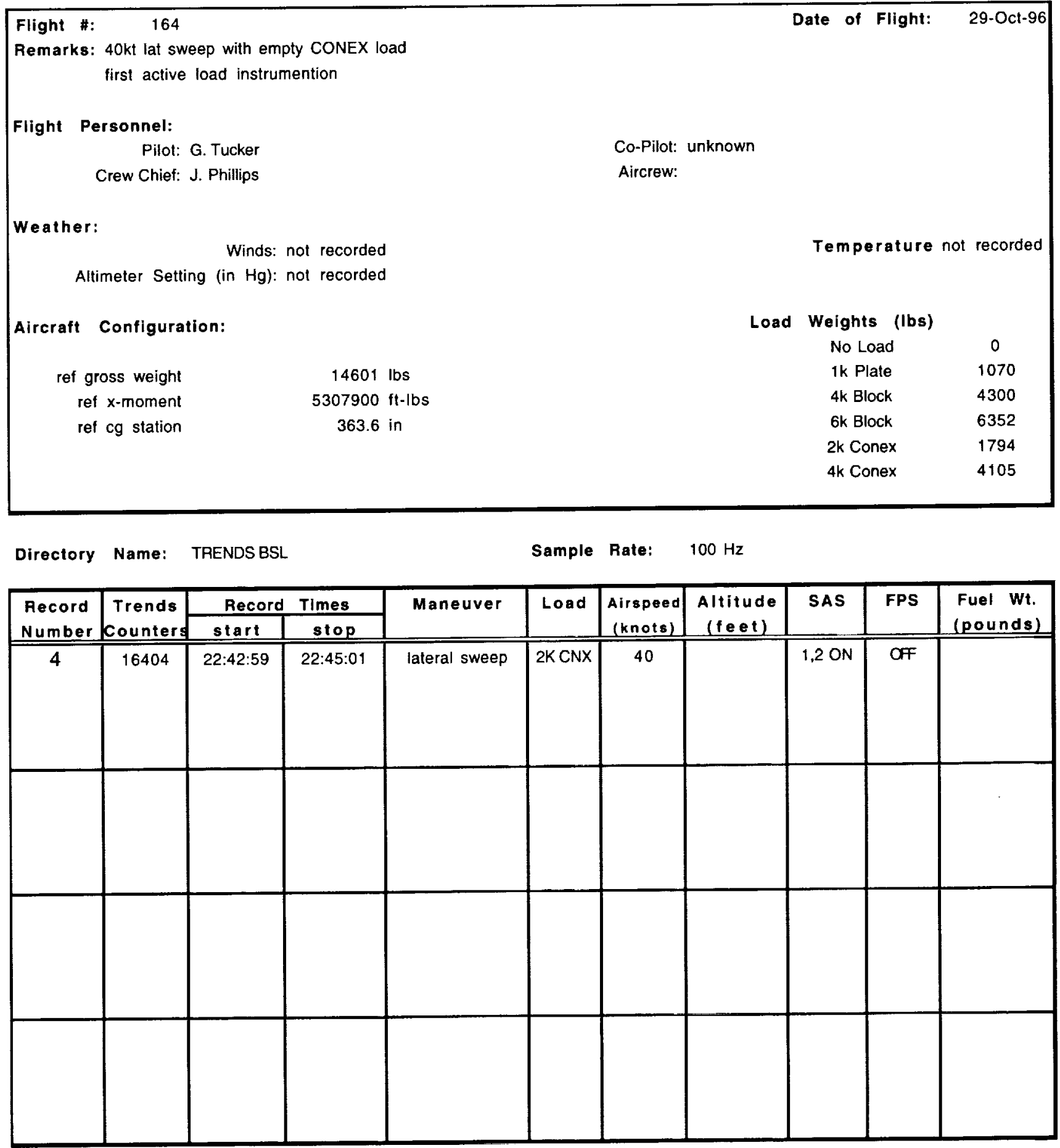




\section{TABLE 3. CATALOG OF DATA RECORDS BY FLIGHT (CONTINUED)}

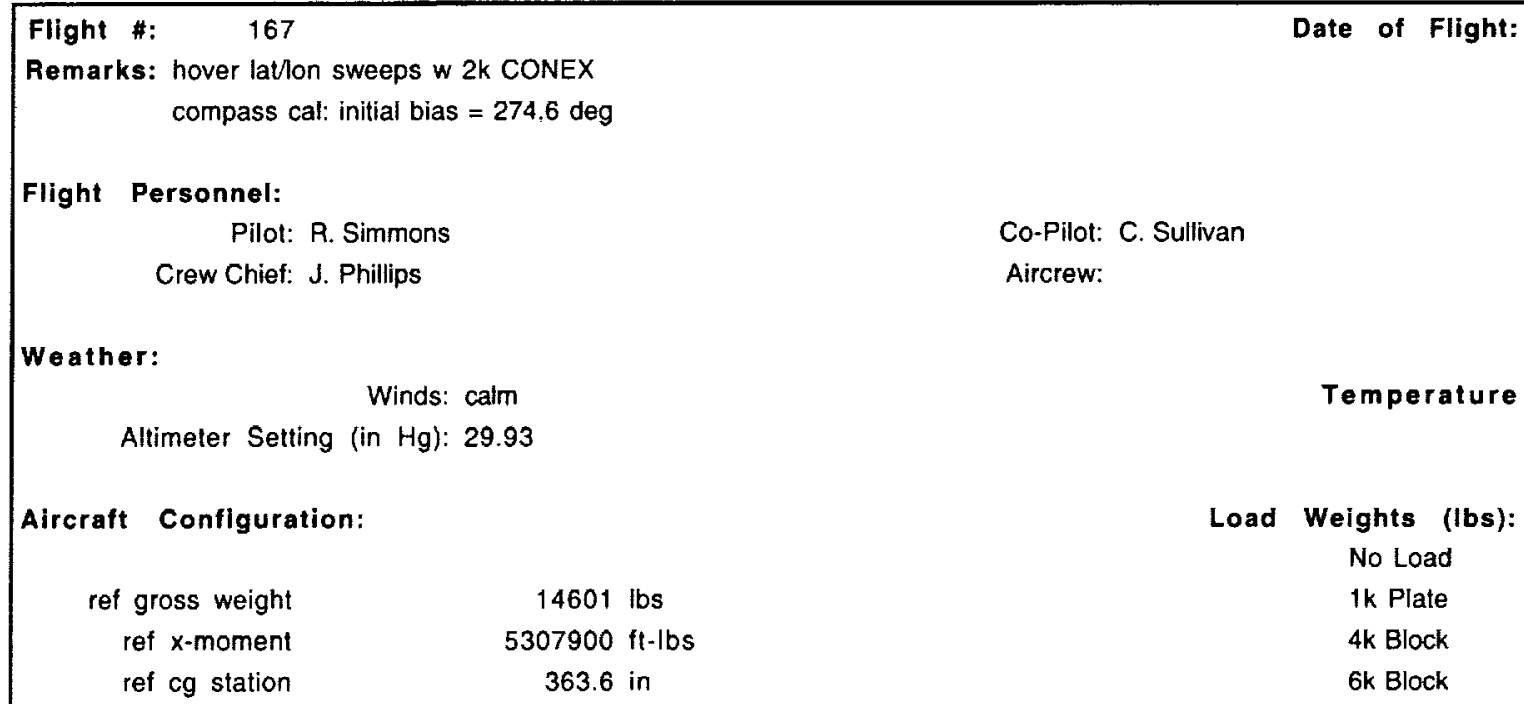

Pilot: R. Simmons

Crew Chief: J. Phillips

Weather:

Winds: calm

Altimeter Setting (in $\mathrm{Hg}$ ): 29.93

Aircraft Configuration:

ref gross weight

ref $\mathrm{x}$-moment

ref $\mathrm{cg}$ station

14601 lbs

$5307900 \mathrm{ft}$-lbs

363.6 in

Date of Flight:

Co-Pilot: C. Sullivan

Aircrew:

28-Jul-97

Directory Name: TRENDSE BSL

Sample Rate: $\quad 100 \mathrm{~Hz}$

\begin{tabular}{|c|c|c|c|c|c|c|c|c|c|c|}
\hline \multirow{2}{*}{$\begin{array}{l}\text { Record } \\
\text { Number } \\
\end{array}$} & \multirow{2}{*}{$\begin{array}{l}\text { Trends } \\
\text { Counter }\end{array}$} & \multicolumn{2}{|c|}{ Record Times } & \multirow[t]{2}{*}{ Maneuver } & \multirow[t]{2}{*}{ Load } & \multirow{2}{*}{$\begin{array}{c}\text { Airspeed } \\
(\text { knots })\end{array}$} & \multirow{2}{*}{$\begin{array}{c}\text { Altitude } \\
\text { (feet) }\end{array}$} & \multirow[t]{2}{*}{ SAS } & \multirow[t]{2}{*}{ FPS } & \multirow{2}{*}{$\begin{array}{l}\text { Fuel Wt. } \\
\text { (pounds) }\end{array}$} \\
\hline & & Start & Stop & & & & & & & \\
\hline 1 thru 12 & $16701-12$ & $16: 08: 13$ & $16: 15: 15$ & control throws & & & on ground & 1 on & off & $h d g=17$ \\
\hline 13 & 16713 & $16: 40: 32$ & $16: 40: 45$ & trim & $2 k C N X$ & hover & 130 & 1,2 on & off & 2075 \\
\hline 14 & 16714 & $16: 44: 10$ & $16: 46: 02$ & long'l sweep & & hover & 130 & 1,2 on & off & 2030 \\
\hline 15 & 16715 & $16: 51: 33$ & $16: 53: 18$ & long'l sweep & & hover & 130 & 1,2 on & off & 1950 \\
\hline 16 & 16716 & $16: 54: 42$ & $16: 56: 22$ & long'l sweep & $2 \mathrm{k} C N \mathrm{X}$ & hover & 130 & 1,2 on & off & •1880 \\
\hline 17 & 16717 & $16: 57: 11$ & $16: 57: 26$ & long'| step & & hover & 130 & 1,2 on & off & $=1870$ \\
\hline 18 & 16718 & $16: 57: 58$ & 16:58:15 & long'l step & & hover & 130 & 1,2 on & off & $" 1860$ \\
\hline 19 & 16719 & $16: 58: 57$ & $16: 59: 14$ & long'l doublet & & hover & 130 & 1,2 on & off & $\cdot 1850$ \\
\hline 20 & 16720 & $16: 59: 34$ & $16: 59: 49$ & long'l doublet & & hover & 130 & 1,2 on & off & 1840 \\
\hline 21 & 16721 & $17: 05: 56$ & 17:06:16 & trim & $2 \mathrm{kCNX}$ & hover & 130 & 1,2 on & off & 1730 \\
\hline 22 & 16722 & $17: 06: 45$ & 17:08:30 & lateral sweep & & hover & 130 & 1,2 on & off & 1700 \\
\hline 23 & 16723 & $17: 09: 29$ & $17: 11: 20$ & lateral sweep & & hover & 130 & 1,2 on & off & 1660 \\
\hline 24 & 16724 & $17: 12: 13$ & 17:13:59 & lateral sweep & & hover & 130 & 1,2 on & off & 1600 \\
\hline 25 & 16725 & $17: 14: 49$ & $17: 15: 08$ & lateral step & & hover & 130 & 1,2 on & off & 1580 \\
\hline 26 & 16726 & $17: 15: 31$ & $17: 15: 55$ & lateral step & $2 k \mathrm{CNX}$ & hover & 130 & 1,2 on & off & 1580 \\
\hline 27 & 16727 & $17: 16: 23$ & $17: 16: 40$ & lateral doublet & & hover & 130 & 1,2 on & off & $\cdot 1570$ \\
\hline 28 & 16728 & $17: 16: 57$ & $17: 17: 13$ & lateral doublet & & hover & 130 & 1,2 on & off & 1550 \\
\hline 29 & 16729 & $17: 17: 57$ & $17: 18: 09$ & trim & & hover & 130 & 1,2 on & off & 1540 \\
\hline 30 & 16730 & $17: 18: 42$ & 17:09:02 & coll doublet & & hover & 130 & 1,2 on & off & •1530 \\
\hline
\end{tabular}




\section{TABLE 3. CATALOG OF DATA RECORDS BY FLIGHT (CONTINUED)}

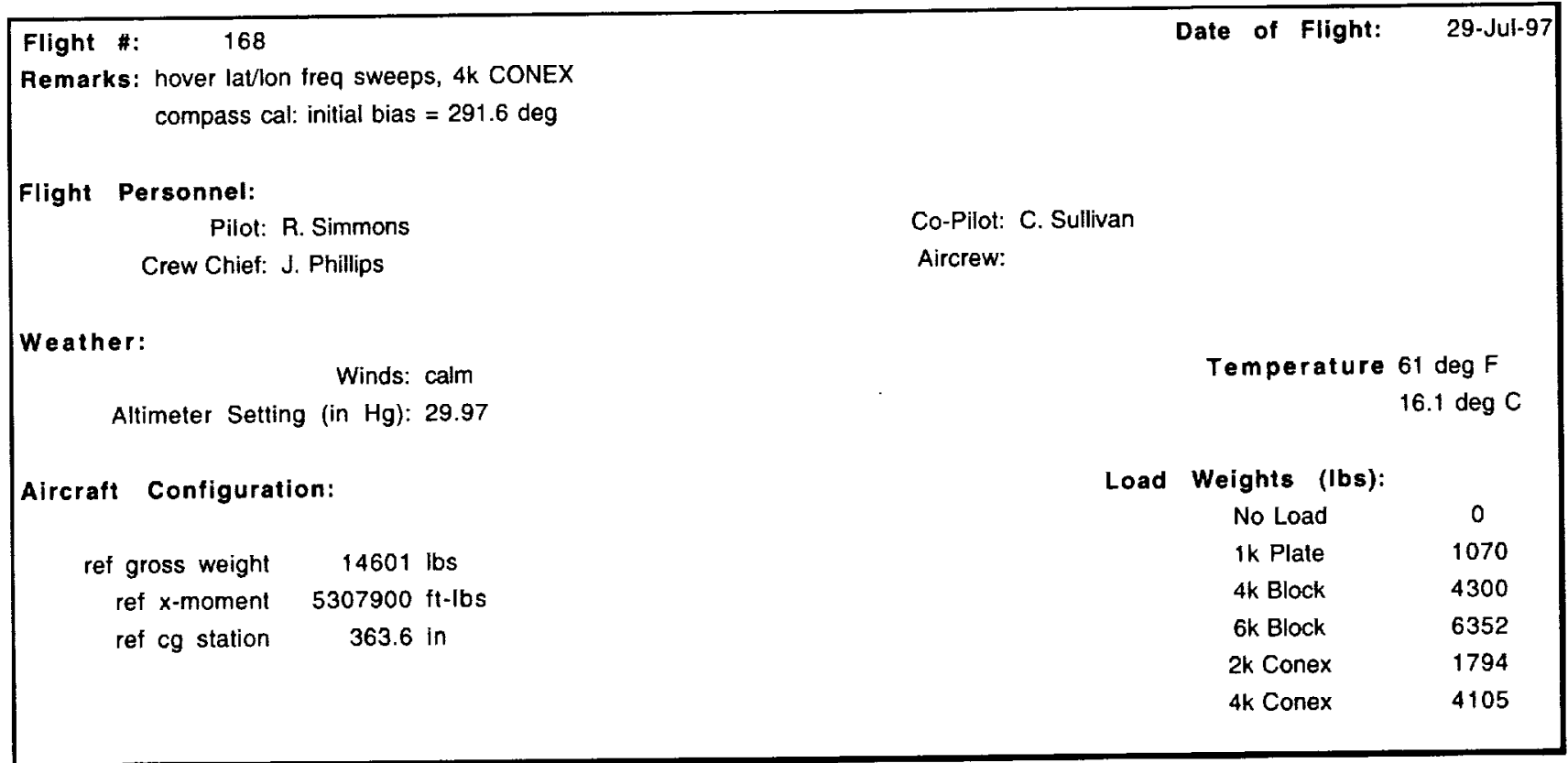

Directory Name: TRENDSBSL

Sample Rate: $100 \mathrm{~Hz}$

\begin{tabular}{|c|c|c|c|c|c|c|c|c|c|c|}
\hline \multirow{2}{*}{$\begin{array}{l}\text { Record } \\
\text { Number }\end{array}$} & \multirow{2}{*}{$\begin{array}{c}\text { Trends } \\
\text { Counter }\end{array}$} & \multicolumn{2}{|c|}{ Record Times } & \multirow[t]{2}{*}{ Maneuver } & \multirow[t]{2}{*}{ Load } & \multirow{2}{*}{$\begin{array}{c}\text { Airspeed } \\
\text { (knots) }\end{array}$} & \multirow{2}{*}{$\begin{array}{c}\text { Altitude } \\
(\text { feet) } \\
\end{array}$} & \multirow[t]{2}{*}{ SAS } & \multirow[t]{2}{*}{ FPS } & \multirow{2}{*}{$\begin{array}{l}\text { Fuel Wt. } \\
\text { (pounds) }\end{array}$} \\
\hline & & Start & Stop & & & & & & & \\
\hline thru 11 & 16801-11 & $14: 53: 10$ & $14: 59: 54$ & control throws & & & on ground & 1 on & off & $\mathrm{hdg}=7 \mathrm{deg}$ \\
\hline 12 & 16812 & $15: 09: 47$ & 15:10:00 & Bad Record & & & & & & "2360 \\
\hline 13 & 16813 & $15: 19: 37$ & $15: 19: 56$ & trim & $4 \mathrm{kCNX}$ & hover & 115 & 1,2 on & off & 2200 \\
\hline 14 & 16814 & $15: 20: 19$ & $15: 21: 59$ & long'l sweep & & hover & 115 & 1,2 on & off & 2130 \\
\hline 15 & 16815 & 15:23:21 & $15: 24: 54$ & long'l sweep & & hover & 115 & 1,2 on & off & 2090 \\
\hline 16 & 16816 & $15: 27: 04$ & $15: 27: 13$ & Bad Aecord & & hover & & & & $* 2030$ \\
\hline 17 & 16817 & $15: 33: 13$ & $15: 35: 01$ & long'l sweep & $4 \mathrm{k} C N X$ & hover & 115 & 1,2 on & off & 1920 \\
\hline 18 & 16818 & $15: 35: 57$ & $15: 37: 45$ & long'l sweep & & hover & 115 & 1,2 on & off & 1850 \\
\hline 19 & 16819 & $15: 38: 20$ & $15: 38: 40$ & long'l step & & hover & 115 & 1,2 on & off & 1810 \\
\hline 20 & 16820 & $15: 38: 50$ & $15: 39: 17$ & Iong'l step & & hover & 115 & 1,2 on & off & 1800 \\
\hline 21 & 16821 & $15: 39: 56$ & $15: 40: 18$ & long'l doublet & $4 \mathrm{k} \mathrm{CNX}$ & hover & 115 & 1,2 on & off & 1780 \\
\hline 22 & 16822 & $15: 40: 46$ & $15: 41: 10$ & long'l doublet & & hover & 115 & 1,2 on & off & 1760 \\
\hline 23 & 16823 & $15: 41: 55$ & $15: 42: 12$ & trim & & hover & 115 & 1,2 on & off & 1750 \\
\hline 24 & 16824 & $15: 42: 36$ & $15: 44: 17$ & lateral sweep & & hover & 115 & 1,2 on & off & 1720 \\
\hline 25 & 16825 & 15:44:39 & $15: 46: 20$ & lateral sweep & & hover & 115 & 1,2 on & off & 1680 \\
\hline 26 & 16826 & $15: 46: 54$ & $15: 48: 44$ & lateral sweep & $4 k C N X$ & hover & 115 & 1,2 on & off & 1650 \\
\hline 27 & 16827 & $15: 49: 14$ & $15: 49: 35$ & lateal step & & hover & 115 & 1,2 on & off & 1610 \\
\hline 28 & 16828 & $15: 49: 56$ & $15: 50: 18$ & lateral step & & hover & 115 & 1,2 on & off & 1600 \\
\hline 29 & 16829 & $15: 50: 45$ & $15: 51: 04$ & lateral doublet & & hover & 115 & 1,2 on & off & 1580 \\
\hline 30 & 16830 & $15: 51: 48$ & $15: 51: 53$ & Bad Record & & hover & & & & $\cdot 1565$ \\
\hline
\end{tabular}


TABLE 3. CATALOG OF DATA RECORDS BY FLIGHT (CONTINUED)

\begin{tabular}{|c|c|c|c|c|c|c|c|c|c|c|}
\hline \multirow{2}{*}{$\begin{array}{l}\text { Record } \\
\text { Number }\end{array}$} & \multirow{2}{*}{$\begin{array}{l}\text { Trends } \\
\text { Counter }\end{array}$} & \multicolumn{2}{|c|}{ Record Time } & \multirow[t]{2}{*}{ Maneuver } & \multirow[t]{2}{*}{ Load } & \multirow{2}{*}{$\begin{array}{l}\text { Airspeed } \\
\text { (knots) }\end{array}$} & \multirow{2}{*}{$\begin{array}{c}\text { Altitude } \\
\text { (feet) }\end{array}$} & \multirow[t]{2}{*}{ SAS } & \multirow[t]{2}{*}{ FPS } & \multirow{2}{*}{$\begin{array}{l}\text { Fuel Wt. } \\
\text { (pounds) }\end{array}$} \\
\hline & & Start & Stop & & & & & & & \\
\hline 31 & 16831 & $15: 52: 06$ & $15: 52: 27$ & roll doublet & $4 \mathrm{k} C N X$ & hover & 115 & 1,2 on & off & 1550 \\
\hline 32 & 16832 & $15: 53: 10$ & 15:53:24 & & & hover & 115 & 1,2 on & off & 1530 \\
\hline 33 & 16833 & 15:53:53 & $15: 54: 16$ & coll doublet & & hover & 115 & 1,2 on & off & 1510 \\
\hline 34 & 16834 & $15: 54: 54$ & $15: 55: 15$ & coll doublet & & hover & 115 & 1,2 on & off & 1500 \\
\hline 35 & 16835 & 15:58:31 & $15: 58: 59$ & pedal doublet & & hover & 115 & 1,2 on & off & 1420 \\
\hline & & & & & & & & & & \\
\hline & & & & & & & & & & \\
\hline & & & & & & & & & & \\
\hline & & & & & & & & & & \\
\hline & & & & & & & & & & \\
\hline & & & & & & & & & & \\
\hline & & & & & & & & & & \\
\hline & & & & & & & & & & \\
\hline & & & & & & & & & & \\
\hline & & & & & & & & & & \\
\hline & & & & & & & & & & \\
\hline & & & & & & & & & & \\
\hline & & & & & & & & & & \\
\hline & & & & & & & & & & \\
\hline & & & & & & & & & & \\
\hline & & & & & & & & & & \\
\hline & & & & & & & & & & \\
\hline & & & & & & & & & & \\
\hline
\end{tabular}




\section{TABLE 3. CATALOG OF DATA RECORDS BY FLIGHT (CONTINUED)}

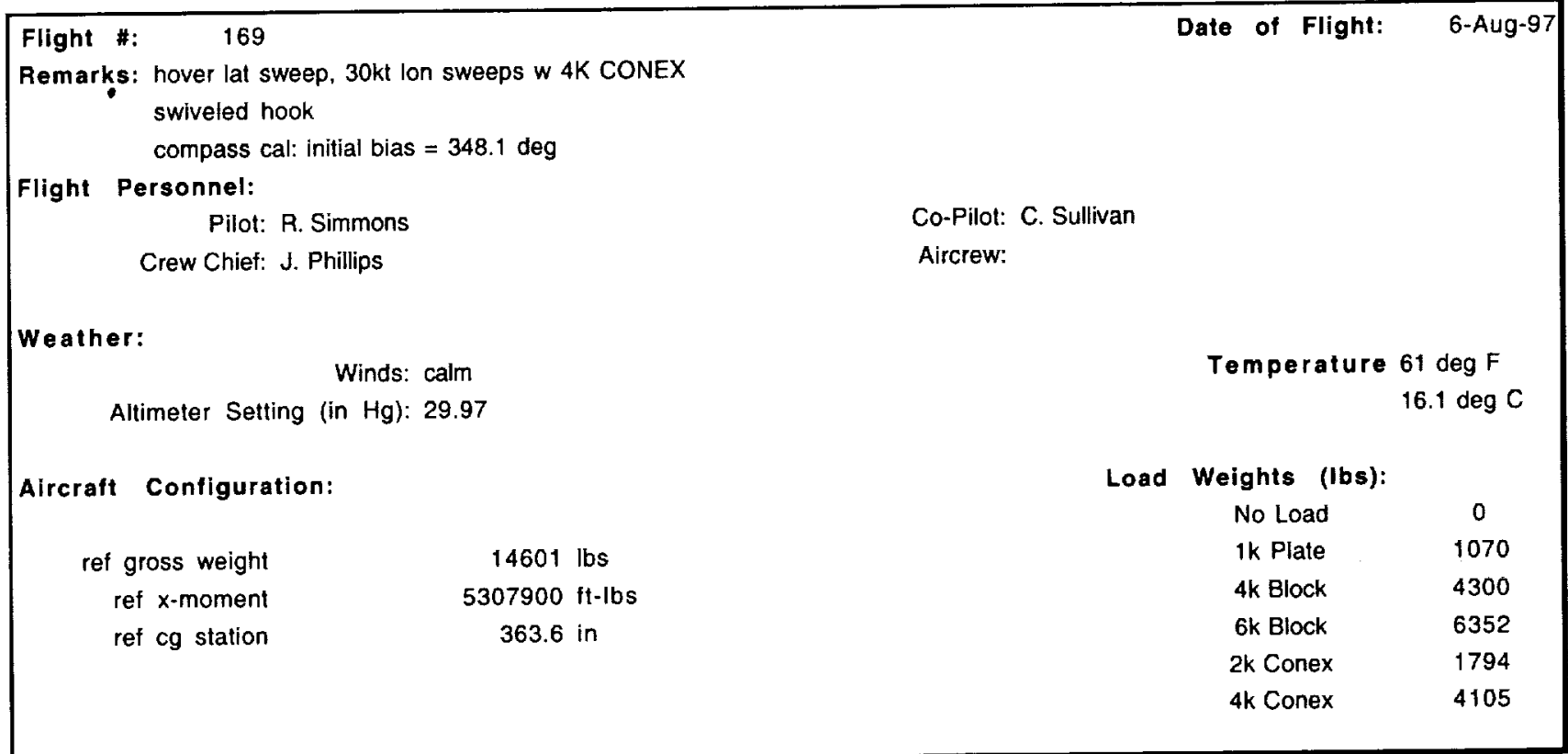

Directory Name: TRENDSBSL Sample Rate: $100 \mathrm{~Hz}$

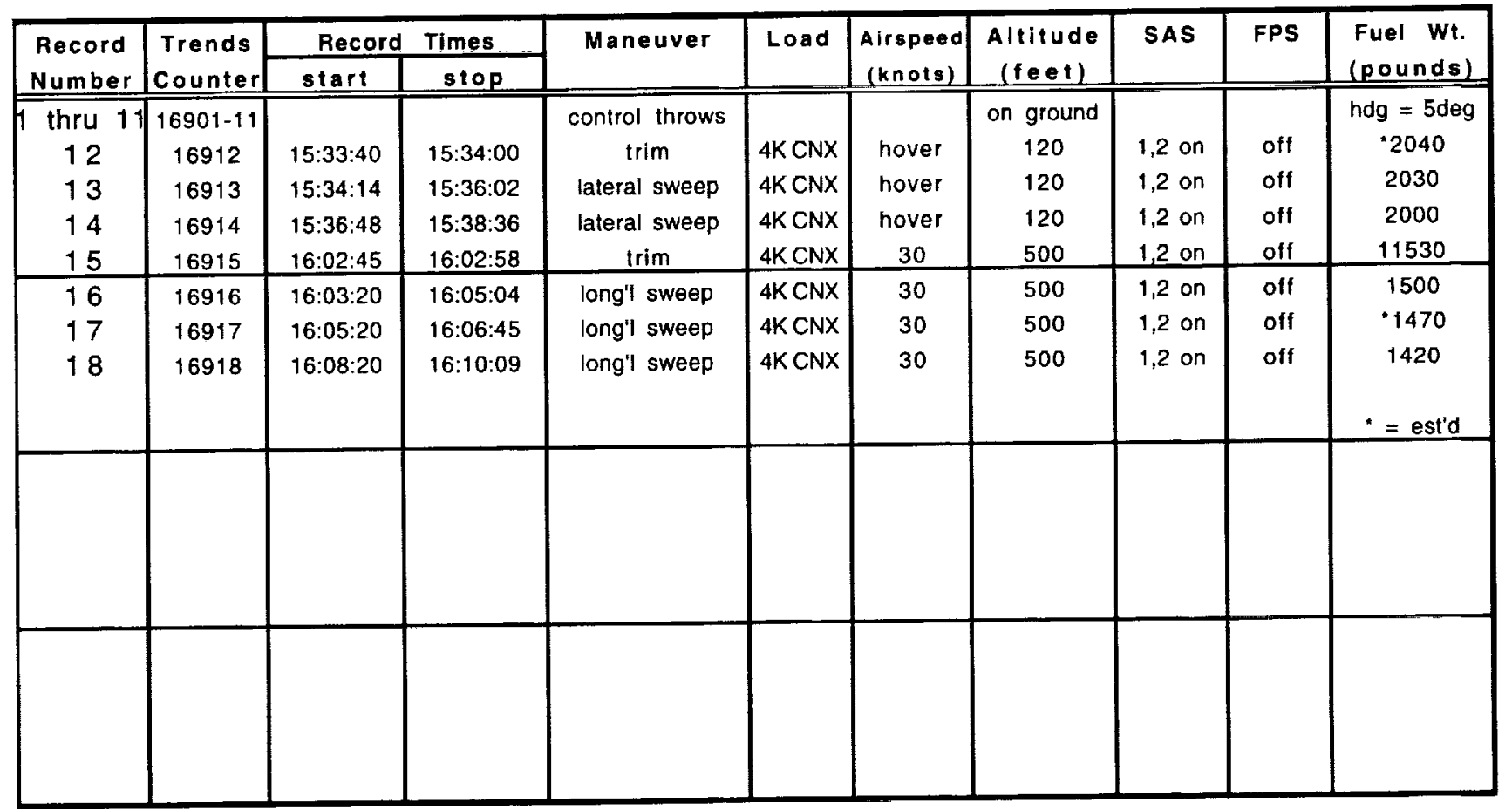




\section{TABLE 3. CATALOG OF DATA RECORDS BY FLIGHT (CONTINUED)}

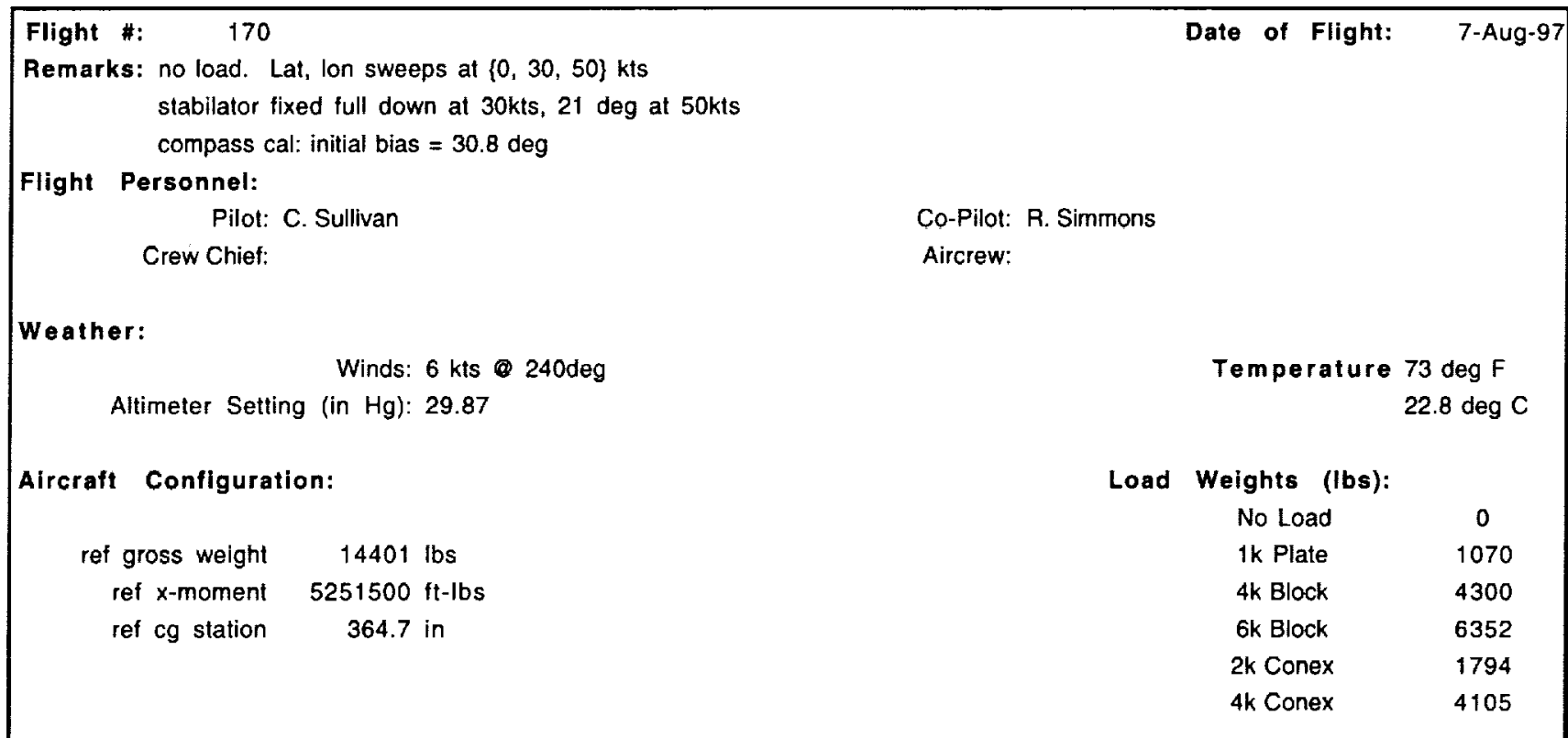

\section{Directory Name: TRENDSBSL $\quad$ Sample Rate: $100 \mathrm{~Hz}$}

\begin{tabular}{|c|c|c|c|c|c|c|c|c|c|c|}
\hline \multirow{2}{*}{$\begin{array}{l}\text { Record } \\
\text { Number }\end{array}$} & \multirow{2}{*}{$\begin{array}{l}\text { Trends } \\
\text { Counter }\end{array}$} & \multicolumn{2}{|c|}{ Record Time } & \multirow[t]{2}{*}{ Maneuver } & \multirow[t]{2}{*}{ Load } & \multirow{2}{*}{$\begin{array}{l}\text { Airspeed } \\
\text { (knots) }\end{array}$} & \multirow{2}{*}{$\begin{array}{c}\text { Altitude } \\
\text { (feet) }\end{array}$} & \multirow[t]{2}{*}{ SAS } & \multirow[t]{2}{*}{ FPS } & \multirow{2}{*}{$\begin{array}{l}\text { Fuel Wt. } \\
\text { (pounds) }\end{array}$} \\
\hline & & Start & Stop & & & & & & & \\
\hline thru 11 & $17001-11$ & $17: 01: 38$ & $17: 10: 25$ & contral throws & & & on ground & 1 on & off & hdg $=320$ \\
\hline 12 & 17012 & $17: 23: 57$ & $17: 24: 09$ & trim & none & hover & $\alpha G E$ & 1,2 on & off & 2240 \\
\hline 14 & 17014 & $17: 25: 28$ & $17: 27: 08$ & long'l sweep & & hover & OGE & 1,2 on & off & 2200 \\
\hline 15 & 17015 & $17: 28: 03$ & $17: 29: 45$ & long'l sweep & & hover & OGE & 1,2 on & off & 2170 \\
\hline 16 & 17016 & $17: 30: 46$ & $17: 32: 23$ & long'l sweep & none & hover & OGE & 1.2 on & off & 2120 \\
\hline 17 & 17017 & $17: 33: 25$ & $17: 33: 50$ & long'l step & & hover & OEE & 1,2 on & off & 2100 \\
\hline 19 & 17019 & $17: 35: 20$ & $17: 35: 40$ & long'l step & & hover & OGE & 1,2 on & off & 2070 \\
\hline 20 & 17020 & $17: 36: 21$ & $17: 36: 35$ & long'l doublet & & hover & OCE & 1,2 on & off & 2050 \\
\hline 21 & 17021 & $17: 27: 08$ & $17: 37: 25$ & long'l doublet & none & hover & OE & 1,2 on & off & 2050 \\
\hline 22 & 17022 & $17: 39: 50$ & $17: 40: 07$ & trim & & hover & OGE & 1,2 on & off & 2000 \\
\hline 26 & 17026 & $17: 42: 06$ & $17: 43: 41$ & lateral sweep & & hover & OGE & 1,2 on & off & 1950 \\
\hline 27 & 17027 & $17: 44: 18$ & $17: 45: 45$ & lateral sweep & & hover & OGE & 1,2 on & off & 1910 \\
\hline 28 & 17028 & $17: 47: 15$ & $17: 48: 46$ & lateral sweep & none & hover & $O G E$ & 1,2 on & off & 1880 \\
\hline 29 & 17029 & $17: 49: 44$ & $17: 49: 57$ & lateral step & & hover & DEE & 1,2 on & off & 1850 \\
\hline 30 & 17030 & $17: 50: 23$ & $17: 50: 36$ & lateral step & & hover & OGE & 1,2 on & off & 1850 \\
\hline 31 & 17031 & $17: 51: 20$ & $17: 51: 34$ & lateral doublet & & hover & OGE & 1,2 on & off & 1830 \\
\hline 32 & 17032 & $17: 52: 00$ & $17: 52: 16$ & lateral doublet & & hover & OGE & 1,2 on & off & 1810 \\
\hline
\end{tabular}




\section{TABLE 3. CATALOG OF DATA RECORDS BY FLIGHT (CONTINUED)}

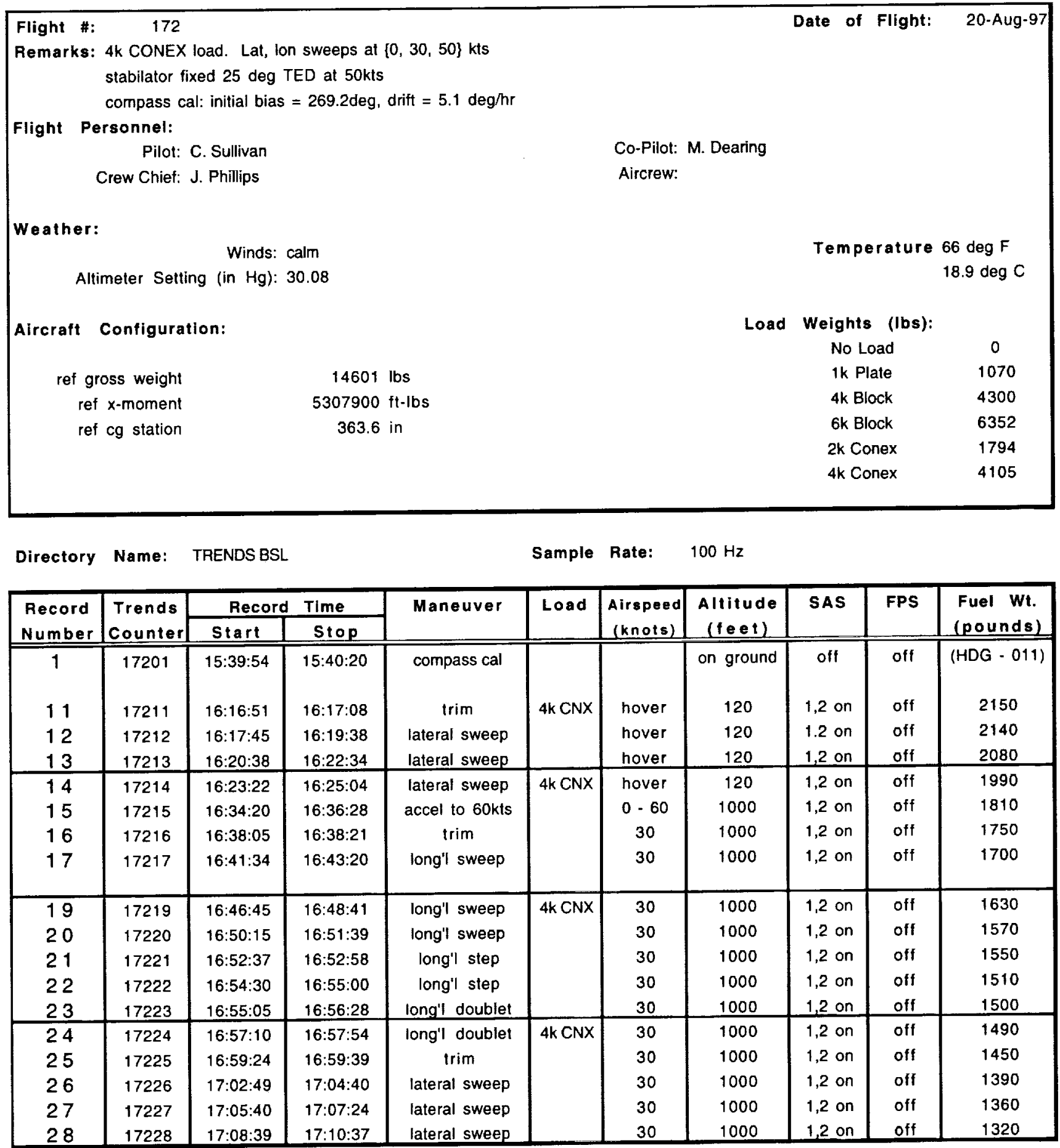




\section{TABLE 3. CATALOG OF DATA RECORDS BY FLIGHT (CONTINUED)}

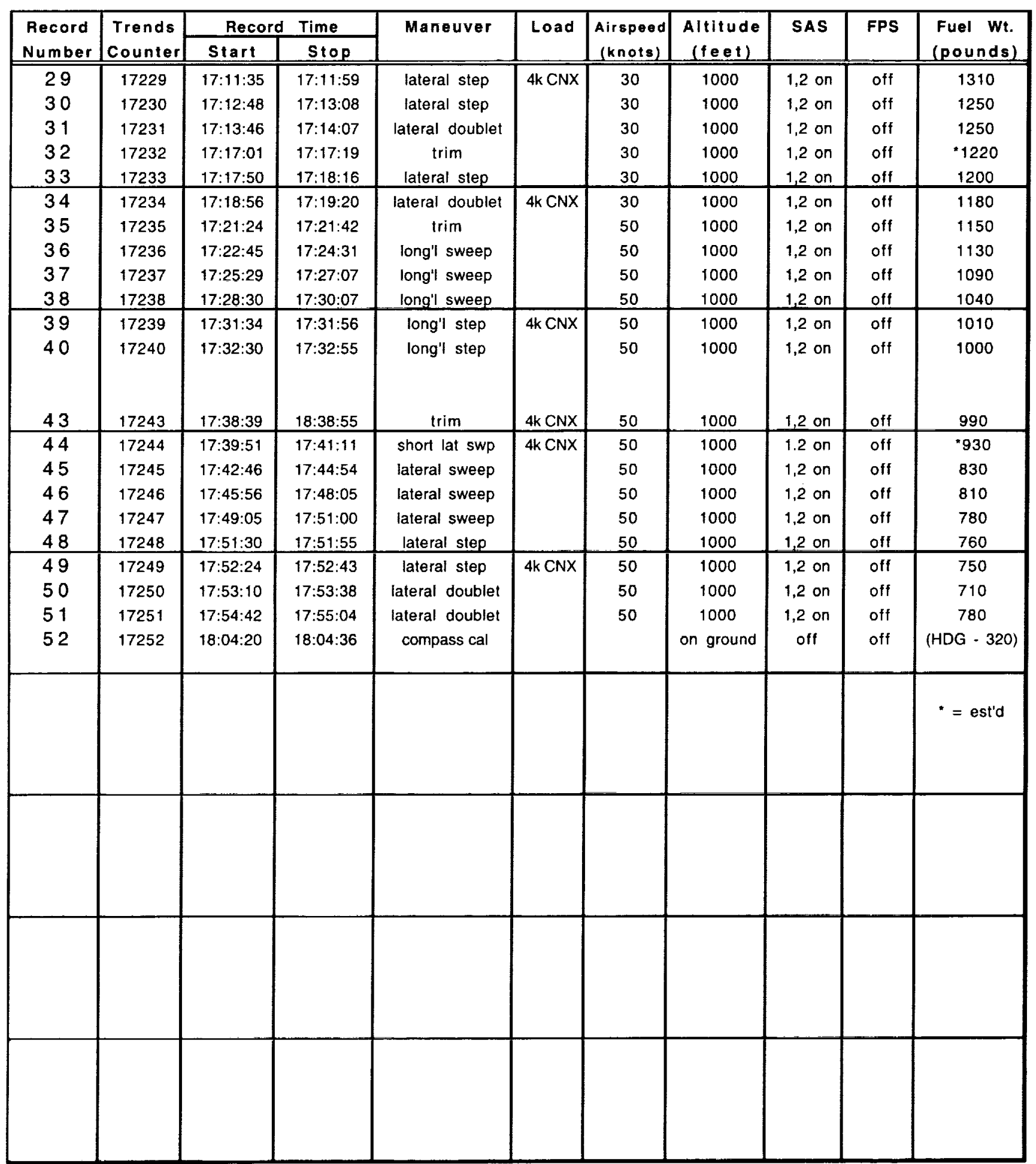




\section{TABLE 3. CATALOG OF DATA RECORDS BY FLIGHT (CONTINUED)}

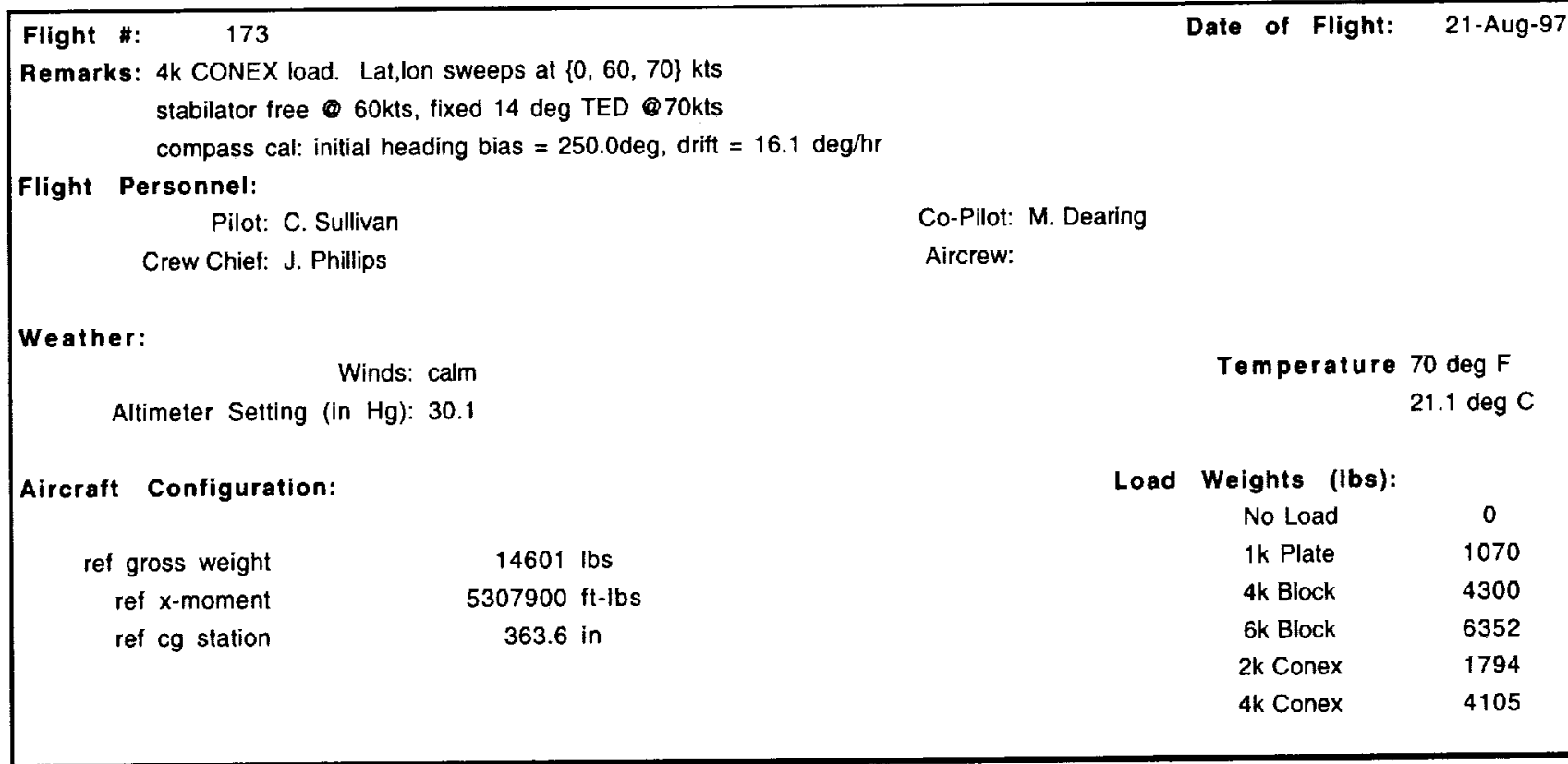

\section{Directory Name: TRENDS BSL Sample Rate: $100 \mathrm{~Hz}$}

\begin{tabular}{|c|c|c|c|c|c|c|c|c|c|c|}
\hline \multirow{2}{*}{$\begin{array}{l}\text { Record } \\
\text { Number }\end{array}$} & \multirow{2}{*}{$\begin{array}{l}\text { Trends } \\
\text { Counter }\end{array}$} & \multicolumn{2}{|c|}{ Record Time } & \multirow[t]{2}{*}{ Maneuver } & \multirow[t]{2}{*}{ Load } & \multirow{2}{*}{$\begin{array}{r}\text { Airspeed } \\
\text { (knots) } \\
\end{array}$} & \multirow{2}{*}{$\begin{array}{c}\text { Altitude } \\
\text { (feet) } \\
\end{array}$} & \multirow[t]{2}{*}{ SAS } & \multirow[t]{2}{*}{ FPS } & \multirow{2}{*}{$\begin{array}{l}\text { Fuel wt. } \\
\text { (pounds) }\end{array}$} \\
\hline & & Start & stop & & & & & & & \\
\hline 1 & 17301 & $16: 04: 30$ & $16: 04: 40$ & compass cal & & & on ground & off & off & $(H D G-045)$ \\
\hline 11 & 17311 & $16: 33: 10$ & $16: 33: 27$ & trim & $4 \mathrm{kCNX}$ & hover & 120 & 1,2 on & off & 2170 \\
\hline 12 & 17312 & $16: 34: 17$ & $16: 36: 01$ & long'l sweep & & hover & 120 & 1,2 on & off & $" 2140$ \\
\hline 13 & 17313 & $16: 36: 52$ & $16: 38: 39$ & long'l sweep & & hover & 120 & 1,2 on & off & 2070 \\
\hline 14 & 17314 & $16: 39: 40$ & $16: 41: 17$ & long'l sweep & $4 \mathrm{kCNX}$ & hover & 120 & 1,2 on & off & 2000 \\
\hline 15 & 17315 & $16: 46: 46$ & $16: 52: 44$ & accel to $80 \mathrm{kts}$ & & $0 \cdot 80$ & 1000 & 1,2 on & off & 1830 \\
\hline 16 & 17316 & $16: 54: 20$ & $16: 54: 40$ & trim & & 80 & 1000 & 1,2 on & off & ${ }^{*} 1790$ \\
\hline 17 & 17317 & $16: 57: 52$ & $16: 58: 08$ & trim & & 60 & 1000 & 1,2 on & off & 1760 \\
\hline 18 & 17318 & $16: 58: 37$ & $17: 00: 20$ & long'l sweep & & 60 & 1000 & 1,2 on & off & 1740 \\
\hline 19 & 17319 & 17:02:30 & $17: 04: 10$ & long'l sweep & $4 \mathrm{k} C N \mathrm{X}$ & 60 & 1000 & 1,2 on & off & 1680 \\
\hline 20 & 17320 & $17: 05: 46$ & $17: 07: 36$ & long'l sweep & & 60 & 1000 & 1,2 on & off & 1640 \\
\hline 21 & 17321 & $17: 12: 43$ & $17: 13: 04$ & Iong'I slep & & 60 & 1000 & 1,2 on & off & 1550 \\
\hline 22 & 17322 & $17: 13: 52$ & $17: 14: 15$ & long'l step & & 60 & 1000 & 1,2 on & off & 1530 \\
\hline 23 & 17323 & $17: 14: 54$ & $17: 15: 17$ & long'l doublet & & 60 & 1000 & 1,2 on & off & 1520 \\
\hline 24 & 17324 & $17: 15: 59$ & $17: 16: 24$ & long'l doublet & $4 \mathrm{k} C N X$ & 60 & 1000 & 1,2 on & off & 1510 \\
\hline 25 & 17325 & $17: 17: 25$ & $17: 17: 42$ & trim & & 60 & 1000 & 1,2 on & off & 1500 \\
\hline 26 & 17326 & $17: 20: 12$ & $17: 21: 56$ & lateral sweep & & 60 & 1000 & 1,2 on & off & 1440 \\
\hline 27 & 17327 & $17: 22: 48$ & $17: 24: 30$ & lateral sweep & & 60 & 1000 & 1,2 on & off & 1420 \\
\hline 28 & 17328 & $17: 26: 26$ & $17: 28: 13$ & lateral sweep & & 60 & 1000 & 1,2 on & off & 1360 \\
\hline
\end{tabular}


TABLE 3. CATALOG OF DATA RECORDS BY FLIGHT (CONTINUED)

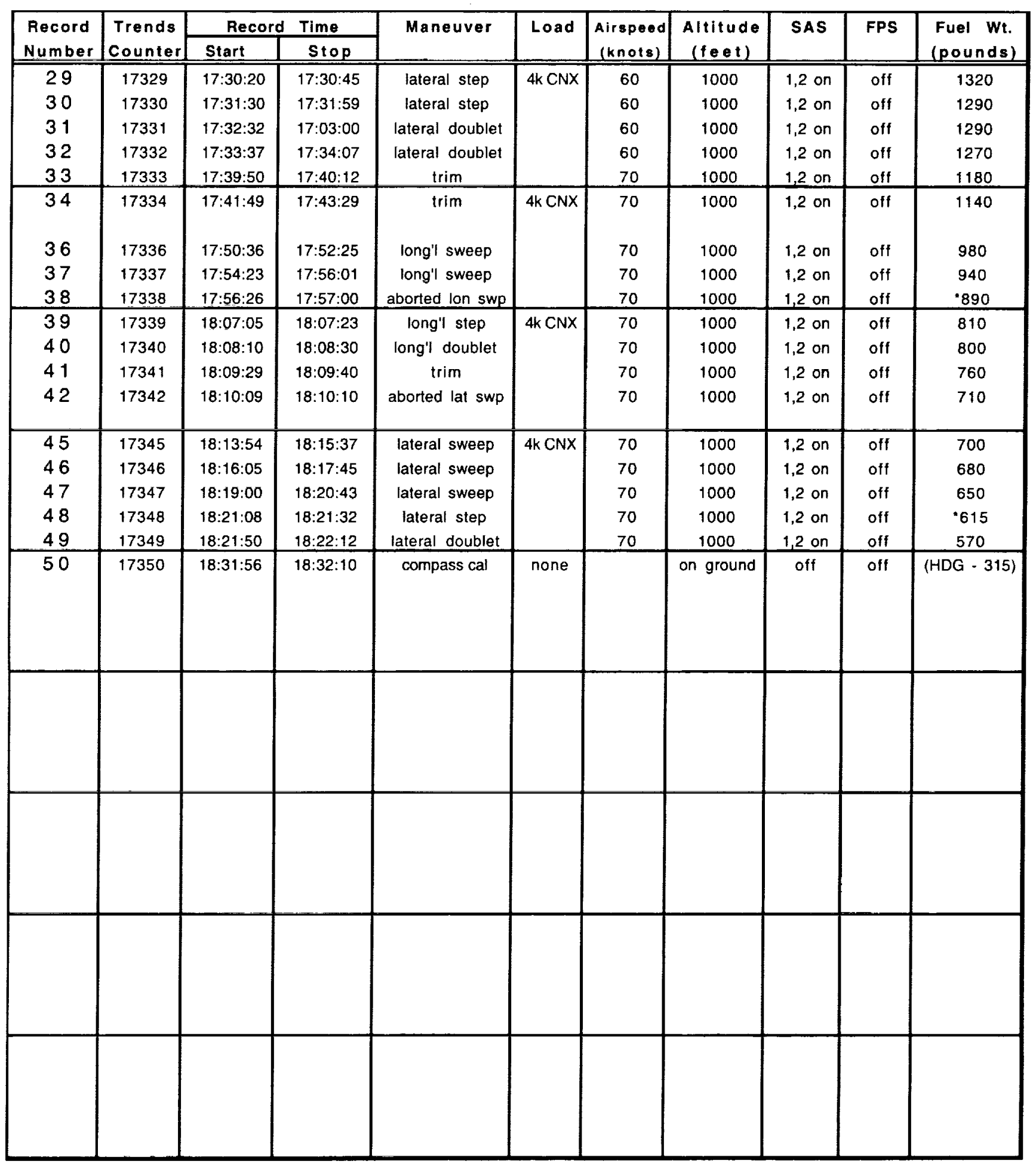




\section{TABLE 3. CATALOG OF DATA RECORDS BY FLIGHT (CONTINUED)}

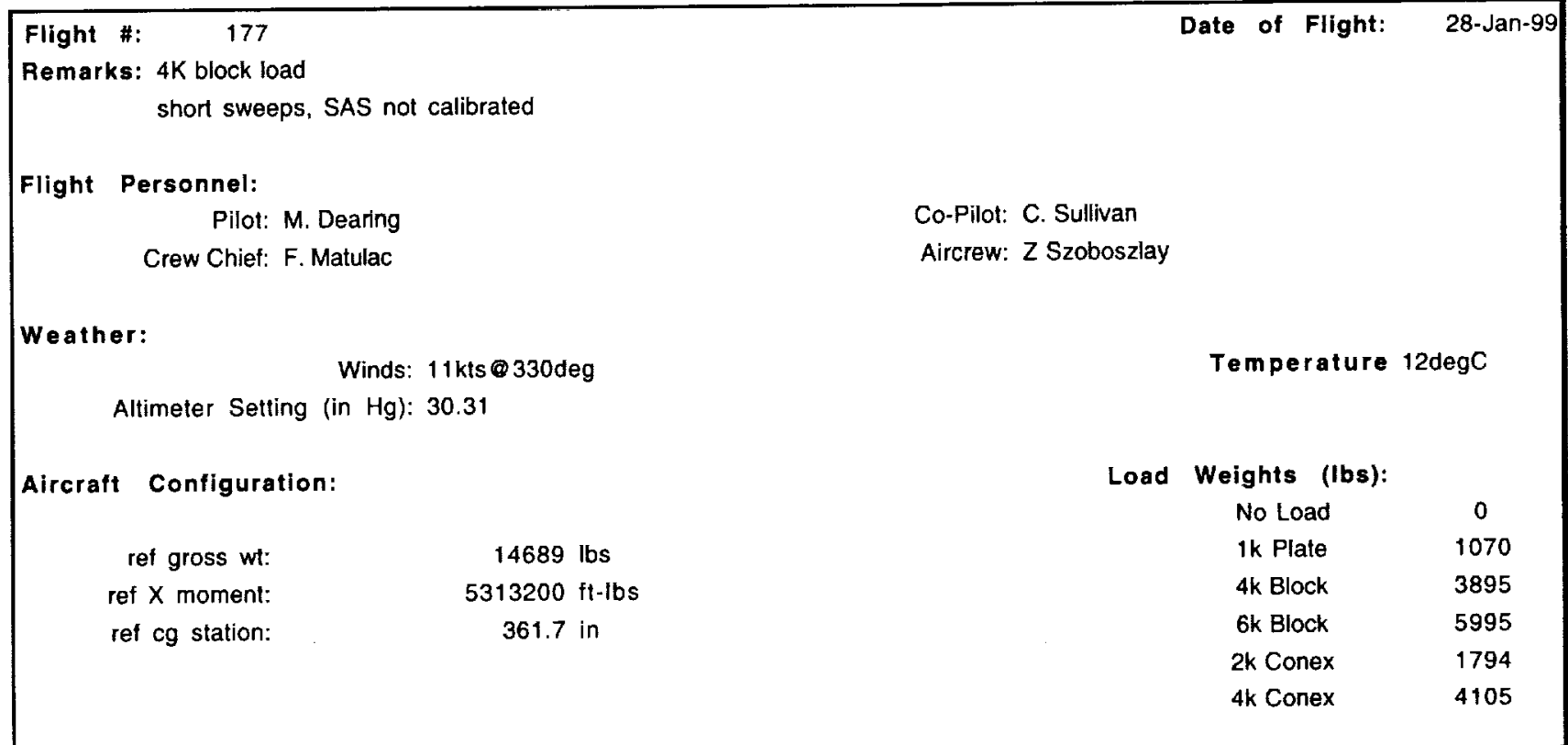

\section{Directory Name: TRENDSBSL Sample Rate: $100 \mathrm{~Hz}$}

\begin{tabular}{|c|c|c|c|c|c|c|c|c|c|c|}
\hline \multirow{2}{*}{$\begin{array}{l}\text { Record } \\
\text { Number }\end{array}$} & \multirow{2}{*}{$\begin{array}{l}\text { Trends } \\
\text { Counter }\end{array}$} & \multicolumn{2}{|c|}{ Record Time } & \multirow[t]{2}{*}{ Maneuver } & \multirow[t]{2}{*}{ Load } & \multirow{2}{*}{$\begin{array}{c}\text { Airspeed } \\
(k n o t s)\end{array}$} & \multirow{2}{*}{$\begin{array}{c}\text { Altitude } \\
\text { (feet) } \\
\end{array}$} & \multirow[t]{2}{*}{ SAS } & \multirow[t]{2}{*}{ FPS } & \multirow{2}{*}{$\begin{array}{l}\text { Fuel Wt. } \\
\text { (pounds) }\end{array}$} \\
\hline & & Start & Stop & & & & & & & \\
\hline 2 & 17702 & $22: 40: 38$ & $22: 41: 39$ & trim & $4 \mathrm{~K}$ block & hvr & OEE & on & off & 1550 \\
\hline 3 & 17703 & $22: 47: 36$ & $22: 48: 59$ & long'l sweep & & hvr & OEE & on & off & 1430 \\
\hline 4 & 17704 & $22: 59: 38$ & $23: 00: 56$ & long'l sweep & & hvr & OEE & on & off & 1260 \\
\hline 5 & 17705 & $23: 01: 53$ & $23: 03: 12$ & long'l sweep & & hvr & 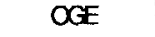 & on & off & 1220 \\
\hline 6 & 17706 & 23:04:09 & 23:04:23 & long'l doublet & & hvr & OEE & on & off & 1180 \\
\hline 7 & 17707 & $23: 05: 26$ & $23: 05: 55$ & long'| doublet & $4 \mathrm{~K}$ block & hvr & OGE & on & off & 1150 \\
\hline 8 & 17708 & $23: 06: 32$ & 23:08:04 & lateral sweep & & hvr & OGE & on & off & 1130 \\
\hline 9 & 17709 & $23: 09: 33$ & $23: 11: 09$ & lateral sweep & & hvr & OCE & on & off & 1080 \\
\hline 10 & 17710 & $23: 12: 16$ & $23: 13: 45$ & lateral sweep & & hvr & OGE & on & off & 1020 \\
\hline 11 & 17711 & $23: 14: 37$ & $23: 14: 58$ & laleral doublet & & hvr & $\alpha a$ & on & off & 990 \\
\hline 12 & 17712 & $23: 15: 31$ & $23: 16: 03$ & lateral doublet & $4 \mathrm{~K}$ block & hvr & OCE & on & off & 970 \\
\hline 14 & 17714 & $23: 18: 03$ & $23: 18: 37$ & coll doublet & & hvr & OCE & on & off & 930 \\
\hline 15 & 17715 & $23: 23: 52$ & $23: 24: 32$ & Irim & & $30 \mathrm{kts}$ & 1000 & on & off & 830 \\
\hline 16 & 17716 & 23:26:09 & $23: 27: 46$ & long'l sweep & & $30 \mathrm{kts}$ & 1000 & on & off & 810 \\
\hline 17 & 17717 & $23: 29: 01$ & $23: 30: 42$ & long'l sweep & $4 \mathrm{~K}$ block & $30 \mathrm{kts}$ & 1000 & on & off & 770 \\
\hline
\end{tabular}




\section{TABLE 3. CATALOG OF DATA RECORDS BY FLIGHT (CONTINUED)}

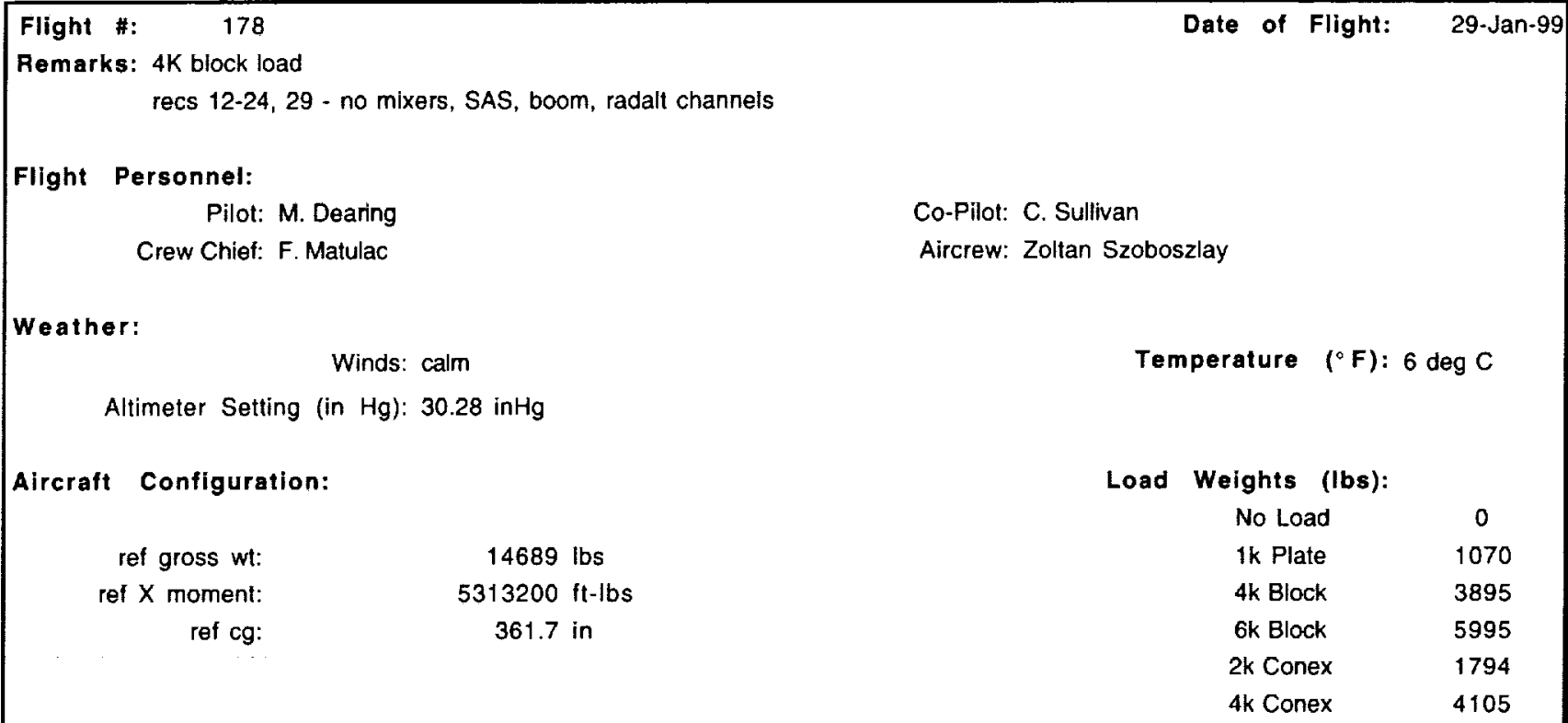

\begin{tabular}{|c|c|c|c|c|c|c|c|c|c|c|}
\hline \multirow{2}{*}{$\begin{array}{l}\text { Record } \\
\text { Number }\end{array}$} & \multirow{2}{*}{$\begin{array}{l}\text { Trends } \\
\text { Counter }\end{array}$} & \multicolumn{2}{|c|}{ Record Time } & \multirow[t]{2}{*}{ Maneuver } & \multirow[t]{2}{*}{ Load } & \multirow{2}{*}{$\begin{array}{c}\text { Airspeed } \\
\text { (knots) }\end{array}$} & \multirow{2}{*}{$\begin{array}{c}\text { Altitude } \\
\text { (feet) }\end{array}$} & \multirow[t]{2}{*}{ SAS } & \multirow[t]{2}{*}{ FPS } & \multirow{2}{*}{$\begin{array}{l}\text { Fuel Wt. } \\
\text { (pounds) }\end{array}$} \\
\hline & & Start & Stop & & & & & & & \\
\hline 1 & 17801 & $10: 13: 48$ & $10 ; 15: 34$ & Ion sweep & $4 \mathrm{~K}$ block & 30 & 1000 & on & off & 2190 \\
\hline 2 & 17802 & $10: 17: 17$ & $10: 17: 46$ & Ion doublet & $4 \mathrm{~K}$ block & 30 & 1000 & on & off & 2140 \\
\hline 4 & 17804 & $10: 20: 11$ & $10: 20: 41$ & Ion doublet & $4 \mathrm{~K}$ block & 30 & 1000 & on & off & $* 2100$ \\
\hline 5 & 17805 & $10: 21: 24$ & 10:23:03 & lat swp (shrt) & 4K block & 30 & 1000 & on & off & 2080 \\
\hline 7 & 17807 & $10: 27: 03$ & $10: 29: 26$ & lat sweep & $4 \mathrm{~K}$ block & 30 & 1000 & on & off & 2010 \\
\hline 8 & 17808 & $10: 30: 55$ & $10: 32: 46$ & lat sweep & $4 \mathrm{~K}$ block & 30 & 1000 & on & off & 1970 \\
\hline 9 & 17809 & $10: 33: 35$ & $10: 34: 05$ & lat doublet & $4 \mathrm{~K}$ block & 30 & 1000 & on & off & 1920 \\
\hline 10 & 17810 & $10: 34: 46$ & $10: 35: 14$ & lat doublet & $4 \mathrm{~K}$ block & 30 & 1000 & on & off & 1900 \\
\hline 11 & 17811 & $10: 36: 24$ & $10: 36: 56$ & coll doublet & $4 K$ block & 30 & 1000 & on & off & 1880 \\
\hline 12 & 17812 & $10: 37: 31$ & $10: 38: 03$ & coll doublet & $4 \mathrm{~K}$ block & 30 & 1000 & on & off & 1860 \\
\hline 13 & 17813 & $10: 39: 18$ & $10: 39: 57$ & trim & $4 \mathrm{~K}$ block & 50 & 1000 & on & off & 1830 \\
\hline 14 & 17814 & $10: 41: 08$ & $10: 42: 41$ & Ion sweep & $4 \mathrm{~K}$ block & 50 & 1000 & on & off & 1820 \\
\hline 15 & 17815 & $10: 44: 40$ & 10:46:16 & Ion sweep & $4 \mathrm{~K}$ block & 50 & 1000 & on & off & 1770 \\
\hline 16 & 17816 & $10: 47: 47$ & $10: 49: 20$ & Ion sweep & $4 \mathrm{~K}$ block & 50 & 1000 & on & off & 1730 \\
\hline 17 & 17817 & $10: 51: 38$ & $10: 52: 08$ & Ion doublet & $4 \mathrm{~K}$ block & 50 & 1000 & on & off & 1680 \\
\hline 19 & 17819 & $11: 03: 20$ & 11:03:55 & Ion doublet & $4 \mathrm{~K}$ block & 50 & 1000 & on & off & 1520 \\
\hline 20 & 17820 & $11: 04: 26$ & $11: 06: 11$ & lat sweep & $4 \mathrm{~K}$ block & 50 & 1000 & on & off & 1510 \\
\hline
\end{tabular}


TABLE 3. CATALOG OF DATA RECORDS BY FLIGHT (CONTINUED)

\begin{tabular}{|c|c|c|c|c|c|c|c|c|c|c|}
\hline \multirow{2}{*}{$\begin{array}{c}\text { Record } \\
\text { Number }\end{array}$} & \multirow[t]{2}{*}{ Filename } & \multicolumn{2}{|c|}{ Record TIme } & \multirow[t]{2}{*}{ Maneuver } & \multirow[t]{2}{*}{ Load } & \multirow{2}{*}{$\begin{array}{l}\text { Airspeed } \\
\text { (knots) }\end{array}$} & \multirow{2}{*}{$\begin{array}{c}\text { Altitude } \\
\text { (feet) } \\
\end{array}$} & \multirow[t]{2}{*}{ SAS } & \multirow[t]{2}{*}{ FPS } & \multirow{2}{*}{$\begin{array}{l}\text { Fuel Wt. } \\
\text { (pounds) }\end{array}$} \\
\hline & & Start & Stop & & & & & & & \\
\hline 21 & 17821 & $11: 07: 46$ & $11: 09: 23$ & lat sweep & $4 \mathrm{k}$ block & 50 & 1000 & on & off & 1480 \\
\hline 22 & 17822 & $11: 11: 17$ & 11:12:31 & aborted sweep & $4 \mathrm{k} \mathrm{block}$ & 50 & 1000 & on & off & 1430 \\
\hline 24 & 17824 & 11:17:13 & 11:19:31 & lat sweep & 4k block & 50 & 1000 & on & off & $• 1355$ \\
\hline 25 & 17825 & 11:22:06 & 11:24:20 & lat sweep & $4 \mathrm{k}$ block & 50 & 1000 & on & off & 1290 \\
\hline 26 & 17826 & $11: 24: 47$ & $11: 25: 32$ & lat doublet & $4 \mathrm{k}$ block & 50 & 1000 & on & off & 1280 \\
\hline 27 & 17827 & $11: 26: 01$ & $11: 36: 41$ & lat doublet & $4 \mathrm{k}$ block & 50 & 1000 & on & off & 1240 \\
\hline 28 & 17828 & $11: 33: 41$ & $11: 35: 51$ & Ion sweep & 4k block & hover & $œ$ & on & off & 1140 \\
\hline 29 & 17829 & $11: 36: 20$ & $11: 37: 50$ & Ion sweep & $4 \mathrm{k}$ block & hover & OE & on & off & 1100 \\
\hline 31 & 17831 & $11: 39: 27$ & $11: 41: 12$ & lon sweep & $4 \mathrm{k}$ block & hover & OCE & on & off & 1020 \\
\hline & & & & & & & & & & * = est'd \\
\hline & & & & & & & & & & \\
\hline & & & & & & & & & & \\
\hline & & & & & & & & & & \\
\hline & & & & & & & & & & \\
\hline & & & & & & & & & & \\
\hline & & & & & & & & & & \\
\hline & & & & & & & & & & \\
\hline & & & & & & & & & & \\
\hline & & & & & & & & & & \\
\hline & & & & & & & & & & \\
\hline & & & & & & & & & & \\
\hline & & & & & & & & & & \\
\hline & & & & & & & & & & \\
\hline & & & & & & & & & & \\
\hline & & & & & & & & & & \\
\hline
\end{tabular}




\section{TABLE 3. CATALOG OF DATA RECORDS BY FLIGHT (CONTINUED)}

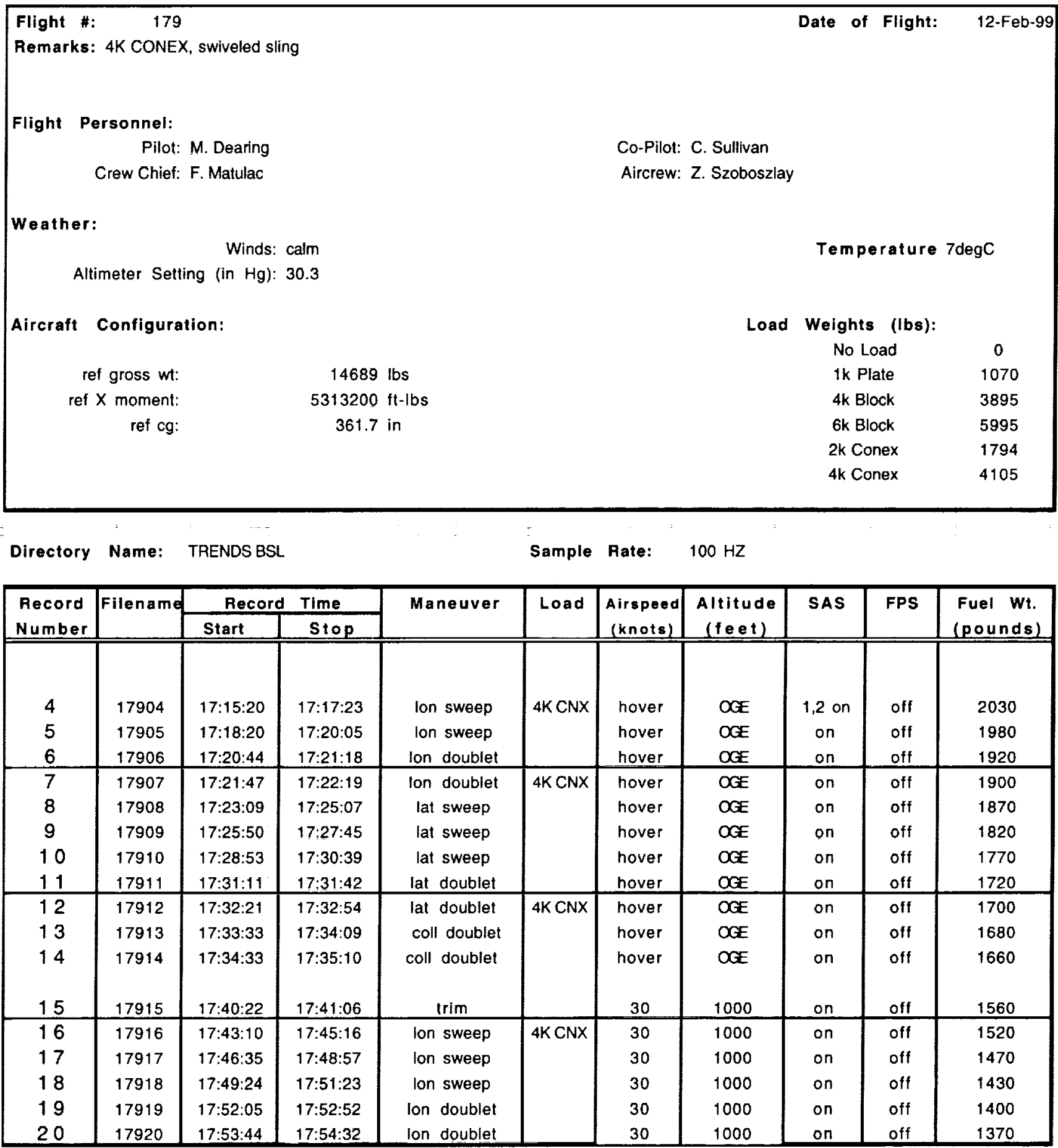


TABLE 3. CATALOG OF DATA RECORDS BY FLIGHT (CONTINUED)

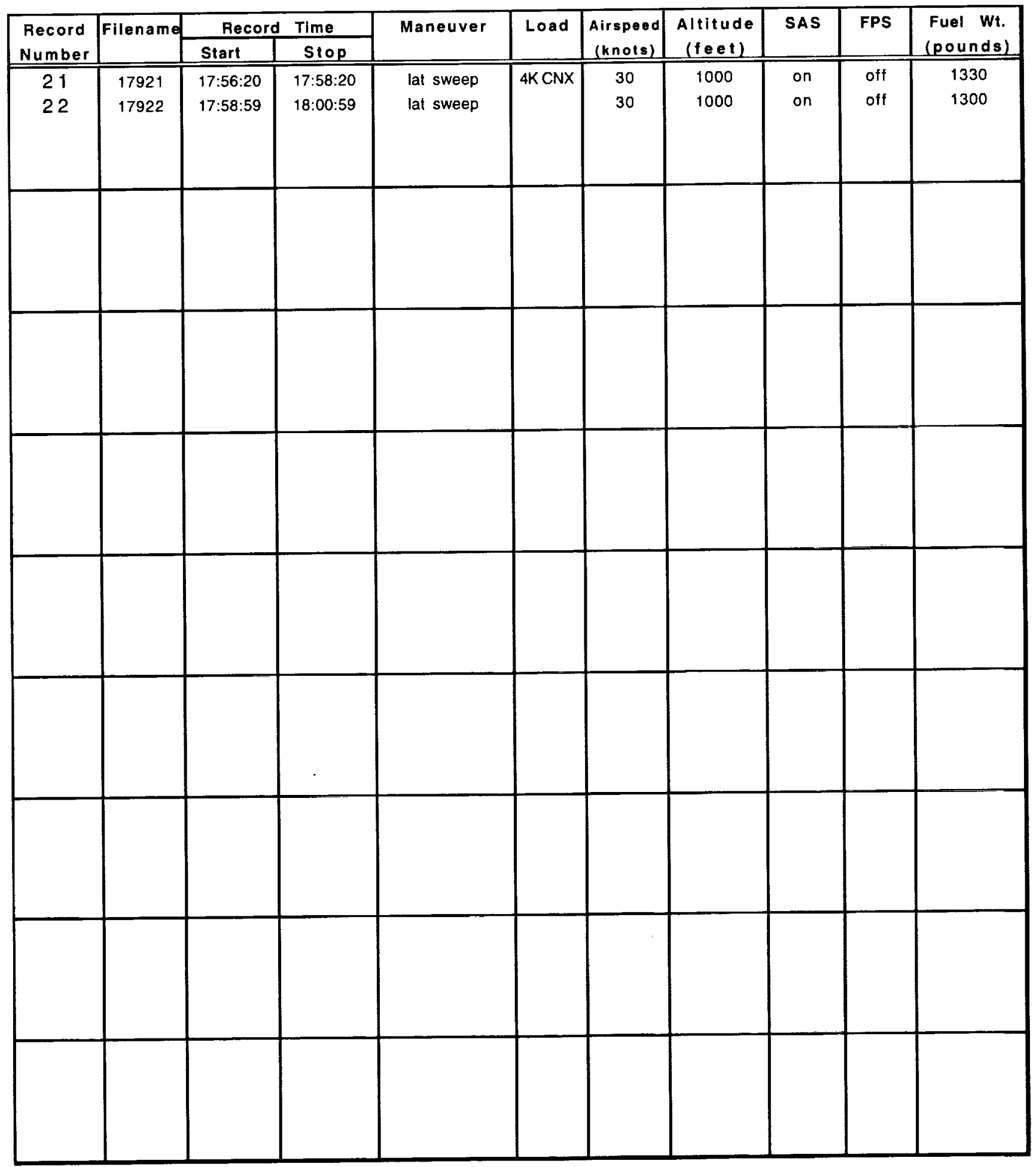




\section{TABLE 3. CATALOG OF DATA RECORDS BY FLIGHT (CONTINUED)}

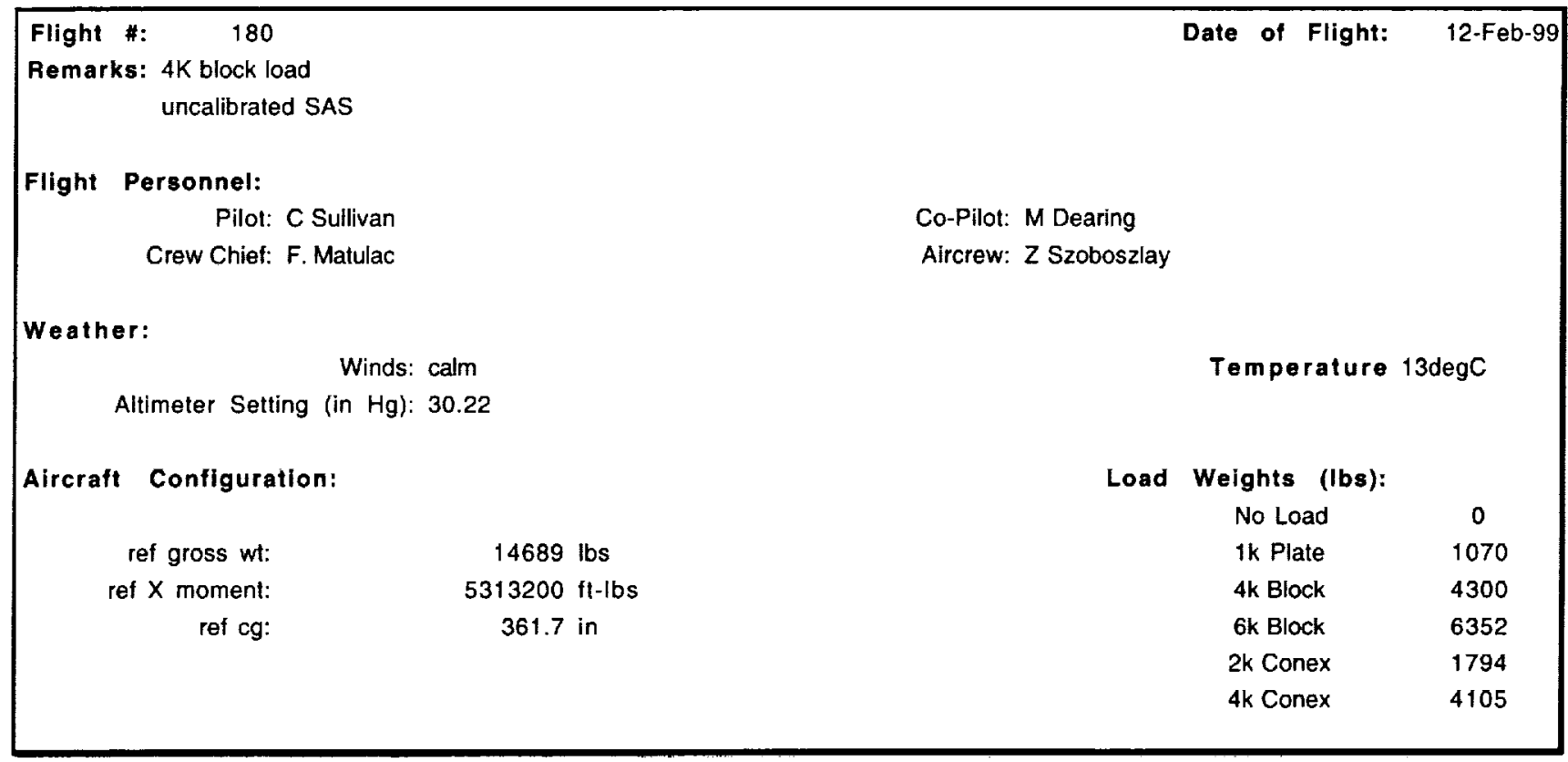

Directory Name: TRENDS BSL Sample Rate: $100 \mathrm{~Hz}$

\begin{tabular}{|c|c|c|c|c|c|c|c|c|c|c|}
\hline \multirow{2}{*}{$\begin{array}{l}\text { Record } \\
\text { Number }\end{array}$} & \multirow{2}{*}{$\begin{array}{l}\text { Trends } \\
\text { Counter }\end{array}$} & \multicolumn{2}{|c|}{ Record Time } & \multirow[t]{2}{*}{ Maneuver } & \multirow[t]{2}{*}{ Load } & \multirow{2}{*}{$\begin{array}{c}\text { Airspeed } \\
\text { (knots) }\end{array}$} & \multirow{2}{*}{$\begin{array}{c}\text { Altitude } \\
\text { (feet) }\end{array}$} & \multirow[t]{2}{*}{ SAS } & \multirow[t]{2}{*}{ FPS } & \multirow{2}{*}{$\begin{array}{l}\text { Fuel Wt. } \\
\text { (pounds) }\end{array}$} \\
\hline & & Start & Stop & & & & & & & \\
\hline 2 & 18001 & $21: 36: 57$ & $21: 37: 37$ & trim & $4 \mathrm{~K}$ block & hover & OGE & 1,2 on & off & 2230 \\
\hline 3 & 18002 & $21: 37: 53$ & $21: 39: 55$ & Ion swp (short) & $4 \mathrm{~K}$ block & hover & OGE & 1,2 on & off & 2200 \\
\hline 4 & 18003 & $21: 40: 26$ & $21: 42: 33$ & Ion sweep & $4 \mathrm{~K}$ biock & hover & OGE & 1,2 on & off & 2160 \\
\hline 6 & 18006 & $21: 44: 35$ & $21: 46: 49$ & Ion sweep & $4 \mathrm{~K}$ block & hover & $O G$ & 1,2 on & off & 2090 \\
\hline 7 & 18007 & $21: 47: 23$ & $21: 47: 47$ & Ion doublet & $4 \mathrm{~K}$ block & hover & OGE & $1,20 n$ & off & 2031 \\
\hline 8 & 18008 & 21:48:09 & $21: 48: 42$ & Ion doublet & $4 \mathrm{~K}$ block & hover & OCE & $1,20 n$ & off & 2010 \\
\hline 9 & 18009 & $21: 49: 05$ & $21: 49: 30$ & Ion doublet & $4 \mathrm{~K}$ block & hover & $\alpha \mathbf{E}$ & $1,20 n$ & off & 1990 \\
\hline 10 & 18010 & $21: 54: 40$ & $21: 57: 01$ & Ion sweep & $4 \mathrm{~K}$ block & 50 & 1000 & $1,20 n$ & off & 1900 \\
\hline 11 & 18011 & $21: 57: 48$ & $21: 59: 48$ & Ion sweep & $4 \mathrm{~K}$ block & 50 & 1000 & 1,2 on & off & $\cdot 1850$ \\
\hline 12 & 18012 & $22: 01: 00$ & $22: 05: 59$ & Ion sweep & $4 \mathrm{~K}$ block & 50 & 1000 & 1,2 on & off & 1820 \\
\hline 13 & 18013 & $22: 03: 16$ & $22: 05: 16$ & Ion sweep & $4 \mathrm{~K}$ block & 50 & 1000 & 1,2 on & off & 1780 \\
\hline 14 & 18014 & $22: 05: 47$ & $22: 06: 18$ & Ion doublet & $4 \mathrm{~K}$ block & 50 & 1000 & 1,2 on & off & 1750 \\
\hline 15 & 18015 & $22: 06: 40$ & $22: 07: 14$ & Ion doublet & $4 \mathrm{~K}$ block & 50 & 1000 & 1,2 on & off & 1740 \\
\hline 16 & 18016 & $22: 08: 57$ & $22: 11: 05$ & lat sweep & $4 \mathrm{~K}$ block & 50 & 1000 & 1,2 on & off & 1720 \\
\hline 17 & 18017 & $22: 12: 59$ & $22: 14: 50$ & lat sweep & $4 \mathrm{~K}$ block & 50 & 1000 & $1,20 n$ & off & 1660 \\
\hline 18 & 18018 & $22: 15: 19$ & $22: 17: 20$ & lat sweep & $4 \mathrm{~K}$ block & 50 & 1000 & 1,2 on & off & 1630 \\
\hline 19 & 18019 & $22: 18: 36$ & $22: 19: 05$ & lat doublet & $4 \mathrm{~K}$ block & 50 & 1000 & $1,20 n$ & off & 1600 \\
\hline 20 & 18020 & $22: 19: 31$ & $22: 20: 07$ & lat doublet & $4 \mathrm{~K}$ block & 50 & 1000 & $1,20 n$ & off & 1580 \\
\hline
\end{tabular}


TABLE 3. CATALOG OF DATA RECORDS BY FLIGHT (CONTINUED)

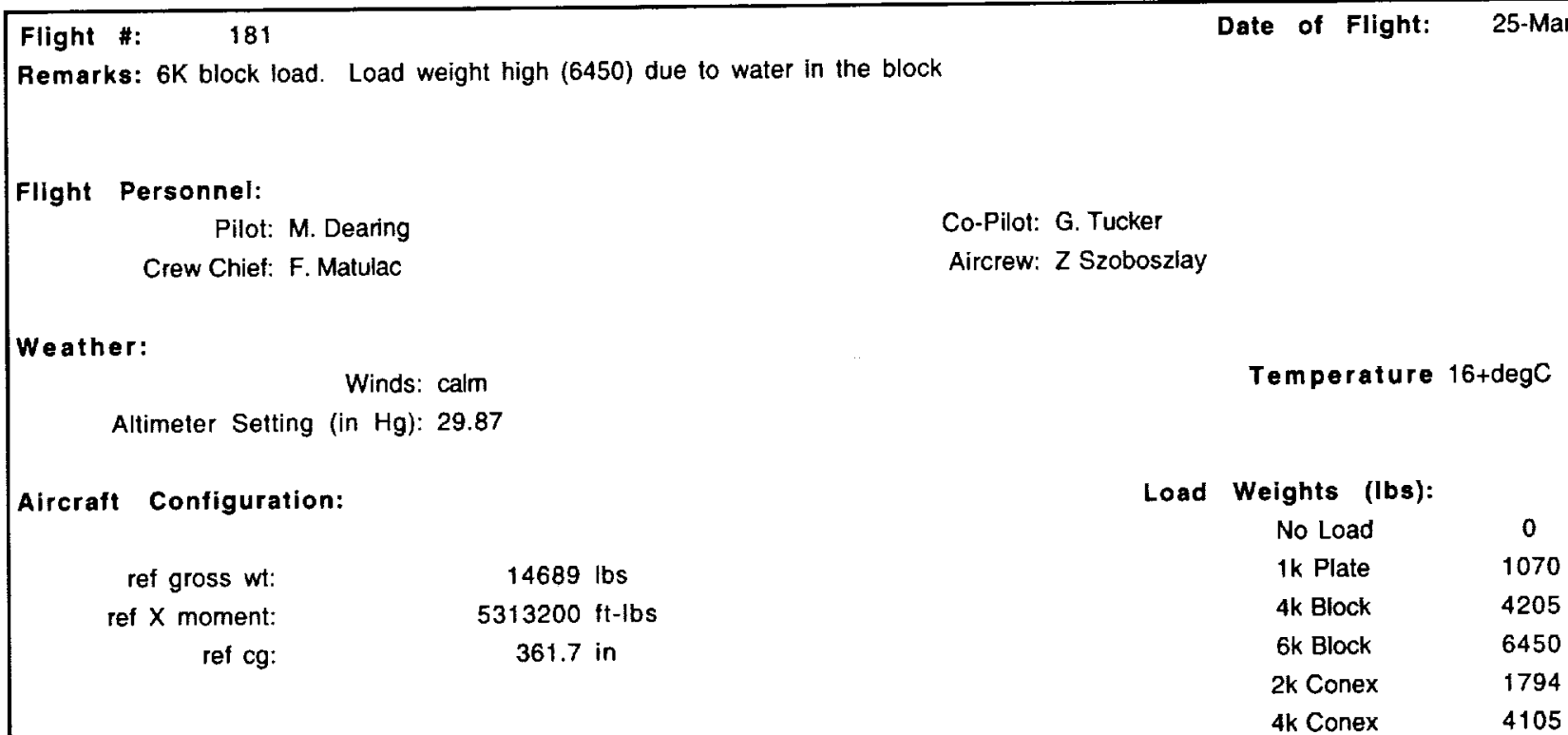

ref gross wt:

ref $X$ moment:

ref $\mathrm{cg}$ :

14689 lbs

$5313200 \mathrm{ft}-\mathrm{lbs}$

361.7 in

Load Weights (Ibs):

No Load

1k Plate $\quad 1070$

4k Block $\quad 4205$

6k Block 6450

2k Conex 1794

4k Conex $\quad 4105$

Directory Name: TRENDSBSL Sample Rate: $100 \mathrm{~Hz}$

\begin{tabular}{|c|c|c|c|c|c|c|c|c|c|c|}
\hline \multirow{2}{*}{$\begin{array}{l}\text { Record } \\
\text { Number }\end{array}$} & \multirow{2}{*}{$\begin{array}{l}\text { Trends } \\
\text { Counter }\end{array}$} & \multicolumn{2}{|c|}{ Record Time } & \multirow[t]{2}{*}{ Maneuver } & \multirow[t]{2}{*}{ Load } & \multirow{2}{*}{$\begin{array}{c}\text { Airspeed } \\
\text { (knots) }\end{array}$} & \multirow{2}{*}{$\begin{array}{c}\text { Altitude } \\
\text { (feet) }\end{array}$} & \multirow[t]{2}{*}{ SAS } & \multirow[t]{2}{*}{ FPS } & \multirow{2}{*}{$\begin{array}{l}\text { Fuel Wt. } \\
\text { (pounds) }\end{array}$} \\
\hline & & Start & Stop & & & & & & & \\
\hline 1 & 18101 & $17: 56: 45$ & $17: 58: 18$ & trim & $6 \mathrm{~K}$ block & hover & OEE & on & off & 960 \\
\hline 2 & 18102 & $17: 59: 44$ & $18: 01: 44$ & long'l sweep & & hover & OE & on & off & 880 \\
\hline 3 & 18103 & 18:02:39 & $18: 04: 33$ & long'l sweep & & hover & OGE & on & off & 830 \\
\hline 4 & 18104 & $18: 05: 23$ & $18: 07: 16$ & long'l sweep & & hover & œE & on & off & 760 \\
\hline 5 & 18105 & $18: 08: 23$ & 18:09:10 & long'I doublet & & hover & OEE & on & off & 710 \\
\hline 6 & 18106 & $18: 10: 10$ & $18: 10: 41$ & long'l doublet & $6 \mathrm{~K}$ block & hover & OGE & on & off & 670 \\
\hline 7 & 18107 & $18: 11: 39$ & $18: 13: 15$ & lateral sweep & & hover & OCE & on & off & 630 \\
\hline 8 & 18108 & $18: 14: 04$ & $18: 16: 13$ & lateral sweep & & hover & OGE & on & off & 620 \\
\hline 9 & 18109 & $18: 17: 10$ & $18: 19: 12$ & lateral sweep & & hover & OCE & on & off & 550 \\
\hline 10 & 18110 & 18:20:08 & 18:21:00 & lateral doublet & & hover & OGE & on & off & 480 \\
\hline 11 & 18111 & $18: 21: 28$ & $18: 21: 59$ & lateral doublet & $6 \mathrm{~K}$ block & hover & OGE & on & off & 470 \\
\hline 12 & 118112 & 19.24 .41 & $19 \cdot 25: 11$ & trim & & 30 & 1000 & on & off & 1370 \\
\hline 13 & 18113 & $19: 27: 12$ & $19: 29: 11$ & long'l sweep & & 30 & 1000 & on & off & 1330 \\
\hline 14 & 18114 & $19: 30: 57$ & $19: 32: 32$ & long'l sweep & & 30 & 1000 & on & off & 1250 \\
\hline 15 & 18115 & $19: 33: 59$ & $19: 35: 31$ & long'l sweep & $6 \mathrm{~K}$ block & 30 & 1000 & on & off & 1230 \\
\hline 16 & 18116 & $19: 36: 30$ & $19: 37: 10$ & long'l doublet & & 30 & 1000 & on & off & 1200 \\
\hline 17 & 18117 & $19: 37: 35$ & $19: 38: 08$ & long'l doublet & & 30 & 1000 & on & off & 1180 \\
\hline 18 & 18118 & $19: 39: 17$ & $19: 40: 59$ & lateral sweep & & 30 & 1000 & on & off & 1160 \\
\hline 19 & 18119 & $19: 41: 29$ & $19: 43: 05$ & lateral sweep & & 30 & 1000 & on & off & 1130 \\
\hline
\end{tabular}


TABLE 3. CATALOG OF DATA RECORDS BY FLIGHT (CONTINUED)

\begin{tabular}{|c|c|c|c|c|c|c|c|c|c|c|}
\hline \multirow{2}{*}{$\begin{array}{l}\text { Record } \\
\text { Number }\end{array}$} & \multirow{2}{*}{\begin{tabular}{c|} 
Trends \\
Counter
\end{tabular}} & \multicolumn{2}{|c|}{ Record Time } & \multirow[t]{2}{*}{ Maneuver } & \multirow[t]{2}{*}{ Load } & \multirow{2}{*}{\begin{tabular}{|c|} 
Airspeed \\
(knots)
\end{tabular}} & \multirow{2}{*}{$\begin{array}{c}\text { Altitude } \\
\text { (feet) }\end{array}$} & \multirow[t]{2}{*}{ SAS } & \multirow[t]{2}{*}{ FPS } & \multirow{2}{*}{$\begin{array}{l}\text { Fuel Wt. } \\
\text { (pounds) }\end{array}$} \\
\hline & & Start & Stop & & & & & & & \\
\hline 20 & 18120 & $19: 44: 38$ & $19: 46: 17$ & lateral sweep & 6K block & 30 & 1000 & on & off & 1090 \\
\hline 21 & 18121 & $19: 48: 23$ & 19:49:00 & lateral doublet & & 30 & 1000 & on & off & 1030 \\
\hline 22 & 18122 & 19:49:32 & 19:50:03 & lateral doublet & & 30 & 1000 & on & off & 1020 \\
\hline 23 & 18123 & $19: 51: 16$ & $19: 51: 45$ & trim & & 50 & 1000 & on & off & 990 \\
\hline 24 & 18124 & 19:52:15 & $19: 53: 43$ & long'l sweep & $6 \mathrm{~K}$ block & 50 & 1000 & on & off & 980 \\
\hline 25 & 18125 & 19:55:26 & $19: 57: 08$ & long'l sweep & & 50 & 1000 & on & off & 940 \\
\hline 26 & 18126 & 19:58:07 & 19:59:38 & long'l sweep & & 50 & 1000 & on & off & 890 \\
\hline 27 & 18127 & 20:00:15 & $20: 00: 50$ & long'l doublet & & 50 & 1000 & on & off & 870 \\
\hline 28 & 18128 & $20: 01: 22$ & $20: 01: 51$ & long'l doublet & & 50 & 1000 & on & off & 850 \\
\hline 29 & 18129 & 20:04:01 & $20: 05: 45$ & lateral sweep & 6K block & 50 & 1000 & on & off & 820 \\
\hline 30 & 18130 & 20:07:20 & 20:09:09 & lateral sweep & & 50 & 1000 & on & off & 770 \\
\hline & & & & & & & & & & \\
\hline & & & & & & & & & & \\
\hline & & & & & & & & & & \\
\hline & & & & & & & & & & \\
\hline & & & & & & & & & & \\
\hline & & & & & & & & & & \\
\hline & & & & & & & & & & \\
\hline & & & & & & & & & & \\
\hline & & & & & & & & & & \\
\hline & & & & & & & & & & \\
\hline & & & & & & & & & & \\
\hline & & & & & & & & & & \\
\hline & & & & & & & & & & \\
\hline & & & & & & & & & & \\
\hline & & & & & & & & & & \\
\hline & & & & & & & & & & \\
\hline
\end{tabular}




\section{TABLE 3. CATALOG OF DATA RECORDS BY FLIGHT (CONTINUED)}

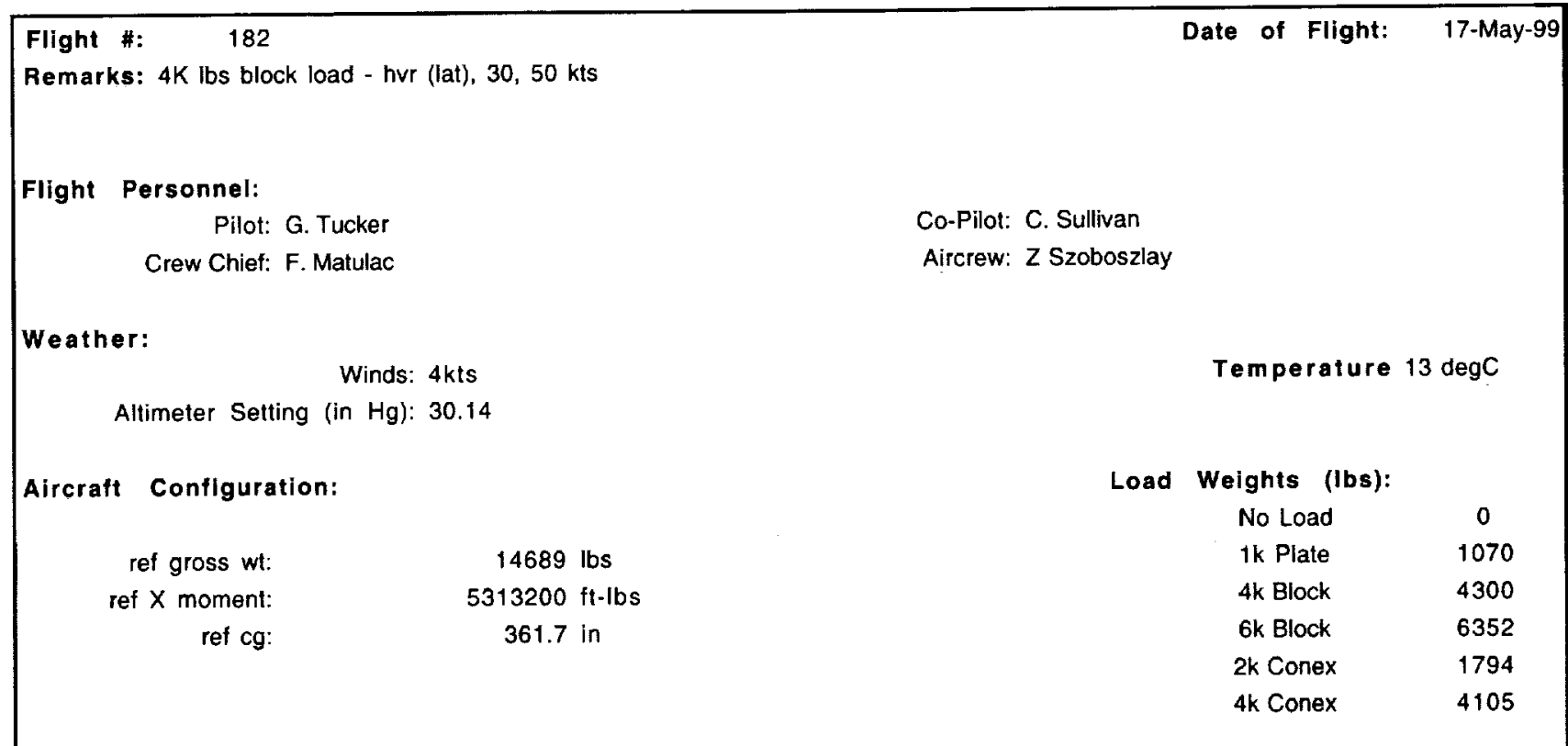

Directory Name: TRENDSBSL Sample Rate: $100 \mathrm{~Hz}$

\begin{tabular}{|c|c|c|c|c|c|c|c|c|c|c|}
\hline \multirow{2}{*}{$\begin{array}{l}\text { Record } \\
\text { Number }\end{array}$} & \multirow{2}{*}{$\begin{array}{l}\text { Trends } \\
\text { Counter } \\
\end{array}$} & \multicolumn{2}{|c|}{ Record Tims } & \multirow[t]{2}{*}{ Maneuver } & \multirow[t]{2}{*}{ Load } & \multirow{2}{*}{$\begin{array}{c}\text { Airspeed } \\
\text { (knots) }\end{array}$} & \multirow{2}{*}{$\begin{array}{c}\text { Altitude } \\
\text { (teet) }\end{array}$} & \multirow[t]{2}{*}{ SAS } & \multirow[t]{2}{*}{ FPS } & \multirow{2}{*}{$\begin{array}{l}\text { Fuel Wt. } \\
\text { (pounds) }\end{array}$} \\
\hline & & Start & Stop & & & & & & & \\
\hline 1 & 18201 & $16: 32: 08$ & $16: 32: 37$ & trim & $4 \mathrm{~K}$ block & hover & OGE & on & off & 2100 \\
\hline 2 & 18202 & $16: 33: 21$ & $16: 35: 36$ & lateral sweep & & hover & OGE & on & off & 2080 \\
\hline 3 & 18203 & $16: 36: 00$ & $16: 37: 38$ & lateral sweep & & hover & OGE & on & off & 2020 \\
\hline 4 & 18204 & $16: 38: 11$ & $: 16: 39: 50$ & lateral sweep & & hover & OGE & on & off & 1980 \\
\hline 5 & 18205 & $16: 40: 28$ & $16: 42: 14$ & lateral sweep & & hover & OGE & on & off & 1930 \\
\hline 6 & 18206 & $16: 42: 40$ & $16: 43: 13$ & lateral doublet & $4 \mathrm{~K}$ block & hover & OGE & on & off & 1890 \\
\hline 7 & 18207 & $16: 43: 31$ & $16: 44: 00$ & lateral doublet & & hover & OGE & on & off & 1830 \\
\hline 8 & 18208 & $16: 48: 28$ & $16: 48: 53$ & trim & & 80 & 1000 & on & off & 1800 \\
\hline 9 & 18209 & $16: 49: 51$ & $16: 51: 52$ & lateral sweep & & 80 & 1000 & on & off & 1780 \\
\hline 10 & 18210 & $16: 52: 56$ & $16: 54: 57$ & lateral sweep & & 80 & 1000 & on & off & 1740 \\
\hline 11 & 18211 & $16: 56: 00$ & $16: 58: 33$ & lateral sweep & $4 \mathrm{~K}$ block & 80 & 1000 & on & off & 1700 \\
\hline 12 & 18212 & $16: 59: 01$ & $16: 59: 37$ & lateral doublet & & 80 & 1000 & on & off & 1670 \\
\hline 13 & 18213 & $16: 59: 56$ & $17: 00: 27$ & lateral doublet & & 80 & 1000 & on & off & 1650 \\
\hline 14 & 18214 & $17: 01: 22$ & $17: 03: 15$ & long'l sweep & & 80 & 1000 & on & off & 1640 \\
\hline 15 & 18215 & $17 ; 04: 20$ & $17: 06: 20$ & long'l sweep & & 80 & 1000 & on & off & 1600 \\
\hline 16 & 18216 & $17: 06: 47$ & $17: 08: 30$ & long'l sweep & $4 \mathrm{~K}$ block & 80 & 1000 & on & off & 1560 \\
\hline 17 & 18217 & $17: 09: 33$ & $17: 09: 54$ & Iong'l doublet & & 80 & 1000 & on & off & 1540 \\
\hline 18 & 18218 & $17: 10: 26$ & $17: 10: 59$ & Iong'l doublet & & 80 & 1000 & on & off & 1520 \\
\hline 19 & 18219 & $17: 11: 23$ & $17: 11: 47$ & Iong'l doublet & & 80 & 1000 & on & off & 1500 \\
\hline
\end{tabular}


TABLE 3. CATALOG OF DATA RECORDS BY FLIGHT (CONTINUED)

\begin{tabular}{|c|c|c|c|c|c|c|c|c|c|c|}
\hline \multirow{2}{*}{$\begin{array}{l}\text { Record } \\
\text { Number }\end{array}$} & \multirow[t]{2}{*}{ Filename } & \multicolumn{2}{|c|}{ Record Time } & \multirow[t]{2}{*}{ Maneuver } & \multirow[t]{2}{*}{ Load } & \multirow{2}{*}{$\begin{array}{c}\text { Airspesd } \\
\text { (knots) }\end{array}$} & \multirow{2}{*}{$\begin{array}{c}\text { Altitude } \\
\text { (feet) }\end{array}$} & \multirow[t]{2}{*}{ SAS } & \multirow[t]{2}{*}{ FPS } & \multirow{2}{*}{$\begin{array}{l}\text { Fuel Wt. } \\
\text { (pounds) }\end{array}$} \\
\hline & & Start & Stop & & & & & & & \\
\hline 20 & 18220 & $17: 14: 50$ & $17: 15: 15$ & trim & $4 \mathrm{~K}$ block & 30 & 1000 & on & off & 1450 \\
\hline 21 & 18221 & $17: 22: 40$ & $17: 24: 37$ & lateral sweep & & 30 & 1000 & on & off & 1370 \\
\hline 22 & 218222 & 17:25:03 & $17: 26: 48$ & lateral sweep & & 30 & 1000 & on & off & 1330 \\
\hline 23 & 18223 & 17:27:44 & 17:29:33 & lateral sweep & & 30 & 1000 & on & off & 1300 \\
\hline 24 & 18224 & $17: 28: 56$ & $17: 30: 29$ & lateral doublet & & 30 & 1000 & on & off & 1260 \\
\hline 25 & 18225 & 17:30:52 & $17: 31: 28$ & lateral doublet & $4 \mathrm{~K}$ block & 30 & 1000 & on & off & 1250 \\
\hline 26 & 18226 & $17: 31: 57$ & 17:33:15 & long'l sweep & & 30 & 1000 & on & off & 1230 \\
\hline 27 & 18227 & 17:34:56 & $17: 36: 43$ & long'l sweep & & 30 & 1000 & on & off & 1200 \\
\hline 28 & 18228 & 17:37:06 & 17:38:46 & long'l sweep & & 30 & 1000 & on & off & 1170 \\
\hline 29 & 18229 & 17:39:30 & 17:40:21 & long'l doublet & 4K block & 30 & 1000 & on & off & 1130 \\
\hline 30 & 18230 & $17: 40: 54$ & $17: 41: 26$ & long'l doublet & & 30 & 1000 & on & off & 1120 \\
\hline 31 & 18231 & $17: 42: 13$ & $17: 42: 47$ & long'l doublet & & 30 & 1000 & on & off & 1090 \\
\hline & & & & & & & & & & \\
\hline & & & & & & & & & & \\
\hline & & & & & & & & & & \\
\hline & & & & & & & & & & \\
\hline & & & & & & & & & & \\
\hline & & & & & & & & & & \\
\hline & & & & & & & & & & \\
\hline & & & & & & & & & & \\
\hline & & & & & & & & & & \\
\hline & & & & & & & & & & \\
\hline & & & & & & & & & & \\
\hline & & & & & & & & & & \\
\hline & & & & & & & & & & \\
\hline & & & & & & & & & & \\
\hline & & & & & & & & & & \\
\hline
\end{tabular}




\section{TABLE 3. CATALOG OF DATA RECORDS BY FLIGHT (CONTINUED)}

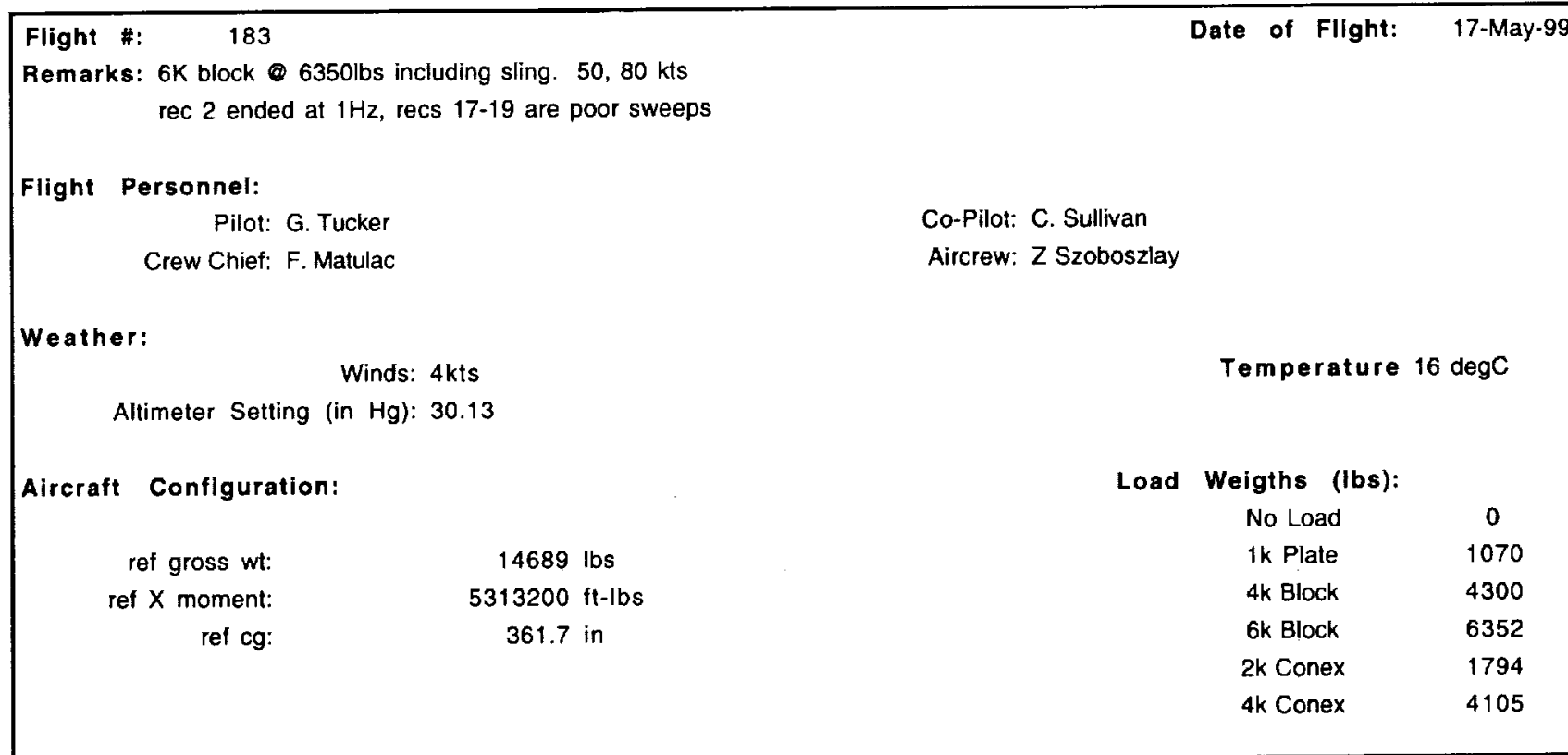

\section{Directory Name: TRENDSBSL Sample Rate: $100 \mathrm{~Hz}$}

\begin{tabular}{|c|c|c|c|c|c|c|c|c|c|c|}
\hline \multirow{2}{*}{$\begin{array}{l}\text { Record } \\
\text { Number }\end{array}$} & \multirow{2}{*}{$\begin{array}{c}\text { Trends } \\
\text { Counter }\end{array}$} & \multicolumn{2}{|c|}{ Record Time } & \multirow[t]{2}{*}{ Maneuver } & \multirow[t]{2}{*}{ Load } & \multirow{2}{*}{$\begin{array}{c}\text { Airspoed } \\
\text { (knots) }\end{array}$} & \multirow{2}{*}{$\begin{array}{c}\text { Altitude } \\
\text { (teet) }\end{array}$} & \multirow[t]{2}{*}{ SAS } & \multirow[t]{2}{*}{ FPS } & \multirow{2}{*}{$\begin{array}{l}\text { Fuel wt. } \\
\text { (pounds) }\end{array}$} \\
\hline & & Start & Stop & & & & & & & \\
\hline 1 & 18301 & $18: 42: 50$ & $18: 43: 37$ & trim & $6 \mathrm{~K}$ block & 80 & 1000 & on & off & 1140 \\
\hline 2 & 18302 & $18: 44: 39$ & $18: 46: 38$ & lateral sweep & & 80 & 1000 & on & off & 1130 \\
\hline 3 & 18302 & $18: 47: 35$ & $18: 49: 19$ & lateral sweep & & 80 & 1000 & on & off & 1120 \\
\hline 4 & 18304 & $18: 49: 40$ & $18: 51: 24$ & lateral sweep & & 80 & 1000 & on & off & 1070 \\
\hline 5 & 18305 & 18:52:25 & $18: 52: 59$ & lateral doublet & & 80 & 1000 & on & off & 1030 \\
\hline 6 & 18306 & $18: 53: 37$ & $18: 54: 07$ & lateral doublet & $6 \mathrm{~K}$ block & 80 & 1000 & on & off & 1020 \\
\hline 7 & 18307 & $18: 55: 30$ & $18: 57: 19$ & long'I sweep & & 80 & 1000 & on & off & 1000 \\
\hline 8 & 18308 & 18:58:20 & 19:00:12 & long'l sweep & & 80 & 1000 & on & off & 970 \\
\hline 9 & 18309 & 19:01:05 & $19: 02: 49$ & long'l sweep & & 80 & 1000 & on & off & 920 \\
\hline 10 & 18310 & 19:03:22 & $19 ; 03: 55$ & long'l doublet & & 80 & 1000 & on & off & 890 \\
\hline 11 & 18311 & $19: 04: 48$ & $19: 05: 15$ & long'l doublet & $6 \mathrm{~K}$ block & 80 & 1000 & on & off & 870 \\
\hline 12 & 18312 & 19:05:59 & 19:06:35 & long'l doublet & & 80 & 1000 & on & off & 850 \\
\hline 13 & 18313 & 19:08:27 & 19:08:50 & trim & & 50 & 1000 & on & off & 820 \\
\hline 14 & 18314 & 19:09:11 & 19:10:49 & lateral sweep & & 50 & 1000 & on & off & 810 \\
\hline 15 & 18315 & $19: 11: 24$ & 19:13:39 & lateral sweep & $6 \mathrm{~K}$ block & 50 & 1000 & on & off & 790 \\
\hline 16 & 18316 & 19:13:54 & 19:15:51 & lateral sweep & & 50 & 1000 & on & off & 760 \\
\hline
\end{tabular}


TABLE 3. CATALOG OF DATA RECORDS BY FLIGHT (CONTINUED)

\begin{tabular}{|c|c|c|c|c|c|c|c|c|c|c|}
\hline \multirow{2}{*}{$\begin{array}{l}\text { Record } \\
\text { Number }\end{array}$} & \multirow{2}{*}{$\begin{array}{l}\text { Trends } \\
\text { Counterl }\end{array}$} & \multicolumn{2}{|c|}{ Record Time } & \multirow[t]{2}{*}{ Maneuver } & \multirow[t]{2}{*}{ Load } & \multirow{2}{*}{$\begin{array}{l}\text { Airspeed } \\
\text { (knots) }\end{array}$} & \multirow{2}{*}{$\begin{array}{c}\text { Altitude } \\
\text { (feet) }\end{array}$} & \multirow[t]{2}{*}{ SAS } & \multirow[t]{2}{*}{ FPS } & \multirow{2}{*}{$\begin{array}{l}\text { Fuel Wt. } \\
\text { (pounds) }\end{array}$} \\
\hline & & Start & Stop & & & & & & & \\
\hline 17 & 18317 & 19:16:42 & 19:18:24 & long'l sweep & 6K block & 50 & 1000 & on & off & 720 \\
\hline 18 & 18318 & 19:19:18 & 19:20:57 & long'l sweep & & 50 & 1000 & on & off & 700 \\
\hline 19 & 18319 & 19:21:17 & 19:22:50 & long'l sweep & & 50 & 1000 & on & off & 650 \\
\hline 20 & 18320 & $19: 23: 21$ & 19:23:45 & long'l dblet & & 50 & 1000 & on & off & 630 \\
\hline 21 & 18321 & $19: 24: 04$ & $19: 24: 28$ & long'l dblet & & 50 & 1000 & on & off & 620 \\
\hline 22 & 18322 & $19: 25: 13$ & $19: 25: 45$ & lateral dblet & & 50 & 1000 & on & off & 610 \\
\hline 23 & 18323 & 19:26:05 & $19: 26: 32$ & lateral dblet & & 50 & 1000 & on & off & 590 \\
\hline 24 & 18324 & $19: 27: 19$ & 19:28:52 & lateral sweep & & 50 & 1000 & on & off & 570 \\
\hline 25 & 18325 & $19: 29: 48$ & $19: 31: 20$ & long'l sweep & & 50 & 1000 & on & off & 560 \\
\hline & & & & & & & & & & \\
\hline & & & & & & & & & & \\
\hline & & & & & & & & & & \\
\hline & & & & & & & & & & \\
\hline & & & & & & & & & & \\
\hline & & & & & & & & & & \\
\hline & & & & & & & & & & \\
\hline & & & & & & & & & & \\
\hline & & & & & & & & & & \\
\hline & & & & & & & & & & \\
\hline & & & & & & & & & & \\
\hline & & & & & & & & & & \\
\hline & & & & & & & & & & \\
\hline & & & & & & & & & & \\
\hline & & & & & & & & & & \\
\hline & & & & & & & & & & \\
\hline & & & & & & & & & & \\
\hline
\end{tabular}




\begin{tabular}{|l|l|l|l}
\hline 1. AGENCY USE ONLY (Leave blank) & $\begin{array}{c}\text { 2. REPORT DATE } \\
\text { January 2001 }\end{array}$ & $\begin{array}{c}\text { 3. REPORT TYPE AND DATES COVERED } \\
\text { Technical Memorandum }\end{array}$ \\
\hline
\end{tabular}

\section{TITLE AND SUBTITLE}

5. FUNDING NUMBERS

$581-30-22$

6. AUTHOR(S)

Luigi S. Cicolani, Ranjana Sahai, George E. Tucker, Allen H. McCoy, Peter H. Tyson, Mark B. Tischler, Aviv Rosen

7. PERFORMING ORGANIZATION NAME(S) AND ADDRESS(ES)

Army/ NASA Rotorcraft Division, Aeroflightdynamics Directorate (AMRDEC), U.S. Army Aviation and Missile Command, Ames Research Center, Moffett Field, CA 94035-1000

9. SPONSORING/MONITORING AGENCY NAME(S) AND ADDRESS(ES)

National Aeronautics and Space Administration

Washington, DC 20546-0001 and U.S. Army Aviation and Missile

Command, Redstone Arsenal, AL 35898-5000

\section{REPORT NUMBER}

A-00V0030

11. SUPPLEMENTARY NOTES

Point of Contact: Luigi S. Cicolani, Ames Research Center, MS 211-2, Moffett Field, CA 94035-1000 (650) 604-5446

12a. DISTRIBUTION/AVAILABILITY STATEMENT

12b. DISTRIBUTION CODE

Unclassified - Unlimited

Subject Category - 08

Available from the NASA Center for AeroSpace Information.

800 Elkridge Landing Road, Linthicum Heights, MD 21090: (301) 621-0390

13. ABSTRACT (Maximum 200 words)

Helicopter slung-load operations are common in both military and civil contexts. Helicopters and loads are often qualified for these operations by means of flight tests, which can be expensive and time consuming. There is significant potential to reduce such costs both through revisions in flight-test methods and by using validated simulation models. To these ends, flight tests were conducted at Moffett Field to demonstrate the identification of key dynamic parameters during flight tests (aircraft stability margins and handling-qualities parameters, and load pendulum stability), and to accumulate a data base for simulation development and validation. The test aircraft was a UH-60A Black Hawk, and the primary test load was an instrumented 8- by 6-by 6-ft cargo container. Tests were focused on the lateral and longitudinal axes, which are the axes most affected by the load pendulum modes in the frequency range of interest for handling qualities; tests were conducted at airspeeds from hover to 80 knots. Using telemetered data, the dynamic parameters were evaluated in near real time after each test airspeed and before clearing the aircraft to the next test point. These computations were completed in under $1 \mathrm{~min}$. A simulation model was implemented by integrating an advanced model of the UH-60A aerodynamics, dynamic equations for the two-body slung-load system, and load static aerodynamics obtained from wind-tunnel measurements. Comparisons with flight data for the helicopter alone and with a slung load showed good overall agreement for all parameters and test points; however, unmodeled secondary dynamic losses around $2 \mathrm{~Hz}$ were found in the helicopter model and they resulted in conservative stability margin estimates.

\section{SUBJECT TERMS}

Helicopter, External/sling loads, Flight testing, Simulation, CIFER identification,

Helicopter handling qualities, Helicopter stability margins

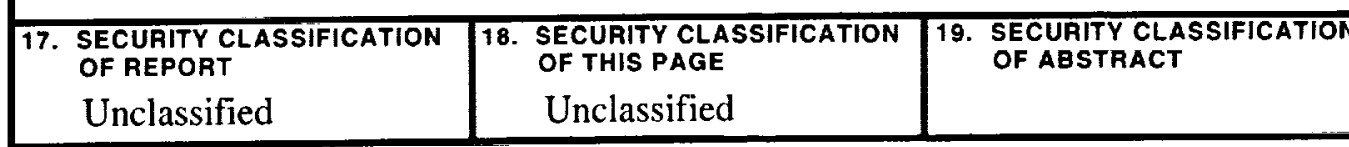

